\title{
Outcomes for young carers: public and third sector provision in Wales, UK
}

\author{
Webb, Enid Vanessa
}

How to cite:

Webb, Enid Vanessa (2016) Outcomes for young carers: public and third sector provision in Wales, UK. Doctoral thesis, Swansea University.

http://cronfa.swan.ac.uk/Record/cronfa52429

Use policy:

This item is brought to you by Swansea University. Any person downloading material is agreeing to abide by the terms of the repository licence: copies of full text items may be used or reproduced in any format or medium, without prior permission for personal research or study, educational or non-commercial purposes only. The copyright for any work remains with the original author unless otherwise specified. The full-text must not be sold in any format or medium without the formal permission of the copyright holder. Permission for multiple reproductions should be obtained from the original author.

Authors are personally responsible for adhering to copyright and publisher restrictions when uploading content to the repository.

Please link to the metadata record in the Swansea University repository, Cronfa (link given in the citation reference above.)

http://www.swansea.ac.uk/library/researchsupport/ris-support/ 


\section{OUTCOMES for YOUNG CARERS:}

Public and third sector provision in Wales

UK

Enid Vanessa Webb

Submitted to Swansea University in fulfilment of the requirements for the Degree of Doctor of Philosophy

Swansea University

$$
2016
$$

Volume I 


\section{Declaration (University standard)}

I declare that this work has not previously been accepted in substance for any degree and is not being concurrently submitted in candidature for any degree.

I declare that the thesis is the result of my own investigations, except where otherwise stated and that other sources are acknowledged by giving explicit references and that a bibliography is appended.

I declare that I give my consent for the thesis, if accepted, to be available for photocopying and for inter-library loan, and for the title and summary to be made available to outside organisations. 


\section{Acknowledgements}

Completing a piece of work such as this relies not just on the student but on help from so many sources.

My thanks go first to my supervisor, Dr. Paul Rees, for his patience and support in seeing me through this incredible process.

The Young Carers Project and its staff who assisted in the development stages of the research deserve much thanks and appreciation.

I am grateful for the help of all the Young Carer Project Workers who provided access to their groups and facilitated interviews and of all the professionals in Social Services and third sector organisations.

The study exists however primarily because of all the young carers who agreed to participate either in the Reference and Pilot Groups or as interviewees and I thank them for giving their time and for sharing their experiences with me.

What should not pass without comment is the kindness of family, friends and colleagues who provided sympathy, food and statistical advice! 


\begin{abstract}
Young carers are those under the age of 18 who provide unpaid care for an adult or child in need of support. The 2011 Census estimated that there were over 11,000 in Wales (Office for National Statistics, 2013) but research suggests that there are many more unidentified. They can be adversely affected by their caring role yet there is a weak evidence base for services and predictors of outcomes. This thesis aimed to explore service provision and outcomes for young carers. It also aimed to identify associations between outcomes and biographical characteristics or caring factors. To meet the aims of the study a mixed methods approach was adopted although the quantitative approach dominated (see section 6.1 for more details). This included a review of literature and two sequential data collection phases.
\end{abstract}

Phase 1 aimed to map and evaluate extent of existing provision for young carers in Wales. Be-spoke questionnaires were completed by representative organisations $(n=22)$ drawn from the two main service networks: Social Services ( $n=12: 55 \%$ of all local authorities in Wales) and Young Carers Projects $(n=10)$.

In response to Research Question about the development of provision, the results of Phase 1 indicated that the Projects, mostly delivered by the third sector, had developed as specialist support for young carers. There was common understanding and a high degree of co-operation between the statutory service and the Projects with some delegation of statutory functions. The stated objectives varied between Projects as did the evaluation of outcomes between sectors and between organisations and the data lacked comparability. Both statutory and third sector services suffered from lack of resources and the future of the Projects was far from stable.

Phase $\mathbf{2}$ had two Research Aims. The first was to examine factors which influenced outcomes for young carers. The second was to evaluate the relative importance of factors. Published measures of 
Educational Attainment (British Ability Scales), Emotional Literacy (SEMERC) and caring responsibilities (MACA-18) were administered alongside a be-spoke structured questionnaire to young carers $(n=62)$ from Projects $(n=10)$ across Mid and South Wales. From the data sources, four outcome indices were calculated for the areas of Education, Emotional Literacy, Health and Social Capital. A Composite outcome index was also calculated.

The results indicated that, on average, young carers' Educational Attainment and Emotional Literacy were lower than those for agematched peers in the general population. A worrying proportion had little or no social activities and personal hobbies outside school hours and outside time spent caring, with a consequent impact on their ability to acquire social capital. There appeared to be strong correlations between outcomes in Emotional Literacy, Health and Social Capital. Counter-intuitively some factors such as being a sole carer or entitlement to free school meals were not associated with any outcome indices.

The strongest predictor of Composite outcomes was the quality of family relationships. Young carers who live in a family with poor quality of relationships are 46 times more likely to experience poor outcomes. Similarly, the higher the level of household responsibilities or emotional care, the more likely they are to experience adverse outcomes as reflected in their Composite index.

The general findings suggest that a cross-cutting approach to policy on young carers requires monitoring in all policy areas. Since current provision leans heavily on the Projects, their funding needs to be reviewed at a strategic level. The large number of young carers still unidentified indicates that the capacity and effectiveness of the services need to be reviewed with other models of service considered. It is hoped that these findings will inform future policy formation and service planning. 
Table of contents

1. Introduction 23

1.1 This Study 23

1.1.1 The choice of subject 23

1.1.2 Why was this research worth doing? 25

1.2 The Context 26

1.2.1 Care in the Community 26

1.2.2 The role of the carer 27

1.2.3 The role of the young carer 28

1.3 The Effects of Young Caring 30

1.4 Available Services 34

1.5 The Perspective of Young Carers 35

$\begin{array}{lll}1.6 & \text { Research } & 37\end{array}$

1.6.1 Challenges 38

1.6.2 Gaps in research $\quad 39$

1.6.3 Methodologies $\quad 40$

1.6.4 Research with vulnerable participants 41

1.6.5 Measuring outcomes 42

1.7 The Structure of the Thesis 43

2. The Development and Recognition of the Concept of "young carer"

2.1 In the Context of "childhood" 47

2.1 .1 Historical 48

2.1.2 Global 53

2.2 What Distinguishes young carers? 57

2.2.1 Identifying the difference between helping and caring

Purpose; Choice; Hours spent caring;

Types of tasks undertaken; Duration of commitment; Responsibility; Impact 
2.2.2 How are young carers different from adult carers?

2.2.3 How are young carers different from other groups of vulnerable children? 74

2.2.4 The distinguishing factors

2.3 What Has Contributed to the Growth and Adoption of the Concept?

2.3.1 Research

2.3.2 Lobbying and campaigning 78

2.3.3 Stakeholders 82

2.3.4 The Rights agenda

2.3.5 "A unifying tool" 83

2.3.6 Service providers 84

2.3.7 A market for services 85

2.4 Terms and Definitions 86

2.4.1 Common useage

Other terms; Paid and unpaid carers;

"Young carer"

2.4.2 The legislative context

Legislation in the UK; Welfare benefits;

Legislation in Wales; Local authorities in Wales

2.4.3 Non-statutory useage

98

Definitions used by Young Carers

Projects; The implications of a broader definition

2.5 Demographic Data 103

2.5.1 Use of data in research

Geographical coverage; Age of sample; Definition used; Hidden population

2.5.2 Available data 
Prevalence; Gender; Age profile;

Ethnicity; Relationship to person cared

for; Sole, main or supporting carer;

Types of task; Condition of person cared

for; Level of commitment

2.5.3 Data specific to Wales

2.6 Summary of Chapter 2

3. Predicted Outcomes for Young Carers

3.1 Adverse Measurable Outcomes

3.1.1 Educational attainment

3.1.2 Emotional literacy 128

3.1.3 Health

129

3.1.4 Social life

3.1.5 Relationship with the person cared for

3.1.6 Parent-child relationship

3.1.7 Personal

3.1.8 Transition

3.1.9 Material welfare

3.2 Positive Measurable Outcomes 138

3.2.1 Maturity and experience 139

3.2.2 Self-worth 140

3.2.3 Relationship with the person cared for $\quad 141$

3.3 Resilience 143

3.4 Agency and Children as Agents 146

3.5 Social Capital 148

3.5.1 The concept of social capital 148

3.5.2 The application of social capital to childhood 155

3.5.3 The relevance of the concept to young carers 157

3.5.4 The role of Young Carers Projects in the context of social capital

3.6 Life Course, Linked Lives and the Ecological Model 
3.6.1 Life course and linked lives

3.6.2 Bronfenbrenner: the ecological model

3.6.3 Applying Bronfenbrenner's model to young carers

The microsystem (i); The microsystem

(ii); The exosystem; The

macrosystem; The chronosystem(i);

The chronosystem(ii)

3.7 Summary of Chapter 3

173

4. Types of Support, Availability and Barriers to Take-Up

175

4.1 Provision

175

4.1.1 Social Services

175

4.1.2 Education sector

178

4.1.3 Leisure and youth services

181

4.1.4 On-line

182

4.1.5 Third sector

184

4.2 Barriers to Take-up

185

4.2.1 Service providers

186

4.2.2 Service users

190

4.3 Summary of Chapter 4

5. Young Carers' Voice

5.1 In Legislation

5.2 In Lobbying

5.3 In Research

200

5.4 Research Carried out Directly with Young Carers:

Measures Used and Lessons Learnt

202

5.4.1 The General Household Survey 1996/7

204

5.4.2 Young Caregiver of Parents Inventory

205

5.4.3 Kidscreen

205

5.4.4 Multidimensional Assessment of Caring 
Activities and the Positive and Adverse

Outcomes of Caring

5.4.5 "Full of care" 207

5.4.6 Kids Life and Times Survey 207

5.5 Young Carers Projects 208

5.5.1 Proliferation of the Projects 208

5.5.2 The rationale behind the growth of the Projects 209

5.5.3 Evaluating the effectiveness of the Projects 211

Literature search for Project

evaluations; Independence of

evaluations; The contents of the

evaluation reports; Methodologies;

Their findings and recommendations;

Funding; Analysis of evaluations

5.5.4 Self-identification

232

5.6 Summary of Chapter 5

5.7 Summary of Literature Review 233

6. Methodology 237

6.1 The Nature of the Inquiry 237

6.2 Research Design 241

$\begin{array}{lll}6.3 & \text { Ethics } & 249\end{array}$

6.3.1 Ethical considerations 249

6.3.2 Implementation 250

6.3.3 Balance of power 252

6.3.4 Ethical approval 253

6.4 Phase 1a: Survey of Young Carers Service in Social Services 255

6.4.1 Participants 255

6.4.2 Measures 255

Development of questionnaire; Piloting 
of questionnaire

6.4.3 Procedure

Recruitment; Data collection;

Recording and coding

6.5 Phase 1b: Survey of Young Carers Projects 259

6.5.1 Participants 259

6.5.2 Measures 259

Development of questionnaire; Piloting of questionnaire

6.5.3 Procedure

Recruitment ; Data collection;

Recording and coding

6.6 Phase 2: Survey of Young Carers 262

6.6.1 Participants 262

6.6.2 Measures 262

Educational Attainment; Emotional Literacy;

Level of caring activity; Development of be-

spoke questionnaire (biographical factors,

caring factors, Educational Attainment,

Emotional Literacy, Health and Social

Capital).

6.6.3 Procedure

269

Recruitment; Data collection; Recording and analysis

7. Findings 276

7.1 Phase 1a: Survey of Young Carers Service in Social 276

7.1.1 How well developed are the services for young carers? (RQ 1) 276

7.1.2 How much partnership working is there? 280 (RQ2)

7.1.3 How accessible are the services? (RQ 3) 
7.1.4 How do the service providers evaluate their service for young carers? (RQ 4)

7.1.5 What do the service providers perceive to be the challenges? (RQ 5)

7.1.6 What is the relative importance of the Projects in provision for young carers? (RQ 6) What is the amount and source of current investment in Projects in Wales? (RQ 7)

7.2 Phase 1b: Survey of YCPs

7.2.1 How well developed are the services for young carers? (RQ 1)

7.2.2 How much partnership working is there? (RQ 2)

7.2.3 How accessible are the services? (RQ 3)

7.2.4 How do the service providers evaluate their service for young carers? (RQ 4)

7.2.5 What do the service providers perceive to be the challenges? (RQ 5)

7.2.6 What is the relative importance of the Projects in provision for young carers? (RQ 6) What is the amount and source of current investment in Projects in Wales? (RQ 7)

7.3 Phase 2: Survey of Young Carers 299

7.3.1 Profile of sample 299

7.3.2 Biographical data 300

7.3.3 Caring profile 304

7.3.4 Level of caring activities (MACA-YC18) 309

7.3.5 Outcomes: EAI; ELI; HI; SCI; COI 311

7.3.6 Tests of association: Correlations between outcomes; Correlations between outcomes and factors in the biographical data; 
Differences in outcomes between Projects

8. Discussion

8.1 Reflections on the Literature Review

8.1.1 The concept and definition of young carer

8.1.2 Types of support available and barriers to take-up

8.1.3 Outcomes for young carers

8.1.4 The voice of young carers

8.2 Phase 1: Survey of Social Services and Young Carers Projects

8.2.1 How well developed are the services for young carers? (RQ 1 )

8.2.2 How much partnership working is there? (RQ 2)

8.2.3 How accessible are the services? (RQ 3)

8.2.4 How do the service providers evaluate their service for young carers? (RQ 4)

8.2.5 What do the service providers perceive to be the challenges? (RQ 5)

8.2.6 What is the relative importance of the Projects in provision for young carers? (RQ 6)

8.2.7 What is the amount and source of current investment in Projects in Wales? (RQ 7)

8.3 Phase 2: Survey of Young Carers

8.3.1 Representativeness of sample

8.3.2 Primary and secondary outcomes

8.4 Outcomes

8.4.1 Outcomes on chosen measures (RQ 8)

8.4.2 Correlations between outcomes (RQs 9 and 10) 
8.4.3 Correlations with biographical and caring factors (RQ 11)

390

8.4.4 Difference in outcomes between Projects (RQ

395

8.4.5 Predictors of positive and adverse outcomes (RQs 13 and 14)

397

8.5 Features Concerning Young Carers Emerging from This Study 399

8.5.1 Factors which can and cannot be changed 399

8.5.2 Importance of social capital 400

8.5.3 Agency

404

8.6 The Service 406

8.6.1 Unmet need 406

8.6.2 The significance of the Projects 408

8.6.3 The effectiveness of the Projects 410

8.6.4 The stability of the service 411

8.6.5 Models of service 412

8.7 Welsh Government Policy 416

8.7.1 Secondary schools 417

8.7.2 Health 418

8.7.3 Leisure and Youth services $\quad 419$

8.8 Limitations of Study 419

8.8.1 Socialised responses $\quad 419$

8.8.2 Time restrictions 420

8.8.3 Expectations of what participants can contribute. 420

8.8.4 Recruiting the sample 421

8.8.5 Representativeness 421

8.8.6 Control group 422

8.8.7 Conditions of ethical approval 424

8.9 Dissemination and Utilisation 425 
9 Conclusions

9.1 Provision 427

9.2 Outcomes in Educational Attainment 429

9.3 Outcomes in Emotional Literacy 430

9.4 Outcomes in Social Capital 431

9.5 Understanding the Needs of Young Carers in BAME Families 432

9.6 Correlations and Potential Predictors of Outcomes 433

Appendices

A Table of Research Objectives, Aims and Questions 435

B Data on numbers of young carers and population in Wales [Data from StatsWales web-site]

C Inquiry into use of telecare service in Wales for young carers

D Social Services questionnaire

E Young Carers Project questionnaire $\quad 446$

F MACA questionnaire $\quad 453$

G Young Carers questionnaire $\quad 454$

$\mathrm{H}$ Inquiry into support for young carers in secondary schools in Wales

I Ethical approval Phase 1

J Ethical approval Phase 2

$\mathrm{K}$ Parental information sheet 466-68

L Participant information sheet 469-71

M Parental consent form 472-74

$\mathrm{N}$ Participant assent form 4757-6 477-78 
Tables

Table $1 \quad$ Research Objectives, Aims and Questions

Table 2 Relationship of cared for person to young carer

Table 3

Data on percentage of young carers performing different types of caring activities

Table 4 Independence of the evaluations of YCPs

Table 5

Provision of activities by Projects

Table 6

Research Objectives, Aims and Questions and Design

Table 7

Research Questions and Design

Table 8

Timetable of research process

Table 9

How the items in the Social Services survey

addressed the Research Questions

Table 10

Recruitment timetable

Table 11

Development of young carers service

Table 12

Assessment tool used to assess young carers

Table 13

Who carries out the assessment of young carers

278

Table 14 Regular strategic meetings regarding young

carers held with other agencies

Table 15

Sources of referrals to Social Services

Table 16

Methods Social Services use to evaluate their

service for young carers

Table 17 How the items in the Projects survey addressed

the Research Questions

Table 18 Number of staff and whether any of them are former young carers

Table 19

Highest qualification of staff members

Table 20

Sources of referrals to Young Carers Projects

Table 21

Operational definition of "young carer" in Projects

Table 22 Activities offered by each Project 
Table 24 Frequency of delivery of awareness raising

sessions by Young Carers Projects to each agency

Table 25 Rating of level of awareness of the needs of 294 young carers in agencies who have received awareness training

Table 26 Details of variation of number in sample of young carers

Table 27

Distribution of family types

Table 28

Quality of family relationships

303

Table 29

Breakdown of participants' conditions

303

Table 30 How well they get on with the person they are caring for 305

Table 31

Conditions of people cared for 305

Table 32

Whether their condition can change at any time 306 without warning

Table 33

Sole, main or supporting carer

306

Table 34

Regular help from outside the family

307

Table 35

Duration of caring 308

Table 36

Time spent on caring each day 309

Table 37

Amount of each activity at group level

Table 38

EAI Reading and Spelling

Table 39

Statistical comparison of performance of young

carers' group with an aged matched general population norm group on Reading

Table 40

Statistical comparison of performance of young

carers' group with an age matched general

population norm group on Spelling

Table 41

Performance at school

Table 42

Performance at school composite weighted score

Table 43 EAI composite weighted score 
Table 45 Statistical comparison of performance of young

carers' group with an age matched general population norm group on Emotional Literacy

Table $46 \quad$ Feelings as a result of caring 318

Table 47

ELI composite

Table 48

Experiencing minor complaints

321

Table 49

Dental and sight checks

321

Table 50

HI Composite weighted score

322

Table 51 Group activities outside school hours at a group level

Table 52 Individual activities outside school hours at a

323 group level

Table 53

Played computer games in the last term

324

Table 54

Use of public facilities

324

Table 55

Composite scores at group level for each type of

325 activity

Table 56

Friendships

326

Table 57

Free time spent with friends

326

Table 58

Time to look after appearance

Table 59

Peer relationships composite

Table 60

Results on coping indicators

328

Table 61

Has used Internet to look for information

328

Table 62

Composite scores for Coping

329

Table 63

What they would like to do after leaving school

330

Table 64

Composite for Aspirations

Table 65

Scores at group-level for each sub-scale of Social Capital

Table 66

Composite of EAI, ELI, HI and SCI

Table 67

Correlations between outcome indices

Table 68

Pearson correlations between outcome indices and biographical factors 
Table 69 Correlations of caring factors with outcome indices

Table 70 Correlations of levels of caring activity measured by MACA with outcome indices

Table 71 Measuring differences in Means in outcomes between Projects

Table 72 Binary Logistic Model of Relation Between COI Overall Outcome and Biographical and Caring Factors

Table 73 Binary Logistic Model of Relation Between EAI 348 Outcome and Biographical and Caring Factors

Table 74 Binary Logistic Model of Relation Between ELI 349 Outcome and Biographical and Caring Factors

Table 75 Binary Logistic Model (1) of Relation Between 351 Health Outcome and Biographical and Caring Factors

Table 76 Binary Logistic Model (2) of Relation Between HI and Biographical and Caring Factors

Table 77 Binary Logistic Model (1) of Relation Between SCI 352 and Biographical and Caring Factors

Table 78 Binary Logistic Model (2) of Relation Between SCI 353 and Biographical and Caring Factors

Table 79 Research Questions and Findings

Figures

Figure 1 Increase in number of peer-reviewed articles published on "young carers"

Figure 2 Example of representation of young carers in newspaper headlines

Figure 3 Outcomes indices and sub-scales for Phase 2

Figure 4 Social Capital domains, sub-scales and indicators 
Figure $5 \quad$ Number worrying while at school

Figure 6 Composite of scores of sample on five indicators for Feelings

Figure $7 \quad$ Correlation of EAI with health conditions of young carers in this sample

Figure 8 Effect of health condition of Cared for person on coping ability

Figure 9 Effect of carer status on Performance at School

Figure 10 Number of people sharing caring

Figure $11 \quad$ Number of older people sharing caring

\section{Glossary}
A
Attendance
$A L$
Feeling Alone
ALN
Additional Learning Needs
AOS
All social activities outside school hours
ASP
Aspirations
BAME
Black Asian Minority Ethnic
BME
Black Minority Ethnic
BAS
British Ability Scale
COLIN
Carers Officers Information and Learning Network (Wales)
CAF Common Assessment Framework
Cfp Cared for person
COI Composite Outcomes Index
$\mathrm{CP} \quad$ Competence
CPG Coping
C(RS)A Carers (Recognition and Services) Act
D Dental checks
Depts. Departments 
DoH Department of Health

EAI Educational Attainment Outcomes Index

ELI Emotional Literacy Outcomes Index

$\mathrm{F}$

Feelings as a result of caring

FACNTF Framework for the Assessment of Children in Need and Their Families

Famrel Family relationships

GHS General Household Survey

H Homework

$\mathrm{HH}$ resps Household responsibilities

$\mathrm{HH}$ tasks Household tasks

HI Health Outcomes Index

HRQoL Health-Related Quality of Life

ILO International Labour Organisation

LE LE Consultancy Ltd.

LEA Local Education Authority

LSYPE Longitudinal Study of Young People in England

MACA Multidimensional Assessment of Caring Activities

MC Minor complaints

NEET Not in Education, Employment or Training

NHS National Health Service

NHS and CC National Health Service and Community Care Act

Act

$\mathrm{OH}$

Self-assessment of own health

ONS Office for National Statistics

OPCS Office of Population Censuses and Surveys (functioning until 2003)

PANOC Positive and Adverse Outcomes of Caring

PC Punctuality

PISA Programme for International Student Assessment

PR Peer relationships

PS Performance at school 
R

RQ

$\mathrm{SCI}$

SCIE

SCRQOL

SEMERC

$\mathrm{SF}$

SGT

SK

$\mathrm{S}$

SS

SSI

ST

T

UK

UNCRC

UNICEF

W

WAG

WGCYPWM

WIMD

YCOPI

$\mathrm{YCP} / \mathrm{s}$

YCPSS

YCRG
Reading measure

Research Question

Social Capital Outcomes Index

Social Care Institute for Excellence

Social Care-Related Quality of Life

Special Education Micro-Electronic Resource Centre

Satisfaction

Sight checks

Smoking

Spelling measure

SEMERC measure

Social Services Inspectorate

Stress

Tiredness

United Kingdom

United Nations Convention on the Rights of the Child

United Nations International Children's Emergency Fund

Worrying at school

Welsh Assembly Government

Welsh Government Children and Young People's Wellbeing Monitor

Welsh Index of Multiple Deprivation

Young Caregiver of Parents Inventory

Young Carers Project/s

Young Carers Perceived Stress Scale

Young Carers Research Group 


\section{Chapter 1}

\section{Introduction}

This chapter sets the context for the study. It explains why this subject was chosen and what aspects of the subject will be covered, finishing by clarifying the structure of the thesis.

\subsection{This Study}

This thesis is a mixed method study exploring the outcomes in terms of a sample of young carers which looks for associations with factors in their biographical background and with features of their caring profiles. If any associations are found, consideration is given to whether they are strong enough to be useful as outcome predictors and as evidence for the support young carers need. This is critical to the pursuit of equality of opportunity and the promotion of quality of life.

The study was located in Wales. After preliminary exploration of the field, it was concluded that the two main forms of support for young carers were to be found in Social Services and the Young Carers Projects (YCPs). The first phase of the study was therefore a survey of provision by those two networks and the second phase was data collection with young carers identified through YCPs across South and Mid-Wales.

\subsubsection{The choice of subject.}

The writer's involvement in a charity providing services to carers highlighted the problems experienced by carers and the struggle to provide them with appropriate, adequate and timely support within available resources. Observing activities in the YCP showed the care and patience of staff in dealing with young people sometimes boisterous, sometimes withdrawn, sometimes in a critical state. In dealing as a Trustee with the budget, the staffing and hence the sustainability of that Project, curiosity was awakened about where 
Projects stand in the overall setting of support services for young carers, about targeting those most in need and about the effectiveness of existing support. Most of all an interest was fuelled in the outcomes that can be expected and predicted and, perhaps more importantly, in the light of this knowledge how planning and delivery of services can best be done.

An initial search of all main databases for 'young carer*' produced 485 titles. English language and Social Sciences only were retained. Duplicates, press reports and publications prior to 1988 were then excluded. Of the remaining titles, 73 articles from the magazine Community Care were noted for background reading. When titles had been screened for relevance, 78 were retained. Reading of abstracts led to the exclusion of articles on children in care and articles focusing on the sick or disabled parent, reducing the number to 65 . This increased with additional titles drawn from references in the selected articles.

A later stage was to search for 'young carer*' combined with specific subject areas: for example "young carer*" and "education", "young carer*" and "school*", "young carer" and "health", "young carer" and "social capital".

Related topics which arose during reading necessitated additional searches. Examples from among these were the concept of childhood, exploration of the development and methods of assessment, telecare and studying specific writers and researchers such as Bourdieu, Sen and others.

Altogether these methods expanded the list as the literature review progressed and the final bibliography numbered 650. Not all these titles were however available and only a small proportion were referenced.

The literature review uncovered the aspects where research had already provided evidence and identified what had been less thoroughly covered. This guided the choice of focus in this thesis which is to explore outcomes. 


\subsubsection{Why was this research worth doing?}

The existence of a class of children and young people who care for family members who are sick or disabled has been recognised in law and to some extent accommodated in service provision (see Section 2.4). As listening to children has become an important element in research methodology, children and young people have shared their feelings and attitudes with researchers and considerable qualitative evidence is now available on what it feels like to be a young carer and what it means for their futures.

Work on estimating the total number of young carers in the population has continued and the number estimated seems to grow with each survey carried out (see Section 2.5). Much of the estimating is speculative because for an array of reasons young carers are a hidden population. Numbers are reached by extrapolation from samples or based on numbers of children living in families with disabled members. The Welsh Government Children and Young People's Wellbeing Monitor (WGCYPWM, 2011) said that any one of the 151,000 children living with a disabled parent in Wales might be a young carer but they are not necessarily so. However it is probably safe to say that there is a significant number of children and young people who care who would benefit from support, many of whom have not yet been identified.

\subsection{The Context}

\subsubsection{Care in the Community.}

The provision of Care in the Community was present as a preferred alternative to institutional care in the United Kingdom (UK) from the 1950s (Becker, 2008). In the 1980s the Government promoted a drive away from institutional care towards home-based care. There was moral justification for a service more capable of being tailored for individual needs (Trnobranski, 1995) but, while the principle of Community Care was supported for humanitarian reasons as "a form of 
social justice" (Heyman \& Heyman, 2013, p. 563), it was also intended by Government as an ideological move away from state provision towards a mixed economy of provision (Kim, 2008). There was a lively debate on the cost-effectiveness of Care in the Community and possible revenue savings for health and social care when research both for and against that view was published. The debate came to a head with the Griffiths paper Community Care: Agenda for Action (1988), commissioned by Government, recommending the "value of a multiplicity of provision" (Griffiths, 1988), and the positive Department of Health (DoH) response Caring for People: Community Care in the next Decade and Beyond (1989). This was followed by the introduction of the National Health Service and Community Care Act (NHS and CC Act) 1990 to lead to the reform of the services in 1993.

\subsubsection{The role of the carer.}

It was a difficult journey from legislation to implementation but, whatever the successes or shortcomings of this reform, the significance for carers of such a policy was the emphasis it placed on their contribution. The unpaid work of informal carers became the foundation stone of implementation. When the replacement costs were calculated, the economic value of carers' efforts became apparent. A calculation of the annual value of their contribution in 1989 was quoted in Parliament by Peter Thurnham, MP. as £24bn (Hansard, 1990). Carers UK commissioned calculations of the economic value of carers work in the UK in 2002, 2007 and 2011 from the University of Leeds using the same methodology each time. This produced the estimates of $£ 57$ billions in 2002, $£ 87$ billions in 2007 and $£ 119$ billions in 2011 . This contained estimates for the value in Wales as $£ 3.52$ billions in 2002, $£ 5.69$ billions in 2007 and $£ 7.72$ billions in 2011 (Buckner \& Yeandle, 2011). In this way the unpaid efforts of carers became one of political and budgetary importance. Set against this value were the loss of tax 
revenue when caring prevented carers from working and welfare benefits for which some carers would be eligible.

In addition evidence had been emerging of how caring could affect adversely the health of family members who cared. Caregiver burden was first identified by Hoenig and Hamilton in 1966 in the field of mental health in their study of carers for patients with schizophrenia.

Subsequent research confirmed and expanded the recognition of the effects of caring (McLaughlin \& Ritchie, 1994; Payne et al., 1999; Travers, 1996; Ward \& Cavanagh, 1997). Unless addressed, this could present a problem in maintaining carers in their supporting role and thus sustaining the model of service which depended on the continuing work of carers. Maintaining carers in their role became an issue of political and fiscal interest and the question of whether for Government the implementation of community care was concerned equally with maintaining the service provided by the carer as with the wellbeing of the carer was raised by Lloyd (2006), Nicholas (2003) and Pickard (2004).

\subsubsection{The role of the young carer.}

What became apparent from research at the time of the introduction and reform of services was that amongst the population of carers there were children and young people under 18 providing this unpaid service. The factor of children taking on a caring role was highlighted by $A$. O'Neill (1988) and Page (1988). Aldridge \& Becker's studies in 1993 and 1994 highlighted the existence of young carers and began to explore the effects this role might have on the children and young people. A campaign by the magazine Community Care in 1995 helped raise awareness of the existence of young carers and their problems.

At first it was not clear how they were defined, what constituted caring for a young carer, how they were to be identified and what were the numbers involved. The definition of young carer was a subject of debate and, it could be said, of confusion for a long time and there is 
still not a complete consensus in practice. Each piece of research about young carers needed to begin by stating the definition on which the study was based. There were some early attempts to estimate the number of young carers in the population, for example 10,000 by Page in 1988 but these early figures were superseded by continually increasing estimates in subsequent years. The data from the 2011 Census was analysed and it was announced that there were probably over 166,000 young carers in England and over 11,000 in Wales (ONS, 2013). The highest estimate to date is the BBC commissioned study by Becker, proposing that $8 \%$ of the under $18 \mathrm{~s}$ were young carers, positing more than 700,000 in England and Wales (Becker, 2010). 8\% of 5-17 year olds in Wales would generate an estimate of 36,400 young carers. Demographic data gathered by Dearden \& Becker (1995b, 1998, 2005) provided in-depth data with detailed profiles of the young carer population and helped clarify the nature of their caring lives. The difficulty of identifying many young carers because of the hidden nature of caring was revealed and explanations offered (Banks et al., 2002b; Gray et al., 2008a; Warren, 2008). It proved especially difficult in practice to make contact with young carers who were outside the formal support network (see Section 8.8.6).

\subsection{The Effects of Young Caring}

It emerged very early on from descriptive studies of young carers by the Carers National Association (Meredith, 1991; Meredith, 1992) and the Young Carers Research Centre at Loughborough University (Aldridge \& Becker, 1993a, Aldridge \& Becker, 1999; Dearden \& Becker, 1995b) that there were serious adverse effects. Numerous subsequent studies have repeatedly described adverse effects on physical health, on mental health, on their education and on their social and personal lives (Bolas et al., 2007; Cree, 2003; Eley, 2004; Gray et al., 2008a) and on the effects of caring for people with particular conditions. There were some studies which looked at the effects of caring in relation to their age and 
their stage of life. Reports on young carers in other countries were also published (Becker, 1995; Becker, 2007; Robson, 2000; Zhang et al., 2009). As studies looked at young carers' needs (Dearden, 1998; Watson, 1999) and at the services being offered (Aldridge \& Becker, 1994; Banks et al., 2002a; Bilsborrow, 1993; Grant et al., 2008; McDonald et al., 2010), attention moved to the effectiveness of existing services and methods of assessment (Purcal et al., 2012).

The perception of young carers as passive subjects began to be counteracted by findings that there could also be positive effects (Aldridge, 2006; Lackey \& Gates, 2001; Pakenham \& Cox, 2012), for example greater maturity and competence, a better relationship with the Cared for person ( $\mathrm{Cfp}$ ). Whilst some young carers but not others experience positive outcomes, the factors explaining the different results in relation to young carers have not yet been fully identified. There were the beginnings of a recognition that young carers albeit minors might be agents in their own lives in studies carried out in Kenya (Skovdal, 2010b: Skovdal et al., 2009) and Australia (Smyth et al., 2011b) exploring children's agency as relevant to young caring although little on this theme has been applied in the UK context.

For central and local government in the UK, there were the same political and practical reasons for supporting young carers as for adult carers. If caring affected their lives seriously, this could reduce the care they could provide and which they often wanted to provide. Nonetheless there were additional reasons for Government to address the issue.

From the traditional position of the obligation of adults to protect children from harm, evidence of the damage that could be done by allowing them to carry out hard, sometimes difficult and certainly ageinappropriate tasks meant that this was a problem that needed to be addressed. In the twentieth century, however, another perspective had become prominent: that children had their own rights pertinent to their age independent of adult obligations. From the first public recognition 
of children's rights in 1923 (Save the Children), adopted by the League of Nations (1924), the movement reached an apotheosis in 1989 with the United Nations Convention on the Rights of the Child (UNCRC). The latter was an international legally binding agreement on what constituted those rights and commitment to that document constituted a promise to ensure that these rights were recognised. From the point of view of children's rights, one of the main demands was that they should not be carrying out activities which might be injurious to their physical, psychological, intellectual and social development (UNCRC, 1989) as a matter of right. The Children Act 1989 in the UK incorporated the philosophy of the UNCRC and this confirmed a change in culture. In terms of young carers, it led to the conviction that children and young people with caring responsibilities should either be prevented from caring or be protected from harm as a result of doing so (Aldridge \& Becker, 1993a). For this to happen, the existence of young carers had to be recognised and responded to by those in a position to develop legislation, policy and appropriate support services.

The UK Government responded with the Carers (Recognition and Services) Act (C(RS)A, 1995) which covered carers of all ages although not mentioning young carers specifically. This lacuna was addressed in the Practice Guide from the Social Services Inspectorate (SSI) in 1995 and the DoH in 1996 by a recommendation that carers under 16 could be identified as children in need under the Children Act 1989 and were entitled to an assessment. The weakness with this route was that it did not lead to young carers' needs both as children and as carers being taken into account. The National Carers Strategy published in 1999 included a chapter on young carers but was couched in very general terms and the improvements suggested were mostly part of a crosscutting agenda.

After 1999, Local Government, Health, Social Care and Education were devolved matters and so government policy on young carers in Wales became the province of the Welsh Assembly Government (WAG). 
Two studies were commissioned on young carers: one to map out the existing situation (Seddon et al., 2003) and the second to look at the everyday lives of young carers (Thomas et al., 2003). As the WAG had no legislative powers, its response to the Carers Strategy (1999) was an Implementation Plan in 2000 in which Young Carers was one of five priorities for action. They continued to be so in the re-focused Carers Strategy Implementation Plan in 2006 which encouraged local authorities each to develop their own Young Carers Strategy. The earlier UK policy of identifying young carers under the child in need category was continued. The Carers' Strategies (Wales) Measure (2010) and the Social Services and Wellbeing (Wales) Act (SS(W)A, 2014) followed the Assembly's early direction of integrating policy across the board on all children's services (Hutt, 1999; Welsh Office, 1998) expecting young carers to be covered in all relevant policy areas such as Social Services, Education, Health and Leisure. The strength of the approach of the Welsh Government might be seen not in legislation but in the networking culture which produced all-Wales bodies such as the Carers Officers Information and Learning Network (COLIN), the Young Carers Workers Network, the Young Carers Forum and the co-operative work of voluntary bodies, for example by Children in Wales, which have managed to make progress at the front-line where statutory powers have been weak. The evidence from this study might be expected to throw some light on the degree to which the cross-cutting approach has been successful in supporting young carers in Wales.

\subsection{Available Services}

A cross-cutting approach could be expected to signal the need for support from all relevant agencies. Chapter 4 of this thesis reviews the sources of support which young carers might access. Social Services have a statutory duty to intervene where it is judged necessary to ensure the welfare of a child. In schools children and young people will usually be in contact with responsible adults and where their caring 
duties are impacting on their performance it could be expected that this would be observed. If those duties are affecting their health, this too is a route by which adverse results could be noticed. Although they have no statutory duty, Leisure Services might be an arena where problems might be noticed or where children might find trained adults in whom they could confide, leading to referrals where appropriate. This study could shed some light on the degree to which agencies are managing to identify and assist young carers.

A counter to the statutory and charitable intention and wish to provide support is the disinclination of some young carers and sometimes also of their families to seek or accept support or even to reveal their situation. The reasons for this can be occasioned sometimes by the performance of the service providers or by the situation, attitudes and fears of the young carers themselves and this is explored in Chapter 4.

\subsection{The Perspective of Young Carers}

It is an important function of the charitable/voluntary sector to highlight concerns and promote attention to the problems affecting people's lives which they are finding in practice. Charitable organisations have produced moving testament to the difficulties and harm experienced by some young carers. Seddon stated in her study of the situation regarding young carers (2003) that attention had been drawn to this issue by the "sustained lobbying of the Carers National Association and organisations concerned with the rights of children". More recently large organisations have been combining their efforts in alliances in order to strengthen the lobbying voice, for example the UK Young Carers in Focus and the National Young Carers Coalition.

It is an important function of academic research to provide objective evidence to politicians and policy makers. The studies of young carers increased from 1990 on and a search for young carers on large research data-bases brought up a continuous increase in the number of articles 
published on the subject (see Figure 1). The pressure of their findings has added to front-line experience as ammunition for the lobbying organisations.

Increase in number of peer-reviewed articles published on 'young carers'

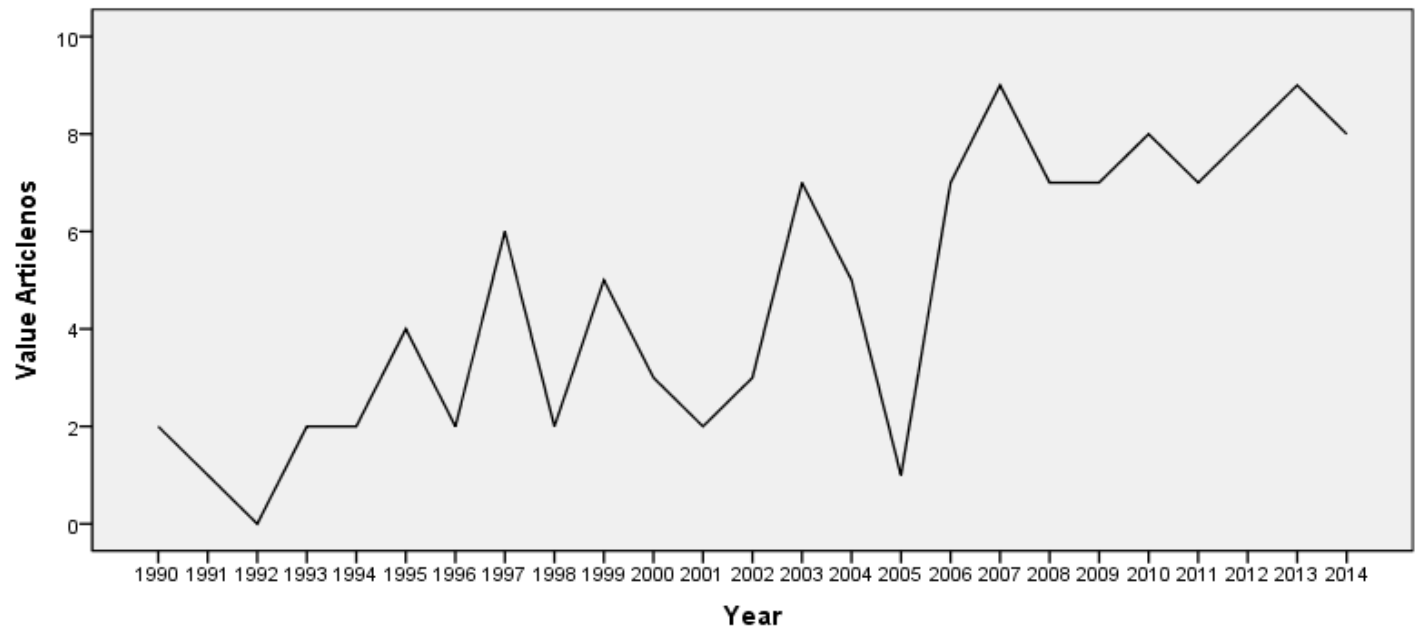

Figure 1. Number of articles per annum 1990-2015 referenced in ASSIA, CSA, IBSS, JSTOR, Web of Science, Zetoc, COPAC data-bases.

There can be little doubt that both the academic research and the lobbying on behalf of young carers helped to compel the statutory sector to tackle the problem of a service resting on the unpaid and sometimes damaging work by children and young people. These two factors combined to elicit responses from the statutory sector. The role of the media in contributing to this heightened awareness was significant but of more mixed benefit and this will be described in the thesis (Section 2.3.2).

However successful lobbying on behalf of young carers was not a sufficient achievement. Articles 12 and 13 of the UNCRC confirmed a child's right to express their views and to be heard in any business which affected them. This implied that it was not enough for their wellbeing to be considered and decisions even well-intentioned ones 
made by others: their voices should be heard and their views should count. It is certainly critical for any child involved in caring for a disabled or sick family member for policy-makers and service-planners that the appropriate decisions be made and that the support provided be effective. The situation cannot be properly understood without hearing from the perspective of young carers and more than simply involving them in providing data directly to researchers. In addition to the efforts of researchers and lobbyists to depict the experiences and problems of young carers, there is now a movement for young carers to represent their own need for recognition and to argue for the support they need. Chapter 5 will describe this development and how far it has progressed.

\subsection{Research}

Recognition alone cannot ensure proper responses; neither can action be correctly designed and targeted without analysing the material of young carers' lives and without measuring the outcomes. In order for young carers to benefit from the requirements in the UNCRC and in the carer legislation, a better understanding of these issues was necessary: how young carer could be defined; what constituted caring for a young person; how many young carers there were in the population; how they could be identified; what their lived experience was; whether caring at a young age would have any effects on the young person. These questions have driven academic research since 1988.

\subsubsection{Challenges.}

Throughout the literature review, studies are cited of many aspects of young carers' lives. A degree of consensus seems to have developed on the effects of caring on children and young people. As a consensus was building up about the existence of young carers, their experience and the potential adverse effects of young caring, another stream of comment was appearing. 
Olsen (1996) pointed out that the emphasis on young carers' difficulties risked implying criticism of disabled parents' ability to fulfil their parental role adequately. A response from the disability rights point of view challenged the focus on young carers and asserted that adequate services to the person needing support would preclude the need for reliance on carers at the same time maintaining the dignity and independence of the service user (Keith \& Morris, 1995; Olsen, 1996).

Newman (2002) contested existing research on a number of grounds. Firstly he took the view that emphasis on supporting young carers was in danger of displacing the parental duty thus causing disabled parents to be seen as a threat to their children's welfare, echoing the concerns of Keith and Morris: "The drive to include ever larger numbers of children within the young carer category, regardless of whether substantial amounts of care are delivered or not, must be resisted" (p. 621).

He challenged also the assumption that adverse outcomes were inevitably the result of young caring, saying that there "was no empirical evidence for the association of adverse outcomes with young caring where the family situation is compounded by poverty" (p. 615). In 2002 it remained for researchers to confirm or disprove this view.

Dearden \& Becker (2002) made the point that the causes of adverse effects had not been researched widely enough especially in reference to education. They suggested that other factors-"IQ, distance from school, poverty and social exclusion, personal interest, parental interest and stimulation" (p. 6)-might be influential. They stated that until these had also been measured it would not be clear whether young carers were any more likely to experience educational disadvantage than other vulnerable groups.

\subsubsection{Gaps in research.}

In addition to that referred to by Dearden and Becker (2002), an aspect of the young carer's experience that has been covered less thoroughly is 
the importance for young people of building social and human capital and the potential of caring to interfere with this aspect of their development. The acquisition of social capital for children was seen originally mainly as a result of parental and family resources (Coleman, 1987; Putnam, 1995). Holland (2008) discussed the possibility that children can function to form their own social capital. Bassani (2007) pointed out that any analysis of the role of youth organisations in acquiring social capital had been overlooked. One of the few attempts so far to examine social capital in the context of young carers is the work by Barry (2011) although Skovdal and Ogutu (2009), Skovdal et al., (2009) and Skovdal (2011) began to explore the concept in studies of young carers in Kenya. Barry assessed the value for a sample of young carers of social networks namely family, friends, school and YCPs. Given the interruption that can occur in personal and social lives as a result of caring, the scarcity of UK research on this topic would seem to require further exploration and in particular examining the relative importance of YCPs in this context (see Chapter 5).

\subsubsection{Methodologies.}

As research into young caring developed and expanded, some gaps were noted in the methods being used and the reliability of findings.

As early as 1999, Qureshi commented on the difficulty of obtaining reliable evidence of the effectiveness of a service: "The achievement of services which are aiming to prevent something happening may be hard to demonstrate. Comparative data about what would happen in the absence of services may be unavailable" (p. 262). Newman (2002) argued for the importance of evaluating the effectiveness of services. Banks et al. (2002a) drew attention to the shortcomings in methodology: the small samples, the lack of control groups and the absence of comparisons with other service models. The lack of comparative studies or of the use of control groups was also remarked on by Roche \& Tucker (2003). Netten (2011, p. 1) stresses that 
"fundamental to the measurement of outcome is the concept of comparison". Subsequently there were examples of research adopting this methodology (Fraser \& Pakenham, 2007; Pakenham et al., 2006; Pakenham \& Cox, 2015).

Pakenham et al. (2006) called for 'empirical validation' (p. 115) of qualitative findings saying that: "Overall, however, there are few welldesigned published studies in which the impact of young care-giving has been systematically investigated using quantitative methodologies" ( $p$. 114). More studies using quantitative methods to measure outcomes have appeared in recent years most notably by Pakenham et al. in 2006 and 2007. Other recent works using this methodology have been published by Cassidy \& Giles (2013), Nagl-Cupal et al. (2014) and Pakenham \& Cox (2015).

\subsubsection{Research with vulnerable participants.}

There are concerns when collecting data from young people over and above those when dealing with adult participants. There is a further issue when dealing with children in a vulnerable group. The vulnerability of some young carers, the possible sensitivity of the subject matter and the age of some samples can present difficulties in involving young carers as participants and the usual research methods are not always the most productive. Principles such as safety, confidentiality must be observed.

This allows nevertheless for a diversity of research methods. Innovative participative methods are being used. Writing, drawing and photography as a means of expression were used by Skovdal et al. (2009) and Skovdal (2010a). The World Cafe method was tried by Aldridge (2008), Lackey \& Gates (1997) and McAndrew et al. (2012).

When collecting quantitative data and using objective measures, such creative approaches have limitations but consideration has still to be given to how best to engage the participants whilst taking into account their welfare. 


\subsubsection{Measuring outcomes.}

This study collected data in three areas: biographical details, caring profile and short-term outcomes. The analysis will look for correlations between demographic and caring factors and those outcomes. This might suggest that a factor may have value as a predictor of outcomes.

What have been less explored are the long-term outcomes. Three possible ways of obtaining data for this purpose came to mind: longitudinal research, obtaining access to educational and personal social services data and interviewing former young carers. They all required resources beyond the capacity of this study. Some studies of former young carers have previously been undertaken although mostly qualitative and with small samples, one such study being "Research with former young carers" (O'Dell et al., 2010). Frank et al. (1999, p. 29) wrote of long-term effects based on the evidence which emerged from the interviews with former young carers. An alternative approach was to look at those short-term outcomes which will themselves influence long-term outcomes.

Interviewing a group of teen-agers, O'Dell et al. (2010) reported that the young carers saw caring as "an obstacle in the way of achieving the 'reality' of being a teenager" (p. 652) and not part of normative development. They concluded that "The need is thus to consider the broad cultural context in which the child develops" (p. 653) rather than only in the narrower framework of age-related development. An analysis of data on the social lives of young carers and on their participation in social and community life could indicate their development in the broader context, the extent to which they are able to build social and human capital and whether this is affected by their role. As a possible pre-condition of longer-term outcomes, this would be of particular interest. 


\subsection{The Structure of the Thesis}

Chapter $\mathbf{2}$ of this thesis will explore the literature to discover in more detail how far these questions have been answered to date: how the concept of young carer developed; how they can be distinguished from those who help at home or from other groups of vulnerable children; how common is the phenomenon.

Chapter $\mathbf{3}$ of this thesis will examine the evidence on the effects of caring either adverse or positive by those under 18 . This encompasses their physical and mental wellbeing, their social and educational development and their prospects for the future.

Chapter 4 will describe the services available at the time of writing and will also summarise the feelings and thoughts which set up complex impediments to accessing services.

Chapter 5 will recount the way the issue of young carers has become public and how young carers are beginning to take an important role themselves in communicating the issues that face them. It will examine the role of the YCPs in countering difficulties for young carers and in promoting positive outcomes. It will explore the role and effectiveness of YCPs.

Chapter 6 will describe the Methodology. It will describe the nature of the inquiry and the Research design. The ethical considerations will be explained and the process of obtaining ethical approval recounted.

Chapter 7 will report the findings of the surveys in both Phases. For the purpose of clarity, the results of each phase will be presented separately within the context of this chapter. Phase 1 will collect data on provision of services to young carers in Wales and the findings should satisfy the first research aim of mapping provision. Phase 2 will collect data from individual young carers on their biographical and caring details, their educational attainment, their health and their personal and social lives. A quantitative analysis will answer the second research aim of 
examining the relationships between outcomes and factors which may have contributed to them and the third research aim of identifying the relative importance of factors affecting outcomes for young carers.

Chapter 8 will go on to discuss the findings and highlight some points which arise from the data.

Chapter 9 will offer some conclusions with recommendations for action and further research. 
Table 1

Research Objectives, Aims and Questions

Research objective

To explore outcomes for young carers

Research aims

1. To map and evaluate extent of existing provision for young carers in Wales.
2. To examine the relationships between outcomes and factors which may have contributed to them.
3. To identify the relative importance of factors affecting outcomes for young carers.

Research questions

1. How well developed are the services for young carers?

2. How much partnership working is there?

3. How accessible are the services?

4. How do the service providers evaluate their service for young carers?

5. What do the service providers perceive to be the challenges?

6. What is the relative importance of the Projects in provision for young carers?

7. What is the amount and source of current investment in Projects in Wales?
8. What are the outcomes on the chosen measures?

9. Is there any association between Educational Attainment and other outcomes?

10 Is there any association between emotional literacy and other outcomes?

11 Is there any significant statistical evidence of an association between outcomes and any factor in the biographical data?

12 Are there any differences in outcomes at group level between Projects?
13 Which of the variables have the strongest association with positive outcomes for young carers?

14 Which of the variables have the strongest association with adverse outcomes for young carers? 


\section{Chapter 2}

\section{The Development and Recognition of the Concept of}

\section{"Young Carer"}

This chapter examines how the concept of young carer has developed historically and geographically and how it has come to be identified as a social problem. It looks at the incidence of young caring and what distinguishes young carers currently from other vulnerable groups in legislation and in practice.

\subsection{In the Context of "childhood"}

Before looking at the development of the concept of young carer, it is useful to look at how the concept of childhood has developed. The changes in how children have been regarded and valued can be observed and fluctuations in what has been seen as acceptable treatment at different points in UK history. A look at varying attitudes to working children shows how what is seen as normal has altered over the centuries and across continents. Locating the boundary between caring and the kind of chores that children might do and even be expected to do at home as part of the family is not a simple task. The historical, global and domestic aspects provide the context in which children who care have come to be regarded in the UK as deserving a separate classification.

\subsubsection{Historical.}

In the West, it was not until the latter half of the 20th century that childhood began to be treated with historical perspective. One of the earliest studies was by Ariès (1962) who is credited as being the initiator of the subject of the history of childhood (Burton, 1989) and acknowledged as a pioneer in the field although criticised later for methodological flaws (Stone, 1981; Wilson, 1980). His understanding was that until the 17th century the period of infancy lasted until 
between five and seven years after which age children were seen as miniature people, mixing with adults, playing the same games and working with adults in the fields and at home. He claimed that the 17th century was the time when that began to change. He traced two influences in bringing about the change: religious belief that children were God's creatures who needed to be protected and a concern for physical health and hygiene. Both of these influences he saw as starting with the middle classes. By the 18th century, he wrote, "the child has taken a central place in society" (p. 44). He believed that this had a gradual effect on the attitudes of the lower classes by the late 19th and 20th centuries.

A major step in understanding the development of the concept of childhood was taken by Stone (1977) with his study of the family, sex and marriage in England. He applied the methods of social science to the study of history and focused on social, economic and intellectual factors as the motors of change. He acknowledged his debt to Ariès (Stone, 1977, 754, note 85) and recognised the emergence of the "identification of children as a special status group" in the late 17th and 18 th centuries (Stone, 1977, p. 221). He attributed this change in attitudes to two currents: the growth of individualism dating from the Renaissance and the Puritan movement which emphasised the responsibility of the individual for their own sin and salvation (p. 224). He noted the growth in affective parenting and the decrease in size of family, believing that this followed rather than preceded the decrease in infant and child mortality. Before that happened, an "emotional investment" (Stone, 1981, p. 74) in an individual child was in danger of being wasted and "family limitation was a gamble with death" (1977, p. 651). This interpretation was later contradicted by Zelizer (1985) who thought conversely that the decrease in mortality was caused by parents placing a greater value on their children.

He did however reject any simplistic identification of trends. In his writing he worked to demonstrate that the development was complex, 
complicated by class, by national differences and by social and economic developments, a process which he refers to as "an unending dialectic of competing interests and ideas" (1977, p. 683), that is individual, kin, family, community, state, Church. Furthermore he believed that this was a continuous process. As he saw it, part of the complexity was also the undeniable effect on children of the history of the parents who controlled them, resonant of Bronfenbrenner's linked lives (1979, p. 19). He agreed with the overall direction of development but produced evidence that there were movements both backwards and forwards, for example the new permissiveness of 18th century upper and middle class parents gave way to the harshness of parenting in the Victorian family. He wrote that "the only steady linear change over the last 400 years seems to have been a growing concern for children" (Stone, 1977, p. 683).

Writing of the United States but having parallels with Britain, Zelizer (1985) referred to new middle-class attitudes in the 19th century as the "sacralization" of the child. An emotional and sentimental interpretation of childhood emerged with expectations of what constituted a "proper childhood".

Zelizer also highlighted the importance of the growth of the public health and safety movement and showed how this concern for children's health led to increased interest in the effects of child labour. In Europe and North America, children had for centuries been considered from a young age as contributors to family income, helping in the fields in rural areas, contributing to work at home in cottage industries, in domestic service and in the manufacturing processes after the Industrial Revolution. They worked often for long hours and sometimes in harmful conditions, sometimes paid, sometimes unpaid. Zelizer wrote that "the birth of a child in 18th century America was welcomed as the arrival of a future laborer and as security for parents later in life" (1981, p. 1038).

With the change in attitude in the mid-19th century towards affective parenting, a perception of child labour as undesirable had 
grown among the upper and middle classes and instead there appeared the phenomenon of the economically worthless but emotionally 'priceless' child" (Zelizer, 1981, p. 1037). Legislation about conditions in the workplace was enacted in Europe and America and the introduction of compulsory schooling also helped to protect children from work outside the home. Zelizer (1985) like Stone observed a struggle and opposition between different interests and different classes. A difference developed between those who wished to respond by regulating child labour conditions and those who wished to eliminate child labour altogether. The aim of eliminating child labour by legislation was resisted by employers who needed abundant and cheap labour and in practice the restriction of child labour and the pressure for school attendance was resisted by poor and low waged families (Olsen, 2000) who needed the money brought in by their children. This was an illustration of the "ebb and flow of battle between competing interests and values" described by Stone (1977, p. 682). Nevertheless the modern view of childhood began to prevail in Europe and North America and children working was seen as acceptable only to promote a child's development and to build character but not to contribute to family income (Zelizer, 1985).

A more detailed, less schematic picture of the history of childhood was provided by Cunningham (2006). In his writing a child-centred view began to emerge. He used a wealth of anecdotal material, both literary and oral, to illustrate the changes in the real life experiences of children over a millennium, whilst also picking out the themes running through the historical development. He traced the belief in the innocent child born without sin back to Rousseau. He highlighted the same themes as those explored by Stone and Zelizer, the role of religion, the public health movement, whilst stressing the complexity of the changes.

It could be argued, however, that changing social and technological circumstances seem not yet to have eliminated a popular attachment to the idealistic concept of childhood but have rather maintained concerns 
about its being disturbed by what Larkin (2009, p. 73) refers to as "a blurring of the boundaries between adulthood and childhood". There are now widespread concerns that childhood is at risk from invasion by adult influences and by preliminary access to adult experience especially through the media and commercial influences. The idea that children are now per se a vulnerable category by virtue of their subjection to impacts inappropriate to their developmental level permeates the young carer discussion. The idea that children might work, even do paid work part-time in the evening or at weekends, to promote their own personal development seems to be acceptable as is the work that children may do to assist their parents in domestic tasks but children working from necessity as young carers do offends the acceptable norm for children.

A most significant contribution by Cunningham was his focus on the development of children's rights. In The invention of childhood (2006), he referred to three major events in this movement: the Geneva Declaration of the League of Nations Declaration (1924), the UN General Assembly's Declaration of the Rights of the Child (1959) and the UNCRC (1989). The principles enshrined in these documents have increasingly permeated legislation and social policy concerning children through the 20th century. For Cunningham, this was another aspect of the concept of childhood that is socially constructed by adults whose view of childhood is that children should be protected and dependent, live in a world separated from the adult world and having the "habit of happiness". In this process, in his view, we have gone too far, casting children as helpless subjects and neglecting children's ability to contribute (2007, p. 13).

\subsubsection{Global.}

Another approach to gaining a perspective on the concept of childhood is to adopt a global viewpoint. White (1999, p. 133) wrote: "All over the world, work of some kind is (and has always been) part of most children's lives". According to an estimate by the United Nations International Children's Emergency Fund (UNICEF) based on data from 
102 countries (2009), at least 150 million children $5-14$ years old worldwide are engaged in child labour hence the norm being very different from that in 21st century Britain.

Furthermore much of that labour is exploitative and harmful. The UNCRC in 1989 recognised that "in all countries in the world, there are children living in exceptionally difficult conditions, and that such children need special consideration" (Preamble). The principle reaction to this situation in the last half-century was to work towards the elimination of child labour. The International Labour Organisation Minimum Age Convention 138 (1973) was entirely about stopping child labour. Later the International Labour Organisation (ILO) compromised on setting the elimination of the worst forms of child labour as a priority with the Convention 182 (1999) but still saw the complete elimination of child labour as the ultimate goal (Dennis, 1999; Invernizzi \& Milne, 2002).

The UNCRC (1989) had wide support, making Article 32 a significant step forward in addressing issues of child labour:

States Parties recognize the right of the child to be protected from economic exploitation and from performing any work that is likely to be hazardous or to interfere with the child's education, or to be harmful to the child's health or physical, mental, spiritual, moral or social development. (UNCRC, 1989, Article 32)

In its Convention 182 (1999) the ILO clarified the improvement of conditions by defining the harmful elements as enslavement, engagement in military actions, the sex and drugs trade and any hazardous or dangerous work. Conditions were specified relating to minimum age, nature of work, number of hours, night work. Unlike the 138 Convention (1973), the Convention 182 had considerable support from governments. The fact that it ceased to distinguish between paid and unpaid work represented another step forward but household work was still excluded from the definition of economic activity. 
However there had ensued after 1989 a struggle to amend the single approach of elimination. Attention was drawn to cultural relativism and the diversity of circumstances and social norms across the world (Miljeteig-Olssen, 1990; White, 1994). It was pointed out that in some economies particularly in developing countries children's earnings were needed by the families. Arguments were put forward that child work played an important and necessary role in different economic cultures, that it had positive socialising outcomes and that it enabled children to play a substantive part in family life (Meljeteig, 1999). Those interested and experienced in the field pointed out that Article 3 of the CRC stated that the best interests of the child should be the "primary consideration" and that those best interests might be interpreted as retaining child labour whilst excluding exploitative or harmful conditions (Myers, 1999).

Furthermore the elimination of child labour positions children solely as victims and discounts their agency. White made the point that child labourers shared the category of "structurally disadvantaged groups" but that it is the only one of those groups for whom preventing their work rather than improving work conditions is seen as the solution (White, 1994, p. 849). Indeed the resistance to the abolitionist resolution of the ILO Convention 182 recalled similar resistance to legislation and compulsory schooling in the UK in the nineteenth century. Significantly the Convention found opposition coming from working children's organisations themselves (Invernizzi \& Milne, 2002). Accordingly, in White's view it was "the abuse of children in work, rather than the fact of their involvement in work" that should be dealt with (White, 1994). For this reason he did not believe that a blanket abolitionist view was appropriate.

An important issue introduced by the resistance from the working children's organisations was the right of children to participate in the policy making that affects them (Invernizzi \& Milne, 2002; Woodhead, 1999). Invernizzi \& Milne highlighted child labour: "There is a crisis in children's rights...The most significant manifestation of this crisis is seen 
in the world of working children" (p. 403). White (1994) noted that although working children were involved in the development of the ILO Convention 182 the Convention itself did not require children's participation in policy making. Their involvement could have the advantages of developing solutions which took into account the preferences of working children themselves and of producing workable solutions. He illustrated this by saying that the kind of child work which agencies were trying to eliminate (unpaid, at home for parents, smallscale) was exactly the kind that children preferred although he gave no reference to evidence this statement.

Another issue arising from the global debate was the place of household chores in the definition of child labour. This had been excluded until a UNICEF report in 2009 which included household chores because it could have the same effect in depriving children of an education and its subsequent benefits but the report did represent a compromise in that it equated a greater number of hours spent in household work with a lesser number spent in "productive" activities because it was considered to be less harmful. So for example for children aged between 5 and 11 one hour of economic activity per week was stipulated as equal to 28 or more hours of household chores (UNICEF, 2009, p. 16).

Once household work was included in the definition of child labour and in the data gathered, another factor became apparent: gender. The Director General's Report to the ILO Conference (2006) stated that girls were less likely to be paid and "spend much longer on such tasks" (para 191). UNICEF data (2009) indicated that $5 \%$ of all girls were engaged in household child labour and $3 \%$ of all boys. This had implications for their education: "...school attendance declines as the number of hours spent on household chores increases - and declines more steeply for girls than for boys." (Progress for Children, 2009) 
In exploring the developments in child labour, Woodhead (1999) pointed out that childhood is not an immutable concept. As it had changed over time, it would continue to change.

\subsection{What Distinguishes Young Carers?}

From the brief review above of historical and global evidence it is clear that the concept of childhood itself has changed and that the perception of what is normal, tolerable or even desirable has varied according to history and geography. Cunningham made the point that the concept was still changing (Cunningham, 2006). In the last chapter of The Invention of Childhood, he described the multiple changes in children's experiences with which society is dealing currently, for example multiculturalism, obesity, consumerism, which would in turn have an impact on the experience of childhood. For these reasons we might conclude that childhood is a social construction (Cunningham, 2007, p. 13; Olsen, 2000, p. 391). This would be however to discount the internal and essential changes which are implicit in a child's development.

\subsubsection{Identifying the difference between helping and caring.}

Defining what constitutes caring by children and young people is a task which rests on the evolving definition of childhood within which it is difficult to distinguish between caring and helping at home.

This issue is hampered by a lack of data on what domestic and caring tasks are taken on by children in non-disabled families. In an article in 2007, Warren observed "the existence of a group of children and young people who sometimes perform more domestic and caring tasks than known young carers". (p. 139). In her study, she found that:

the types and levels of domestic and caring tasks undertaken by young carers compared with other children and young people in the general population has, until recently, remained unknown. No baseline exists for establishing normal expectations of children help 
in running a household (SSI, 1995) and there has been no comprehensive study to date to compare child domestic and caring responsibilities in families where there are disabled/ill and nondisabled/well members. (Warren, 2007, p. 137)

It is also made difficult by the lack of consensus on what defines a young carer and of what a young carer does as opposed to a child who is helping in the home. Becker et al. (1998) referred to there being "no universally accepted definition as to what precisely constitutes a 'young carer'". The DoH said in its National Strategy Caring for carers that "There may be only a narrow dividing line between helping round the house which many children do, and providing personal care for a relative" (DoH, 1999). Even in 2009, Richardson et al. (2009, p. 151) referred to "what is or is not considered to be the norm" in trying to draw a line.

The survey by the Strathclyde Centre for Disability Research (1999, p. 811 ) said: "Few of the 14 young people who had been identified as young carers by professionals were found to be fulfilling a primary caring role". Means et al. (2008) said that a distinction was increasingly being made by researchers between informal helping and heavily involved caring (p. 14) but Means et al. did not make clear the exact difference between the two.

Legislation and policy is replete with phrases such as "inappropriate levels of caring responsibilities" (CA, 1989) and "significant responsibilities for care" (1999, p. 75). But inappropriate and significant were not defined.

Mahon et al. (1996) blurred the lines even further by rejecting the configuration of helping and caring as normal and deviant respectively. They warned against the pathologising of young carers as a social problem in a society in which family forms are so diverse.

However, since there is now a legal basis, even a loosely defined one, and a service planning issue for identifying problems associated 
with young caring, it is important to explore what marks out helping at home from caring. In the absence of any definitive standard, there are practical elements that could help indicate where the boundary lies: purpose of the work, whether the child has a choice in whether to do the work, the amount of work, the types of tasks undertaken, how often they carry out the tasks, the degree of responsibility they assume, the length of the commitment and the impact of caring.

\section{Purpose.}

The concept of the child helping out at home is regarded currently as part of the modern family dynamic as evidenced in Rutherford's analysis of 300 child-rearing advice articles (2009). It is even perceived popularly as a socialising process and developmentally valuable (Blair, 1992; Dunn, 2004). Meredith wrote in an article in Community Outlook in 1992 that "Helping out can be a healthy part of a child's family life". Aldridge and Becker (1993b) acknowledged the view that "adapting to responsibilities through the performance of minor domestic tasks is an important factor in the development of children's lives". A study by Rheingold (1982) demonstrated that children as young as 30 months, even before they can verbalise their attitudes, showed signs of wanting to engage in household tasks with their parents. Articles on how beneficial it is for children to help and advice to parents on how to encourage this are abundant in the popular press and media and on the Internet. It was even proposed as a predictor of future success for the child if practised before the age of four (Rossmann, 2002). In a study of 790 homes in Nebraska by White and Brinkerhoff (1981, p. 791), the child's development was very much the main reason given for assigning tasks so that it emerges as the "normative" purpose.

A further factor in separating helping from caring is whether the work done outweighs the adult's time and effort spent supervising (Researchworks, 2002). In young children the accomplishment of a task often requires help and monitoring from the parent even when not actually necessitating the completion of the task by others or clearing 
up afterwards. "Until adolescence, children's chores probably represent more, rather than less, work for the parent" (White \& Brinkerhoff, 1981, p. 792)

Older children are often engaged in the supervision and care of siblings particularly in larger or single parent families where there is no disability involved. Yet in none of these situations does the task of sibling carer on its own earn the young person the definition of young carer.

There are families who have no long-term sick or disabled members where children carry out a substantial amount of domestic and household tasks. In some cases the practical contribution of the child is necessary for the functioning of the family. This means that the help is required of the child for the sake of the parents or family rather than for the benefit of the child.

There is a strong body of opinion arguing against this definitional separation of helping and caring. An official from the Office of the Children's Commissioner for Wales expressed the view in interview (Oct. 6th, 2011) that it is not safe to set boundaries too prescriptively as this risks some young people who are affected adversely by their caring duties finding themselves on the wrong side of the boundary and thus not getting the help they need.

On the other hand, Newman (2002) foretold attempts to maximise the numbers involved and to boost the effects of caring in order to support the case for resourcing the service. He counselled against "the weakening of definitional boundaries" (p. 620) as it would lead to a considerable extension of the services before their effectiveness had been properly evaluated.

It does seem that the functional purpose of the work may distinguish between caring and helping. However, since young people in families with no disabled member carry out essential work, the functional purpose is not unique to young carers. 


\section{Choice.}

Rutherford (2009) suggested that the prevailing culture today is one of "choice". In this ethos, parents are encouraged to offer a child options and not to force them to do anything but children who care for family members may not in reality have a choice whether they wish to care or not. Olsen (2000) maintained that it is the social construct of young carer which masks the fact that it is disadvantage and poverty of support which removes the choice from the children. Keith and Morris (1995) held the view that the provision of services to maintain the independence of the disabled person should remove the necessity for young people to act as carers. Whilst this view has credence in terms of disability equality, appropriate services are not always available to relieve young people of the duty of carer or may in any case not reach some families. Becker wrote as recently as 2013 in the Foreword to the Children's Society report Hidden from view:

despite government rhetoric and advances in recognition and services for young carers over recent years, young carers are still no more likely than other children to be in contact with social services and educational welfare services - services that are mandated to offer them support. (p. 3)

There is also an argument that some young carers' situations are complex or unpredictable and so it is difficult to design a service which could relieve them of stress. Examples of this would be where the condition of the person cared for changes without warning or where there are difficult family relationships apart from the disability or illness.

The situation where young people's work is essential to the functioning of the family is incompatible with the view that it should not be necessary for children to work. The comparatively recent Western expectation that parents' role is to protect and support their children is contradicted by the situation in which a parent has no choice but to depend on a child. This attitude can in turn lead to the perception of 
the child who cares as of a victim who has no choice and not as an agent (see Section 2.3.2). The dispute in global terms between those who wish to end all child labour and those who wish to acknowledge the essential role of the child as worker and to ameliorate the conditions in which children do much needed work is mirrored in the current argument. There is the view that children should not be carers and that services should be sufficient to eliminate the necessity for them to care (Keith \& Morris, 1995), even if that were to be possible. In contrast, there is the view that recognises that where choice is not available there should be a focus on support that will avoid harmful effects for the young carers who have no choice.

Whether it is because the condition of the disabled person requires care or, as suggested by Newman (2002) and Olsen (1996), for reasons of disadvantage, it does seem that lack of choice characterises the situation of the young carer. Nevertheless, as with Purpose, this may not be unique to young carers.

\section{Hours spent caring.}

In reaching a definition of caring, the comparison with helping at home is not necessarily a helpful one because addressing this question is hampered by a lack of norms for what domestic and caring tasks are taken on by children in non-disabled families. A study of 105 two-parent families by Cogle et al. (1982, p. 452) found that adolescents (aged 1217) spent an average of 64 minutes per day on household tasks which equates to $7 \frac{1}{2}$ hours per week. In the White and Brinkerhoff study (1981, p. 792), the median time spent across the age range (0-17) and gender was 4 hours per week. They produced a table graded according to age showing that duties increased towards the early teens and then tailed off. These were not families with disabled members.

Meanwhile, in the 2004 Report on Young Carers in the UK commissioned by the Carers' Trust and the Children's Society, Dearden and Becker stated that half the young carers questioned were caring for 10 hours or less weekly but approximately $2 \%$ were caring for more 
than 50 hours each week. Data from the Longitudinal Study of Young People in England (LSYPE, 2010) cited in Hidden from view (Woolley, 2013) stated that many young carers were only caring for a few hours a week.

Whilst there is no legal specification of the number of hours that define caring, Lloyd (2006, p. 946) said that in policies on adult carers they have "come to refer to anyone who carries out 20 or more hours per week of caring activities".

Although there does appear to be some gradation, there is not a great deal of existing evidence which can mark a clear difference on the basis of number of hours alone.

\section{Type of tasks undertaken.}

Suggestions abound on the Internet about what tasks are suitable and age-appropriate for non-carers.

Many guides to parenting offer advice on age-appropriate tasks. These are mostly depicted as helping the adult with the normal running of the household and at age 14 upwards they are recommended to take on adult tasks themselves such as mopping the floor and cleaning windows and looking after young siblings. In the study by Cogle and Tasker (1982, p. 396), the range of tasks undertaken by the children aged 6-17 in 105 families included housekeeping, food preparation, dishwashing, maintenance of home, garden, car, pets, shopping and caring for clothing. Even with caring for clothing, the least favourite task, $14 \%$ of the participating children carried it out. In the White and Brinkerhoff study (1981), the chores performed by children under 10 were usually about their own surroundings and activities such as picking up their toys; at the age of ten, children moved on to tasks for the family and from 15 they were "replacing parents by assuming full responsibility for some tasks".

Most of the range of tasks described above as normal household chores are similar to those performed by young carers. The 2004 report on young carers (Dearden \& Becker, 2004) based on 6,178 young 
carers under- 18 found that $66 \%$ were indeed providing domestic help and $11 \%$ childcare. However they found also that $18 \%$ of young carers were providing intimate personal care, $48 \%$ nursing-type care and $82 \%$ emotional support. These latter are surely types of care which are ageinappropriate and distinguish young carers from other children. For Becker (2010), the provision of intimate care was the best proxy marker of being a young carer. Warren (2007) held the same view although this was challenged by Smyth \& Samia (2010) who maintained that the level of responsibility was a more valid marker.

The view of one official from the Office of the Children's Commissioner for Wales (personal communication, Oct. 6th, 2011) was that children should absolutely never be involved in toileting or the administration of medication or manual handling and that this amounts to child abuse and is therefore unacceptable.

According to Dearden \& Becker (1998), young carers, even from the age of five, are in this way for some of their time "acting as providers of familial care" (Fox, 1995, p. 221).

In spite of the lack of information about domestic and caring tasks in the general population, there does seem to be sufficient evidence to suggest that the type of care provided could prove to be a valid marker of caring as opposed to helping.

\section{Duration of commitment.}

Children who are not carers may from time to time provide some kinds of personal care for relatives for example such as combing hair or assisting movement when an adult is temporarily ill or incapacitated but this is usually time-limited and not on an on-going basis unlike caring which can start very early and can be long-term. Dearden and Becker's 2004 study reported that in their very large sample $36 \%$ had been caring for up to 2 years, $44 \%$ for $3-5$ years, $18 \%$ for $6-10$ years and $3 \%$ for over 10 years (p. 3).

The characteristic of the young carer is that the commitment often has no end date since the condition of the person cared for is frequently 
long-term or having no prognosis of improvement or recovery. This can in some cases result in the young person not being free to pursue their further or higher education or career opportunities (Audit Commission, 2010; Woolley, 2013). Whilst this latter characteristic may be present in adult caring, it does not have the same meaning in that context and so could be seen as a feature which distinguishes caring from helping for children and young people (see Section 3.1.8 on Transition).

\section{Responsibility.}

The example of administering medication is a good demonstration of the particular situation of the young carer. This is a task which in hospitals requires a qualified person to supervise and in residential homes requires two trained adults but we have children having to take responsibility alone for a task which if wrongly carried out could have harmful or even fatal consequences. Similarly for paid workers, helping with mobility has strict professional

If I don't do it, no-one else will' (female carer,

11, Full of care, 2009, 25). guidelines requiring dual handling to prevent injury to the care-workers or nurses but there are many young carers who have to do this alone and untrained. There is evidence of children having to take charge of the

household budget and finances, providing food and dealing with medical and social work staff. These are tasks which are not typically part of childhood helping out but way beyond a child's expected capacity. They are in fact taking on "a level of responsibility which would usually be associated with an adult" (Dearden \& Becker, 2000c; SSI, 1995).

The Carers' National Association web-site (2014) stated: "Helping out can be a healthy part of family life. But where this becomes a responsibility there can be serious effects on a child's personal and educational development."

Young carers may be sole carers, that is the only person in the home taking responsibility for caring, a supportive carer, that is one who 
assists another adult to care, or one who helps to care for a sibling, that is a sibling carer. Frank (1995) uses these terms and definitions to classify different levels of responsibility. There are additional situations which imply varied levels of responsibility, for example being the oldest sibling to care or having more than one person to care for. Therefore it might be useful to refine the definition of supportive carer further into main carer, that is one who shares the caring but is the older or the one who takes the main responsibility, and supporting carer, that is one who carries out tasks but together with older or more responsible carers. This will allow testing for correlations between outcomes and variables such as responsibility, workload, time spent.

For Smyth et al (2011b, p. 512), responsibilities is very much a distinguishing feature of being a young carer as opposed to a helper. Perhaps taking on responsibility can be considered a critical factor in separating helping at home from being a young carer.

\section{Impact.}

As early as 1992, Meredith suggested in his Community Outlook article that the limits of helping out can be set by the possible adverse outcomes.

The element of impact was specified in the survey by the Strathclyde Centre for Disability Research (1999). They noted that few of those identified as young carers by the professionals were playing a primary role in caring yet, regardless of the type of caring involved, there was more evidence of depression, of low self-worth and negativity in outlook than in non-carers (p. 811).

Since then evidence has been accumulating about the harmful effects and the breadth of the impact of caring on young people, summarised by Becker in the section on young carers in the Blackwell Encyclopaedia of social work (2000): "impaired psychosocial development, including poor educational attendance and performance, and restricted peer networks, friendships and opportunities" (p. 378). This was re-enforced by Larkin's view (2009, p. 78): "being a young 
carer has been found to adversely affect educational performance, school attendance, emotional and physical health and transitions into adulthood". Woolley (2013) pointed out the adverse effect on their social lives and, drawing on evidence from the LSYPE, on their educational and career outcomes. The effect on health both physical and mental (Cree, 2003; Frank et al., 1999) can be added to the list of the potential harmful effects of caring on some young people. This is examined further in Section 3.1.

Examples have also shown the impact on school attendance and performance of household chores carried out by a child in a family with no disabled members. It is admitted in Becker et al. (1998) that other vulnerable children may experience the same restrictions as those living in poor or deprived families. With that in mind, it would be invalid to use impact alone as a marker although that is not to discount the need for assessing and tackling adverse outcomes.

\subsubsection{How are young carers different from adult carers?}

The London and Welsh Governments have opted for including young carers as part of the overall population of carers. This has some advantages as there are some issues in common. In the light of this policy direction, it is logical to ask whether there are any policy issues which distinguish young carers from adult carers as a separate vulnerable group. The most obvious answer would in turn be their age. Noble-Carr (2002) wrote: "...the unique vulnerabilities of young carers because of their age distinguish them from other carers and need to be specifically addressed." This view was again expressed strongly by the Children's Commissioner for Wales (2009): "Young carers have very different needs to older people and adults who may be carers". One of the main differences between young people and adults caring might be for example the energy levels usual for the different age groups.

Aldridge and Becker (1993) said that the research "suggests that the age of carers is of critical importance... in terms of the influence on lifestyles, needs, opportunities, and health". They differ significantly 
from adult carers because of the stage of their cognitive and intellectual development, their lack of life experience and knowledge which exposes them to additional and different risks from those of adult carers.

Education, training and the acquisition of qualifications are an important part of a child's or young person's life and a huge factor in success in later life (Pickard, 2010). This is less often a factor in an adult carer's life. Some evidence of the adverse effects on some young carers' education has already been found (Children's Commissioner for Wales, 2009; Dearden \& Becker, 2004; Fox, 1995) and this is further explored in Section 3.1.1.

It can be argued very strongly that for a young person as opposed to an adult caring can interrupt the normal psychosocial developmental process and the transition from child to adult. Aldridge \& Becker (1993) referred to the "particular needs which are age and developmentally specific". The problem with transition to adulthood is examined in Section 3.1.3.

Most carers suffer some degree of stress not excluding young carers (Children's Commissioner for Wales, 2009). Stress however has a proportionately greater effect on children than on adult carers because of their developmental stage. Cohen et al. (2012) analysed the impact of family caregiving on self-reported psychological well-being and they concluded that "Adolescence is a stressful developmental period without the added dimensions of caring for family members with health problems" (p. 254).

Finally Collins and Bayless (2013) in their comparative study of young carers and young non-care-givers reported comments by parents of the young carers that they had difficulties with peer relationships. This provides a clue to disturbances in the personal and social lives of young carers which might be less critical for adult carers who will already have formed friendships and social groups.

The observation of the Officer from the office of the Children's Commissioner for Wales interviewed in October, 2011 was that young 
carers are marginalised by being subsumed into the general category of carers and so their very different concerns do not receive proper attention. This is why the Children's Commissioner for Wales (2009) was asking for a National Young Carers Strategy in Wales. It explains why lobbyists such as Carers UK want to see staff in Social Services with particular responsibility for Young Carers.

\subsubsection{How are young carers different from other groups of vulnerable children?}

In the light of comments by Becker et al. (1998), Newman (2002) and others that it is not young carers alone that experience adverse outcomes, it would be helpful to look at what differentiates young carers from other groups of vulnerable children and whether anything justifies young carers having a separate category.

Larkin (2009) identified numerous vulnerable groups but did not include carers as a distinct group: lone parents, people with disabilities, older people, ethnic minority groups, the mentally ill, the homeless and asylum seekers/ refugees and children. Young carers may be members of or involved in any one of these vulnerable groups and share their vulnerability factors. For example, a young carer may have a disability or be a member of an ethnic minority family. In fact Larkin did refer to young carers as amongst the "particularly vulnerable" (p. 78).

Larkin deduced from the literature a list of vulnerability factors for children (2009, pp. 74-8): poverty, diet and obesity, risk-taking behaviour, maltreatment and health. Among the factors pre-disposing children to poverty are belonging to a lone-parent family (Larkin, 2009, p. 74) and many young carers will belong to this group and share the ensuing problems. Dearden and Becker reported that $56 \%$ of young carers are living in lone-parent families (2005, p. 3). Unemployment is often a contributory factor to family poverty and in the same study it was found that only $4 \%$ of those with care needs who responded were in employment and $54 \%$ of the adult family members not receiving care were in employment. Again these are factors not exclusive to young 
carers but it can be argued that their role as carer would be in addition to these vulnerability factors.

What then does the young carer experience that is dissimilar from other vulnerable groups of children? One central factor which characterises the life of young carers but not necessarily that of other groups of vulnerable or disadvantaged children is the effect on their role in the family. This has been referred to as the parentification of the child (Barnett \& Parker, 1998). It leads to the erosion of their experience of childhood, not as visualised in the idealistic perspective of the Victorians but in the normal developmental process (see Sections 2.1.4 and 3.1.3). Both the adverse and positive potential impact of this is described more fully in Chapter 3. A second feature is the lack of time and opportunity they have for socialising, resulting in greater social isolation (Barry, 2011, p. 524). The impact of this can be the inability to build human capital, a significant facet of development in this age group.

\subsubsection{The distinguishing factors.}

The descriptions above have attempted to establish the difference between young carers and children who are not considered to be carers, between young and adult carers and between young carers and other groups of vulnerable children.

Having examined the nature of helping and caring, a case can be made from the literature review for the distinguishing factors being: the type of work required which is often inappropriate for their age, the indefinite commitment and the responsibility undertaken which often sees them carrying out adult functions. Other factors may be present but cannot be said to be unique to young carers.

There are characteristics specific to their age which distinguish them from adult carers. One is the potentially greater impact on their mental and physical health because of their developmental stage; another area of impact is their education and social development where the impact can hinder full healthy intellectual and emotional growth and have long- 
term consequences. These mean that the issues for young carers may need specific attention.

Whilst the adverse outcomes may be shared by other vulnerable groups of children, it is the fact of caring duties and its impact which distinguishes them within their age group. Caring alone can bring in its wake a disturbance in the normal adult-child relationships in the family and issues of social, psychological and educational development which may affect the course of their lives but will not necessarily occur for other vulnerable children.

\subsection{What Has Contributed to the Growth and Adoption of the Concept?}

If we accept that young carer is a social construct, it is helpful to search in the literature for indications of how and why the concept developed and was used in research and policy. It became identified as a social problem with the realisation that there might be-and as evidence has shown that there is in fact-an unidentified category of young people who need support because of the caring role they are called on to perform within the family and who may experience disadvantage because of that role.

From the literature it is possible to discern seven strands driving the development of the concept, mixed and combined.

\subsubsection{Research.}

The existence of young carers sprang to attention with two quantitative works in 1988, surveys of the incidence of young carers in Sandwell and Tameside. The Young Carers Research Group (YCRG) based at Loughborough University was established in 1992 under the directorship of Dr. Saul Becker and their studies highlighted the concerns surrounding children and young people "whose lives are restricted because they provide care for sick and disabled family members". Their research and that of others continued and continue to explore the phenomenon. The motivation of researchers drives them to want to find 
out more about this category of need, the who, the where, the how and the why and then the what is effective.

The evidence produced of the extent of the problem and of the potential adverse outcomes for young carers has contributed to the gradual recognition of the need for appropriate support.

\subsubsection{Lobbying and campaigning.}

Undoubtedly the lobbying movement has played a critical part not only in raising awareness of the phenomenon of the young carer but also in putting pressure on law and policy makers to accommodate their needs (Aldridge, 2006).

The Carers' National Association and other voluntary organisations took up the issue in the early 90 s and together with professionals began lobbying and as part of their general campaigning strove for the recognition of the existence of young carers and for appropriate support. Their method is to follow up political lobbying with monitoring to see whether the agreed actions are taken (Cook, 2007).

The Community Care magazine ran a campaign raising awareness of young carers in 1995, running articles by practitioners (Thompson et al., 1995), by academics (Cunningham) and by social workers (Rickford, 2001a, 2001b) to elucidate the issues.

During that process, government responded with the C(RS)A 1995 and the National Strategy for Carers in 1999. This process is described by Fox (1995, p. 223): "organised pressure groups, media attention, governmental responses" all contribute to the development of identification of a social problem.

As more is known and understood about this process, lobbying will remain an important function. Diverse and imaginative ways are used to draw attention to the issues. Carers UK has initiated an annual Carers' Rights Day and a Carers Week. The Children's Society has organised a touring Young Carers Portrait exhibition to raise awareness and educate the public. 

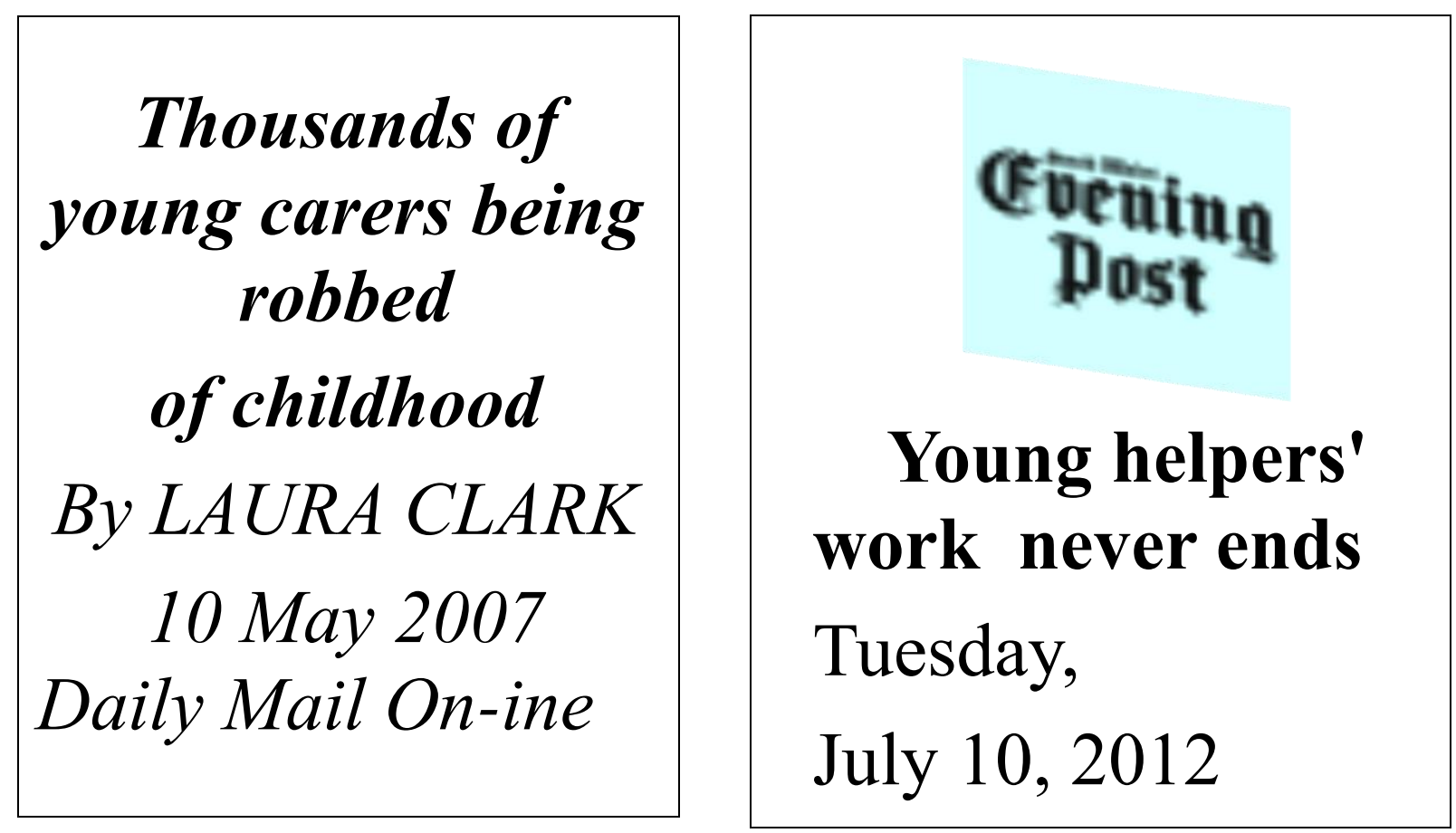

Figure 2. Examples of representation of young carers in newspaper headlines.

Lobbying and campaigning has not however been without its problems. Campaigns for the recognition of young carers have sometimes led to the over-simplification of the complex reality. Presenting the facts about their lives has sometimes led inadvertently to their depiction as passive players and sacrificial victims of their role and this has been partly the fault of the way media represented young carers (Aldridge, 2008). Although dramatising the issue and reporting the more extreme cases to attract attention may help to capture public attention, in the long-term this is a form of reification which does not aid understanding.

In describing the ways in which the media have represented young carers, Deacon (1999) agrees that coverage helped raise the profile of young carers in the early days of campaigning but that the sensationalist tendency of journalism may become problematic once 
discussion of the more nuanced matters of policy and service planning are needed.

Aldridge pointed out that the media tended also to present caring as "work", praising the young carers' work ethic, thus implying that they have a choice and weakening the children's rights aspect.

There is a tension between campaigning separately for young carers and for the Cfp. Lobbyists have sometimes sought to promote their interests in a common agenda (Fox, 2007). The move by Government towards a whole family approach, expressed as "Think Family" (Social Exclusion Task Force, 2008; Social Care Institute for Excellence, 2009; Think Family Toolkit, 2009), implemented the idea of a common cause for parents and children obtaining the best conditions by including both in the planning and delivery of support. The combined interests might be well served by a holistic family approach in many cases but there are situations where the relationship between young carer and Cfp is not good, where services may focus more on supporting the Cfp, where young carers have not been included in the assessment process or appropriately assessed. This can suggest a disharmonious strain between the child's rights and his/her duty to the family. Lobbying bodies recognise the existence of such situations and endeavour to ensure that there is sufficient focus on the young carers specifically.

Another coalition of interests which has been mooted is that of carers and care workers. Certainly the issue of the availability and working conditions of care workers are highly relevant to carers and there is therefore a common interest but the different interests of carers who are paid and those who are unpaid could present a conflict.

Lobbying often involves an issue over who are valid representatives of those being lobbied for (Hobson, 2003; Lloyd, 2006). When awareness of the situation of young people who care increases, the number of organisations gathering information and attempting to influence policy-makers can increase. This can add to the strength of the lobby but potentially cause differences over theory and practice 
which can detract from the results. An example of this is the argument over whether young carers should be doing any caring at all (Keith \& Morris, 1995) or the difficulty of treating the young carer as both a carer and a child (Dearden et al., 2000). Lobbying on behalf of young carers has been carried out at a UK level by Carers UK, the Children's Society, Family Action, Barnardo's, Action for Children. The move to form a National Young Carers Coalition is a positive response to create a common agenda and so to forestall any potential weakening of the lobby. The unresolved question is how the voice of young carers themselves is best represented and this is explored in Chapter 5.

\subsubsection{Stakeholders.}

Qureshi (1999, p. 260) points out the importance of positive outcomes for carers in that they benefit not only the care recipients and so ultimately the carers themselves but also the wider world of stakeholders. User outcomes are of interest not only to service-users, that is in this case young carers, but also to stakeholders: central and local government, volunteers and staff involved in caring work, the public and tax payers (see Chapter 1 ). If carers cannot maintain the work they do, the statutory authority will have to provide and fund more support. In some cases, it is young carers who are substituting for a statutory service. The Audit Commission (2010) illustrated the size of the issue with the fact that young carers who are not in education, training or employment ( 210,000 people) cost the public purse $£ 13$ billion in 2008 and $£ 22$ billion in opportunity costs.

\subsubsection{The Rights agenda.}

Once the social problem of the young carers had been recognised and the needs identified, legislation became a major factor in paving the way for action to secure the "best interests" of children who are carers. The "full and harmonious" development of every child is a central concept in the UNCRC (1989): "the right of every child to a standard of living adequate for the child's physical, mental, spiritual, moral and social development." (Article 27) 
A counter view to the Rights approach was expressed by O. O'Neill (1988). She argued that unlike other oppressed groups children were necessarily by the fact of their age dependents and would naturally reach independence, therefore obligation is a more appropriate approach than rights. However it is the Rights approach which has gained predominance in UK legislation and has acted eventually as a driver for the welfare of young carers.

Legislation in the UK has imbibed the UNCRC articles. The Children Act (1989) for the UK confirms the legal right to a reasonable standard of health or development [Para 17 sub-section (10), (a)]. The Welsh Government adopted the Convention as the basis for all policy making for children and young people in Wales in 2011.

The social problem of young carers was recognised later and the needs identified. A prime concern in supporting young carers is the impact that their duties and responsibilities will have on their development and consequently on their later lives. The awareness that the UNCRC objectives have outcomes in adult life suggests that the pathways between childhood and adulthood and the life stages of young carers should be explored. Thus the application of human development theories can help us understand and analyse not only the strategic but also the individual situation (see Section 3.6).

\subsection{5 "a unifying tool".}

In order to make progress, there is a need for what Fox (1995) calls a "unitary discourse", that professionals come together to debate the phenomenon and any actions and practice necessary to address the situation of young carers (Fox, 1995, p. 224). Baago (2007, p. 4) describes the usefulness of the term young carer as a unifying tool. She says that defining young carers as a separate specific category provides "a useful departure point for studying their common needs and experiences". Lloyd (2006, p. 952) describes the advantages of networks and physical meeting points where "individual carers can 
derive strength from a collective identity and material benefit from exposure to information about entitlements and benefits".

In Wales, although there is currently no National Young Carers Strategy, there seems to be the beginning of a collective identity with the Young Carers' Network, a Young Carers Workers Forum and the setting up of the Carers Officers Learning and Improvement Network which brings together local authority officers with responsibilities for carers including young carers from the whole of Wales.

\subsubsection{Service providers.}

Simultaneously with the growth of evidence and the pressure of lobbyists from 1990 onwards, both statutory and charitable agencies have responded to this new category of need through legislation and provision. Policy makers have begun to incorporate the term into provision planning. Estimates in further research of the number of young people finding their prospects limited by their responsibilities have escalated (see Section 2.5.2) with the result that service providers in the statutory and third sectors have experienced strain on their resources. This strain has increased as recognition of genuine need and the seriousness of the phenomenon has grown.

\subsubsection{A market for services.}

As awareness of young carers' situations has developed, so has pressure to develop a service to meet their needs. Situations involving young carers overlapped with the needs of other service users such as those requiring care, carers generically, disadvantaged or disengaged children. This represented an increased demand on the capacity of the statutory sector and the requirement for an additional specialism. As we see with the multiplication of third sector managed YCPs, the result was a large degree of outsourcing of support services by the statutory sector. Consequently the external organisations, premised on the need of their constituent group, took on provision gradually as an important strand of their programmes. With their close knowledge of the service users, their culture of integrated agendas and the room for innovative 
approaches, the third sector represented added value for purchasers of services in health and social care (Curry et al., 2011).

Yet changes in the way local authorities and health boards approach the purchasing process for health and social care services mean that the third sector is now subject to new processes of competition for commissioning, tendering and contracting. A report commissioned in 2011 by the King's Fund and the National Council for Voluntary Organisations on the implications of the proposed National Health Service (NHS) reforms makes it clear that providers will have to compete for contracts in a market situation in health and social care:

Competition, choice and information will be the key drivers of quality in the new system. NHS markets will be opened up to alternative providers under an extension of the 'any willing provider' policy, enabling consortia to commission services from any licensed provider. It is intended that providers (be they from the NHS, the private sector or voluntary sector) will compete on a level playing field for NHS contracts. The policy of any willing provider is intended to increase competition (and therefore, it is hoped, innovation, improvement and productivity) while reducing barriers to entry to the market. (Curry et al., 2011, p. 7)

It is possible that increased competition will result, in the words of the report, in "innovation, improvement and productivity" in services for young carers. Providers may be able to capitalise on gaps in statutory provision or will expand into areas which have hitherto been the sole territory of statutory agencies. It is also possible that services for young carers may lose the attention of commissioners or fail to command purchasing power.

Since health and social care are devolved matters, it remains to be seen whether this move towards a market economy in this field is adopted in health and social care in Wales. 


\subsection{Terms and Definitions}

Language and its vocabulary reflect our understanding of the world. Evidence of the recognition of the concepts of carer and young carer can be found in the inception and use of the terms themselves to refer to a role which had until the late 1980 s been assumed on the whole as part of the family dynamic. What people mean by them has varied since they were first coined and has varied according to the context. The meaning and use of the terms have developed together with the assimilation of the concept into society.

Once the concepts of carer and young carer were established as a social reality, we find various agencies developing their own definitions and interpretations. From the literature we can identify a number of strands: general useage, legislation and use in the non-statutory sector.

\subsubsection{Common useage.}

\section{Other terms.}

Searches of databases (ASSIA, CSA, IBSS, JStor, Web of Science) have discovered other terms used with similar or related meanings and the frequency of their use.

Caregiver was the other term found most frequently. The earliest reference was found in the Web of Knowledge (WoK) data-base in 1970 to "Widow as caregiver in a programme of preventive intervention with other widows" (Silverman). There were 78 references in total in WoK through the 1970s but with broad application including funeral directors'

Categorisation of the world by language is an on-going social activity since new things have to be named (Romaine, 1994). wives (Strugnel \& Silverman, 1971) and hairdressers (Wiesenfeld \& Weis, 1979) seen as caregivers. Over 12 thousand references came up in the combined data-bases Cinahl, Social Care Institute for Excellence (SCIE),

HMIC. This term has been used frequently up to the present day (3113 references in ASSIA alone) with quite heavy usage in the last two years. 
Another common term has been informal carer. The earliest reference was found in 1986 in WOK in "Research on the informal carer: a selected literature search" (Goodman, 1986). This has been used often but not exclusively in medical fields.

The term care provider was, like caregiver, found first in 1986 and repeatedly up to the present day although it has been used mainly in the context of health and residential care and applied to paid workers as in Barer (1992) or to organisations.

There are a number of less well used terms. Just over 30 references were found to private carer, starting with a paper called $A$ politician's view of care in the community delivered by Sir David Price at a 1991 BASE conference. It was also used in the NHS and CC Act 1990 with no stipulation as to age, amount or type of care: "a person who is not employed to provide the care in question by anybody in the exercise of its function under any enactment" (Section 46 (3) d) ). There were occasional references to family care provider meaning unpaid family carers (Aneshensel, 1993). There were also examples of references to a parent as a child care provider (Connelly, 1992) and to a parent care provider (Martire et al., 1998), both having a specific and different meaning from the one being explored here.

\section{Paid and unpaid carers.}

With the development in carer-related legislation and the growth of the care industry, a distinction needed to be observed between paid and unpaid carers and also between qualified social workers and others in the field. The terms in general use for paid carers have since the early 1990s been care worker and support worker across a wide field including health and education. However voluntary organisations representing the interests of unpaid carers have been disturbed to find examples of confusion between the two terms, not infrequently by Cfps themselves. A campaign was started by Carers UK in 2005 for the use of the term carer to be used exclusively for unpaid carers (Carers UK, 
2005). Indeed this is confirmed by the SCIE website which said, referring to the 2004 Carers Act:

The term 'carer' does not include people who work as volunteers or paid carers; these people should be referred to as 'care workers' or, better still, this confusion could be minimised by the use within the sector of the term "support worker" to describe those who are paid to provide care. (SCIE, 2014)

Lloyd (2006) points out that this differentiation is less relevant to young carers.

\section{"Young carer".}

Although there were references to carers in the literature before 1988, the use of the age-specific term was used in a survey of the number of young carers in Sandwell secondary schools (Page, 1988). Another study of young carers in Tameside (A. O'Neill) was published in the same year. Soon after, the term was used in an article "Stolen Youth" in the Nursing Times in 1989 (Lyall) and again in the same year in an article "The costs of caring" (White) in Young People Now. In 1990 "Young carers: a Hidden Workforce?" (Meredith) was published in the Carelink magazine. In 1991 a physiotherapist tried to start a service for young carers and an article about his efforts was published in Therapy Weekly. An article appeared in the popular press in Woman's Realm on January 24th called "Stolen Childhood" cited in Williams, $1995 . \quad$ "Young Carers: Saints or Slaves?" appeared in 1991 (Middleton). Then it began to be used in the early 90 s together with variations such as children who care whilst the term child carer has generally been used for those who care for children rather than for a child who is a carer.

The term really took root after the Young Carers Research Centre was established at Loughborough University in 1992 and studies in this area began in earnest. In 1993 Aldridge and Becker published "Children Who Care: Inside the World of Young Carers" (1993a), and in the following year an article appeared in the British Medical Journal with the 
title "Who Cares for Young Carers?" (Jenkins \& Wingate, 1994) with two follow-up letters (Sturge et al., 1994; Travis \& Bruce, 1994). From then on the term was used with increasing frequency. Dearden and Becker commented in 1997 that "the term 'young carer' is now becoming more widely accepted" and Clements could say in 2011 "Carers who are under the age of 18 are generally referred to as 'young carers"

\subsubsection{The legislative context.}

\section{Legislation in the UK.}

In the legal field, the term carer needed to have more precision and for statutory services such as Social Services it needed operational clarity for reasons of targeting, transparency and accountability. Clements and Thompson (2011) said that there is no legislation which specifically refers to young carers and even within general carers legislation it can be seen that the status, acknowledgement and definition of young carers has been unstable. Young carers only gradually became disentangled in law from coverage of carers.

There are several elements that are included from time to time in legislation concerning carers: age of person cared for, age of carer, paid or unpaid, relationship to the person receiving care, amount and type of care, residential qualification.

The first reference to carers in legislation was in the Disabled Persons Services, Consultation and Representation) Act 1986 $[D(S C R) A]$. The first allusion in this particular Act was to the disabled person's "authorised representative" but later offered the alternative of "any person who provides care for him" [Section 4 (c)]. This was defined as a person who provides unpaid "a substantial amount of care on a regular basis" [Part I, para 3, sub-section 1 (a)] thus setting some sort of boundary but an incomplete one on who could be designated as a carer. For example there was no age specification either for the carer or cared-for person, no residential or relationship qualification and no explanation of what substantial and regular meant. This broad definition which excluded only paid carers progressed through subsequent years 
towards a narrower statutory interpretation assisted by policy and practice guidance.

Before young carers appeared overtly in legislation, it can be seen retrospectively that the Children Act 1989 was an important step towards legal recognition of the phenomenon. This Act reflected the principles of the UNCRC. It stated that "the child's welfare shall be the court's paramount consideration". Part III of the Act referred to children in need and stated that a child should be regarded as being in need if "he is unlikely to achieve or maintain, or to have the opportunity of achieving or maintaining, a reasonable standard of health or development without the provision for him of services by a local authority" [Para 17, sub-section (10) (a)] and if "health or development is likely to be significantly impaired, or further impaired, without the provision for him of such services" [Para 17, sub-section (10) (b)]. The meaning of development was clearly defined as "physical, intellectual, emotional, social or behavioural" and health delineated as both physical and mental (Para 17: sub-section 11). Reports of harm arising from caring for family members by children opened up the potential for young carers to be assessed as children in need.

The D(SCR) and the NHS \& CC Acts 1990 referred to carers but did not specify age (para 3.28) and therefore could be taken to cover young carers but with no definition other than the general age-free definition of a carer. The Policy Guidance to the 1990 Act did not assume a residential qualification, including family, friends and neighbours in the definition of carer.

In the landmark C(RS)A 1995, the definition of the Cfp extended from being a child to include adults but still there was no age specification for carer. Neither was there any residential or relationship qualification, saying that the definition included "people who may or may not be a relative and who may or may not be living with the person for whom they are caring" although volunteer carers from voluntary organisations were excluded. The central definition, "a substantial 
amount of care on a regular basis", continued unchanged but the Practice Guide to the Act (1996) was more explicit about the types of activity of which caring consisted (Annexe I para 3) and contained information about the numbers of hours carers were undertaking (Annexe I para 4) based on commissioned research by Parker and Lawton (1994). By 2006, Lloyd refers to substantial being generally recognised as 20 or more hours per week (Lloyd, 2006, p. 946).

Although no lower age limit for a carer was specified in the 1995 $C(R S) A$, there was no overt reference to young carers. However this was clarified by the Practice Guide to the 1995 Act issued by the SSI (1996) which had a special section about young carers. It stated that the most appropriate route for assessing young carers was the 1989 Children Act under whose terms a young carer could be identified as a 'child in need'. It indicated the identification of a child in need as one who should not be carrying inappropriate levels (para 15.2) or one who had a burdensome level of caring responsibilities (15.6) or similar levels of caring responsibilities as adults (para 15.2). In a letter to Directors of Social Services, the Chief Inspector of Social Services recommended that young carers who had significant caring responsibilities should "therefore be seen as children in need" (Guidance letter CI (95)12 Annex A para 1.1). Clements and Thompson $(2011,551)$ write that "it will be more appropriate for a young carer to be assessed under the Children Act 1989" and, following the issue of the Practice Guide, the category of child in need was established as a basis for service provision across the UK.

The Children (Scotland) Act 1995 made the situation in Scotland much clearer by adding a fourth sub-category to its definition of children in need which is children "adversely affected by the disability of any other person in his/her family" (Section 94 (4) (a)).

Meanwhile, an age limit for a carer was introduced in the Carers and Disabled Children Act 2000 where carers were specified as being 16 and over. In the 2004 Carers (Equal Opportunities) Act, because no age was 
specified, in the meaning of the Act the definition of carer reverted to including those under 16.

\section{Welfare benefits.}

In written regulations relating to young carers eligibility for welfare benefits, a very tight and narrow definition is used. The precision is necessary for the administration of benefits but the narrowness of the criteria excludes many who are likely to be in need of financial support. Welfare benefits play a critical role in the social care field and eligibility criteria represent another definition or a limitation on who can be included.

The government web-site (https://www.gov.uk/browse/benefits) gives the information that Carers are only eligible to apply for Carer's Allowance if they are over 16 and spend at least 35 hours per week caring, thus excluding young carers under 16 . The Cfp must be in receipt of one of a list of benefits. The carer will not be eligible if they are in full-time education or studying for more than 21 hours per week therefore excluding many young adult carers. They are not eligible for Carer's Allowance if they are also claiming a benefit relating to unemployment such as Job Seekers' Allowance or Incapacity Benefit, a further restriction on the number who would be eligible. The result is that the majority of young carers will fall outside Social Security's eligibility definition.

It is also worth noting that there is no residential requirement for eligibility.

\section{Legislation in Wales.}

After the first stage of devolution to Wales (1999), as a result of not having legislative powers, actions in Wales relied on implementing UK legislation and guidance. For example the UK Carers Strategy triggered the 2000 Carers Strategy Implementation Plan which was succeeded by the 2006 review of that Plan (Carers Strategy Implementation 2006), the new 2007 Plan (Carers Strategy re-focused) and the Delivery Plan 2013-16. 
When the National Assembly for Wales acquired primary legislative powers, a Carers Strategies (Wales) Measure was passed in 2010 and ratified in 2011. It placed a duty on health and social care authorities to prepare a strategy on how it proposed to ensure the provision of information to carers and consultation with carers at both a strategic and personal case level. This was mainly concerned with the implementation of carers' rights by ensuring consultation and the provision of information. It covered carers of all ages but there was no specific mention of young carers. The definition of carer remained as someone who provided substantial care on a regular basis but paid carers and volunteers were excluded.

Carers are the main focus of the SS(W)A (2014). The right to assessments and support are guaranteed in the Bill. There is no age limitation on the definition of carer and young carers are mentioned only as "carers under 16" in a sub-paragraph but the right to assessment and support for children and young people who care is established as part of the general carers' rights. Combined assessments of the carer and the person with care needs together are dealt with in detail in the Act.

\section{Local authorities in Wales.}

The guidelines to local authorities in Wales submitting data on the number of young carers and service provided before the 2014 Act were as follows:

A 'young carer' is someone aged under 18 who takes responsibility for someone who is ill, disabled, elderly, experiencing mental distress or affected by substance use, or substantial responsibility for caring for a sibling. Include only those young carers known to Social Services. A Young Carer may be from any family. They may be the person providing all of the care but may also help someone else to provide the care. Care is not only the things that people can see, like changing bandages, helping someone to use the toilet 
or have a wash, but it's also about how you feel or think because of your care role. Include: initial assessments, core assessments and carers' assessments. (WAG, personal communication, August 11th, 2011)

It is the broadest possible interpretation of young carer with little attempt to clarify the elements of caring which distinguish them from adult carers or other groups of vulnerable children. There is no necessity to consider the impact of caring; it is not restricted to family members; residence is not specified; it is not confined to those under 16 as a child in need. With this breadth of definition, we could in theory anticipate quite high numbers but in fact official figures fall well below the lowest estimate. This suggests that the problem lies not with the narrowness of legal, operational, formal definitions but with the matter of identification. There may be an additional hidden population in Wales which could at its lowest stand at 11,000 (ONS, 2013). It would be useful to know more about how local authorities identify those children and young people who need support as a result of their caring responsibilities, how pro-active they are and how far they may be deterred by capacity and resource issues.

\subsubsection{Non-statutory useage.}

The implementation of legislation, service delivery and budgetary control requires clarity yet it depends upon terms such as substantial, regular, significant, inappropriate, burdensome. Undefined, these can create difficulties in operational terms and in targeting those most in need.

Nevertheless too much narrowing down of the definition can leave outside the legal boundary of entitlement some people whose caring duties undoubtedly impact adversely upon their health, their employment and their personal lives. The LE Consultancy report to the Welsh Government (2010) draws attention to this: 
Our understanding of the nature and effects on young people of caring duties has expanded and we know that some young people who do not strictly fit the definitions of 'young carer' are still adversely affected by their caring duties (LE, 2010).

The definition of young carers by Becker et al. in 1998 indicates a wider interpretation with no attempt to define the effects of caring by terms such as significant, burdensome:

Young carers are children and young people under the age of 18 who provide care to another family member, usually a parent, who has a physical illness or disability, mental ill-health, a sensory disability, is mis-using drugs or alcohol, or who is frail. (Becker et al., 1998, p. xi)

Adopting narrower definitions presents difficulties also for third sector organisations who provide services for young carers because their philosophy is user-led and so they tend to adopt more flexible definitions with no specification on age or relationship: "A carer is someone of any age ... who provides unpaid support to family or friends who could not manage without this help due to illness, disability, mental ill-health or a substance misuse problem" (Princess Royal Trust website, 2010).

Indeed Becker et al. say in 1998 that there is "no universally accepted definition as to what precisely constitutes a 'young carer"' (Becker et al., 1998, p. xi). Means et al. state that "client groups are really bureaucratic and/or medical labels." (Means et al., 2008, 8).

The wider definition invites the discussion as laid out above of what is the norm for children and young people assisting and when does a child or young person cease to be part of family activity and justify definition of a young carer. There is a spectrum which stretches from helping out, "a beneficial and routine part of childhood development" (Becker et al., 1998) to being a sole full-time carer. Difficulties relating 
to the definition of young carers are concerned with what is and what is not considered to be the norm (Richardson et al., 2009, p. 151).

The boundary must be influenced to some extent then by the impact of those duties on the young carer. "Children whose lives are restricted because they provide care for sick or disabled family members" is how Dearden and Becker (1997) describe young carers.

Ultimately the lack of precise quantitative definition in the Acts and the intentionally broad definitions used by the social care sector leaves us with a functional definition. In the same way as the Disability Discrimination Act (1995) defined disability in the social model of disability as: "a physical or mental impairment which has a substantial and long-term adverse effect on his ability to carry out normal day-today activities" (Section 1 (1)) so this can be seen as the adoption of a social model of caring.

What is implicit in this approach is that young carers be treated as independent individuals with dignity and rights of their own. The Crossroads website suggests that young carers can be self-defining and not depend on the statutory pathway to get support. Their web-site lists a number of key indicators and explains that, if any of these apply, then the reader could be a young carer. If the young person him- or her-self feels the need of help and support then that defines them as a "young carer" and implies that support should be available. In other words, the best way of deciding whether someone falls within the category of a carer in need of support is not the statutory definition but the carer's own perception: "A radical solution might be simply to trust carers who ask for assistance in such situations and who confirm that their caring role is both regular and substantial." (Clements and Thompson, 2011, 529).

\section{Definitions used by YCPs.}

The majority of support specifically for young carers as recounted in the literature review is in Projects provided by the third sector. Children and young people access these Projects mainly via referrals made by 
Social Services (Butler \& Astbury, 2005). This suggests logically that referrals will initially be the result of an identification as a child in need, the criterion being that their health and development is likely to suffer without support.

Additional referrals may come to the Projects also from a range of sources such as schools, education welfare officers or educational psychologists. There are also a number of self-referrals. This happens less often because "young carers find it difficult to present themselves, and rarely if ever do so" (Grant et al., 2008, p. 273). However Grant et al. do go on to say that the Barnardo's Liverpool Project "Keeping the Family in Mind" has succeeded in attracting self-referrals by the awareness-raising work that it was able to resource.

It is difficult to find any common criteria for definitions or criteria for access by YCPs. Apart from directories of Projects (Aldridge \& Becker, 1998; Dearden \& Becker, 1995a) and an evaluation of four Projects (Dearden \& Becker, 2002), there is little in the way of mapping or of cross-Project analysis.

\section{The implications of a broader definition.}

Whilst the use of the broader definition will have positive results in terms of inclusion and identifying those in need, two problems may arise.

Research on the number of carers and young carers (see Section 2.3.2) suggests that the number needing support is a hidden population whose size if reached would greatly exceed the current capacity of the statutory and commissioned independent sector to provide services: "until a way is found of enabling young people to feel comfortable about discussing their caring role, services provided to support young carers will only touch the tip of the iceberg." (Banks, 2002b, p. 230). In the eventuality of growing need being identified, a second issue would be the need to develop informed criteria for targeting those most in need for operational purposes. 


\subsection{Demographic Data}

\subsubsection{Use of data in research.}

Lobbying, research, political and practical action have ensured that there is now social and legal backing for recognition of and support for young carers.

However, as Dahlberg et al. (2007) remark: "regulations in law do not necessarily mean that carers are provided with appropriate support" (p. 440). In order to provide support that is appropriate, it is important to accept that young carers are not a single homogeneous group (Kachorek \& Shifren, 2003) and a statistical breakdown is at least a start in recognising the characteristics of varying sub-groups which should influence the range and type of support provided.

Four principle difficulties can be observed in reading and providing statistical data:

\section{Geographical coverage.}

Comparing data from different sources is not always appropriate because the variety in geographical coverage makes comparisons difficult. Some literature may have data applying to England, to England and Wales, to Great Britain or to the UK (which includes N. Ireland). Now that some legislative powers have been devolved, we must also be aware of figures applying to England and Wales separately.

\section{Age of sample.}

Sources vary also in the age range in their data. A child under the Children Act 1989 is under 16 so young carers identified under this Act as children in need will be under 16 . The SSI has used the definition "under 18" in its Practice Guidance (SSI, 1995a). The 2000 Act includes provision for carers aged 16-18. Walker's work (1996) on the data from the Office of Population Censuses and Surveys (OPCS) takes a sample aged 8-18; Dearden and Becker (2005) study a sample of 0-18. In the Office for National Statistics (ONS) survey of carers (2009/10), carers aged 18 are included in the adult population. The Census 2011 (ONS, 
2011a) provides data on a 5-17 age group and the effect of caring on Health uses a category of 0-24 years. Consequently data from different sources might not always allow for valid comparisons.

\section{Definition used.}

In addition to the difficulties with geographical coverage and age of sample, there is the difficulty of what definition of young carer is being used: "The variability in prevalence rates is due, in part, to varying definitions of what constitutes a young carer" (O'Dell et al., 2010, p. 644). The lack of an agreed definition means that it is difficult to make comparisons between various studies (Blyth \& Milner, 1997, p. 59).

\section{Hidden population.}

A further difficulty for original research is that young carers are a hardto-reach group. "It is difficult to estimate the number of children and young people who act as young carers and the exact numbers remain unknown" (Olsen and Clarke 2003; Siddall, 1994). The reasons for being a hidden population are explored in Section 4.2 below. This makes the task of calculating a reliable total number of young carers or other demographic data problematic. Nevertheless Dearden and Becker (2002) recommend using what data is available to obtain approximate numbers: "While there are no exact figures on the number of young carers nationally, some data do exist that give us an idea of the extent of the issue." (p. 1)

\subsubsection{Available data.}

Before embarking on a study of outcomes for young carers, it would be helpful to obtain some idea of the numbers of young carers in the population to set against the numbers being supported by the services. This is explored in the next section on Prevalence.

It is also essential to gather data on the biographical and caring factors in young carers' lives so that services can be shaped to suit the carer and family and so that adverse or positive outcomes can be tested for associations. The features referred to most frequently in the literature review are: gender, age; ethnicity, relationship to the person 
cared for, being a sole carer, what tasks are carried out as part of caring, the condition of the person cared for, the hours spent caring and for how long they have been caring. Data on these features in the general young carer population are described in paragraphs below.

Surveys by Dearden and Becker in 1995 and 1998 were groundbreaking in producing descriptive data on this population overall. An additional significant contribution to the descriptive data available was made by their 2004 survey drawn from a sample of 6,178 young carers which provided further and more detailed information about the number of unpaid carers aged $5-17$, the family situation, the caring activities, the hours spent and the effect on their health. Since then other studies have produced additional descriptive data but the Dearden and Becker work provides an invaluable base-line for evaluating trends and new evidence.

\section{Prevalence.}

Attempts have been made by researchers since 1991 to deduce a working number. In an early attempt to extrapolate national numbers from a small sample, Meredith (1991) posited 10,000 young carers "nationwide". The Sandwell study of young carers (Page, 1988) provided data which enabled the Carers National Association later (1993) to extrapolate a similar total of 10,000 children with primary caring responsibilities nationally. Mahon and Higgins (1995b) extrapolated a much higher figure from their Project data and estimated that there were between 15,000 and 40,000 young carers nationally which is $2.1 \%$ of all children and they believe even this to be an underestimate. Walker (1996), analysing figures from the ONS, calculated that in the 1990 s there were between 19,000 and 51,000 young carers in the UK. The National Strategy in 1999 stated that there were "between 20,000 and 50,000 young carers" (Carers National Association, 1999). Olsen (1996) said that the lack of reliable data suggests that these figures deserve a degree of scepticism because these are not all heavily involved young carers. 
Census data is another source of information although their conclusions must be treated with some caution since the census form was completed by the adults in the households. The 2001 Census was the first to include a question about caring duties. A figure of 140,000 young carers aged 5-17 was observed for England and 11,000 for Wales (ONS, 2013b). A little later the Combined Policy Guidance to the 2000 and 2004 Acts (2005, p. 1) quoted the Census 2001 figures of almost 150,000 young carers in England and Wales.

In the same year, Dearden and Becker (2005) and Carers UK estimated the even higher figure of 175,000 in the UK based on the same 2001 Census figures. The data available from the Census (Walker, 1996) was based on the number of hours of caring activity and applied to under 16s. Dearden \& Becker appeared however to use the age range of $0-18$.

Butler \& Astbury (2005) found nearly three million children in the UK living in households with a family member who has persistent illness or disability (Butler and Astbury, 2005) suggesting that this might be a proportional guide to the total number of young carers. If the definition is not limited to heavily involved caring, it is possible that even Dearden \& Becker's 2005 figure could be an under-estimate. However, the later figure from the 2011 Census observed a similar figure of 166,000 for England and nearly 12,000 for Wales (ONS, 2013).

The difficulty of obtaining a definitive number is echoed in the study of the incidence of young carers commissioned by the BBC in 2010 and carried out by Becker. In this study, the sample numbered 4,029. The study made it clear that the definition of young carer used was based on the types of activity carried out rather than the hours of caring activity. In this study, the amount of personal care was described by Professor Becker as the best proxy indicator of caring activity. On this basis, the young people who carried out personal care a lot or some of the time were classified as young carers and comprised $8 \%$ of the sample. If this can be generalised across the population 5-17 years old, the 
resulting 700,000 for England and Wales is considerably higher than the 2011 Census figure of $2 \%$ (177,918 young carers). In Wales, where the 2011 Census estimate was $2.6 \%(11,555)$, $8 \%$ yields 35,000, again much higher than the 2011 Census figure. Statistics on numbers of young carers known to Social Services were made available annually on the Welsh Government web-site from 2006 (see Appendix B). Separate figures are given for those identified, assessed and receiving services. The total identified, assessed and receiving services in 201112 was 1,070 (StatsWales, 2015), again a much lower number than any estimate reached by researchers.

Whatever the sources, it is clear that over the years estimates of the total number have increased as more is understood about young carers. Improved medical care, the increase in life expectancy, the growing predominance of the nuclear family and the current pressure on statefunded care and support make it more likely that children will have to assume caring roles (Olsen, 1996). This means that a large number of young carers are either unknown to services or, if needing support, are not receiving services. There may be any of a number of reasons for this and it will be helpful to explore how accessible the services are (see Chapter 4 on Barriers to take-up).

\section{Gender.}

Gender bias in carers is an issue which appears on a global scale (UNICEF, 2009).

A sharp difference between the proportion of girls and boys who were carers was found in the OPCS statistics (1992). Girls represented $61 \%$ of young carers and boys $39 \%$. Dearden and Becker found very similar figures in their 1995 survey (1998). Later, on the basis of their national study of over 6000 young carers in 1997, Dearden and Becker (1998) calculate that $57 \%$ are female, a slight shift. In their 2004 report, their sample shows $56 \%$ girls, a further small shift in the same direction. Their data shows also that there is a proportionate difference in the types of tasks most frequently carried out by each gender. 
Census data confirms this imbalance. The 2001 Census (ONS, 2014) showed that in a group of young carers aged between 5 and 15 54\% were female $(61,000)$ and $46 \%$ were male $(53,000)$. The 2011 Census shows continuing evidence of a gender difference, estimating that $2.8 \%$ of males aged 0-24 are unpaid carers but 3.5\% of females.

\section{Age profile.}

Blyth and Milner $(1997,62)$ mention that there is "evidence of some children under the age of five undertaking caring tasks" and in Dearden and Becker's national survey (1998) the sample starts at age 3 (p. 7). The largest cluster in their survey is between 11 and 15 (54\%). In their 2004 Report, they show no young carers in the 0-4 bracket but 4\% aged 5-7. The largest cluster is 56\% for those aged 10 to 15 .

The mean age of young carers is calculated by Dearden and Becker in both their 1995 survey and their 2004 report to be 12 years. Other estimates gather around that number but differentiate between male and female, finding the mean for females to be lower than that for males. Whilst Blyth et al. (1995) show a male/female split of mean ages of 12.4/11.3. and Mahon and Higgins (1995a) show a 13.5/13.8 split, there is clearly a cluster around the 11 to 13 years age group.

It raises doubt about successful identification of carers in the age group below the age of the cluster. However the greater number of young carers identified in the early teens suggests that this age group would offer the best chance of finding a representative sample.'

\section{Ethnicity.}

The paper by the Institute for Research and Innovation in Social Services (2010, p. 1), covering Great Britain, states that "policy documents are replete with statements about the difficulty of obtaining accurate information about the size and nature of the Black Minority Ethnic carer population". This is consequently true for young carers.

Dearden and Becker (2005) found that $90 \%$ of young carers were White Europeans and 10\% Black Minority Ethnic (BME). The difference had lessened slightly by the time of their 1997 survey when the 
proportions had altered to $86 \%$ and $14 \%$ (Dearden \& Becker, 1998). The estimate of all Black Asian Minority Ethnic (BAME) carers by the NHS Health \& Social Care Information Centre (2010) produced a similar estimate for England of 2 million (92\%) / 200,000 (8\%). In Kirklees YCP, where there had been a deliberate focus on reaching BME families, they succeeded in raising the proportion of their members from BME families to 33\% (Blyth \& Milner, 1997).

The analysis of the 2011 Census data by Carers UK (Carers UK, 2014) suggests that a smaller proportion of sections of the BAME population provides care than the White British population because it is a younger population and therefore less likely to have older parents or other relatives needing care. In contrast, the LSYPE, based on a sample of over 15,000 of young people aged $13-14$, found that the young carers among the sample are 1.5 times more likely than their peers to be from BAME communities (cited in Woolley, 2013), Woolley states that this reflects previous research and the experience of the Children's Society that BAME young people are less likely to recognise themselves as 'carers' and are possibly less likely to know what help is available.

The majority view seems to be that there are many unidentified young carers in the BAME population and that it will be harder to find them to include in a sample. This means that collecting data on the experience of those young people and on any differences with nonBAME young carers may be difficult to accomplish.

\section{Relationship to person cared for.}

Dearden and Becker (1995b) report that mothers represent the largest "cared for" group (61\%). This is confirmed by Blyth and Milner (1997) who add that data from YCPs show that many young carers come from single parent families. In their 1997 survey, Dearden and Becker found a fall in the proportion of mothers and fathers being cared for but a rise in the proportion of siblings, with grandparents remaining at 4\% (1998). 
Figures from their later report on young carers in the UK produced in 2004 broadened the groups of mothers and fathers to include stepmothers and step-fathers. The most significant change is the increased proportion of siblings being cared for from $24 \%$ to $31 \%$ whilst mothers decreased to $52 \%$. They found minimal change in the proportion of fathers - $14 \%$ - and grandparents - $3 \%$.

Table 2

Relationship of cared for person to young carer

\begin{tabular}{lcccccc}
\hline Year & Age range & Mother & Father & Parents & Sibling & $\begin{array}{c}\text { Grand } \\
\text { parent }\end{array}$ \\
\hline $\mathbf{1 9 9 5}$ D. \& B. & $<18$ & $61 \%$ & $17 \%$ & $78 \%$ & $17 \%$ & $4 \%$ \\
\hline $\mathbf{1 9 9 7}$ D. \& B. & $<18$ & $58 \%$ & $13 \%$ & $71 \%$ & $24 \%$ & $4 \%$ \\
\hline $\mathbf{2 0 0 4}$ D. \& B. & $<18$ & $52 \%$ & $14 \%$ & $66 \%$ & $31 \%$ & $3 \%$ \\
\hline $\mathbf{2 0 1 1}$ Census & $<16$ & - & - & $28 \%$ & $51 \%$ & $12 \%$ \\
\hline
\end{tabular}

D. \& B.: Dearden \& Becker

In Table 2, the figures from the 2011 Census are not exactly comparable for several reasons. Firstly Dearden \& Becker's figures are based on under $18 \mathrm{~s}$ and the Census is based on under $16 \mathrm{~s}$. Secondly, as referred to in Section 2.3.2, the Census responses are given by the adults in the household in contrast to Dearden \& Becker's estimates which are based on interviews with young carers themselves.

It could be that the quality of the rapport between the young carer and the person cared for might differ substantially according to the family relationship and it could be hypothesised that outcomes would therefore be different. If data on the perception of the quality of the relationship with the Cfp were to be available, this could be tested for.

\section{Sole, main or supporting carer.}

This is another aspect of the work on Young Carers which is bedevilled by the lack of agreed definitions. Frank (1995) uses sole carer in a situation where there are one or more young carers without an able 
adult to provide care to the care receiver. Supportive carers are for Frank young carers helping an adult carer. Although a significant difference can be observed between situations where there is or is not an able adult to share the care, it misses what could be a significant difference in terms of outcomes between the young carer sharing the care with other children and being alone in carrying the responsibility.

Some of the major works on this subject do not provide data on how many young carers are sole carers in their family (Dearden and Becker, 1995b, 1997, 2004) although it would seem to be an important factor in the degree of responsibility and hence of stress borne by the young carer.

\section{Types of tasks.}

There is a broad similarity in the way the caring activities performed by a young carer might be classified. Blyth and Milner (1997) identified three types: domestic, which is the type of tasks that might be performed by any child helping in the household although young carers do so with a greater degree of responsibility; caring for other children; caring for the care recipient. The latter category they divide again into three types: practical help such as mobility; intimate care such as toileting; emotional support such as keeping them company. The General Household Survey (GHS, 2000) categorises them as domestic, personal, physical, "keeping an eye on" the Cfp and providing company but has a separate category for "giving medication". The periodic surveys by Dearden \& Becker (1995b, 1997 and 2004) of the types of tasks carried out are particularly useful in that they are using the same definitions each time and so afford an observation on trends (Table 3). The categories they use are: domestic tasks, general caring (including mobility), intimate care, emotional support and sibling care. 
Table 3

Data on \% of young carers performing different types of caring activities

\begin{tabular}{lllll}
\hline $\begin{array}{r}\text { Type of } \\
\text { activity }\end{array}$ & $\begin{array}{c}\text { D \& B } \\
1995^{\mathrm{a}}\end{array}$ & $\begin{array}{c}\text { D \& B } \\
1997\end{array}$ & $\begin{array}{c}\text { GHS } \\
2000^{\mathrm{b}}\end{array}$ & $\begin{array}{l}\text { D \& B } \\
2004\end{array}$ \\
\hline Domestic & $65 \%$ & $72 \%$ & $71 \%$ & $66 \%$ \\
\hline General & $61 \%$ & $72 \%$ & & $48 \%$ \\
\hline Intimate & $23 \%$ & $21 \%$ & $26 \%$ & $18 \%$ \\
\hline Emotional & $25 \%$ & $43 \%$ & & $82 \%$ \\
\hline Childcare & $10 \%$ & $7 \%$ & & $11 \%$ \\
\hline
\end{tabular}

a Dearden and Becker

${ }^{b}$ General Household Survey

What is most noticeable from this table is the dramatic increase in the amount of emotional support and the overall decrease in the amount of general care being provided over the nine years.

The GHS (2000) is a source of information on the situation at that time. Some of the categories they use differ from those used by Dearden \& Becker but the GHS estimate of $71 \%$ performing domestic work fits well with the trend shown by the three Dearden \& Becker surveys. In the GHS survey, keeping an eye on the Cfp (60\%) and providing company (55\%) together seem to equate with emotional care and appear to fit well between the 1997 and 2004 surveys. If we equate GHS' personal care with Dearden \& Becker's intimate care, the GHS estimate of $26 \%$ is somewhat higher than the downward trend of the three surveys but not far away.

By 2010, a research team including Becker (Joseph et al.) had developed a standard format for gathering data from young carers on types and ordinal levels of caring activity called the Manual for Measures of Caring Activities. This retained much the same categories with more guidance on what comprised each category to assist researchers and 
front-line workers in using the measure. The Multidimensional Assessment of Caring Activities (MACA) and a second measure of the Positive and Adverse Outcomes of Caring Questionnaire for young carers (PANOC) furnished an instrument based on experience and evidence ready for use by people working with young carers and a source of data which could facilitate comparative studies in that aspect of young carers lives.

\section{Condition of person cared for.}

The Dearden \& Becker 1997 survey shows that the most common condition in 1995 was physical disability which appeared for $60 \%$ of those receiving care from a young carer, with mental health appearing for $25 \%$, learning disability for $6 \%$ and sensory impairment for $4 \%$ (Dearden \& Becker, 1995b). By the 2004 survey, although sensory impairment had remained roughly the same at $3 \%$, the proportions of the other categories had changed significantly with the physical disability cohort decreasing to 50\%, mental health and learning disability rising to $29 \%$ and $17 \%$ respectively. These changes could explain the rise in the proportion of emotional support referred to above.

\section{Level of commitment.}

The 2004 Report by Dearden and Becker (2005) shows about $50 \%$ of the young carers caring for 10 hours per week or less, $33 \%$ for $11-20$ hours per week and $16 \%$ for over 20 hours per week. Some $(2 \%)$ are caring for more than 50 hours each week.

In the article by Doran et al. (2003), it was pointed out that the latter contravened the European Working Time Directive for paid workers. One of the aims of this Directive was to prevent excessive working times damaging health. The inference that long hours of work could damage health makes the hours spent caring by young carers an important datum to be tested against health outcomes. 


\subsubsection{Data specific to Wales.}

A study of young carer issues (Thomas et al., 2003), commissioned by the National Assembly for Wales in 2001, did not attempt to arrive at a figure for the total number of young carers in Wales.

In beginning their study of young carers in Wales, Seddon et al. (2003), also commissioned by the National Assembly, found a lack of data on the number and distribution of young carers in Wales. After conducting a survey of statutory and voluntary agencies concerned with young carers, they had found that only a very small number had tried to estimate the number of young carers in their area and one of their recommendations was for more work on this issue.

A leaflet for schools from the WAG in 2002 quoted the figure of 3000 young carers in Wales based on an estimate of 51,000 young carers in the UK. Later on the Co-ordinator of the Young Carers Festival in Wales in 2007 told the press that the 2001 Census had calculated that there were about 11,000 young carers under the age of 17 in Wales but that there were probably more "hidden" (Press release, Aug. 29th, 2007, WAG web-site).

In Full of care $(2009,5)$, the survey of the Children's Commissioner for Wales could still state that "It is difficult to estimate the number of children and young people in Wales who have a significant role in caring for others". In the foreword to his survey, he quoted the 2001 census as saying that in Wales "there were approximately 860 children under 18 years old providing more than 50 hours of care a week". He stated that 240 of these children were of primary school age. These figures were based on the ONS analysis of the 2001 Census (NomisWeb, 2006). That same analysis showed also that in Wales there were 1,887 under 18 s providing $20<$ hours of care weekly. However it must be borne in mind that the Census figures were the result of questions answered by adults in the households and may therefore be open to question. The 2011 Census gave the figure of 11,555 young carers under 18 in Wales. 
The data in the BBC study (Becker, 2010) was collected directly from young people in secondary schools and if we extrapolate from their conclusion that $8 \%$ of those aged $5-17$ are young carers, that yields a number of young carers in Wales as 36,408.

There are startling differences in the estimates and the definitions on which they are based continue to vary. Amongst all these approximate estimates, it is interesting to look at the official data on the number of young carers in Wales (Appendix B). These started to appear on StatsWales, the WAG Statistics web-site, in 2006/7. They recorded the number of young carers at three stages: those identified by local authorities, those assessed and those provided with services. In the first year only 14 of the 22 local authorities supplied data. In the following year, all but one authority supplied a full set of data. It should be noted that in every year from the start of the StatsWales tables, the figures showed a considerably smaller number identified than the number estimated even by WAG itself. This table and the individual authority data (Appendix $B$ ) revealed some interesting points.

Firstly a steady increase can be seen in each year at all three stages.

Secondly, however, it must be assumed from the all-Wales data that some young carers would have received services without having received an assessment up to 2009 in some authorities and up to the present day in four authorities.

Thirdly, looking into the figures for individual authorities, one is led to doubt that all local authorities were using the same criteria in calculating figures for submission and so it is difficult to be sure of patterns of performance. For example, in Local Authority 20 the number identified decreased each year from 2006-11 from 23 to 10 which suggests that they were giving the number identified during that year whilst the number identified in LA 13 over the same period rose from 4 to 106 which suggests an aggregated number. There does not appear to be any national system in place at present for monitoring the data. 
Fourthly, Seddon et al. (2010, p. 1484) observed that local authorities do not have the mechanism for capturing the number of times a service is provided only the number of times it is offered thus casting doubt on how the third category of information can be interpreted.

It is worth noting that reporting in 2010 on provision of respite services LE said:

Some members of the Carers Learning and Information Network, who we met in April 2010, did not have a high degree of confidence that this (local authority) data provided a good overall picture (of respite services) in Wales. (para 2.4.1)

\subsection{Summary of Chapter 2}

From the literature review, it can be seen that the concept of young carer appears to evolve. Since caring by children and young people is not regarded as unacceptable in other historical and global settings, this points towards it being a socially constructed concept. In 20th century Western society, it has been identified as a phenomenon with features which distinguish it from children helping at home, from adult carers and from children in other vulnerable groups. It can be argued from the analysis of the literature that the factors which distinguish helping at home from caring currently are the types of task required, the duration of the commitment and the degree of responsibility borne, with the last being perhaps the most significant.

Acceptance of this as a separate role has grown through general use to incorporation into legislation and the provision of services. There is evidence of its having become further identified as a social problem because of adverse outcomes. Young carers are a hidden population and statistical estimates of the total number vary greatly but it seems clear that the actual number exceeds those identified and there are therefore many unknown to the service providers. 
Uncertainty remains about the definitions being used by service providers both statutory and third sector, thus making it difficult to evaluate the effectiveness of the services and of the outcomes for young carers. 


\section{Chapter 3}

\section{Predicted Outcomes for Young Carers}

In this chapter both adverse and positive outcomes for young carers are explored and the importance of acquiring social capital as one of those outcomes is described. The relevance to young carers of other factors such as resilience and agency is assessed. The outcomes for young carers in the contextual framework of linked lives is shown as significant.

From the 1950s onwards, clinical research sought to identify signs of maternal deprivation in the children of sick parents (Rutter \& Madge, 1976). Evidence specific to children who care began to emerge in the late 1980s. The Loughborough University Young Carers Research Centre was responsible for early research positing the effects of caring on children and young people (Aldridge \& Becker, 1993) and were followed by studies on the potential psychological, social and physical outcomes (Barnett \& Parker, 1998; Frank et al., 1999) including work on the effects of the particular condition of the person cared for: Grimshaw (1991) on Parkinson's disease, Segal \& Simkins (1996) on Multiple Sclerosis, T122yler (1990) on Huntington's Disease, Walker \& Lee (1998) on alcohol problems (see 3.2.3 for further details). Surveys such as Dearden \& Becker's in 1995, 1997 and 2004 interviewed large samples of young carers to produce considerable demographic data and evidence of educational difficulties.

An additional aspect of measuring the effects of caring which emerged early on (Hoenig \& Hamilton, 1966; Montgomery et al., 1985; Reinardy et al., 1999) was the dichotomous nature of burden. The importance was observed of distinguishing between subjective burden, which concerns the emotions and attitudes of the carer, and objective burden, which causes disruption to events and activities. It was further pointed out by them that the correlates with the characteristics of the 
carer and of the Cfp might differ according to each type of burden therefore having significance for indicating the type of support needed to reduce the caregiver burden: "without adequate knowledge of the correlates of both burden and of the caregivers' differential experiences, effective intervention strategies cannot be designed or targeted." (Montgomery et al., 1985, p. 19).

Predicted outcomes as demonstrated in research to date are outlined below together with other related factors.

\subsection{Adverse Measurable Outcomes}

Although the possibility of positive outcomes was referred to (Becker \& Aldridge, 1993; Blyth \& Milner, 1997), social research concentrated more on the adverse outcomes for children who cared for a family member as illustrated by the paragraphs below. Indeed Pakenham et al. (2006) commented on the need to look more carefully at positive outcomes. They noted also that consideration was needed of long-term as well as short-term effects (Pakenham et al., 2006).

\subsubsection{Educational attainment.}

Fox (1995) wrote about CHRs (Children with Home Responsibilities) and provided some evidence of the effect of caring on them: "It has been estimated that $10 \%$ of all school absences are due to children undertaking duties associated with their homes" (Fox, 1995, p. 221). Dearden and Becker's 2004 Report found that $22 \%$ of young carers aged between 5 and 15 missed school or experienced educational difficulties.

In their 2004 report on young carers, based on data collected directly from young carers, Dearden \& Becker (2004) confirmed that caring has adverse effects more widely on educational attainment for young carers. Possible adverse effects are sometimes immediately apparent in poor concentration, lack of punctuality, school absences, failure to complete work and lack of engagement in school activities (Dearden \& Becker, 2002; Smyth et al., 2011a). Zhang et al. (2009) quoted the cases they studied as having difficulties in concentrating in school. 
Dearden and Becker found that the proportion of those of secondary school age experiencing difficulties in education decreased from $42 \%$ (1995b), through $35 \%$ (1997) to $27 \%$ (2004). The decrease was attributed by them to the improvement in awareness and support in schools influenced by the work of YCPs although concern was expressed about the $27 \%$ due to this being the age when they would be 'making educational decisions, taking formal examinations and preparing for their future' (Dearden \& Becker, 2004). Gray et al. (2007) stressed the importance of raising awareness and mentioned schools specifically as needing this work.

In Full of Care (Children's Commissioner for Wales, 2009), an allWales consultation with 149 young carers, there was some more recent evidence of the adverse effect of being a young carer. When asked whether they fell behind with school or work responsibilities because of caring duties, $20 \%$ replied always, $18 \%$ replied most of the time and $25 \%$ said sometimes. When asked how often they missed a day at school or work, $8 \%$ said always, $9 \%$ said most of the time and $17 \%$ said sometimes.

Fraser and Pakenham (2009) found that disengagement was associated with adverse outcomes in young carers of parents with mental health issues. This was echoed by Moore et al. (2009) in their study of the educational needs of young carers generally. They found that engagement with education was an emerging theme with the sample of 51 young carers who were identified through carer programmes.

The work on disengagement from school by Broadhurst et al. (2005) is not specific to young carers but is relevant to their experience. The researchers offered three models of disengagement from school, each describing a different life course. The sources of the problem were identified as (a) the relationship with the school, (b) the inability to participate and (c) a chaotic life style which left them unable to engage long-term. Applying this approach to young carers could identify possible parallel patterns where the young carer's difficulties arise for 
example (a) from schools' lack of understanding of the circumstances and effects on the young carer of their responsibilities (b) from the effects on them and/or their family of the condition of the cared-for person and (c) as a result of other socio-economic circumstances related to the condition of the Cfp perhaps especially when the Cfp is the responsible adult.

Academic results show young carers at a disadvantage with an adverse impact on formal qualifications. Literacy is strongly associated with educational performance at GCSE (see Section 3.1.1). The LSYPE 2004-2010, (cited in Woolley, 2013) reported that "the average total GCSE points score for a young person who had caring responsibilities in year 9 was 333, compared to 386 for young people who were not young carers in year 9." This is a difference of 53 points, equivalent to nine GCSE grades overall.

These factors may also have long-term outcomes in terms of further and higher education, employability, income potential and quality of life. Research with young adult carers (Aylward, 2009) has shown that ongoing caring responsibilities meant that young adult carers were less likely to be in further or higher education. Research by the Audit Commission in 2010 found that young adult carers between the ages of 16 and 18 had a much greater chance of being not in education, employment or training (NEET). Of these, $75 \%$ had been NEET at least once (compared with $25 \%$ of all young people) and $42 \%$ had been NEET for six months or more (compared with $10 \%$ of all young people). There is a one in three chance that a young carer in year nine will become NEET between the ages of 16 and 19, compared to a one in four chance for those without caring responsibilities. The NEET profile for young carers was higher than the national profile. The Department for Education (2013) produced statistics, cited in Hidden from view (Children's Society, 2013)), showing that there are adverse long-term effects of being NEET in terms of employment prospects and of physical 
and mental health. . In a report on NEETs, Allen (2014) reported that the risk of criminality was five times higher for young male NEETs.

Literacy was perceived as the gateway to success in the rest of the curriculum as well as being a useful indicator of outcomes in adult life (Dugdale \& Clark, 2008). An objective test of literacy would be useful as a measure of outcomes and would facilitate an opportunity to identify associations with any biographical or caring factors. It would also allow for comparison with other vulnerable groups such as Looked After Children (Rees, 2013). A search for results of objective tests of literacy levels in young carers proved unsuccessful. This leaves a key element in outcomes lacking objective data although it is one of the factors which may influence the outcomes for a young carer by excluding them at the start from the labour market by a lower than average level of literacy.

International comparisons show that parental involvement is likely to lead to better reading attainment levels in 15 year olds (Borgonovi \& Montt, 2012). For a young carer, the condition of the person cared for may impede the parent sharing in the child's reading life. The caring activities may also be a reason for a lack of shared time for parent and child.

It could be argued that a concentration on the formal academic route neglects the importance of informal opportunities for developing potential. Heyman and Heyman (2013) regard the importance accorded to educational qualifications and employability and the 'one chance only' attitude to education as a reaction to the downturn in the economic climate since 2007. For this reason, for those such as young carers who are below average achievers in school, greater importance could be assigned to later opportunities for career and personal development.

\subsubsection{Emotional Literacy.}

There is evidence also of a less overt effect on young carers. Their emotional development as individuals can be damaged by the situations in which they find themselves (Becker, 2007; Frank, 1995). 
In a large quantitative study of 100 young carers in Australia published in 2006, Pakenham et al. reported lower life satisfaction for young carers compared to non-care-givers. In a later study with a control group of non-care-givers, Collins and Bayless (2013) reported that young carers were rated by their parents as having more conduct problems and more difficulties with peer relationships. The same study asserted that there could be an adverse effect on self-esteem and the development of identity.

Pakenham et al. (2007) said that there was a need for more evidence of the effect of young caring on emotional development and adjustment. They believed that identifying valid predictors would help research and practice. General measures of emotional literacy or emotional intelligence were becoming available but the lack of quantitative evidence of psychological outcomes in young carers led to the design of instruments suitable for measuring psychological outcomes specifically for this group. Early et al. (2006) developed and tested a measure called the Young Carers Perceived Stress Scale (YCPSS) which demonstrated correlations of burden of care with psychological distress. The need to measure positive as well as adverse psychological outcomes led to the development of the YCPSS by Cassidy and Giles (2013) by adding an 8item benefit finding measure.

Pakenham et al. (2006) produced and tested a measure for young carers whose parents had mental health illnesses called the Young Caregiver of Parents Inventory (YCOPI). The aim was to produce a measure which would test empirically qualitative themes which had already been identified such as health, life satisfaction and distress. Later Ireland and Pakenham (2010) designed the Youth Activities of Caregiving (YACS) which would identify predictive associations between adjustment and factors in the care-giving situation.

\subsubsection{Health.}

There is repeated evidence of the adverse effect of caring on the health of young carers (Becker \& Becker, 2008; Lloyd, 2013) both physical and 
mental. Frank et al.'s work with former young carers (1999) was an important contribution to understanding the immediate and long-term effects of caring on young people particularly on their health. Examples were given by young carers in their study of the physical effects. They included weight loss, hair loss, asthma and triggering of epileptic attacks. Thomas et al. (2003) mentioned the potential physical damage resulting from lifting and handling someone with mobility difficulties. This may apply too in caring for someone who is not compliant. Cree's study (2003) pinpointed the effects of caring also on the mental health of young carers. Interviewing 61 young carers in an Edinburgh Project, she found that their worries ranged from sleeping and eating problems to self-harm and attempting suicide.

McAndrew et al. (2012) raised the issue of young carers not having access to support for their health problems either because they hadn't the time to go to their GP or because their problems were not recognised by professionals. They quoted also the SCIE report (2009) that between one-third and two-thirds of young carers for adults with mental health illnesses would go on to develop mental health conditions themselves.

There is a lack of quantitative data in relation to the health of young carers which if added to the qualitative data available would give a fuller picture. However the analysis of the results of the 2001 Census by Doran et al. (2003) did give an indication of the health of young carers. They stated that out of 18,000 identified young carers aged between 5 and 15 the health of $773(4.3 \%)$ was reported as not good. The quantitative data from the Census 2011 confirmed the adverse effect of caring on the health of young people aged 5-17 in that for those carrying out unpaid care a greater percentage reported that their health was not good than those not providing care. Furthermore there was a correlation between hours spent caring and the percentage of those reporting their health as not good. Some caution should be exercised with census results as the responses are given by the adults in the households (Newman, 2002). 
One alternative is to rely on self-reports of health. In a recent study by Lloyd (2013) comparing outcomes for young carers with non-carers, young carers graded themselves lower on health. In a more recent study by Nagl-Cupal et al. (2014), young carers aged 5-18 in Austria rated themselves having a higher level of adverse physical and mental effects than non-young carers. For example $4 \%$ young carers suffered headaches compared to $2 \%$ non-carers and $8 \%$ young carers worried compared to $1 \%$ non-carers.

Since young carers come from a wide variety of backgrounds and caring duties, it prompts a question about which factors other than caring might be affecting their health outcomes and this remains to be tested.

\subsubsection{Social life.}

Early et al. (2006) commented that research with young carers had previously been mainly descriptive and the evidence demographic. They noted the lack of evidence on the "wider social, educational and developmental issues" (p. 171). One of the external effects of caring at a young age is that it is likely to make inroads into young carers' social lives. Social activities outside school hours can be influential in personal development by facilitating peer and group relationships, in acquiring social and physical skills, by broadening contacts and networks. This can be critical when the school experience and academic attainment is not very successful.

One of the foremost figures in raising awareness of young carers and promoting services, Sylvia Heal, drew attention in an article in Community Care (1997) to the detrimental effect caring had on social life. The article described the experience of young carers and the positive contribution of YCPs in Merseyside in this respect. Newman (2002) commented that caring could lead to social isolation. Numerous academic studies have affirmed the implications of caring for networking, participation in leisure activities and forming friendships (Aldridge and Becker, 1993; Bilsborrow, 1993; Dearden \& Becker, 1998; Gray et al., 
2007; Pakenham, 2006, 2007; Smyth et al., 2011a) but this research has mostly been unrelated to specific factors in their background.

\subsubsection{Relationship with the person cared for.}

This is a feature which can appear in both the positive and adverse columns (see Section 3.2.3).

Prior research in attachment theory has argued that lower parentchild attachment security would be associated with poorer youth adjustment (Bowlby, 1969). Ireland and Pakenham (2010) cite multiple examples of research findings that parental disability or illness can interfere with the strength of the attachment but their own findings did not support a correlation between attachment security and good adjustment in the young carer.

Walker (1996) suggests that there can be a disturbance in "normal" family relationships in effect by a reversal of roles between child and adult and the child being responsible for the adult, referred to as parentification (Aldridge, 2006; Cassidy \& Giles, 2013; Collins \& Bayless, 2013; Early et al., 2006; Earley et al., 2007; Hooper, 2007) which can be interpreted as the loss of childhood for the young carer.

\subsubsection{Parent-child relationship.}

From the point of view of the Cfp, Keith and Morris (1995) construe this dislocation as implying that their disability prevents them from carrying out their parental role and denying them their right. In their view adequate support for the Cfp would restore to the young carer their proper childhood role and to the adult their independence and their ability to take on their proper parental role. No studies were found in the literature which tested this hypothesis.

The relationship might be affected in other ways by the parent being the person cared for. What cannot be disregarded is the evidence of distress which can be experienced by a young person seeing a family member at close quarters in pain or difficulty and the wish of many young carers to help and support their parent. 
Fallon (2012) refers to young carers having anxiety about the possible inheritance of mental health conditions. This can of course apply also to physical conditions which have a genetic character. It is also possible that young carers will be plagued by anxiety without foundation about inheriting a condition where there is no genetic character or about inheriting a pre-disposition in a way that young non-carers do not experience.

\subsubsection{Personal.}

The personal reaction of the young carer to the activity of caring must also be taken into account when considering outcomes.

Lackey and Gates (2001) interviewed people who had previously been carers for adults with chronic physical conditions when they were aged up to 18. Whilst collecting demographic data about the type of tasks and level of activity, the researchers explored in semi-structured interviews what they had liked and disliked about caring. Some quite intimate reactions were described such as distaste for unpleasant smells and sights but also the more serious emotional impact of watching the painful physical symptoms of someone they loved and in some cases watching them deteriorate. Being able to help depended partially on having the skills to do so and the importance of competence in caring is supported by the views of some of the participants in Lackey and Gates' study. Playing a part in someone else's distress left them feeling powerless because they did not know enough about the condition to help or to deal with an emergency. As young people they were living with the constant possibility of deterioration or death and some felt that they had too much responsibility.

\subsubsection{Transition.}

In a survey with over 6000 young carer participants, Dearden and Becker (2004) found that the average age of young carers under 18 was 12 . This is the age at which the beginning of their transition to adulthood might be expected. Transition from childhood to adulthood involves a 
young person in practical changes to life style and changes in the way they relate to the world.

Frank et al. (1999) stress the fact that the effects of caring can have long-lasting effects through and beyond transition to adulthood. It may prove very difficult to make that move successfully. The former young carers they interviewed were able to look back at their years as young carers and confirm that this had affected their lives as adults.

In a practical way, the normative transition for a young person from dependence on parents and family is to independent living (Dearden \& Becker, 2000). The need to remain at home as a carer might delay this or even interrupt it in a traumatic way. The delay may arise in some cases from a lack of appropriate services and thus the need for the young people to continue as carers or from the personal commitment of the young carers themselves.

Any educational disadvantage incurred by caring can increase the chance in the future of unemployment or poorly paid employment (Dearden \& Becker, 2000) thus further delaying the transfer from dependence to independence for financial reasons. Frank et al. (1999) suggested that it may limit their aspirations or restrict their choices by the immediate demands on time and energy or social exclusion causing loss of confidence. As a result they may choose continuing to care as the only option or some form of caring profession as the safest career option. There is evidence of this in their sample where $65 \%$ of the former young carers were working in caring settings.

There is an aspect of transition other than the practical and material results of caring and that is the psycho-social development of a young person. Teenage years are a time when young people have a growing sense of their own identity, their place in the world and are developing self-confidence. Where they are unable to take part to any degree in activities outside the home and with their peer group, this can interfere with that maturing process. Social exclusion, a form of behaviour adopted or necessitated in order to sustain the family, can continue into 
adult life. Frank et al. (1999) identified in some of their interviewees "developmental immaturity" (p. 27) being the cause of impairing the ability to communicate. Earley et al. (2007) identified the delays in the maturing processes which may occur due to the caring experience: the 'loss of self', the delay in individuation. The evidence adds up to an indication that caring might have the potential for an adverse effect on psycho-social development in some cases. Thinking of the future and the kind of life they want, developing their own aspirations can be obscured by the existing demands (Heyman \& Heyman, 2013). One of the themes that emerged from the World Cafe event with young carers organised by McAndrew et al. (2012) was worry that the future was ignored.

Adult responsibilities taken over from parents by a young carer can affect their relative roles and thereby the normative relationship between parent and child. Aldridge challenged the inevitability of role reversal however and suggested that "role adaptation" is sometimes possible where the parent retains their status as a parent. Cassidy and Giles (2013) stated that "only a small percentage of young carers exhibit clinical-level symptoms and some researchers have even suggested positive outcomes" (p. 644). Early et al. pointed out that parentification can be positive where it nurtures maturity or destructive where it distorts the parent-child relationship. By contrast Pakenham et al. (2007) blamed the disruption of the parent-child relationship for adverse effects which they refer to uncompromisingly as "distress". It seems from the evidence that the effect on transition of the redefinition of roles alone is ambiguous.

\subsubsection{Material welfare.}

The economic situation of a young carer's family as for all young people can be a factor in their immediate material wellbeing. Being a young carer is often associated with low family income (Hunt et al., 2005; Metzing-Blau \& Schnepp, 2008; Smyth et al., 2011a). It is noted by Dearden \& Becker (2004) that a high proportion of young carers live in low income and single parent families giving rise to a higher proportion 
of poorer financial resources. In an article in 2001, they explain that even families who are not poor may experience reduced circumstances as a result of the illness of the adult in the family. The data from the DoH. (2013) on NEETs gives a more recent picture of the adverse material outcomes that are likely for a high proportion of young carers.

Welfare benefits are by statutory regulations available for adult carers but not for those under 16 and for only limited categories of those aged 16 upwards thus closing off another resource.

One short-term effect of having caring responsibilities can be the lack of time and of a reliable timetable to do part-time jobs and to earn their own money which might otherwise allow them the opportunity to ameliorate their own situation. A second and longer term effect can be that the inability to take up casual or part-time employment or even voluntary work deprives them of the opportunity to acquire valuable experience of the adult world and employment contacts which might be helpful later. Data on the socio-economic status of young carers has been linked to outcomes in education and in health but not to personal and social capital outcomes. For this reason it would be interesting to explore how much young carers are able to take on paid or voluntary work.

\subsection{Positive Measurable Outcomes}

In the beginning, the emphasis was very much on the adverse effects but this was soon tempered by the suggestion that outcomes were not all or necessarily adverse. Aldridge and Becker (1993) noted young carers' positive feelings because of caring. They observed that the role could result in an increase in the sense of self-worth although Frank (1995) challenged this by quoting the lack of any evidence of positive effects in her sample. However, the attention to positive outcomes increased with time.

Pakenham et al. (2007) carried out a literature review of positive outcomes and they cite an impressive list drawn from anecdotal 
evidence: "enhanced skill development, maturity, independence, selfefficacy, self-reliance, self-esteem, sensitivity and empathy for others and a fostered capacity to accept responsibility".

The adoption of responsibility for others leads sometimes to the development of competencies and maturity to a higher level than is usually found in children of the same chronological age who do not care for a family member. Ironically these arise to some extent from the same experience as some of the adverse effects such as the reversal of the parent-child relationship, the age-inappropriate responsibilities and the need to make adult judgements at a young age. They could be summarised under three headings: maturity and experience beyond their years, subjective feelings of worth, and relations with the person cared for.

\subsubsection{Maturity and experience.}

This covers a wide range of characteristics and skills. Lackey and Gates (2001) interviewed adults about their experiences as carers up to 18 years. They looked for participants' views of both positive and adverse outcomes. In terms of positive outcomes, the participants appreciated acquiring what are usually considered adult skills such as dealing with benefits and administering medical treatments. The participants in the study by Heyman and Heyman (2013) are not unaware of the adverse factors in their situation but they are conscious that the skills they have acquired will help fit them for employment in a way that is not developed in a school setting.

Other studies have found character development in the form of increased maturity. Banks et al. (2001) mention maturity but include also an enhanced capacity for empathy and nurturing as outcomes of caring. The dominance of some form of caring profession as a choice of career evidenced in a number of studies could be taken as supporting this effect (Banks et al., 2001; Frank et al., 1999). 


\subsubsection{Self-worth.}

Heyman and Heyman (2013) found a discrepancy between the specialist young carer workers' views of the young carers in their study and the views of the young carers themselves. Most of the workers focused on the riskiness of being a young carer whilst the young carers in their study did not see themselves as vulnerable but were critical of the lack of suitable support provided. It is true that the sample in Heyman and Heyman's study included young adult carers and moreover young carers who were involved in specialist Projects so it is possible that they are not typical.

Participants in Lackey and Gates' study enjoyed playing a more significant role in the family than children would normally play. MetzingBlau and Schnepp (2008) reported that the care-giving role might have a positive impact on self-esteem and what they term "coherence" (p. 6). Bolas et al. (2007) reported the same results in their participants plus the fact that the "good" image of caring helps them counteract the adverse features of their lives. The sense of self-worth seems to be strongly promoted by the recognition and valuing of the young carer's work (Cassidy \& Giles, 2013; Skovdal, 2010b).

In a study of benefit finding in young carers, Cassidy and Giles (2013, p. 652) suggested that "resilience in young carers was enhanced through a positive identity as a carer based on social recognition of the value of the caring role". This correlates with the findings of Skovdal et al. (2009) with young carers in Kenya who have a clear role in their society and perceive themselves as actors. One of the conclusions that Skovdal et al. (2009) drew from their studies was that "children's coping is determined by the extent to which they are able to participate in community life and negotiate support from it". There is much evidence of many young carers and their families in the UK not disclosing their problems so it is possible that this could preclude young carers here from benefiting from the kind of social recognition that leads to a greater sense of self-worth enjoyed in the communities where Skovdal was 
working. It may lead also to the inference that other sources of respect and self-esteem are proportionately more important here.

\subsubsection{Relationship with the person cared for.}

In contrast to the evidence of adverse outcomes from the young carer's relationship with a disabled or sick parent, another possibility which is reported by some studies is that caring can result in a closer relationship between the carer and the Cfp. Sometimes the caring role damages the relationship with the person cared for but there is also evidence of it deepening it. This dichotomy is illustrated in Lackey and Gates' study (2001) where some participants felt that the relationship with their Cfp grew closer whilst for others caring increased tension and stress.

Varied significant emotional elements are cited in the good relationships described by young carers: satisfaction at helping a family member (Banks, 2002); a sense of duty (Frank et al., 1999); obligation (Smyth et al., 2011b).

The characteristics of a Cfp's illness can also affect the relationship with the young carer. Whether the onset is sudden or gradual can influence adjustment to the new family situation (Sieh et al., 2010). The nature and degree of the impairment can change the on-going relationship as for example if it interferes with communication as in young onset dementia or sensory impairment. Perhaps most deeply affecting is the prognosis and whether the illness is heritable (Segal and Simkins, 1996).

Writing about vulnerable young people including young carers with poor relationships with parents, Gilligan (2000) stated that the adverse effect on attachment security can be ameliorated by a good supportive relationship with another adult in the family or even with an adult outside the family. This is a significant reflection on the potential role of schools and Projects. 


\subsection{Resilience}

A useful definition of resilience is offered by McMurray et al. $(2008,300)$ as "the ability to withstand or recover from difficult conditions". Gilligan $(2000,37)$ defined it similarly as "a capacity to do well despite adverse experience".

The concept of resilience roused interest because of the observed variances in outcomes for people subject to high risk factors. Rutter (1987) was prominent in directing the focus to "positive exceptions" by looking at why some children achieved in spite of adverse factors. His view of resilience was as a process of interplay between adverse circumstances or events and protective factors rather than being directly and deterministically due to absolute factors or independent variables. $\mathrm{He}$ and other researchers of the period saw resilience not as a personality trait but as a developmental process rather than an absolute characteristic (Luthar et al., 2000). It is particularly pertinent to this current study that Rutter wrote about the critical importance of turning points and opportunities in the life course when risk factors can be reduced in their effect and the protective process can assist a child or young person to find an adaptive route. This supports the perception of plasticity, that individuals can change, can have some control over their life course and indeed Luthar et al. (2000) identified an internal locus of control as one of the protective factors in children and young adults.

Resilience rather than lack of resilience, the causes of good rather than poor outcomes, began to be regarded as the more normal feature although McMurray et al. were still able to remark in 2008 that "social workers may be attuned to looking for the deficit factors rather than the strengths within the assessment process, and that an understanding of resilience theory might counteract this" (p. 302).

In recounting the history of the study of resilience, Luthar et al. (2000) pointed to three domains where protective functions had been identified: the personal characteristics of a child, the family setting and the external environment. Like Rutter, they laid emphasis on seeing 
resilience as a process which can be mediated for prevention of adverse outcomes. They pointed out some theoretical and methodological flaws in the previous research into resilience, recommending that more research was needed to understand the risk and protective processes and to direct researchers towards how that understanding could inform interventions.

Gilligan's work on resilience of children in need (2000) has direct relevance to young carers. His work was directed more to front-line work and the importance of interventions. He advised professionals that it was not always the big things that made a difference but stressed how crucial small details could be. He believed that everyday happenings could sometimes be of more help than specially designed interventions. He identified five practical factors associated with the protective function: reducing the number and range of pressures on the child, optimising turning points, having a secure base, self-esteem and self-efficacy. All of these, he observed, could be serviced to some extent by external sources where the primary sources, the home and immediate family, were not succeeding. What is particularly relevant to young carers is Gilligan's comment on "the importance for those children who experience adversity at home to have havens of respite or asylum in other spheres of their lives" (2000, p. 38). He wrote further of the benefit of relations with teachers and other interested adults for young people doing well despite stressful home circumstances. He added a caution: that resilience is not necessarily present in all domains in one person nor is it necessarily consistent over time (Gilligan, 2004).

Five domains of influence with some similarities with Gilligan were later discerned as protective factors in the views of social workers with children at risk (McMurray et al., 2008). The mother's behaviour was observed as influential, normally more so than any other member of the family. Education was seen potentially as another protective factor where the child could see the possibility of success and receive support. Professionals were regarded as making an important contribution to the development of resilience. As well as social workers, this included 
professionals such as family support workers who had more time to spend with the children and to listen to them. A fifth protective factor, as it appeared to the social workers in the study, was a sense of personal identity which they sought to nurture because this was a means of strengthening resilience.

Gilligan was particularly interested in the influence of the school experience and out-of-school activities in the protective process because of their potential for offering 'turning points' and because their potential was less studied. Gilligan identified five areas of spare-time activities as capable of contributing to greater resilience: "cultural pursuits, the care of animals, sport, helping and volunteering, and part-time work" (2000, p. 42). In these activities, a young person might acquire and improve a range of skills whilst strengthening their self-esteem and self-efficacy. The beneficial effect of social connectedness is confirmed by the findings of Fraser and Pakenham (2009). They served also to create multiple identities which he maintained encouraged good mental health, the implication for young carers being the importance of having time for activities other than caring.

It seems that further study of resilience in young carers might confirm a correlation with agency or indeed with other factors.

\subsection{Agency and Children as Agents}

In contrast to much of media representation, in a social care theoretical framework young carers are active agents by virtue of the contribution of their labour and by the fiscal implications of their contribution (Smyth \& Samia, 2010) whether this is from choice or because there is no-one else to provide the necessary care (Noble-Carr, 2002). In spite of this theoretical analysis, young carers may not realise their agency and may not be encouraged to realise it although recognition of their contribution is something which many young carers desire (Smyth et al., 2011b).

In their study of young carers aged 11-25 in Australia, Smyth et al. (2011b) pointed out the limitations of the agency of young carers. In the 
microsystem, they are affected by family and neighbourhood bonds. The frequency of low income and unemployment in the families of young carers (Dearden \& Becker, 2004) imposes other constraints. Added to those are the limits of what services can provide to ameliorate the work load. In the macrosystem, young carers are viewed within the specific social and political context of their historical period and geographical place (Gladstone et al., 2006). So in Kenya (Skovdal et al., 2009) the importance of their contribution is recognised whereas in the West the normative view has often been through the narrow prism of children in need who are seen as dependent on adults rather than as competent actors (Abebe, 2012). Recognition of young carers' agency has been helped in recent years by the legal requirement that young carers be involved in the assessment of adults with disability or illness and by the right to an assessment as individuals ((C(RS)A, 1995; C(EO)A, 2004). This has strengthened the acknowledgement of them as actors in the caring situation.

From an individual psychology-based view, young carers need to make sense of their own experience. Balanced with any perception of constraints and burden are the positive feelings engendered in many young carers. When they realise their relative maturity and coping skills compared to their peers, this can give them self-confidence about moving into independence (Smyth et al., 2011a). Closer family relationships as a result of caring can lead to a more significant position in the household than is usually accorded to children who are not carers. Where their role and contribution are recognised, their work gains a worth beyond the intrinsic value of helping with household tasks.

\subsection{Social Capital}

The opportunity to build social capital including human, financial and cultural capital (Bourdieu, 1986; Bourdieu, 1989; Bourdieu, 1997) is a most important part of childhood and teenage years. This is a function which may be impeded for a young carer and therefore needs 
investigating. The lack of free time, less opportunity to participate in peer networks, absence of contacts with adults outside the home experienced by young carers might cause them to be more disadvantaged than other vulnerable young people. If this proved to be the case, the loss of this chance to acquire social capital in preparation for adult life would be one of the most serious adverse effects of their responsibilities because of its impact on their life prospects.

\subsubsection{The concept of social capital.}

The idea of benefit accruing from social relations has a long and respected history going back to the nineteenth century but the term social capital was first coined by Coleman (1988). Since its inception, the concept of social capital has given rise to "increasingly diverse applications" (Portes, 1998). "Social capital" says Morrow "is an elusive concept" (1999, p. 744) and "a nebulous concept" (p. 749). Six years later, Leonard was able to write that "social capital remains an elusive concept" (2005, p. 605).

In explaining social action, Coleman (1988) identified two main schools of thought: the economist's and the sociologist's, each of which he believed to be deficient in a different way. The first envisaged the actor as a rational being acting independently and motivated by selfinterest. The second depicted the individual acting within a social context, influenced and restrained by the norms in which $\mathrm{s} /$ he operated. Coleman pointed out that the economic school of thought made no allowance for the interplay between actor and social context, what Granovetter (1985) termed the embeddedness engendered by the relationships of the actor within the social setting. This vision of interplay recalls also the macro-system in Bronfenbrenner's theory of linked lives (Bronfenbrenner, 1979, cited in Crawford \& Walker, 2002). On the other hand the sociologist's explanation did not provide room for personal motivation in action. The solution put forward by Coleman et al. was to identify a third factor, social capital, as a "conceptual tool" (Coleman, 1988, S.96) which combined and explained both self-interest 
and the influence of social context. In addition it offered a conceptual explanation of how the individual was linked, as Bronfenbrenner believed, to others in the social context (Furstenberg \& Hughes, 1995).

Coleman et al. described this concept as existing not in the actors themselves but in the relations between and among members of a group, community or organisation. It could take various forms, such as incurring obligations which should be repaid, the exchange of information and the development of shared norms and expectations. In this way, social capital is productive "making possible the achievement of certain ends that in its absence would not be possible" (Section 98). He stated also that the outcomes could be both material and non-material, a point picked up and examined later by Bourdieu (1998).

As pointed out by Gillies and Edwards (2006), Coleman focused mainly on interpreting social capital in terms of the family and the community. His own extensive work on drop-out rates in high school (1961) led him to make the connections between socio-economic factors in the parents and the performance of their children in school. He developed the central concept of social capital to cover "physical capital" (material goods), financial capital (wealth, income) and "human capital" (education, abilities and skills) but his conclusion was that it was not the parents' possession of financial, physical or human capital alone that improved the children's chance of success. It was the relations between the parents and children that made the difference, that is that created social capital. This inferred that it was the time that parents spent with their children and the quality of their attention that made the difference. He deduced from this that lone-parent families, larger families and families where both parents are earning generate less social capital.

This can be seen as a conservative, some would say reactionary, view (Gillies \& Edwards, 2006), supporting the traditional family structure where children's status depended on their parents, whilst in Bourdieu we have a development of the social capital concept with a Marxist materialist interpretation. Bourdieu's view starts with the nature of 
capital as an accumulated resource. Accumulation implies that time and effort are required in the building of capital. A network for Bourdieu is the result of "investment strategies" by the participants. His categories of capital are economic, educational and cultural. Cultural capital, that is abilities, skills, education, cannot be transmitted instantly or quickly as economic capital can be. It is possessed by the person and dies with him but social capital enables an actor to convert their educational and cultural capital into economic capital. For example an investment in education can obtain qualifications which in turn can access paid employment. Parents can generate cultural capital for their children by investing time and effort in them. Social capital is the means of doing so. So far this has something in common with the view of Coleman et al. They give common explanations of the ingredient that holds groups together, the "closure" which enables norms and sanctions and trust to develop and be accepted and implemented by the members of a group.

However there are some major differences in their views. Bourdieu (1998) argued that capital is firstly economic: "economic capital is at the root of all the other types of capital" (p. 54). The amount of cultural capital available to a family or that a family is able to generate depends upon factors related to economic capital, that is the time a mother has available to spend with her children, the length of time a child can continue in education, which are themselves dependent upon "an expenditure of time that is made possible by the possession of economic capital" (p. 54). Bourdieu went on to assert that other forms of capital are valid only insofar as they are convertible to economic capital. He cited education: "academic investment has no meaning unless a minimum degree of reversibility of the conversion it implies is objectively guaranteed" (Bourdieu, 1997, p. 51).

He introduced another concept, that of symbolic capital. Symbolic capital is capital that is unrecognised as capital and in its disguised form it is a means of acquiring power. For example social capital is used by 
parents to pass on privilege through the generations and this promotes inequality.

Furthermore Bourdieu maintained that it is this disguising of economic capital that threatens the environment and trust in which social capital operates: "these transformed, disguised forms of economic capital...produce their most specific effects only to the extent that they conceal the fact that economic capital is at their root" (Bourdieu, 1986, p. 54).

Case studies presented by Gillies and Edwards (2006) contrasted the non-economic exchanges between members of a working-class neighbourhood and the way in which members of a middle class group exchange favours but often include payment in the inter-change. They commented that this economic element decreases the risk of mistrust or uneven obligations. In the context of larger groups, Bourdieu (1986) said that the system of "delegation and representation" (p. 53) can malfunction as a result of non-economic exchanges of favours whose significance is in fact economic particularly where the power of the members is weak leading to poor governance. Similarly the patronage described in Putnam's study of modern Italy (1993) demonstrated that the seeking and granting of favours is on a wider scale an obstacle to good governance.

In the two expositions of Coleman et al. and Bourdieu, there are significant similarities about the concept of social capital but, according to Gillies and Edwards (2006), both are flawed. They believed that Bourdieu ignored the emotional and personal benefits that can follow from membership of a group. On the other hand, Coleman et al., they feel, failed to recognise the adverse effects of group norms. In a positive light, the norms could be seen to impose constraints which facilitate a safe and healthy environment. On the other hand, it is clear that the social norms on which the operation of social capital depends could stifle innovation and creativity. The norms are an invisible means of social control. 
From a feminist point of view, on the evidence of their case studies, Gillies and Edwards (2006) rejected the thesis of Coleman et al. that there is a lower level of social capital amongst single parent families. It could also be added that there have been substantial developments in the definition of family in the years since Coleman et al. wrote (Edwards, 2004). In contrast to the earlier nuclear family model, there are now families extended by divorce and re-marriage, same-sex couples with children, complex and novel family arrangements, family structures in some minority cultures, all of which make Coleman et al.'s analysis less relevant.

In his study of civic traditions in modern Italy, Putnam (1993) interpreted social capital in terms of its role in economic and social development on a broader scale. He depicted social capital as a characteristic of communities. Reviewing the contrasting social and economic development of North and South Italy, he introduced the alternatives of vertical and horizontal relations. Good governance in his study, as operating in the North, is characterised by "horizontal relations of reciprocity and cooperation", while poor governance, as demonstrated in the South, displays "vertical relations of authority and dependency" ( $p$. 88). In a society with good governance shared norms can develop among the population and social capital can be generated whereas in a society with poor governance the welfare of an individual depends on the will or favour of another superior individual and there is less potential for generating social capital. In this context, it is interesting to refer to Coleman et al. who found decreasing social capital amongst some of the families in his study. The young people in families with poorer relations between parents and children related more to their peers and shared norms existed between peers more than between parents and their children, that is a horizontal connection (1988, S.106). The concept of horizontal relations and its relevance to families with young carers will be examined below. 
In applying the concept of social capital to families and communities, Putnam (1995) identified three types of social capital: bonding representing social capital acquired from family and friends, what he called "getting by"; bridging representing social capital acquired at school and college, called "getting on"; linking represented by social capital drawn from non-family adults for example teachers, called "getting around". The degree to which these types of capital are available to young people and in particular to young carers is important and will be referred to below.

The effect of class on social capital was also raised by Putnam who saw tighter bonds of family and friends, that is getting by, more usual in working class but looser wider social ties, that is getting on, more usual in middle class families. This pattern was also described in case studies by Gillies and Edwards.

A further divergence in the treatment of social capital, the individualistic view and the contextual view, was recognised by Morrow (1999) and attributed to the different drives of U.S. and European research respectively.

The acquisition of the different forms of social capital are intrinsic to the normal transition from childhood to the mature state and how this applies to young carers is examined in Section 3.5.3.

\subsubsection{The application of social capital to childhood.}

In Coleman et al.'s study of social capital in families, Coleman et al. represented children as accessing social capital through their parents only. Hence their view that families with less adult human capital led to children having less access to social capital. Morrow (1999) challenged the assumption that children's social capital is only mediated through parents and argued that it took no account of children's ability to influence their own environment. According to Morrow (1999), "the social capital research has not yet moved beyond adult-centred perspectives" (p. 757). 
However it is important to note that the varying ability of children to generate their own social capital had already been linked to the class of the family. Allatt (1993) drew profiles of three middle class families and analysed how all kinds of social capital are transferred from one generation to the next. In the cases she described, the children are encouraged to develop their own skills and techniques for acquiring social capital thus counteracting the view of children as only passive recipients of social capital.

The effect of siblings as a peer group and as a network is also missed by Coleman et al. In her critique of Coleman et al.'s views, Morrow rejected his adverse view that the more children there are the less is the family's stock of social capital in favour of the possibility that having siblings can increase opportunities to generate social capital and can produce norms of their own (1999, p. 752).

An additional way in which children can develop their own networks and create their own social capital is through employment, the Saturday job or holiday work even when still in full-time education. The attitude towards children working has changed over time and it has been seen for some years as acceptable mostly as a beneficial preparation for adulthood, an opportunity for developing useful skills, self-discipline and confidence, and not as a contributor to the family income. For the children it often means access to financial capital but longer-term it can also provide some of the getting on and getting around capital identified by Putnam.

On the other hand there is a major constraint on children's ability to generate social capital compared to adults because of their legal status as minors therefore less scope for taking part in civic society. They are also dependent on adults for access to activities and have no control over policies which affect provision of and access to facilities. For example leisure activities which are a prime setting for networking amongst children are limited by the ability of parents' with low financial and social capital to support the activities either with transport or funds or personal 
care such as washing sports kit. It is also limited by what is made available in the community by government or adult associations or by accessibility and cost.

\subsubsection{The relevance of the concept to young carers.}

Whilst there is now much useful material on the application of social capital theory to children and young people, there is little focusing specifically on young carers. Neither is their access to social capital well documented comparative to non-caring children and young people. A literature search was made on the main data-bases (ASSIA, CSA, Copac, IBSS, JStor, Web of Science, Zetoc) for social capital combined with young carer/s. There were 63 references but only two proved relevant: Barry (2011) and Skovdal et al. (2009). Skovdal et al.'s studies related to young carers in rural Kenya and were concerned more with resilience in the social context so are perhaps of limited relevance in the UK context. Consequently Barry (2011) was the only relevant result retrieved.

Questions present themselves about whether caring impedes their ability to acquire social capital, if so whether it is caring itself which is the obstacle or the attendant circumstances such as low income and what is the long-term effect of any deficit.

Looking firstly at social capital within the family, there is considerable evidence of a high proportion of young carers belonging to low-income and lone-parent families as well as of the material impact of illness and disability in the family (Dearden \& Becker, 1998; Dearden \& Becker, 2005). Where the Cfp is a parent, the high level of unemployment (Dearden \& Becker, 2004) suggests that the level of financial capital will tend more often to be low. Where the Cfp is a sibling, this reduced the openings for building social capital through social and contact networks. If the Cfp is a grand-parent for example, this may not be pertinent at all. If we reject Coleman et al.'s position, this will not necessarily be seen in itself as a disadvantage for the young carer. 
There is little evidence to be found on whether the level of human or cultural capital is significantly different for parents of young carers from those of young non-carers so the critical issue might be the relations between the young carer and the Cfp which will allow the young carer to benefit from any financial, human or cultural capital belonging to the parent. It may be that the closeness in some cases encourages the build-up of social capital of the bonding type within the family unit of a young carer where the situation binds parent and child more closely together than in non-carer families although greater closeness cannot be assumed in all cases. In the sample of young carers interviewed by Barry (2011), the participants found that the caring responsibilities were "a definite bonding mechanism" (p. 529).

Moving to the wider social context, the impediments to being part of peer friendship groups (Robson et al., 2006; Collins \& Bayless, 2013) may reduce access to social capital of the bonding or getting by type. The problems experienced by young carers in school and college may get in the way of building up social capital of the bridging or getting on type by extra-curricular activities and relationships with mentoring adults. The low income characteristic of many young carers' families means that it is often not possible for the family to support the young person with funding, transport or personal support should they wish to participate in community or civic activities. Barry (2011) related that young carers tended to keep their family separate from their school and college worlds because they often didn't want people to know about their responsibilities for fear of ridicule, bullying or ostracism thus reducing the opportunities for bridging capital. Their responsibilities made it difficult also for them to participate in leisure activities outside school and in the community (Gray et al., 2008) thus preventing them from creating social capital of the linking or getting around type.

If young carers through lack of time, energy or predictable life-styles are less likely to have paid work, this in turn stands in the way of contact with the adult world and the world of work. All of these factors create a 
risk of isolation (Barry, 2011) and reduce drastically the opportunities for children and young people with caring responsibilities to build their own social capital be it financial, human or cultural. Ultimately, whether or not Bourdieu's economic-based interpretation is accepted, their lack of peer group involvement, a lack of access to influential adults and other networks would limit their access to building capital of all types.

Heyman and Heyman (2013) challenged the singularity of education and employability for young carers and proposed that there are "alternative routes to employment, and of personal development other than through the formal education system". Faced with the evidence of poorer outcomes for young carers through the formal systems, the acquisition of social capital can be seen as an important element for them in securing positive outcomes.

From linking the most common features of young carers lives with what is already known about young non-carers' building of social capital, it seems that there may be sufficient grounds for developing a theoretical framework for measuring this in relation to young carers.

\subsubsection{The role of YCPs in the context of social capital.}

It is in the context of social capital that the contribution of YCPs could be relevant and significant in outcomes for young carers.

It is suggested in research that Projects could compensate for many gaps in the young carers' life experiences (Dearden \& Becker, 2002; Gilligan, 2000). They may substitute to some extent for the relations and links that young non-carers are able to develop which lead to the generation of social capital.

The first and most obvious is the opportunity for the formation of a social peer group. It can be difficult for young carers to do this in the usual way because of the practical restrictions of caring responsibilities and sometimes because of their own and their families' reticence to admit to the practical difficulties because they do not want to divulge their problems (Aldridge \& Becker, 1993b) fearing interventions once their circumstances are known (Dearden \& Becker, 1998). Professionals 
interviewed by Gray et al. (2008) identified social and peer group isolation as a major problem.

The second is by the offer of the emotional support which is greater and more complex than that which is needed by adolescents in noncaring situations. To some extent this might be gained from the sessions with the other participants and this version is more relevant because of their common experiences but may also be provided by discussion and structured support sessions (Gray et al., 2007). Filling these first and second gaps can provide opportunities for accessing social capital of the bonding type.

Thirdly the personal contact with an experienced, sympathetic and knowledgeable adult outside the family which young carers may miss might be substituted by the Project workers (Banks et al., 2002). This is a relationship which could be the means of acquiring the bridging social capital that they fail to acquire in school or college when their education is curtailed or interrupted.

The fourth is that the Projects are in a position to accommodate the practical problems and thereby facilitate participation over and above what is needed in general school and community activities, that is by providing transport, arranging respite care, funding activities, accommodating unpredictability. Projects often organise visits to facilities and events in the community which young carers might not be able to access on their own (Mahon et al., 1995). This is the chance for creating social capital of the linking kind.

The fifth is that the Projects are a venue where information and advice on their rights and entitlements, on their parents' conditions, on the way the social system works can be made available (Aldridge $\&$ Becker, 1997; Warren, 2007). Where this is not provided by any other agency, the Projects could act as a safety net. Some Projects organise skills sessions and processes in preparation for work. The young people may not be able to access this from parents or educational sources but the trusting relationships that are built up with Project workers can 
generate the social capital which facilitates the transfer of this type of human capital. There is one category of provision which young carers often value most highly and that is "fun". In terms of social capital, this can constitute the bonding capital with friends and peers that they may lack elsewhere (Barry, 2010).

Barry (2011) identified an additional category of social capital to add to Putnam's getting by, getting on and getting around which is particularly relevant to young carers: she calls it getting away and suggests that it lies outside the categories of bonding and bridging capital and constitutes a separate category of respite social capital. The validity of this concept and its relative importance in the role of YCPS could perhaps be tested further.

Schlarmann et al. (2011b) made a similar point in their evaluation of the impact on children of attendance at Germany's first Young Carers' Project. Their findings confirmed the value of access to a friendship group and to information and also they mentioned the respite aspect of the Project.

\subsection{Life Course, Linked Lives and the Ecological Model}

\subsubsection{Life course and linked lives.}

The study of human development takes the data gathered from case studies beyond a snapshot view of the individual. The theory of acquisition of social capital, as described above, provides one framework for analysing histories of personal development and generalising from them. Another framework is the life course theory. There seem to be three different elements in studying the life course: the temporal, the inter-personal and the political/cultural.

The temporal approach views the individual on a continuing changing personal pathway with various developmental stages. This is the life stage development theory, variously called life course, life cycle, life span and narrative approach. Grant et al. (2003) distinguished between life course and life cycle, attributing to life course an element of agency 
which is lacking in the second term (p. 343). "A core assumption of LP" (Life Span Developmental Psychology) "is that development is not completed at adulthood but that it extends across the entire life course." (Baltes et al., 1999, p. 472)

The inter-personal approach presents the individual as part of a group of family, friends, neighbourhood or community who inter-act. It takes as its basis the fact that the lives of individuals are intertwined with each other as a result of relationships or events or location. Consequently people influence one another's development and more specifically their reactions and choices. This can be between partners, generations or siblings or with friends and acquaintances in the neighbourhood, community and workplace. Examples are King \& Elder's study (1995) of the links between three generations, Hwang's study (2009) of the effect of having autistic siblings, Smith \& Zick's study (1994) of the crucial effect of married partners on one another.

The political and cultural perspectives see the development of the individual as belonging to a layered society in which $\mathrm{s} / \mathrm{he}$ is affected by what is happening and changing politically, culturally and historically on a larger scale. Heinz \& Kruger (2001, p. 29) defined this model as the "focus on the interplay of institutional and personal dynamics through a person's lifespan". It is described by Schweiger \& O'Brien $(2005,517)$ as "the interconnectedness of experience across contexts". Baltes (1987, p. 619) emphasised "The role of a changing society in co-determining individual development" and Baltes and Staudinger (1996, p. 518) defined it as "the impact the wider society has on how families function and view themselves".

The three elements are not necessarily distinct and a study may combine some or all of these elements. There is an argument however that no study of an individual is complete without taking into account all three aspects. 


\subsubsection{Bronfenbrenner: the ecological model.}

A full expression of an integrated approach is to be found in Bronfenbrenner's theory of ecological development which incorporated all three of the above aspects. He visualised four levels at which the individual inter-acts with others: between parents and children which he terms a microsystem and between siblings, a second microsystem, the two microsystems forming a mesosystem; with a wider range of friends, neighbours, workmates and community contacts which constitute an exosystem; at a third level the societal factors which he calls a macrosystem; lastly the chronosystem which covers the individual's development over a period of time.

Bronfenbrenner's own study with colleagues of the effect of maternal employment on parents' perception of their children (1984) provided a useful example of the ecological approach. Amongst the initial findings was the result that mothers in full-time employment had higher opinions of their daughters than of their sons if they had higher schooling but lower opinions if they had a lower level of schooling:

It is a cardinal principle of ecological research that the distribution of people across real-life settings is never random; those who inhabit one context rather than another are likely to differ not only in their psychological characteristics but also in their life histories. (Bronfenbrenner et al., 1984, p. 1370)

The researchers questioned their findings firstly for their construct validity, that is whether these variations were due to other variables arising from characteristics of the parents such as their personal willingness or otherwise to give praise. Secondly the findings were questioned as to the direction of causality: whether maternal employment was a cause of these findings or an effect of socio-economic factors in the macrosystem. For example the better educated mother might have already been affected by feminist thinking consequently praising competence and self-confidence in her daughter. This is not 
supported but not ruled out by further testing. Thirdly the findings were interrogated for evidence of influence within the exosystem, in this case the mother's employment circumstances. The factors of the mother's hours of work and her status at work were added to the analysis and the indication was that these factors did influence parental perceptions but the researchers concluded that there was still no evidence that the parental perceptions affected the parent-child inter-action nor did it demonstrate what effect the parent-child inter-action had on the longterm development of the child. The causal chain remained to be proved (1984, p. 1376).

\subsubsection{Applying Bronfenbrenner's model to young carers. The microsystem (i).}

The illness or disability of a parent is likely to affect their child in several ways. Bury (2012) analysed ways in which the adult as a result of the onset of a long-term condition might undergo changes to their personality as well as in their practical life-style. Pain and any degree of incapacity could change their self-perception and relationships with their family including with their children. Bury (1982) conducted semistructured interviews with 30 rheumatoid-arthritis patients who had just been diagnosed and again after consultations. He recounted anecdotal evidence of the changes in their perceptions of themselves and how they understood and were coming to terms with their condition. For a young carer, beyond the physical facts of caring, the changes in the person they care for might have a significant impact on the balance of power, control and responsibility.

The impact on the young carer might vary according to numerous characteristics of the condition of the person cared for: whether the onset is sudden or gradual; whether the condition is stable or changeable; how the person copes with the condition; how they adapt to it. 


\section{The microsystem (ii).}

The other aspect of Bronfenbrenner's microsystem is the relationship between siblings. The sibling may be the person cared for or the child in the family who is looked after by the young carer because the disabled or sick parent is not able to fulfil the parental role. It is not only the caregiving and care-receiving roles that steer these relationships as explained by Hafford (2010, p. 299). In the context of immigrant families, sibling care-giving is often normative but this raises issues of safety and security which may result in the decision to recommend their going into care, an option feared by many hidden young carers. In this situation, Hafford (2010, p. 300) pointed out that sibling bonds foster protective capacities and it is the affection between the children which has to be considered in their placement. The affection is the result of the interaction between sibling carer and cared-for.

\section{The exosystem.}

The evidence shows that the network of friendships for young carers is likely to be interrupted by their role. The desire of the family to keep their problems to themselves might interrupt or reduce neighbourhood relationships. The setting of workplace for adults in the exosystem is presumably equivalent to school and college for many young carers and, again from the evidence, it seems that young carers cannot be assumed to enjoy an untroubled relationship with school/college and teaching staff. Crawford and Walker (2002) remarked that these settings are "specific culturally in time and location" and with this in mind it is interesting to compare young carers in the UK with the structure in which young carers for people with AIDS operate in Western Kenya (Skovdal \& Ogutu, 2009). There the existence of extended family networks, strong communities, active churches, subsistence agriculture provides a very different context for developing coping strategies. It appears that "children's ability to cope is determined by the extent to which they are able to participate in their community and negotiate support from it" (Skovdal et al., 2009, Abstract). An important factor is the different 
construction of childhood in that community as "a time of duty and service" (p. 593). In that setting most young carers were respected for their role and in contrast to non-carers were able to construct positive identities. As a consequence, the exosystem was for them the setting of positive personal development.

An article on orphans in Ethiopia (Abebe, 2012) demonstrates a similar setting. The children in this study were absorbed into the extended family, were caring for family members with AIDS and doing work in family business such as farming. This affected their position in the community. They were viewed positively because of the contribution they make to the family over time both in terms of care and income generation.

\section{The macrosystem.}

At a third level are the societal factors which Bronfenbrenner calls a macrosystem. Each individual lives whether consciously or unconsciously in a particular social, political and historical epoch. The ideas that are prevalent or even those that are developing at any specific period will affect their personal lives. As Wright Mills (1959, p. 32) urged, personal problems are connected with public issues.

When Pollack (2002) wrote of sibling carers in the period 1900-1970, she wrote about a particular cultural setting when handing responsibility for children to their siblings was a normative action. Furthermore she traced the historical change from the perception of children as workers to that of children as innocent dependents. The context in which she grew up was a societal climate in which mothers made their decision to relinquish maternal duties and hand them to their older children. She referred to the children as assistant parent, assistant mother, auxiliary parent (p. 32), supplemental parent (p. 34) and surrogate parent ( $p$. 38).

This meant that, in current thinking, they were taking on inappropriate responsibilities at a time when they were not developmentally ready and had to "handle ... developmental conflicts and 
needs" (p. 33) against a background of dealing with younger children and their needs. Pollack described the experience of being a sibling carer and went on to portray the damage this could do to their own parenting abilities as adults. She also drew attention to the experience of the child being cared for ( $p .33$ ) which itself has repercussions for the adult sibling relationships, thus also illustrating Bronfenbrenner's microsystem and chronosystem (see Section 3.6.3).

It is interesting to note that this is a very adverse picture which does not pay regard to any research exploring the positive outcomes of being a young carer, including a sibling carer. Another point specific to that period that Pollack did not comment on was that there was no mention of transferring care to fathers. Fathers' involvement with young children was rare in the period and class about which Pollack writes and only became a widespread feature of life later in that century. The role of the adult partner in caring, whether father or mother, can have implications for the children in the family even in current times.

Inevitably the question must be asked as to whether improving an individual young carer's life can be achieved by supporting the individual without wider cultural and strategic changes.

\section{The chronosystem (i).}

Lastly Bronfenbrenner defined the chronosystem which covers the individual's development over a period of time.

In 2003, Grant et al. published a study of care-giving in families supporting people with intellectual disabilities. Although that study focused on adults and on one particular condition, its account of developmental phases in the carers' progress across a period of time-a chronosystem approach-is applicable to young carers generally.

Seddon (1999) (cited by Grant et al., 2003) observed carers to have passed over a period of time through transitional points: managing uncertainty, trial and error, getting to grips, establishing the upper hand and keeping going. This understanding indicates the need when collecting data on young carers to include a question on the length of 
time they have been in a caring role. It is possible that this method, equating to a life course approach to young carers' narratives, will identify typical stages of progressive temporal adjustment even if they are not identical with those analysed by Seddon.

\section{The chronosystem (ii).}

Searching on life cycle brought up an article by Keenan et al. (2009) which discussed the situation of young carers for parents with Huntingdon's Chorea, a heritable condition, emphasising the inter-action of parents and children thus demonstrating linked lives as in Bronfenbrenner's microsystem but also in the chronosystem the impact that their parents' condition will have on their lives long-term both medically and psychologically. One example of this is the outcomes for children of the mental health of their parents (SCIE, 2009). This may be as an effect of the caring role or it may be a genetic condition. Applying this to young carers invokes the realisation that for young carers of parents with any disability or mental health illness there is a complex question of whether the condition is heritable and whether they have a right to the knowledge. If so, they may need to be given the genetic facts (Newman, 2002) and the prognosis. It is a matter of judgement at what age they would be able to absorb the information and whether they will be able to cope with it. Millenaar et al. (2014), writing about young carers for a parent with young onset dementia, stressed the need of the young people for information and explanation and discussed suggestions about how that can best be done and by whom.

\subsection{Summary of Chapter 3}

There is considerable evidence of adverse outcomes of caring for children and young people. The areas of their lives affected are potentially education, health, personal and social lives and material welfare. Less well documented but equally important is the effect on their acquisition of social and human capital. It is in the latter area that the YCP might be performing a significant function. Applying the Bronfenbrenner model of 
linked lives to the situation of the young carer shows how the caring role can have a long-term effect on the way in which they make their place in the community and in the wider society.

There is also some evidence of positive outcomes in terms of maturity and competence greater than usual for their age group in the general population. The drive to safeguard and protect young carers can sometimes present them as passive figures and thus obscure the agency they exercise by contributing in a constructive way to the welfare of the family.

One feature which will result in more positive outcomes is their personal resilience and this characteristic may be correlated with several factors in the young carer's situation which need to be explored further.

The adverse and positive outcomes, at least in the short-term, have been well evidenced since 1993. There has been sensitive research with young carers themselves although the majority has been qualitative. In recent studies, especially in Australia, there have been attempts to collect objective data, to use quantitative methods and to design comparative schemes (Fraser \& Pakenham, 2008; Pakenham et al., 2006; Pakenham et al., 2007). More remains to be learned however about which are the factors in the micro-, macro- or chrono-systems as defined by Bronfenbrenner which pre-dispose young carers to the adverse and even more important to the positive outcomes in any of these areas and for this to include some objective methods in doing so. 


\section{Chapter 4}

\section{Types of Support, Availability and Barriers to Take-up}

This chapter describes the services which may provide support for young carers and explains the barriers to take-up, stemming from both service providers and service users. Two networks are identified as the main forms of support.

\subsection{Provision}

There is a range of potential support for young carers. The degree to which the support is accessible and/or effective will be discussed.

Both statutory and non-statutory agencies are able to support carers. There is strong evidence that two networks stand out as the major providers of services for young carers: Social Services and YCPs. Social Services must be regarded as the major provider since they have statutory responsibilities. The third sector, apart from generic youth support services, complements the statutory service in the form of dedicated Projects. These are often commissioned by the statutory agencies.

\subsubsection{Social Services.}

Social Services do now have statutory obligations towards young carers but, as for adult carers, this has been reached by a painstaking legal journey. 
Initially children whose health or developmental progress was threatened would have been entitled to an assessment as a child in need under the Children Act 1989. This meant that they were entitled to services which adult carers were not. Clements (1995) commented that "there is no limit to the services which social services can provide for her support under Section 17 of the 1989 Act" (p. 28). The child in need solution did however draw the criticism that young carers were to be assessed as children but not as carers.

Young carers were covered by the C(RS)A in 1995 which established the right of carers of all ages to a carer's assessment, although only when the Cfp was being assessed and there was no duty on local authorities to provide services. Although this provision catered for children as carers, the interpretation of the C(RS)A by the SSI (DoH, 1996), which followed the Act, recommended that young carers should still be treated as children in need.

The Combined Policy Guidance to the Carers and Disabled Children Act (2000) and the C(EO)A (2004) perpetuated the stance that it was more appropriate to assess young carers as children in need under the 1989 Act. It did though place a duty on LAs to tell those who were caring about their right to an assessment and expanded the interpretation of needs to include education, work, training and leisure.

The assessment process for children in need was developed and explained in the Framework for the Assessment of Children in Need and their Families (FACNTF, 2000). It represented progress by identifying 
young carers specifically (para 3.63), referring both to their right to an assessment under the $C(R S) A 1995$ and to the need to refer them if necessary for an assessment as a child in need (CA 1989) as recommended by the Policy and Practice Guidance (1996).

The Children Act 2004 (Section 53, para 17) amended the Children Act 1989 , so that in any assessment the wishes and feelings of the child should be ascertained as far as is reasonable and given due consideration.

In Wales, the decision to adopt a generic policy towards carers of all ages was implemented in the Carers Strategies (Wales) Measure 2010. In this document, carer meant an individual "who provides or intends to provide a substantial amount of care on a regular basis" with no age, relationship or residence qualifications. It doesn't mention the right to an assessment because at this point Wales was still subject to UK primary legislation and therefore to the 2004 Act.

The SS(W)A (2014) continues with the very broad definition of eligibility for services and the right to an assessment. There are paragraphs on "children who care" specifying their developmental needs. There is a duty to assess where need is judged to exist.

There are four main types of support which can help young carers: medical help for the disabled or sick person; support offered to the disabled people themselves in the form of help with running their home and family; respite breaks; advocacy to assist the young carer with their education, employment. and other activities. These do not have to be 
provided by the local authority itself: the SS(W)A 2014 places on the local authority the duty to encourage the development of social enterprises and third sector organisations who can provide social care support and preventative services. It states also that the assessed needs can be procured from any of these agencies.

The use of Information Communication Technology to provide health and social services has been taken seriously by the UK and devolved Governments since 2003 and in the social care setting pilots have usually included the relief of pressure on carers as one of the aims. In Wales, funding in 2007/9 from the Welsh Government triggered the thinking about this form of service delivery and facilitated pilots by Social Services. Subsequently responsibility for sustaining these pilot services was delegated to local authorities. This innovation evoked the question of whether this service was applied to the situation of young carers. Gray et al. (2008) referred to young carers worrying whilst away from their family member and this form of telecare could be an effective way of alleviating that particular problem.

A brief inquiry was made of all twenty-two telecare services in Wales as to whether they had any cases supporting young carers (Appendix C). Only one authority had been approached to support a young carer. The barrier to doing so had been the legal status of a young carer as a minor and so the service was reluctant to risk notifying a minor as the responsible person in a case of emergency. Even where the young carer was sixteen plus, it was said that the charge for the service might have 
been a deterrent to take-up in some families and grant-aid would need to be sought. It would seem unlikely on the basis of this inquiry (Appendix C) that telecare is as yet a form of support for young carers.

The literature review did not uncover any systematic surveys of the statutory young carer service, of how the service is being delivered or how effective it is. A review of provision might allow an analysis of these questions.

\subsubsection{Education sector.}

As shown in previous studies (Dearden \& Becker, 2002; Larkin, 2009; Woolley, 2013), one of the potentially adverse impacts of caring is on education and schools are in a good position to identify, support and refer young carers.

The National Strategy (1999, p. 80 ), published by the DoH with the Carers National Association, had recommended that schools should be encouraged "to designate someone to act as a link, for young people who are carers, with Social Services, the Health service and any Young Carers' Project".

Recommendations about how to manage this responsibility were issued by several agencies from 2002. WAG published a leaflet called Is someone you teach a young carer? A ydych chi'n dysgu gofalwr ifanc? in 2002 and circulated it to schools. In 2005 they produced a training pack and DVD for schools: Caring for young carers - raising awareness of young carers' issues. This included information and advice to schools on how to identify and support young carers. It warned that it might not 
always be obvious that someone was a young carer but that they should take care where there was an indication that they might be (WAG, 2005).

In 2009 the Children's Commissioner for Wales commissioned a report called Full of care which consulted 125 young carers and which widely disseminated their summarised views and made recommendations for schools to have a designated liaison worker to support young carers and for the development of a Young Carers Strategy.

In 2010 the Princess Royal Trust for Carers in co-operation with the Children's Society produced a guide for schools Supporting Young Carers: A Resource for Schools:

Ofsted recommends that councils and partners should ensure that professionals within universal services are aware of the needs of young carers so that they can be identified and supported. The key to supporting pupils who are young carers is through early preventative work and supporting families in ways that prevent inappropriate caring...a multi-agency approach...to remove the barriers to learning experienced by this vulnerable group of pupils. (Princess Royal Trust for Carers and Children's Society, 2010)

This was followed by further publications by them in various formats up-dating and expanding the guidance and designed for primary and secondary schools and colleges, Leadership teams, non-teaching staff and governing bodies. A Young Carers in Schools programme was set up 
recently in England to share good practice, to develop a toolkit and provide Continued Professional Practice.

The recommendations from WAG, the Children's Commissioner for Wales and The Princess Royal Trust had all three advised that a named member of staff in each school be designated with responsibility for young carers. So it could be assumed that schools had already been alerted to this responsibility but how far they had progressed in implementing these recommendations is relevant to young carers today (see Appendix $\mathrm{H}$ ).

\subsubsection{Leisure and Youth services.}

Youth services might be expected to have adults who were aware of young people having problems, offer a shoulder to cry on and refer to needed support agencies. Indeed the National Strategy $(1999,80)$ had added to its encouragement of Social Services and educational support the need "especially to ensure that young carers have access to leisure and recreational activities". The most recent Wales Carers Strategy (2013) also referred repeatedly to the importance of social and leisure activities for young carers, matters which they specified had been raised with them by young carers themselves.

The problem with expecting referrals from this service is that the most stretched young carers are less likely to have the time or flexibility to access them either with or in the same way as their peers especially to ensure that young carers have access to leisure and recreational 
activities. Little of any substance was found on literature searches for leisure services with reference to young carers.

\subsubsection{On-line.}

McLuhan (1967) is best known for his statement "The medium is the message". In the 1960s, he began to explore the effect of technology on lives and attitudes, suggesting that changes in the forms of communication technology used could in themselves change society. Tapscott $(1998,1999)$ recognised the power of digital media in the economy, commerce, entertainment, education and government. He described how young people are "bathed" in technology (1999, p. 7) and was optimistic about how the "N-Geners" would benefit from the new media in developing self-expression and self-discovery.

Young people born after approximately 1980 are mostly at home with social media and are commonly referred to as the net generation, digital natives, the i-generation and other distinguishing titles (Kennedy et al., 2010; Jones \& Czerniewicz, 2010) with their wide-spread use of mobile phones, e-mailing, texting, social networks. Kennedy et al. found that the Web and instant messaging were the most used rather than the advanced technologies.

On the basis of evidence of widespread use of the Internet, it would seem to be relevant to explore its use for reaching the hidden population of young carers who experience a restricted social life or isolation from their peers yet Gray et al. (2008) cited the view of Aldridge and Wates 
(2005) that: "...little research has been conducted on the importance of technology in the lives of carers and young carers" (p. 171).

There are now many web-sites offering information and advice to young people generally covering relevant issues, for example helplines (Childline), rights (Children's Legal Centre), advocacy (National Youth Advocacy Service), sexual health (Brook Young People' Information Service), bereavement (RD4U), eating disorders (Beat) etc. At the time of researching this study, there were few sites specific to young carers. What few sites there were either provided information often with links to other relevant youth sites although sites which were inter-active or participatory, for example involving young carers in compiling and editing, were not numerous.

The Carers Trust managed www.youngcarers.net and this appeared to be the only site dedicated to young carers UK-wide. As well as featuring information, stories, help on school work and on dealing with caring, it ran a weekly chat line and had links to other useful sites. It did not however carry any Welsh information or links. Some large charities ran sections for young carers. For example Macmillan ran a site aimed at young carers who cared for adults with cancer and had a helpline.

Other sites were set up with specific target audiences in mind. Riprap, based in the University of Sheffield, aiming at the same audience as Macmillan, had an on-line discussion forum and details of local groups. Sibs was a site for those of any age who had a disabled sibling and provided e-mail information and a chat room for those under 18. 
There were some generic youth sites for Wales: Meic, Cliconline and Funky Dragon. The latter is the Campaign for Children's and Young People's Assembly and is currently suspended until further funding becomes available.

At local authority level, there were many sites run by local authorities or local services in England and Wales with statements about Young Carers services and their rights. They had useful links and local information but were mostly one-way communication. There were generic youth sites which included information for young carers. There were sites for some YCPs in Wales. Of these, Powys appeared to be the most innovative in design and facilitated the participation of young carers themselves.

Although young people's increasing use of the Internet for their information is a fact of life, this study did not explore the effectiveness of these sites as part of the service to young carers.

\subsubsection{Third sector.}

The third sector organisations such as the Carers' National Association (subsequently Carers UK), the Children's Society, the Princess Royal Trust for Carers, Children in Wales, are involved in support for young carers through policy advice at strategic level. They also contribute to raising awareness by campaigns and the provision of training, practical advice and information on the delivery of services.

Apart from these roles, it is the third sector who are also largely responsible for managing the support service dedicated to young carers 
in the form of Young Carer Projects. Pitkeathley (1998), one of the best known campaigners for young carers, said that "YCPs are widely accepted as one of the most appropriate mediums to support young carers". Barnardo's, Action for Children, Crossroads, Mind all play a part in managing Projects for Young Carers. The National Carers Strategy (1999) stated that there were 110 Projects in existence in Britain mostly managed by the voluntary sector although often with statutory funding. Seddon educed the information in 2003 that by then there were 140 in the UK of which 19 were in Wales. Gray et al. (2007) recommended YCPs as being an effective example of good practice on the basis of the views of young carer participants' in their study. This form of provision merits closer examination to find out exactly what functions they perform currently and what needs they address.

In the context of resilience, McMurray et al. (2008) quoted social workers in their study as attributing the resilience of children at risk to other workers without case loads and therefore with the time to act as confidants and positive role models. Workers in the Projects for young carers could be seen to fulfil this role.

\subsection{Barriers to Take-up}

The literature review revealed multiple reasons why young carers were not accessing services. Moore and McArthur in particular gave a comprehensive summary of the possible barriers. Although their study was based in Australia, it seems to correspond with other studies based 
in the UK. The reasons given fell into two main groups: those arising from the service providers and those from the service users' situation.

\subsubsection{Service providers.}

One initial barrier is the failure by agencies outside Social Services to identify children who are acting as carers. The simplest explanation for this is a lack of awareness of young carers' issues. McAndrew et al. (2012, p. 16) referred to the "variability in skills" of professionals across service providers even when dealing with those identified as carers.

It may even apply to other departments (depts.) of Social Services including adult services where attention might be focused on the adult needing the support and not recognising the young family member as a young carer with needs. This may still be happening in spite of the government move to a whole family approach. The result is that some may not be gaining access to the support they need. One of the most informative early studies on this aspect of services is Dearden and Becker's survey (2004) of over 6,000 young carers. They reported that the legal right to an assessment is not always satisfied and this may be so whether or not young carers have been referred to Social Services, indicating the size of the gap. Their sample had been recruited through YCPs so all had been referred either from Social Services or had selfreferred directly to the Projects. Even so, only $18 \%$ had received an assessment and, although this had increased since their 1997 finding, the $82 \%$ not assessed was still considerable. 
Where services are stretched, there can be an uneven response. There may be a conflict of interests between ensuring that the ill or disabled person is cared for and the interests of the young carer. Dearden \& Becker (2004) uncovered inequality of access to an assessment for young carers at a statistically significant level. Young carers from minority ethnic backgrounds were more likely to have been assessed overall, $25 \%$ compared to $17 \%$ of white young carers. A breakdown into assessment as children in need and as carers found that $21 \%$ of BME young carers received an assessment as a child in need compared to $11 \%$ of all young carers but $3 \%$ assessed as carers compared to $6 \%$ of white children. They found also that all young carers in families with someone with drug/alcohol problems were more likely to receive an assessment as children in need (28\%). A higher percentage of young carers in one parent families received assessments compared to those from two parent families ( $14 \%$ to $8 \%$ ). It could be deduced that these were prioritised responses to perceived need. For example young carers in a one parent family are likely to carry a greater caring load and therefore be at comparatively greater risk. Though findings on the effect of different conditions are inconclusive, it is possible that those caring for family members with mental health conditions or drug and alcohol issues would be prioritised because of the evidence of the greater adverse effects on the young carer. For example the incidence of missed school and educational difficulties is much more marked for these young carers; 34 per cent were missing school and 40 per cent in total were missing 
school or had other indicators of educational difficulties (Dearden \& Becker, 2004). In mitigation, it should be pointed out that there may have been a proportion of young carers who had had an assessment but not recognised it as such.

The next consideration is how many are receiving services. Provision is sometimes unavoidably stretched so as to exclude the ability to offer preventive action or early intervention. This means that help will not be forthcoming until the family or the young carer have reached crisis point. Again Dearden \& Becker (2004) relayed the significant information that the only support received by one fifth of the young carers and their families in their sample at that time was contact with a specialist YCP.

There are references in research to a lack of collaboration between services. In Australia, Moore and McArthur (2007) in particular specify the need for protocols for identifying and assessing young carers between Adult and Child services and senior lead on young carers in authority. They recommend also a whole family approach involving all agencies including education, third sector and other relevant agencies.

The evidence shows that there are many more children who care than have been referred to the statutory authorities and the broad legal definition of eligibility (SS(W)A, 2014) increases the potential service user base. The broader definition in the Wales legislation can be justified as elsewhere on the grounds that it will not exclude anyone who might need support. On the other hand, in the current context, where many young carers are not receiving an assessment or support, a larger 
number of referrals will inevitably require the resources to assess and supply the assessed needs. The commissioning and purchase of suitable services from the independent sector might help to solve the supply problem but may not necessarily solve the problem of how this is to be funded.

Becker (1998) implies the principle of targeting those most in need when he suggests that the number of young carers could perhaps exclude individual children taking on caring duties who do receive appropriate support, whether that is from family and friends or from statutory services, or those whose health and development do not appear at the time of assessment to suffer excessive difficulties or children whose burden of care does not seem enough to qualify for referral or statutory support.

This could be challenged firstly on the grounds that it does not assist if the aim is to prevent children acting as carers altogether. Secondly, it is important to recognise that, even if they are coping well currently, their role may affect their relationship long-term with their parents and family, the psychological impact may be hidden and any adverse impacts may not appear until later in life, thus leaving a grey area where children are carrying out unsuitable roles however well and the need for help may be missed (FACNTF, 2000). A lack of valid predictors does nothing to clarify this quandary.

Because of the strong evidence of the effect that caring can have on educational attainment, hearing from young carers themselves what 
schools and colleges need to do is important. A study by Moore et al. (2009) was intended specifically to discover from young carers what their educational needs were. Although set in Australia, the young carer's experience might be considered universal. The positive roles which schools played for them were to act as a respite from home, to be somewhere they could access sympathetic adults and an opportunity for connection with their non-carer and carer peer group since they often could not get out to socialise otherwise. What they wanted schools to provide was understanding of their situation from teachers and best of all a specific person on whom they could call. They explained also the need for more flexibility in the provision of education to accommodate their difficulties. Other comments included the need for a change of culture amongst both pupils and staff regarding attitudes to disability, illness and addiction.

Eley's study (2004) found similar views in her small sample of 11 carers aged 10-17 in Scotland. Again they stressed the need for better attitudes from teachers who should be aware of and accommodate their difficulties. The idea of a named person for pastoral care, a "trusted teacher" was suggested. Schools were viewed by the young carers in this sample as having the most potential to help young carers with teachers better placed than social workers to identify and support young carers. Heyman \& Heyman (2013) concluded from their interviews with young adult carers and specialist young carer workers that one of the 
ways of supporting young carers is for the educational system to become more sensitive to their needs.

The same barriers can appear in Health. The report by Her Majesty's Government (2010) commented on the dissatisfaction of carers with the way health professionals treated them. Sprung and Laing (2014) remark on the the failure of health professionals, front-line workers and even GPs to recognise young carers and on the lack of appropriate training to imbue this skill.

\subsubsection{Service users.}

There are a variety of reasons for not accessing support services which arise from the carers themselves and there is considerable common ground in this between adult and young carers.

Sometimes young carers are hidden because they are not aware that they are carers. Perhaps they have not met the concept of young carer and regard their caring role as part of the family dynamic. Alternately it may be a concept which does not fit with a loving or dutiful relationship (Smyth et al., 2011a). To take on the identity of a carer involves complex emotional processes. Where a child is caring for a parent for example, to think of oneself as a carer conflicts with the essence of the parent-child relationship. It ignores also the mutuality of relationships in which the young carer may also be receiving love and support from the Cfp (Parker \& Clarke, 2002).

A second reason is that, even when they experience difficulties and realise their role, they may not know that they are entitled to help or 
what help they might receive. Access to reliable information about the services available may be due to a failing on the part of information providers but it could also be due to their age or to their disengagement from sources of public information. In some cases it can be for cultural reasons, for example in BME families, or for communication difficulties, for example families whose English is not fluent or who use primarily sign language.

However there are many more complex emotional reasons which stop young carers from seeking help. The young person may feel ashamed or guilty about friends and neighbours knowing of their difficulties. Sometimes it is the unwillingness of the Cfp to reveal their situation which keep their problem hidden. This can be especially true where the problem is subject to stigma such as one of mental health or addiction. The young carer may fear discrimination, bullying or isolation and not want to talk about it.

Families often have a number of fears and anxieties about approaching Social Services Depts. for help or about being referred to them by other agencies. (FACNTF, para 3.32)

Several researchers have written that the effort to appear "normal" and to keep up appearances is usual with children in deviant situations (Anderson \& Bury, 1988; Goffman, 1963; Meijer et al., 2000). Frank et al. (1999) refer specifically to young carers feeling that because of their difficulties they needed to shun participation in much of their peers' social life so as not to expose themselves to being regarded as abnormal. 
Banks et al. (2002, p. 230) commented that "until a way is found of enabling young people to feel comfortable about discussing their caring role, services provided to support young carers will only touch the tip of the iceberg".

Banks et al. (2002) made the point that the intervention of statutory agencies can feel to some like an intrusion into their privacy. For others it feels threatening because there is a lack of trust of adult professionals. Children may fear the family being broken up or the parent being removed (Aldridge \& Becker, 1993, 1994) although Mahon and Higgins (1995a) and Blyth et al. (1995) suggested that this could be exaggerated. Dearden and Becker (2000) suggested later that this was the third most common reason for being admitted to care in England thereby supporting the fears of the young carers and their families. The estimate of the Department for Children, Schools and Families (2009) was nevertheless that only $5 \%$ of young carers in 2008 were admitted to state care because of parental ill health or disability.

Barry (2011, p. 525) comments on the "adverse perceptions which many young carers have of supportive adults such as teachers or health professionals" causing anxiety about leaving the Cfp to the providers. Participants in Moore and McArthur's study (2007) referred to the poor quality of service in general that they received. The LE report (2010, p. 40) suggested that in the case of residential and respite adult carers may not want to entrust their family members to the services "unless they have some confidence that they will be of high quality" and this can lead 
to them not using the service. This cannot be rejected as a possible feeling by young carers also.

Another reason for not wanting to use services may relate to the young carer's sense of their own adequacy. They may be afraid of appearing incompetent or unable to manage so they do not want to talk of difficulties in their role (Barry, 2011, p. 523, para 2.2) or to be seen to depend on outside agencies. Dearden et al. (1995) suggested that this might result in their being reluctant to cede the power and control which their role accords them unusually for someone of their age and place in the family hierarchy. "Additional help may not always be welcome; the socialisation of young people into the caring role may result in their reluctance to relinquish such a role" (Dearden et al., 1995). Perhaps, rather than being socialised into the caring role, it is their agency they are reluctant to give up.

\subsection{Summary of Chapter 4}

There is a range of agencies which might provide support for young carers. Social Services is responsible for the statutory duty of assessment and review and arranging for appropriate support.

Schools and colleges have a duty and an interest in identifying those whose performance is affected by caring responsibilities. Information and advice of various kinds are provided by the Third Sector and among their services are YCPs most of which are managed by this sector. The Internet provides some help, but this is under-developed as yet. 
The barriers to take-up of services arise from two sources. Service providers are not always able to provide all the support needed and service users often do not for a mixture of reasons take advantage of what is available.

Two networks appeared from the literature review to provide the main forms of support for young carers: Social Services and the YCPs. The literature review had not uncovered any systematic surveys of the statutory young carer service or of the Young Carer Project service in a geographical area. What has not been done yet and needs to be done is to obtain more comparable information about provision and access to it. 


\section{Chapter 5}

\section{Young Carers' Voice}

This chapter describes how the voice of young carers themselves has emerged through legislation, lobbying and research. It examines how the involvement of young carers in research has developed and the tools which have been used. It argues that the Projects are shown to play a major part in promoting the self-identification of young carers. Existing examples of evaluating the effectiveness of Projects are analysed.

\subsection{In Legislation}

The representation of the interests of young carers as that of numerous vulnerable groups followed after legislation and practice in children's rights. Significant steps were taken by the UNCRC in 1989:

1. States Parties shall assure to the child who is capable of forming his or her own views the right to express those views freely in all matters affecting the child, the views of the child being given due weight in accordance with the age and maturity of the child.

2. For this purpose, the child shall in particular be provided the opportunity to be heard in any judicial and administrative proceedings affecting the child, either directly, or through a representative or an appropriate body, in a manner consistent with the procedural rules of national law. (UNCRC, Article 12)

The legal pressure to consult children was re-enforced in the UK by the Children Act (1989) and documents from the DoH (1998, 2001, 
2002). Its implementation in considering their point of view in policymaking applied to young carers. In Wales, in 2004 WAG adopted children's rights as the framework for all its legislation and policy-making concerning children and young people. This was followed by an Action Plan, Getting It Right, in 2009.

Another force promoting participation in decision-making was the growth of the consumerist movement from the 1980 s and its application to public services, including services for young carers (Mahon et al., 2007).

Franklin and Sloper (2005) queried how far children's participation had progressed in social care. In their study of participation by Social Services Depts. in England, they commented that the existence of documents establishing consultation as policy did not necessarily change practice (Franklin \& Sloper, 2009, 9). They stated that proper consultation requires a transfer of power (p. 14) for it to have an effect on policy. They pointed to research which explained the complexity of children's participation, for example the children's own understanding of the process and their place in it (Kirby \& Bryson, 2002, cited in Franklin \& Sloper, 2005). Because of their developmental stage, their disabilities and sometimes other barriers, the consultation methodology needed to be developed. From a practical perspective, "training and resources" were required and "confidence, expertise, determination and a 'can-do' attitude" (p. 14). They mentioned the need for accessible information and child-friendly material. Facilitating participation required more 
creative methods and the time and resources to achieve it (Franklin \& Sloper, 2009).

The implementation of the right of children and young people to participate in decision-making in healthcare was argued by John and Griffith (John \& Griffith, 2011). They described delays in adopting a rights-based approach in healthcare, blaming the persisting influence of historical attitudes and the dominance of a paternalist mind-set.

Side by side with the legal rights and consumer perspectives, there is a purely practical reason for listening to young people. John and Griffith pointed out that in healthcare listening to children ensures greater effectiveness and efficiency in treatment. In the family of a person needing caring, it can result in arranging support for the Cfp more effectively, for example by facilitating the young carer's contribution and by choosing the most appropriate and sustainable arrangements for the Cfp (McAndrew et al., 2012). The full understanding of the home situation including the capacity and contribution of any young person in the family will assist this.

\subsection{In Lobbying}

Hart (1992) wrote that the degree of the involvement of children has varied in its validity from manipulation at the lowest level to childinitiated shared decisions with adults at the highest level, a paradigm which was adopted by UNICEF in 1997.

Much lobbying reports the existence and extent of young caring using young carers' stories to illustrate and lend colour to the reports. Photos 
are used and young carers are often quoted.

The awareness training delivered by the Projects where it involves young carers is realising the need for them to communicate directly with stakeholders themselves. In the process of explaining to others, it helps young carers to analyse their own experiences.

When young carers are capable of self-identifying and sharing their experiences, they are able to speak for themselves and increasingly they are participating more formally as speakers at seminars and conferences. This is nevertheless as yet mainly within adult settings and under the guidance of adults.

There are examples emerging of young carers taking a leading role in consultation and lobbying. The Young Carers in Focus (YCiF) partnership, led by The Children's Society and funded by the Big Lottery Fund, is giving young carers a voice, and the recognition and support they so desperately need to generate public awareness opportunities and improve public understanding about the issue. It brings together partners from Rethink Mental Illness, The Fatherhood Institute, DigitalMe and YMCA Fairthorne Group. YCiF aims to recruit more than 200 young carers "champions" over four years to attend workshops and training to gain skills, resilience and confidence. They will be supported to advocate at a national and local level to raise awareness and make positive changes to the lives of young carers across the country.

In Wales, in October 2007, young carer representatives from across Wales met and produced their own report on what they needed and a 
10-point Action List was submitted to the Assembly Minister who met them then in February 2008. Their suggestions were mostly in tune with contemporary work on young carer issues but more innovatively they wanted the age of the Young Carer to be raised to 25, free bus passes issued and an ID card produced for Young Carers. The Minister was very receptive but, as in Scotland in 2002, she was cautious about any proposals with resource implications. Her main proposal at the time was the development of a policy proofing toolkit which has now been published and an ID card has been piloted.

\subsection{In Research}

In the early days of research into young carers' issues, descriptive data were collected from children who were involved only as the subjects of research (Page, 1988; A. O'Neill, 1988). Very soon young carers' experiences were being studied and their views of their lives being invited (Aldridge, 1993; Aldridge \& Becker, 1993); their status could then be described as participant-observers. Researchers were aware of the power imbalance that could occur between adult researcher and young participant particularly in one-to-one interviews so more imaginative and creative methods which reduced the power imbalance were soon being used to collect data directly from young carers such as focus groups (Butler \& Astbury, 2005), photography (Aldridge, 2009), drawing (Skovdal, 2010b) and videos (Blazek, 2015). These methods involved the participants in greater personal contributions but not necessarily in control. 
The research conducted by the Powys Carers Service on behalf of the Children's Commissioner for Wales in 2009 used a range of participatory methods. A questionnaire devised with the help of young adult carers was answered on individual i-pads with the results of each question displayed on a whiteboard, allowing dialogue around the results. There was also a Big Brother Diary Room in front of a video camera for making a video diary and telling stories about their experiences. Masks were provided if they wished to remain anonymous. This resulted in valuable descriptive data about young carers and their lives in Wales and a report, Full of Care, was published.

Involving young carers in the planning of the research and the collection of data were a further innovative step in giving young carers a chance to shape the methods and findings of research. Moore and McArthur (2007) in Australia involved young carers in a study of what services young carers and their families needed and what obstacles there were to accessing them. Their methodology included training a group of young carers to be consultants on the Project, advising on the research themes, the questions and the language used and in recruiting participants. Later in a research Project (2009), the same researchers employed a young carer as a Project consultant to work with them on the emerging themes from the qualitative data obtained from young carers aged $12-21$.

Another example of developing research skills in young carers was Skovdal et al. (2009) where the method was photo-voice, a combination 
of photography and interpreting the photos, and the participants were trained in the skills of using photography as a reporting method.

The Open University runs a Children's Research Centre which is developing ways in which children and young people can engage in designing, implementing and sharing findings from their own research into areas that interest them. In this setting, a research paper about young carers was produced by a young carer with the support of an adult academic and published (Tarapdar, 2007).

However there is a tension between action by young carers being initiated and facilitated by adults and young carers initiating action themselves. Because of the median age of young carers being under 18, the literature review shows that the balance has necessarily been with the former and it is unusual to find examples of action by young carers unless it is within a framework provided by adults albeit well intentioned. The increasing recognition of the needs of young adult carers could though result in young carers with more experience representing themselves by identifying the issues they wish to see researched and shaping the research becoming more common. On an individual basis, Tarapdar (2007) is one former young carer who progressed to formal research and publication on the subject of young carers.

\subsection{Research Carried Out Directly with Young Carers: Measures}

\section{Used and Lessons Learnt}

A search was made for measures already used with young carers to inform the choice of measures in this study. It was necessary to be 
concerned with three aspects: measures of social care outcomes, measures suitable for use with children and young people and those appropriate for use with young carers. It was the combination of these three elements that made it difficult to find a suitable tool.

There had been pressure to develop valid measures for use in evaluating social care to catch up with the development of HealthRelated Quality of Life (HRQoL) measures. Work had been undertaken to design and pilot suitable tools for adults such as the Social Care-Related Quality of Life (SCRQoL). The SCRQoL measures had been adapted and used with a range of types of adult service users including carers but when young people are to be the subjects of research there are particular factors that need to be taken into account, for example the communication skills to be expected in the age group participating and the level of conceptualisation at their stage of development. Questionnaires must be couched in terms they will not only understand but respond to and not be alienated by. This is not only a matter of the complexity versus simplicity of the language used but also the use of words and terms contemporary for them. In addition accessibility must include the matter of design and layout. There is the decision to employ qualitative or quantitative methods, to use objective or subjective indicators, to decide how precisely they can be expected to remember and to self-report for the study to obtain accurate and valid responses.

When young carers are the subject of research, there are additional concerns. Firstly many of them are under some degree of stress and 
may not be as free mentally or emotionally to respond accurately or truthfully to personal questions. The design of any measure needs to be simple and easy to administer in what were as yet unknown and varied settings and the availability of norms would be crucial.

A number of measures using both quantitative and qualitative measures were examined in order to study the objectives, domains, outcomes, indicators employed and to observe their methods of conducting surveys with children and young people not necessarily young carers. Only six questionnaires specifically for young carers were identified. Other measures were identified which were either about caring but not for children or alternatively for children but not primarily for young carers. They were however useful as examples in identifying the issues and in the sensitive and appropriate use of language.

\subsubsection{The GHS 1996/7 (ONS, 2002).}

This was an early effort to gather information about the existence of young carers by including a section on young carers in the general survey as a trailer for later research. It had 19 questions with multiple choice answers on what later became standard items for research on caring, for example number of hours spent in caring, the tasks performed. The language was very accessible but designed for an adult in the home to answer by proxy for the young carer. The measures did not include any item to measure outcomes. 


\subsubsection{YCOPI (Pakenham et al., 2006).}

The twin aims of this study were to validate the main qualitative themes in young care-giving, particularly coping and adjustment, and to test the hypothesis that young caregivers would show poorer adjustment in a comparison with young non-caregivers. The researchers remarked on the dependence of previous researchers in this field on "anecdotal and descriptive evidence" so this was designed as a quantitative study. A Likert scale questionnaire was used with responses at five levels and the researchers noted that to make the items accessible and comprehensible the wording was drawn from prior qualitative interviews. Unfortunately the full text of this questionnaire was not found.

\subsubsection{Kidscreen (Schlarmann et al., 2008).}

The researchers set out to evaluate the family-oriented support for young carers being developed in Germany. They found no appropriate measure for assessing the service outcomes so they decided to review the available HRQoL measures relating firstly to their use with children and secondly to their suitability for use with young carers.

The criterion for inclusion as a young carer was that caring had had an impact on their lives. They relied on the Dearden \& Becker 1997 survey for the types of activities: housekeeping, general care, intimate care, emotional care, siblings care, and on German sources for the categories of adverse outcome: peers, moods, leisure, social life, school, family/autonomy, mental, physical. 
The finding at that stage was that there was no specific measure suitable for measuring HRQoL in young carers. They concluded that measures developed for use with adults were not suitable for use with children but that an HRQoL designed to be used with children, allowing use of self- and proxy-reporting, was satisfactory. They reasoned that self-report was more likely to be valid than proxy as long as the questions are formed for the developmental level of the young subject.

Their view was that measures needed to be adapted not just for children but also for different age groups due to continuous developmental changes both cognitive and perceptual. Other factors to be taken into consideration were the length of any questionnaire and the use of visual clues and illustrations. They asserted also that a measure cannot be assumed to work un-adapted in all languages and cultures. KIDSCREEN was recommended as the most suitable of the generic measures for children for use with young carers.

\subsubsection{MACA and PANOC (Joseph et al., 2009).}

This is a set of questionnaires designed for use by professionals in both research and practice, for measuring the extent and type of caring activities and for recording the effects of caring. They were all selfreported measures with a mixture of text and quantifiable responses. They were based on the previous extensive studies of young carers by Aldridge, Becker and Dearden but the language and presentation were designed for use directly with young carers hence accessible and easy to 
respond to. The effects measured were mainly subjective except for two questions on punctuality and absence at school.

\subsection{5 "Full of care" (Children's Commissioner for Wales, 2009).}

This survey was carried out on behalf of the Children's Commissioner for Wales. The purpose was to collect data relating to the access of young carers to the children's rights specified in the UNCRC. The questionnaire provided one half of the data collected, the other half being provided by a variety of tools (see p. 201 for more detail on the methods used).

Some of the items were very close to items in the MACA and PANOC although this survey of young carers included only two questions directly on caring. This suggests that the aim was mainly to learn about young carers as a sub-group of young people rather than in a social care framework. As such it provided a self-reporting account of outcomes in their health, social life etc.

\subsubsection{Kids Life and Times Survey; ARK (Access, Research, Knowledge, 2013).}

This is an annual self-report survey for children in Northern Ireland who are aged 10-11 and at the end of their primary school education. Initiated in 2008 , it was not aimed exclusively at young carers but there were six questions about caring. Some questions were very broad, presumably to suit the target age, and may not produce precise data, for example where they fulfil the role of a young carer they were asked "What kinds of things do you help them with?" 
The 77-item questionnaire was based on the KIDSCREEN 27-item measure. This version was designed to be completed on-line in schools and takes about 20-25 minutes. For psychological wellbeing, measures from KIDSCREEN were used and this enabled the researchers to make comparisons on a European norm.

It is useful as an example of a style used with children aged 10-11 and the kind of measures suitable for that age group. The font of Comic Sans was obviously chosen to look informal and friendly. The language was simple, probably to keep the answering time within a reasonable limit for children of that age. There was a version available for children in an animated comic form on the web-site. It demonstrated that it is possible to secure valid data with entertaining design and child-friendly language.

\subsection{YCPs}

\subsubsection{Proliferation of the Projects.}

In an article in Children and Society (1993b), presumably having been written in 1992, Aldridge and Becker said that "there are no services aimed at meeting the needs of children who care".

At about that time, the first known YCP was being established in 1992 in Merseyside. In fact there were two Projects in Wirral and Sefton with a third starting soon after (1993) in St. Helens. They were initiated by Merseyside Regional Health Authority. In 1993 another Project was started in Camden, London, by the Camden Family Service Unit. By 
1995 there were nearly 40 Projects with the same function across the UK.

In that year the publication Community Care ran a campaign to highlight the existence of these initiatives, "Young carers - back them up", and a first Directory of YCPs was compiled by Dearden and Becker, supported by the Carers National Association (1995a). The following years saw the expansion and enrichment of the movement with Projects set up specifically for Black and Minority Ethnic young carers: the Sahara Asian Carers' Project and the Greater Manchester Black Young Carers' Project in 1997. By 1998 there were over a hundred, enough for Aldridge and Becker to publish a National Handbook of YCPS.

This type of service provision had become so recognised and valued by 1999 that the National Strategy for Carers placed a responsibility on local authorities to "sustain and enhance the number of YCPs" (p. 78). By 2008 Becker and Becker (2008) wrote that there were more than 350 Projects serving young carers in the UK. By this time bespoke Projects had been developed to support sibling carers, young carers in specific racial groups, young carers for parents with specific conditions and those caring for family with drug or alcohol use.

\subsubsection{The rationale behind the growth of the Projects.}

The popularity of these Projects can be seen in two ways: as a means for the statutory services to solve the problem of how to provide for a newly identified need and as a flexible form of provision for a broad and varied group. 
The UNCRC, which stated in 1989 that "the best interests of the child shall be a primary consideration" (Article 3 ) followed by the UK Children Act (1989), accelerated the growth of the Children's Rights agenda. This afforded fertile soil for the campaigning of the Carers National Association and others backed by the evidence produced by academic researchers such as the YCRG of Loughborough University. Government and Local authorities needed to respond to this newly identified population.

When the legislation responded, additional support for the family at home was initially the usual solution to those cases identified. However it was found that services such as home helps and respite were not always adequate to ease the stress felt by families (Banks et al., 2002, p. 243) and in addition this form of service was not carer-centred. In any case young carers had "needs apart from difficulties associated with physical tasks" (Banks, 2002). In short young carers needed not just help to continue caring but to be able to live so that their long-term development and wellbeing was not damaged.

The virtue of the Projects was that they enabled local authorities to provide young carers with some respite, an opportunity to enjoy social and leisure activities and to inter-act with their peers in a welcoming and non-judgemental environment. Managed by non-statutory agencies, it was cost-effective in that voluntary sector organisations and charities were able to access some of their funding from other sources. They were in addition able to engage with young carers who fell outside the legal 
definitions used for budgetary reasons by Social Services to qualify a limited number for support. Becker et al. (1998) pointed out also that the Projects were particularly useful to accommodate families who were resistant to the involvement of statutory agencies. Indeed they were often more acceptable to the young carers themselves than a Project run by social workers because of the frequent fear of the family being separated. These Projects were able in addition to be young-carercentred and to develop individually to answer local need (Becker et al., 1998). In an evaluation exercise of three Projects, Dearden and Becker (2002) noted that they were appreciated by the young carers but also by parents and professionals. This seemed to be a win-win situation and it is easy to understand the rapid growth in the number.

Nevertheless some adverse views did appear. Banks et al. (2002a) pointed out the shortcomings of relying on Projects so that this might be the only form of support in many cases. They believed that the Projects could be complementing a service that was unsatisfactory or even nonexistent. There was also a concern that the Projects might become a "dumping ground" (p. 54) for children with a range of problems not arising from caring alone.

\subsubsection{Evaluating the effectiveness of the Projects.}

\section{Literature search for Project evaluations.}

There was initially some comment on the absence of evaluations of YCPs. Banks et al. (2001) said that there had been little research on the effectiveness of these schemes and they wrote again in 2002 that 
"Independent, external evaluations and assessments of outcomes are lacking" (p. 54). Referring specifically to Crossroads schemes of which there were over 100 in the UK, Richardson et al. (2009) said that there had not been enough evaluation (p. 152).

A literature search for young carers or young caregivers and Projects or initiatives and evaluation or assessment was made in twenty academic data-bases in the categories of social work, social policy, sociology and health and social care. Among several hundred, there were nine relevant references: Mahon and Higgins (1995a) on three Projects in Merseyside; Dearden and Becker on Projects in Nottingham (1996) and Sheffield (2000b); Newton and Becker on Capital Carers in Southwark (1999); Noble-Carr's research Project in Canberra, Australia (2002); Butler and Astbury on a Project in Cornwall (2005); Grant et al. on a Barnardo's Project in Liverpool (2008); Fraser and Pakenham on a Project in Queensland, Australia (2008), and Richardson et al. on three Projects in Merseyside (2009). A search on Google brought up an evaluation by Essex County Council of their twelve YCPs (2008).

A study of young carers services for the Scottish Government (Banks et al., 2002a) gave brief information on evaluations of three Projects in Scotland, one of the North Lanarkshire Project (1999), two of the West Lothian Project (1999 and 2001) and one of Dundee Social Inclusion Partnership (2001). A short evaluative report on a Project in Northumberland (2004) was retrieved from the Internet. The search on Google also retrieved brief outlines of initiatives for young carers which 
the Big Lottery had funded and numerous brief local authority accounts of their Projects but none of these were in sufficient depth to merit inclusion. When accessed, the Noble-Carr report (2002) was not a study of a YCP but a more general study of young carers in Australia and therefore not relevant.

There was another Project in Wirral which Dearden and Becker wrote about but as its activities were limited to being a homework club the evaluation was excluded as not being comparable to the others identified for the purposes of this study.

All the Projects were generic except the Liverpool Barnardo's and the Queensland Projects which focused on young carers in families with mental health issues and the Northumberland Project which concentrated on children in families with substance misuse.

Although it was based outside the UK, a special mention should be made of Schlarmann et al.'s description (2011a) of the setting up of the first German YCP. The account went into great detail about the design, the implementation process and the lessons drawn from what was in effect a pilot. However, since the setting in German involves practical differences in the statutory arrangements, this example has not been included here.

A different model of service was described by Aldridge and Becker (1996) in which the design was to recruit volunteers to act as befrienders to the young carers. Although not a Project in the sense of the examples 
examined here, it is still interesting as a pilot study of a different model of service.

It was possible to obtain the text of eight of the evaluations. The only information available on the evaluations of the Crossroads Nottingham Project (Dearden \& Becker, 1996), the North Lanarkshire Project (1999), the West Lothian Project (1999 and 2001) and the Dundee Project were the accounts in Banks et al. (2002). The paragraph on the Dundee Project was too brief to be useful in this summary. Searches of the Reference sections of the above evaluations did not uncover any additional evaluative accounts.

The work by Banks et al. is relevant for another reason: it reprinted in the body of the text the standards for YCPs produced by the $\mathrm{NCH}$ (Scotland) from their work on the North Lanarkshire Project. Two other files of related interest were retrieved by Google: Guidelines for Practice from the YCP on Merseyside (Ames-Reed, 1994) and Issue 4 of the Centre for Child and Family Research, an evidence paper on evaluation reports of dedicated young carer Projects (Dearden \& Becker, 2002).

One useful study of a different kind appeared in 2008. Produced and published by Crossroads and the Princess Royal Trust, it carried out an economic evaluation of young carer interventions. This considered a number of representative schemes using the Theories of Change method but did not analyse or evaluate any one scheme and was limited to schemes for the children of parents with drug and alcohol use. 
The reports included here, mostly from England but one in Australia and two in Scotland, were all in some degree setting out to evaluate the Projects. Beyond that, there was considerable diversity in the approaches in methodology, complexity and depth. It is important to make clear that the following analysis is limited in its ability to present an accurate picture of the Projects themselves because of the varying importance given to different factors by the evaluators. Perhaps what it is able to do is to summarise how evaluators have approached their task and what seemed to be of importance to them.

\section{Independence of evaluations.}

It can be seen from Table 4 that all but one of the evaluations were carried out by an external evaluator. With one of the external evaluations, ContinYou in Essex, it was not clear whether this was a peer-reviewed evaluation. The report of the Northumberland Project said that members of the Tavistock Institute had visited but it is not clear that they were responsible for the evaluation. West Lothian was the subject of two evaluations, the first in-house, the second by an external evaluator (Boyle, 2001). The Evidence Paper on Nottingham, Sheffield and two in Merseyside (Dearden \& Becker, 2002) made it clear that external evaluation was built into the four Projects studied by them.

Meanwhile there is no mention of the need for evaluation at all in the $\mathrm{NCH}$ Standards or in the Guidelines developed from the Merseyside Projects (Ames-Reed, 1994). 
Table 4

Independence of the evaluations of YCPS

\begin{tabular}{lll}
\hline \multicolumn{1}{c}{ Location } & \multicolumn{1}{c}{ Evaluator/s } & Date \\
\hline Merseyside & Mahon \& Higgins & 1995 \\
\hline Nottingham & Dearden \& Becker & $1995 / 6$ \\
\hline Southwark & Newton \& Becker & 1999 \\
\hline Sheffield & Dearden \& Becker & 2000 \\
\hline Northumberland & Tavistock Institute & 2004 \\
\hline Cornwall & Butler and Astbury & 2005 \\
\hline Liverpool & Grant et al. & 2008 \\
\hline Essex & ContinYou & 2008 \\
\hline Queensland & Fraser \& Pakenham & 2008 \\
\hline Merseyside & Richardson et al. & 2009 \\
\hline N. Lanarkshire & NCH Action for Children (Scotland) & 1999 \\
\hline West Lothian (i) & In-house & $2000(?)$ \\
\hline West Lothian (ii) & Boyle & 2001 \\
\hline
\end{tabular}

\section{The contents of the evaluation reports.}

Aims and objectives.

One of the NCH Standards for Projects is to have a written statement of purpose. Not all the evaluations reported the schemes' aims and objectives. It was not clear whether this was because there were no overt statements or because the evaluators did not report them. Where they were reported, it was not clear whether these were written or explained verbally.

Where described, they varied from the general, for example Capital Carers raising the profile of young carers needs (Newton \& Becker, 1999), to the specific, for example Nottingham's direct work with BME 
communities. Some were about principles such as Liverpool Barnardo's recognition of the structural and environmental factors affecting young carers and some were more practical. A good example of the practical approach was one of the Essex Projects planning objectives for each activity and reviewing outcomes at the end. Most of the Projects included raising awareness, working with other agencies or partnership building and developing services.

The majority of Projects had framed their aims and objectives in terms of inputs and outcomes for the Project. The focus is on the actions of the Project as in Capital Carers' "assist young carers in identifying their needs, supporting each other and informing future service provision" and in Cornwall's "maximising opportunities for social, educational and personal development". The Northumberland and Australian Projects were somewhat different in this respect, the emphasis being more on outcomes for the individual young carers and the psychological process they needed to undergo: "to enable children to explore the world in which they live and to enable them to make sense of their parent's substance mis-use, developing strategies to manage the impact it has on their lives." (Drugscope, Northumberland) and "to increase mental health literacy, connectedness with peers and repertoire of coping skills." (Fraser \& Pakenham, 2008, p. 1044)

However it is important to note that some of these Projects had included more strategic objectives in their thinking such as partnership building and awareness raising: "Awareness raising activities have 
altered the perception of young carers in Cornwall." (Butler \& Astbury, 2005, p. 302)

The Merseyside Projects in the early nineties were the first dedicated Projects for young carers and as innovative ventures were expected to address some key organisational questions about such Projects. Provision.

The information in Table 5 is based on what was specifically mentioned by the evaluation reports but it should be noted that the evaluations may not have given a full picture of the activities of each Project. It could be seen as good practice by evaluators to give a factual account of the programme of the Project they were evaluating since there might have been some correlation between the choice of activities and the outcomes.

The Essex evaluation made an insightful point on its twelve Projects, saying that each had placed itself somewhere on a spectrum from a focus on respite to respite with personal development and positive leisure activities. This could be a helpful concept in classifying Projects with a varied selection of services. Dearden and Becker classify the activities differently: firstly to provide social and leisure and then "to counter some of the more adverse aspects of caring without adequate professional support" (2002). Richardson et al. (2009, p. 158) described activities as either physical or filling a "gap for social and emotional wellbeing". 
Table 5

Provision of activities by Projects

\begin{tabular}{|c|c|c|c|c|c|c|c|c|c|c|c|c|c|}
\hline Project & $A$ & $B$ & $\mathrm{C}$ & $\mathrm{D}$ & $E$ & $\mathrm{~F}$ & $\mathrm{G}$ & $\mathrm{H}$ & I & J & $\mathrm{K}$ & $\mathrm{L}$ & M \\
\hline Merseyside 1995 & $\checkmark$ & $\checkmark$ & & & $\checkmark$ & $\checkmark$ & $\checkmark$ & & $\checkmark$ & & & $\checkmark$ & \\
\hline Nottingham & $\checkmark$ & & & & & & & & $\checkmark$ & $\checkmark$ & & $\checkmark$ & \\
\hline Southwark & $\checkmark$ & $\checkmark$ & $\checkmark$ & $\checkmark$ & $\checkmark$ & $\checkmark$ & & & $\checkmark$ & $\checkmark$ & $\checkmark$ & $\checkmark$ & \\
\hline Sheffield & $\checkmark$ & $\checkmark$ & & $\checkmark$ & & & & & $\checkmark$ & & & $\checkmark$ & \\
\hline Northumberland & $\checkmark$ & $\checkmark$ & $\checkmark$ & $\checkmark$ & & & & & & & & & \\
\hline Cornwall & $\checkmark$ & $\checkmark$ & $\checkmark$ & $\checkmark$ & & & & & & & & $\checkmark$ & $\checkmark$ \\
\hline Liverpool & $\checkmark$ & $\checkmark$ & & & $\checkmark$ & & $\checkmark$ & & $\checkmark$ & & & $\checkmark$ & \\
\hline Essex & $\checkmark$ & $\checkmark$ & $\checkmark$ & & & & $\checkmark$ & & & & & & $\checkmark$ \\
\hline Queensland & $\checkmark$ & $\checkmark$ & & & & & $\checkmark$ & & & & & & \\
\hline Merseyside 2009 & $\checkmark$ & $\checkmark$ & $\checkmark$ & $\checkmark$ & & & & & & & & & \\
\hline N. Lanark-shire & $\checkmark$ & $\checkmark$ & & & & & & & & & & & \\
\hline W. Lothian & $\checkmark$ & $\checkmark$ & $\checkmark$ & $\checkmark$ & & & & & & & & & \\
\hline
\end{tabular}

\section{KEY:}
A Social and leisure activities
B Group work/meetings
C Outings
D Residential trips
E Information and advice
F Advocacy
G Training for young carers
$\mathrm{H}$ Counselling
I One to one support
J Befriending
K Respite
$L$ Awareness raising
$M$ Mentoring

Social activities and group work are standard with a majority providing outings and residential trips but Merseyside (Mahon \& Higgins, 1995 ) and Southwark (Newton \& Becker, 1999) ran more complex programmes. This variation may have been due to the design of the programme, as in the Queensland pilot where measuring the quantitative 
outcomes was the aim, and in some cases it was probably due to available resources. The question of resources will be discussed later. Referrals.

Although most of the Projects seem to have kept records of referrals, only the Southwark Project covered these in any detail. No information on referrals was found in three of the evaluations: Southwark (Newton \& Becker, 1999), North Lanarkshire (Banks et al., 2002) and Merseyside (Richardson et al., 2009). However there was some common experience amongst the others.

The hidden nature of the young carer population meant that awareness raising was important for its ability to attract referrals in a number of Projects. It was remarked on particularly in Merseyside (Mahon \& Higgins, 1995), West Lothian (Banks et al., 2002), Barnardo's Liverpool (Grant et al., 2008), Essex (ContinYou, 2008) and Sheffield (Dearden \& Becker, 2000b). Predictably the referrals to the Projects focusing on the children of parents with mental health issues (Queensland and Liverpool) came mostly from mental health professionals. The major source of referrals for the others was Social Services, community services and organisations. There was only one mention of self-referrals (Banks et al., Northumberland) and one mention of carer support workers in the Cornwall Project (Butler \& Astbury, 2005). The poorest source of referrals in several was GPs, schools nurses and schools. 
The Essex Projects (ContinYou, 2008) were unusual in that they stressed the informality of their referral process, not always on paper, sometimes consisting of a telephone conversation, which they saw as a strength. They had no eligibility criteria except for age (8-18) and no waiting lists.

Unusual in an opposite direction was the West Lothian Project (Banks et al., 2002). The participants had been selected because it was a pilot and it had not been publicised in order to avoid creating unreal expectations.

Assessments.

It might have been expected that assessing their own performance and effectiveness in terms of the outcomes for their members would have been an important activity for these Projects. However there was very little about assessment in these evaluations. Only five mentioned assessment of the young carer or assessment of need.

The North Lanarkshire Project used an Assessment of Needs form but no details were given. In Essex, some Projects used the Common Assessment Framework (CAF, England) form of assessment and some used their own formats but they recommended all Projects in their area to move to using the CAF form. The Sheffield evaluators were told that the Project intended to become more involved with the Social Services assessment procedure. In Cornwall they relied on the Social Services assessments. 
The very specific quantitative aims of the Queensland evaluation meant that there was an assessment but that it was strictly related to the measurements being made that is mental health literacy, connectedness, coping strategies, depressive symptomatology, life satisfaction, strengths and difficulties, the care-giving experiences and participant satisfaction.

The most interesting approach to assessment and possibly consequently the one whose evaluation gave the most information was the Barnardo's Liverpool Project. As well as the usual group work and one-to-one interviews, they incorporated the assessment into creative activities: role-playing, videos, poetry workshops, storyboards: "Rooms provide pictorial and written evidences of other children's lives and interests, designed to make it conducive for children who attend to feel encouraged to tell their own stories." (Grant et al., 2008, p. 274) Projects' self-evaluation.

In their three evaluations, Dearden and Becker wrote in the Evidence Paper from the Centre for Child and Family Research: "All of the Projects had their own stated aims and objectives and were measured against these and against their own policy and procedure documents." (Dearden \& Becker, 2002)

The Theory of Change model was utilised by the Cornwall evaluation who later call it the AAAQI model (Assumptions, Aims, Activities, Questions and Indicators). This is a model based on the following principles: it has to be evidence-based; it must have close engagement 
with stakeholders; it should focus on the process whereby outcomes are achieved rather than just on the outcomes; it should explore the assumptions, aims, activities, questions and baseline indicators on which the Project is founded.

A different generic model used by the West Lothian in-house evaluation is the $A B C D$ : Achieving Better Community Development. As described in Banks et al. (2002, p. 67), this focuses on: stakeholders including participants and their families and service providers; inputs (funding, staff input, information); the processes whereby inputs are used to produce outputs); outputs; outcomes; measures; indicators (proxy measures).

The variances in approach are well demonstrated by the contrast of the above with the statement on data analysis below: "The data were analysed using a thematic content analysis approach .... The analysis focused on identification and interpretation of data themes and recurring motifs." (Richardson et al., 2009, 154)

The Project evaluated by Fraser and Pakenham (2008, p. 1041) adopted a resilience model, explained by the evaluation as a method "whereby the potential harmful effects of risk factors are removed or mitigated by the influence of protective factors". They had themselves reviewed evaluations of the effectiveness of interventions and had chosen to study one example of a particular type of intervention called the Koping Adolescent Group Programme which employed the resilience model. The intention was for their findings to be used as an evidence 
base for this type of intervention. The risk factors identified were social isolation and a low level of mental literacy. The protective factors were identified as "a repertoire of coping skills and intact peer relationships" (p. 1042). To analyse the incidence of these factors, they used measures such as the Children's Depression Inventory, the Satisfaction with Life Scale, a Strengths and Difficulties Questionnaire and the Young Caregiver of Parents Inventory.

\section{Methodologies.}

Three of the Projects were evaluated by Becker in co-operation with either Dearden or Newton: Nottingham (1996), Southwark (1999) and Sheffield (1999). Not surprisingly, these showed a similar methodology of mixed quantitative and qualitative data collection, interviewing young carers, parents and professionals. All three also compared the Project data with national data on young carers. These seemed to be working towards a model of evaluation for YCPs. The Cornwall report (2005) does in fact refer to the work of Becker and his colleagues as a standard.

All the evaluations included young carers in their data collection to a greater or lesser degree. The various models varied from one-to-one interviews to focus groups, a questionnaire completed as part of an interview (N. Lanarkshire), semi-structured interviews (Cornwall) or written feedback (Essex). Parents were interviewed face to face in five of the Projects; in one other Project they were interviewed by phone and in another they were sent a questionnaire by post. It is clear from four of the evaluations that the staff of the Projects were interviewed and from 
six that "professionals" were interviewed, presumably senior managers in Social Services and other service providers.

Apart from data gathered in interviews, in six of the Projects demographic data were reported to have been collected from referral and monitoring forms and compared to national data. The Southwark report gives a particularly detailed breakdown of the participants in terms of age, gender, ethnicity, condition cared for.

\section{Their findings and recommendations.}

It is clear in all the evaluations that the qualitative evidence showed that young carers found participating in the Projects to be a positive experience. Some caution can be expressed because of the relatively low number of evaluations and the lack of access to all the full texts. Caution at another level is expressed by the evaluators of the Liverpool Project:

"However, the results we have reported are based on only one Project, and with interviews with a small sample of young people, so some caution is required in extrapolating the outcomes to other localities and populations'. (Grant et al., 2008, p. 280)

Certain elements in the Projects were almost universally approved: the need for awareness raising, providing social and leisure opportunities and the chance to inter-act with peers who were also carers, the collection and recording of data, training of staff. Where it was observed that they were lacking, managers were encouraged to adopt them.

Several strategic issues were identified across a number of the evaluations where room for debate was indicated: 
(i) The participation of young carers in planning was often evident and praised but the North Lanarkshire Project reported that the young people "were not really interested in policies and procedures, and as such participation is primarily in terms of 'having fun'" (Banks et al., 2002, p. 66). Otherwise consulting young carers was the default approach.

(ii) Whether support for young carers should be via a dedicated service or mainstreamed was picked up early on by the Merseyside report. "Funding and services for Young Carers should remain ring-fenced in the short term, until such time as their needs were fully recognised and services could be absorbed into the mainstream without Young Carers being overlooked." (Mahon \& Higgins, 1995a, p. 93). Another aspect of this is explored by the Essex evaluation (ContinYou, 2008). Considering the shortfall in capacity in the face of increasing demand, they recommend a different three-tier service model in which young carers assessed as being in greatest need would receive targeted support, a specialist service would be reserved "for those young carers who need and want them" and "universal services available to all young carers and their families" (p. 11).

(iii) There was some hesitation about raising child protection issues. In the North Lanarkshire Project (Banks et al., 2002, p. 66), staff said that this might lead the young carers to view them in the same threatening light as they did social workers. 
The adverse attitudes towards social workers expressed by young carers in this and the West Lothian Project are therefore significant in the debate about who is best placed to provide the type of support represented by Young Carer Projects. Some Projects are managed by Social Services although most are managed by third sector organisations. In the 1995 Merseyside study (Mahon \& Higgins, 1995a), one of the potential drawbacks of a Social Services base was felt to be that Young Carers would be reluctant to contact the Project in case they were taken into care or came to the attention, in a formal way, of agencies of authority (p. 90). Mahon and Higgins attempted to clarify the situation by their suggestion that the voluntary sector was the best location if a Project was to have a campaigning or advocacy role but that Social Services was better if it was to be mainly a service provider and therefore linked in to other statutory services.

\section{Funding.}

This is such a strong theme that it merits its own section. Funding, its proper source and its inadequacy are repeated themes in these evaluations. There are a number of examples of the service being curtailed because of lack of resources. As early as 1995, Mahon and Higgins wrote about the first Merseyside Projects (1995a): "As demand on the Projects grew less time was available for one to one work and group activities were more frequently arranged as a mean to maximise scarce resources." (Mahon \& Higgins, 1995a, p. 104) 
Banks et al. (2002) cited Dearden and Becker saying in the Nottingham report that the lack of continuity and security is damaging the work. They repeated this view in the Sheffield evaluation saying that funding needs to be long-term and assured for the work of the Project to develop. In Cornwall (Butler \& Astbury, 2005), funding was needed to extend and expand the Project to cater for the numbers expected. The Sheffield Project had reached capacity after 2 years and had to instigate a waiting list. The openness of the Essex Projects was threatened by the potential demand and the evaluator anticipated "eligibility or priority criteria" having to be introduced. The single worker in Southwark was stretched when membership rose to 73 in 21 months. The need for more staff and volunteers was cited in the report on the Southwark Project in order to meet current and any possible future developments and it makes a plea that the services should not be further restricted. Clearly this is something that emerges as a critical and undisputed finding. Newton and Becker could be speaking for all the evaluated YCPs when they wrote of the Southwark Project:

there are now real fears for the future of this Project. This, unfortunately, is a situation all too common for such Projects...The work of this Project (and others) is too important and valuable to be solely dependent on short-term funding and the vagaries of the lottery. (Newton \& Becker, 1999, p. 50) 
Mahon and Higgins had already raised the question early on (1995) as to whether Health or Social Services were the appropriate funding source. They concluded that it should properly be Social Services.

\section{Analysis of evaluations.}

Varying functions.

The functions of the evaluations were reflected in the Projects themselves but there appeared to be three strands, what might be called the pragmatic, the strategic and research, and they can be observed in various combinations.

The pragmatic uses of evaluations included helping to improve performance and outcomes but also assisting with funding and tendering procedures. Many practical points are made about the operations and management. ContinYou (2008) recommended that in Essex there should be clear statements of aims and objectives with intended outcomes. In the Nottingham report, Dearden and Becker (1996) pointed out that in the Nottingham Project there was no mechanism for involving young carers in planning the programme and that there was no policy on inter-agency work. A number of improvements were recommended for the West Lothian Project (Boyle, 2001, cited in Banks, 2002 , p. 68) including training for professionals and written information for young carers. Action on these recommendations required a set of practical tasks for managers and workers to address.

Other evaluations are intended to have a broader more strategic reach. They anticipate their work being useful for other Projects or 
service providers: "it is intended that the evaluation of the Cornwall YCP will be able to inform similar YCPs throughout the UK, especially those in rural areas" (Butler \& Astbury, 2005, p. 302). Fraser and Pakenham noted that the Project they were evaluating was similar to other Projects in Australia "so the effectiveness of this program will contribute to the evidence base for this group of interventions" (p. 1042).

It was in the Australian study that a research element was to be found. Fraser and Pakenham sought evidence of the effectiveness of this type of intervention. They concluded that their own results did not confirm the effectiveness of all aspects of the intervention on the children of parents with mental illness although they left room for doubt about the reliability of their own methodology, for example lack of randomisation, utilisation of a control group from the waiting list and lack of follow-up on the control group. They recommended that testing for the effectiveness of interventions such as their subject should continue. Since most of the evaluations use mainly qualitative evidence, this might indicate the need to explore methods of measuring the outcomes for the young carers more precisely.

The impact on young carers.

Overall there was a strong feeling from the evaluations that the Projects were considered a successful form of service. The qualitative data were used to show the satisfaction of the young carers, in most cases of parents and professionals too. For example, the Southwark evaluation says: "This Project has in a short space of time established itself as a 
very successful service, highly valued by the young carers, their families and the professionals who refer to it." (Newton \& Becker, 1999)

But some important cautions were expressed too, for example in the SSI Surge of Support (1996) cited by Banks et al. (2002): "The SSI noted certain difficulties or dangers in relation to the development of Projects. These included Projects taking over statutory responsibilities, being used as a 'dumping ground' regardless of the young carers' needs and being over-extended." (SSI, 1996, p. 54)

Another angle on the value of the Projects is highlighted in West Lothian where they noted "over dependence with some of the participants having difficulties where the group ended" (Banks et al., 2002, p. 67). This raises the question of whether the aim of a Project can be on-going support as long as the young carer fulfils that role or whether it is meant to equip them with better coping strategies within a limited period.

Comparability.

While evaluations are potentially useful by providing practical assistance for their Project managers and for commissioning bodies, they may also be informative for policy makers deciding on support services for young carers.

It was noticeable that some information which would facilitate comparability was not given in every evaluation, for example, as mentioned above, the source of referrals and the assessment process used. The NCH developed in 1999 a set of benchmarks for Projects to 
self-assess. With more Projects to learn from and with the wisdom of hindsight, they might be open to amendment but anyone starting an evaluation of a YCP might find it useful to have a basic template which will make it easier to compare different models of provision without impinging upon the evaluationary process.

Whilst the evaluations were united in their conviction that the Projects were "a valuable and much needed resource" (Richardson et al., 2009 , p. 159), and one would not wish to challenge the mass of qualitative evidence, there is room for some quantitative work, as in the Fraser and Pakenham study (2008), and for mixed methods. Without measurable outcomes, there is no way of establishing correlations between independent and dependent variables. In addition, as stated by Fraser and Pakenham, the lack of control groups, the lack of follow-up data etc. make studies less reliable.

\subsubsection{Self-identification.}

In answer to a common view of young carers as victims, it should be said that some of the literature reports some young carers seeing themselves in quite a different way.

Heyman \& Heyman (2013) found their young carer participants opposing the problematisation of young caring in contrast even to the approach of young carers workers who are in a good position to understand them and their situation. In semi-structured interviews, the young carers spoke of the difficulties of their role whilst also being aware of the benefits it brought in personal development. What stood out for 
the researchers was that the young carers did not see themselves as at risk and dealt with their lives in a practical day-to-day way. Meanwhile they were critical of any lack of support for their families and Cfps but appreciative of the specialist YCPs. The literature available on the YCPs suggests that their role in promoting self-identification is convincing.

\subsection{Summary of Chapter 5}

This chapter describes how the voice of young carers themselves has emerged through legislation, lobbying and research. It examines how the involvement of young carers in research has developed and the tools which have been used. It quotes opinion from the literature that the Projects play a major part in promoting the self-identification of young carers. Existing examples of evaluating the effectiveness of Projects are analysed.

\subsection{Summary of the Literature Review (Chapters 1 to 5)}

A review of childhood and young carer in the literature leads towards the conclusion that they are both social constructions and are continuously evolving. At any one point in time, it has proved difficult to settle on an agreed definition of young carer for all purposes. In spite of this, the concept of young carer has been adopted in law and in practice as a result of research and lobbying. There is evidence that caring at a young age produces adverse outcomes on education, health, personal development, social life and material welfare. It can affect also their ability to build social capital as their peers would normally do. For this reason it has been identified as a social problem. 
However there are numerous obstacles to dealing effectively with this social problem. The lack of awareness and of an agreed definition means that estimates of the size of the problem are inexact and planning is challenging. This is exacerbated by emotional barriers on the part of young carers and their families to being labelled and to intrusion from external agencies. These factors result in the existence of a hidden population.

The emphasis on adverse outcomes has gradually given way to the realisation that not all young carers experience the same degree of disadvantage from caring and furthermore that there can also be positive outcomes in the form of greater maturity and competence than usual for their age group in the general population. Researchers have begun to recognise also that some young carers demonstrate a degree of resilience which can ameliorate the worst effects of the caring responsibilities. Evidence gathered from some young carers has shown an even more positive picture in that they see themselves as active agents playing a constructive role rather than the passive figure presented by so much of the media coverage.

There is a range of ways in which young carers in need of support can be helped. They are entitled to help both under the Children Act 1989 as children whose development might be damaged and under the 2014 Social Care Acts as carers. Social Services have a statutory duty to assess and review their needs and to provide support. This might be directly from the local authority or by referral to other agencies 
especially those in the third sector. YCPs, the majority of which are managed by the third sector, appear currently to be the only dedicated service available outside the Social Services provision. They could be seen from the accounts in the literature review to play a major role in provision. Young carers might also receive support from their schools and colleges and even from youth and leisure services. Health agencies could also be expected to play a role in assisting them.

One factor which emerged strongly from the literature review was that many children and young people with caring responsibilities are not receiving the support they need. The initial difficulty is that many are not known to the relevant agencies since many children are not identified as young carers or not referred but it seems that not all who are referred are assessed and not all who are assessed receive the support they need.

Much research has been done to understand the experience of young carers and to measure outcomes since the pioneering work by the Loughborough YCRG. The demographic data of Dearden and Becker's surveys (1995b, 1997, 2004) have been invaluable in representing the details of young carers' lives. Nevertheless some studies have commented that there are still aspects that would benefit from attention. More quantitative studies, more studies with control groups, more use of objective measures have been recommended. Evidence of correlations between background and the positive or adverse outcomes would obviously be helpful to service planners and providers particularly if 
research could show evidence of factors having predictive value. In the light of the apparent importance of the Projects, more systematic studies of their work would be useful.

In the spirit of Articles 1 and 2 of the UNCRC, the growth of selfidentity is an important issue in the study of young carers. In researching methods, they have moved gradually from being subjects to being participants in an increasingly pro-active way. In the field of lobbying, young carers, originally involved in order to personalise and so colour a public issue, have begun to move to a more central role and the methods of campaigning employed have started to change to being more young-person friendly. The YCPs might by virtue of their activities be playing a major role in the progress towards self-identification by their young-carer focused work. Evaluating the effectiveness of Projects is therefore an important process but it seems still to have some way to go before there are standards and stability. 


\section{Chapter 6}

\section{Methodology}

\subsection{Nature of the Inquiry}

The human situation is one of constant change. It can be argued from the literature review that the concept of young carer and even of childhood itself are social constructs. However the distress, as described in the body of work of researchers such as Aldridge, Dearden, Becker and others, exists in this society at this point in social history. Knowing more about the nature and if possible the causes of adverse outcomes and whether and how resilience contradicts adverse predictions could provide a basis for useful practical conclusions and lead to more efficient shaping and targeting of support services. Lloyd wrote in 2006 that in spite of the success of lobbying in bringing the issue of young carers to public attention the outcomes of existing policies remained less well understood. The phenomenon merits examination and analysis even more from the point of view of social and moral responsibility. The literature review shows clearly the evidence that there is a social phenomenon of children and young people taking on caring responsibilities that are more suitable for an adult and that there are adverse effects for some of them. This situation exists for some children even when hidden from outside view. Although thresholds and definitions may be social constructs, the reality of the young person caring belongs to an external reality. 
It is from this positivist view that this current study was designed and the methodology selected. There was no pre-formed hypothesis and so the method was inductive. Previous valuable and valid research provided a map of which questions had been asked and which remained to be asked about the young carers' experience, about the demographics and to some extent about outcomes. The largest gap was in measuring objective outcomes.

The assumption on the part of service providers was that the effects of current interventions, especially participation in YCPs when accessed, were positive. Studies of the experience of young carers and of the selfreported and subjective measures of outcomes support this assumption. Nevertheless evidence is still needed that these interventions are the cause of a difference in the long-term prospects and future capacity of young carers in their adult lives and if so how this is achieved.

Starting with a question but no stated hypothesis, this study was intended to gather empirical data on the outcomes. It is concerned with the relationships between outcomes and between outcomes and factors influencing outcomes in existing groups and is therefore a nonexperimental and correlational study.

More data is needed on both "subjective and objective burdens" (Reinardy et al., 1999, p. 107) in order to seek associations with outcomes.

Some questions seeking subjective data will be included in the questionnaires to both the professionals and the young carers. For 
example the professionals in Social Services and the YCPs will be asked for their views on the challenges faced by them and the young carers they support. The young carers will be asked about their feelings as a result of caring and to assess their relationships with the person they care for. Although this is a predominantly quantitative inquiry, it is intended that it will invite questions about meaning and causality and thus provide a basis for further qualitative work. It can therefore be seen as a mixed methods study of the type classified by Wisdom and Cresswell (2013, p. 2) as an 'explanatory sequential design'.

The choice of subject and the assistance of a host charity arose from the researcher's voluntary position within that charity. However, contact with the YCP had been solely at a strategic and administrative level so there had been no personal contact with young members. This was conducive to the philosophical and methodological approach taken for this study and once permission had been given to host the research efforts were made to maintain the personal distance and to avoid any contact with the young carers prior to the data collection. This was intended as an endeavour to record as objectively as possible the current factors in their situations and to measure the outcomes of their responsibilities. This led to the choice of a survey as the method to be used.

One of the weaknesses of the survey method is its inability to explore the meaning of social action and causation. This study is interested in collecting structured data about a population rather than about 
individuals. It will look for quantifiable data that can be subjected to statistical analysis and those results will enable the researcher to look for correlations between variables. With this quantitative approach, the strengths of the survey method would seem to suit the research aims and its weaknesses less relevant. The survey of provision and of the Projects being carried out with professionals presents no more than the expected challenges for a survey. Using the survey method with young carers however requires special efforts to ensure completion, comprehensibility and accuracy. This may be even more pertinent with young carers for whom the adverse effect on their education may result in slower literacy development than usual for their chronological age. The involvement of young carers in the preparation of the questionnaire is intended to help in addressing these challenges (see pp. 266-269).

Administering the survey in face-to-face interviews entails more ethical considerations but helps counter-act the other weaknesses of the survey method (see section 8.8.7). There were also practical reasons for choosing an interviewer questionnaire as the method. A variety of locations were to be used, most of them unknown and the details of the situations uncertain. This suggested that to go in person in order to adjust to the circumstances would achieve the optimum response.

The researcher regarded herself as an observer and not a participant. The data collection was to happen at the young carers' venues and within their known group. There was to be no ambiguity over the role of the researcher. While it cannot be denied that some influence of a 
researcher is inevitable in the design, in the development of the questionnaires, in the inter-action with the interviewees and in the interpretation of the data, the drive in this study was to remove personal views and researcher bias as far as possible from the process.

That is not to say that the attitude adopted in interviews was cold or unfriendly. Some degree of rapport made the interview more comfortable for the interviewee and more productive. But the focus of the relationship and any exchanges verbal or gesture were as far as possible only on helping the interviewee produce an answer that they were satisfied with. This limit was occasionally breached to some extent if an interviewee showed signs that they might become stressed or upset.

It can be argued that this study has some element of evaluation research. The area of evaluating YCPs is, as the literature review shows, under-developed and, in that section which examines the outcomes from participation in Projects, there is an element of evaluation in comparing outcomes at group level (pp. 344-346) and the study is intended to be useful. Having said that, as an academic study and unlike evaluation research, it is not commissioned, has no duty to report to any outside body and is not intended for application by any specific organisation.

\subsection{Research Design}

The Research Aims, Questions and techniques chosen are laid out in Tables 6 and 7.

Research Aim 1 was to map provision for young carers in Wales.

Research Aims 2 and 3 were to examine the relationship between 
outcomes and factors which may have contributed to them and to identify the relative importance of factors affecting those outcomes. The study was carried out in two phases.

The first phase to address Research Aim 1, had two sections, Phases 1a and $1 b$ :

Phase 1a (Young Carers service in Social Services) used a survey instrument comprised of Likert, closed and open questions (see Appendix D).

Phase 1b (YCPs) used another survey instrument of a similar design (see Appendix E).

These surveys produced descriptive data which were summarised and presented at group level.

The second phase addressed Research Aims 2 and 3.

Phase 2 (Young Carers: direct contact) employed an independent subjects design.

Objective measures employed in Phase 2 included British Ability Scales (BAS) for Reading (BAS III) and Spelling (BAS III). A measure from the Special Education Micro-Electronic Resource Centre (SEMERC) was employed for Emotional Literacy and MACA-YC18 was employed for measuring the level and types of caring activity (see Appendix F). A bespoke interview schedule was also used (see "Measures" and Appendix G). 
For the purpose of addressing Research Aims 2 and 3, four key outcome indices were also established. Phase 2 yielded data on these indices (see Fig. 1):

- Educational Attainment

- Emotional Literacy

- Health

-Social Capital

Outcomes indices and sub-scales for Phase 2

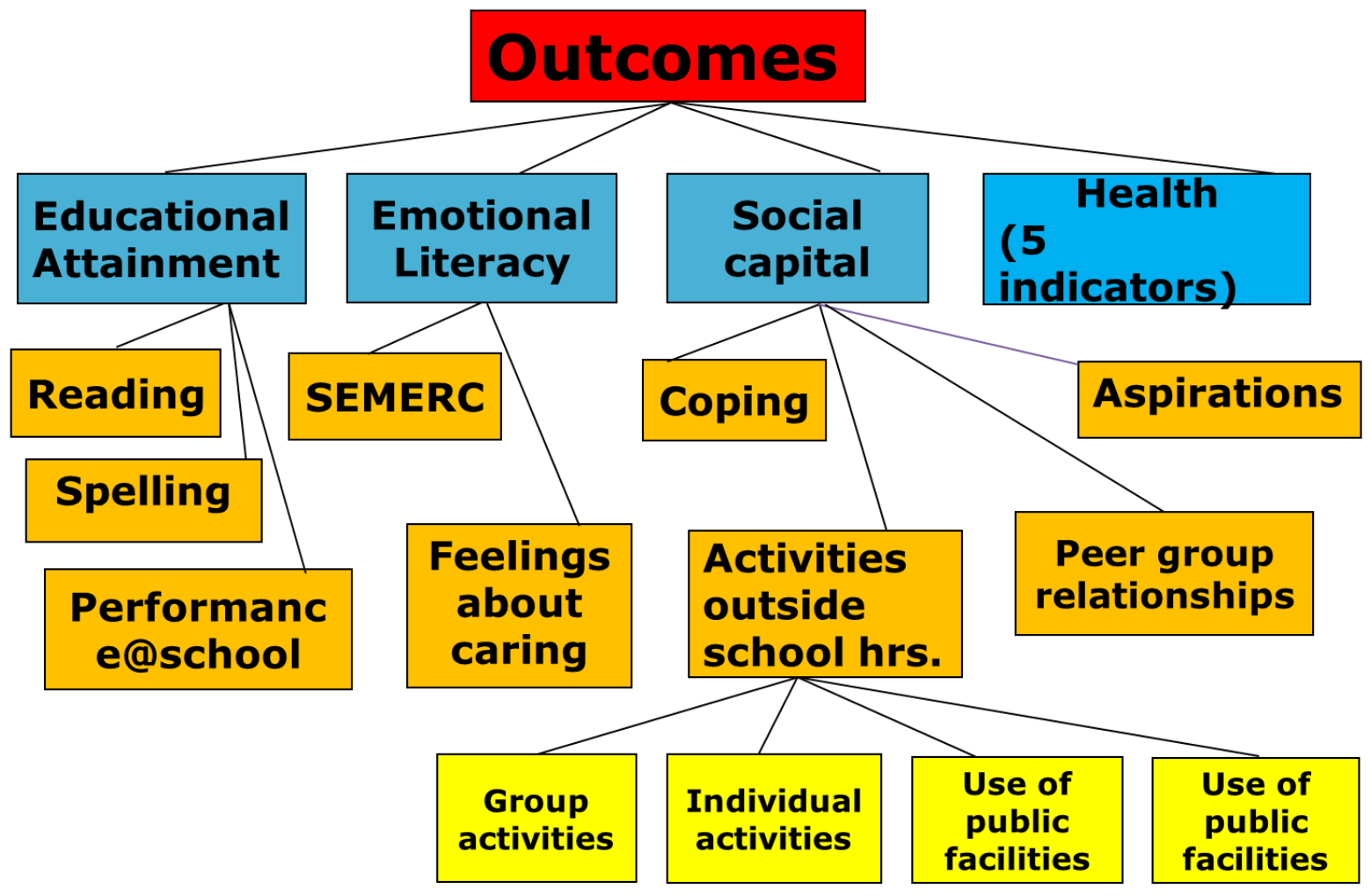

Figure 3 Outcome indices and sub-scales for Phase 2

The Educational Attainment Index (EAI) was comprised of ReadingBAS III (R), Spelling-BAS (S) and Performance at school (PS); Performance at school comprised data on attendance (AT), punctuality 
(PC), homework completion (H) and concentration in school (C) collected in the Young Carers be-spoke questionnaire (see Fig. 3).

Factors were weighted and included in the following formula to calculate the EAI:

$E A I=R(S S)+S(S S)+10 \times P S(A+P C+H+W)$

The Emotional Literacy index (ELI) was comprised of the Emotional Literacy measure SEMERC (SS) and self-reported feelings of satisfaction (SF), competence (CP), stress (ST), tiredness ( $T$ ) and aloneness (AL) collected in the Young Carers be-spoke questionnaire.

Factors were weighted and included in the following formula to calculate the ELI:

\section{$E L I=S S+10 \times(S F+C P+S T+T+A)$}

The Health index (HI) was comprised of a self-assessment of overall health $(\mathrm{OH})$, minor complaints $(\mathrm{MC})$, frequency of dental checks (D), frequency of sight checks (SGT) and smoking (SK).

Factors were weighted and included in the following formula to calculate the HI:

$H I=10 \times(O H+M C+D+S G T+S K)$

The Social Capital Index (SCI) comprised data on all social activities outside school hours (AOS), peer relationships (PR), coping (CPG) and aspirations (ASP) (see Figure 4). 
Factors were weighted and included in the following formula to calculate the SCI:

\section{$S C I=3 \times(A O S+P R+C P G+A S P)$}

Social Capital domains, sub-scales and indicators

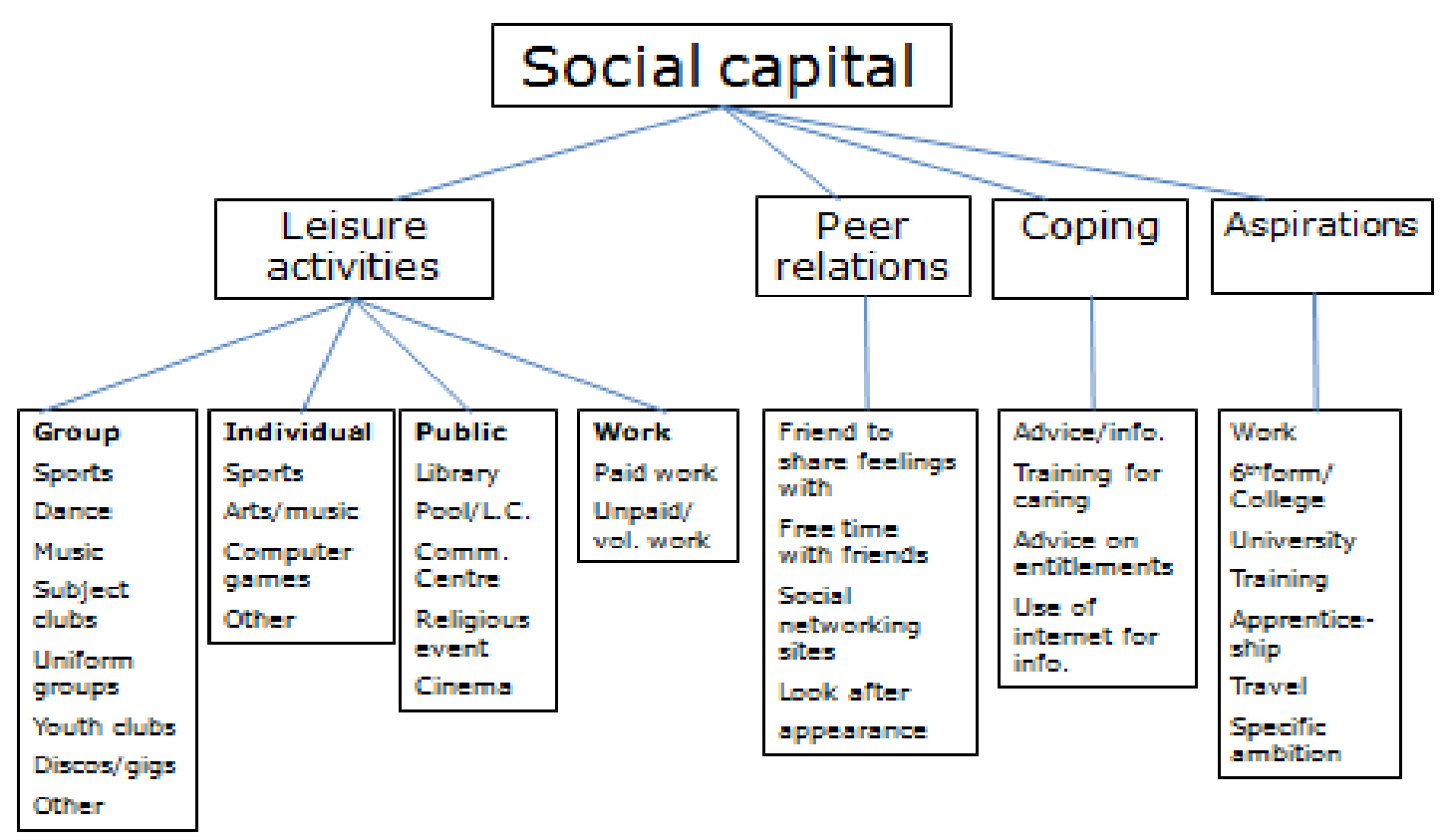

Figure 4. Social Capital domains, sub-scales and indicators

In addition to the four key outcome indices, a composite outcome index (COI) was calculated. The composite index was comprised of the four key indices (see Fig. 3).

Factors were weighted and included in the following formula to calculate the COI:

\section{$\mathrm{COI}=(\mathrm{EAI}+\mathrm{ELI}+\mathrm{HI}+\mathrm{SCI})$}

Data were collected on a range of independent variables covering biographical details, for example age, gender, family structure, and the 
caring profile, for example tasks, time spent, condition of person cared for.

The following techniques were used to analyse the data (see Tables 6 and 7)

In Phase 1, qualitative data from Phase $1 \mathrm{a}$ and $1 \mathrm{~b}$ surveys were tabulated and summarised (RQs 1-7). Descriptive statistical techniques were used to summarise quantitative data from Phase $1 \mathrm{a}$ and $1 \mathrm{~b}$ surveys.

In Phase 2, descriptive quantitative techniques were used to summarise data (RQ 8).

Correlational techniques were used to explore associations between outcome indices (RQs 9-10).

Correlational techniques and ANOVA were used to explore associations between outcome indices and biographical and caring factors (RQ 11). ANOVA tests were used to discover any difference in means in outcomes between Projects (RQ 12).

Binary logistic regression analysis was used to identify factors which are predictive of outcome indices for young carers and to explore the strength of those factors identified (RQ 13-14). 
Table 6

Research Objectives, Aims, Questions and Design

Research objective

To explore outcomes for young carers

Research aims

1. To map and evaluate extent of existing provision for young carers in Wales.
2. To examine the relationships between outcomes and factors which may have contributed to them
3. To identify the relative importance of factors affecting outcomes for young carers.

Research questions

1. How well developed are the services for young carers?

2. How much partnership working is there?

3. How accessible are the services?

4. How do the service providers evaluate their service for young carers?

5. What do the service providers perceive to be the challenges?

6. What is the relative importance of the Projects in provision for young carers?

7. What is the amount and source of current investment in Projects in Wales?
8. What are the outcomes on the chosen measures?

9. Is there any association between Educational Attainment and other outcomes?

10 Is there any association between Emotional Literacy and other outcomes?

11 Is there any significant statistical evidence of an association between outcomes and any factor in the biographical and caring data?

12 Are there any differences in outcomes at group level between Projects?
13 Which of the variables have the strongest association with positive outcomes for young carers?

14 Which of the variables have the strongest association with adverse outcomes for young carers? 
Table 7

Research Questions and Design

Design

\begin{tabular}{|c|c|c|}
\hline RQs 1-7 & RQs 8-12 & $R Q s$ 13-14 \\
\hline Positive & Phase 2 & Data analysis \\
\hline $\begin{array}{l}\text { Inductive } \\
\text { Mixed methods }\end{array}$ & $\begin{array}{l}\text { Survey of young } \\
\text { carers. }\end{array}$ & $\begin{array}{l}\text { Descriptive } \\
\text { analysis: }\end{array}$ \\
\hline $\begin{array}{l}\text { Consultations with } \\
\text { professionals in } \\
\text { relevant fields }\end{array}$ & $\begin{array}{l}\text { Select age-appropriate } \\
\text { Emotional Literacy } \\
\text { test. }\end{array}$ & \multirow{4}{*}{$\begin{array}{l}\text { - t-tests } \\
\text { - ANOVA } \\
\text { Inferential analysis: } \\
\text { - Correlation } \\
\text { - Binary Logistic } \\
\text { Regression }\end{array}$} \\
\hline $\begin{array}{l}\text { relevant fields. } \\
\text { Literature review }\end{array}$ & $\begin{array}{l}\text { Select age-appropriate } \\
\text { literacy test. }\end{array}$ & \\
\hline $\begin{array}{l}\text { Examining existing } \\
\text { measures. }\end{array}$ & \multirow{4}{*}{$\begin{array}{l}\text { Focus group of young } \\
\text { carers to develop a } \\
\text { new be-spoke } \\
\text { questionnaire with } \\
\text { both closed and open } \\
\text { questions in order to } \\
\text { record biographical } \\
\text { data and data which } \\
\text { may provide evidence } \\
\text { on outcomes. }\end{array}$} & \\
\hline Phase $1(a)$ and (b) & & \\
\hline Surveys: & & \\
\hline $\begin{array}{l}\text { (1a) bespoke semi- } \\
\text { structured } \\
\text { questionnaire to } 22 \\
\text { Social Services } \\
\text { Depts. in Wales. }\end{array}$ & & \\
\hline $\begin{array}{l}\text { (1b) bespoke semi- } \\
\text { structured } \\
\text { questionnaire to } 26\end{array}$ & $\begin{array}{l}\text { Identify volunteers } \\
\text { through YCPs in South } \\
\text { Wales. }\end{array}$ & \\
\hline $\begin{array}{l}\text { YCPS in Wales. } \\
\text { Descriptive and } \\
\text { summary statistics } \\
\text { recorded in Excel. }\end{array}$ & $\begin{array}{l}\text { Administer all three } \\
\text { tests to a target } \\
\text { sample of } 60 \text { young } \\
\text { carers age } 11 \text { to } 16\end{array}$ & \\
\hline $\begin{array}{l}\text { Content analysis } \\
\text { coded manually. }\end{array}$ & Recorded using SPSS. & \\
\hline Descriptive statistic & & \\
\hline
\end{tabular}




\subsection{Ethics}

\subsubsection{Ethical considerations.}

In the design of this study, reference was made to relevant research and professional guidelines: the UNCRC, the codes of ethics of the British Sociological Association, the Social Research Association, the British Association of Social Work and the Guidelines for Research with Children and Young People from the National Children's Bureau (Shaw et al., 2011). The common basic principles were: the voluntary nature of participation, informed consent, anonymity, confidentiality, sensitivity of participants, protection from harm, all of which were observed in the design and implementation of this study. Particular notice was paid to the stricture of the British Sociological Association that the researcher must "ensure that the physical, social and psychological well-being of research participants is not adversely affected by the research".

With Social Services and the YCPs, the respondents were professionals or trained volunteers with experience of completing surveys and a place within a supportive structure and therefore not judged to be vulnerable. It was anticipated therefore that the main ethical concern for those participating would be the nature and status of the research followed by anonymity and confidentiality for themselves and their organisations. The initial invitation to take part was accompanied by an explanatory leaflet outlining the design of the study, its purpose and potential dissemination and use, reassuring them of anonymity and confidentiality. 
In the survey of young carers, on the other hand, the welfare of the participants was anticipated to be a major issue. Protecting them from harm required particular care due not only to their age but to their possible vulnerability. They were likely to be stressed as a result of their lives as carers and in participating they would be asked to reveal personal and family information about which they might be embarrassed or ashamed.

Firstly they needed to know that participation was entirely voluntary and that they were free to refuse or to leave at any point during the process. They needed to be convinced of the anonymity and confidentiality of their identity and responses. It was also an essential duty to ensure that they understood the purpose of the research and what their part in it would involve, a task made easier by the fact that many had been introduced to the concept of research at school. From the perspective of the study itself, the interviews were more likely to be productive and truthful if trust in the researcher and the research process was built up. The offer of feedback was felt to be important as this would show that the young carers' part in the research was valued (Morgan, 2005).

\subsubsection{Implementation (see Table 8).}

Beforehand the setting of the interviews was discussed with the Project workers to ensure privacy and confidentiality but in a safe situation. In each Project willing to participate, an introductory talk was given to the workers and members in which all these points were explained. Samples 
of the questionnaire, of the data sets and of a published thesis were used to illustrate the explanation. The Project leaders were asked to repeat this information in group sessions and to ensure particularly that the participants had understood their right not to participate and to withdraw at any point without consequences. The points were repeated in the information sheet to potential volunteers (see Appendix $L$ ) and in the letters to their parents (see Appendix K) and were repeated when relevant during the interviews. Informed consent was further assured by the provision of assent forms to accompany the letter for the under-16s (see Appendix $N$ ), consent forms to go with the letter for their parents (see Appendix M) and the requirement for these to be returned with signatures. A version of this letter was prepared for those aged 16 with a participant consent form but an information sheet was also supplied for their parents. The verbal and written explanation of the confidentiality principle included the caveat that if someone were hurting them or causing them harm then 'I would have to let another appropriate person know.' (FACNTF, para 3.48). This eventuality would have triggered the process recommended in the All Wales Child Protection Procedures. As it happened, most young people were familiar with this principle already. The offer of a return visit by the researcher later to tell them about the results if they wished was welcomed by Project workers.

An important element in adopting ethical practice is that it protects the researcher also from challenges or accusations of inappropriate behaviour or any physical harm which might occur. The setting of the 
interviews within the Project venue with staff present therefore also helped ensure the protection of the researcher.

The atmosphere at the visits for individual interviews was friendly and relaxed due mainly to the helpful and encouraging attitude of the Project workers towards the research in all Projects. Volunteers were offered the chance to split the exercises into two or even three sessions if they preferred and this was offered again after the end of each exercise. The questionnaire itself included options in some sensitive items such as Don't know and Not sure to reduce pressure.

For the sessions with the Reference and Pilot Groups, two Project workers transported the participants and remained throughout the discussions. This was by consent and did not prove to be an inhibiting factor since the relationship between the workers and the young people was extremely close, supportive and trusting. Food, nibbles and drinks were provided because of the timing of the session.

All those who took part were given a certificate, a personalised letter of thanks and a list of helpful organisations, phone lines and web-sites. The participants in the Reference and Pilot groups were also given vouchers for $£ 10$, an amount judged not to be coercive.

\subsubsection{Balance of power.}

The Statement of Ethical Practice for the British Sociological Association, (2004) reminds researchers that "research relationships are frequently characterised by disparities of power and status" (para 14). In the current study, there was no power imbalance due to differences in 
ethnicity, culture or language but there was no disguising the potential effect of the age difference. With the method chosen, there was little room for activities which could place the researcher in the "least adult role" (Dorner, 2015). There was a small element of participation in that young carers were involved in the development of the questionnaire but this was not sufficient to qualify it as participatory method. It was hoped that the researcher being introduced through trusted adults, that is the Project workers, was able to ameliorate any strangeness or distance caused by the chosen method.

\subsubsection{Ethical approval.}

The applications for ethical approval for the surveys of Social Services provision for young carers and of the YCPs were made together to the College of Human and Health Sciences Research Ethics Committee at Swansea University as Phase 1(a) and (b) and approval was granted on July 2nd, 2012.

The separate application for the research with young carers themselves was made later as Phase 2 was submitted on July 22nd, 2013, and approval was granted on August 2nd, 2013. 
Table 8

Timetable of research process

\begin{tabular}{|c|c|c|}
\hline Phase & Tasks & Undertaken \\
\hline \multirow{3}{*}{$\begin{array}{l}\text { Prelim. } \\
\text { research }\end{array}$} & Literature review & July - Dec. 2011 \\
\hline & $\begin{array}{l}\text { Informal interviews with } \\
\text { professionals in the field }\end{array}$ & \\
\hline & Discussions with host charity & \\
\hline \multirow[t]{7}{*}{ Phase 1} & $\begin{array}{l}\text { Development of Social Services } \\
\text { questionnaire }\end{array}$ & Jan. - May 2012 \\
\hline & $\begin{array}{l}\text { Development of YCP } \\
\text { questionnaire }\end{array}$ & Feb. - Sept. 2012 \\
\hline & Ethical approval Phase 1 & July 2nd 2012 \\
\hline & $\begin{array}{l}\text { Piloting/production of Soc. } \\
\text { Services questionnaire }\end{array}$ & May. - Oct. 2012 \\
\hline & Survey of Social Services & \\
\hline & $\begin{array}{l}\text { Piloting and production of YCP } \\
\text { questionnaire }\end{array}$ & \\
\hline & Survey of YCPs & \\
\hline \multirow[t]{6}{*}{ Phase 2} & Ethical approval Phase 2 & Nov. 5th $2012-$ \\
\hline & $\begin{array}{l}\text { Recruitment in host charity } \\
\text { Development of } Y C \\
\text { questionnaire: }\end{array}$ & June 12th 2013 \\
\hline & $\begin{array}{l}\text { - Reference Group } \\
\text { - Pilot Group }\end{array}$ & \\
\hline & Recruitment in remaining area & Sept. - Oct. 2012 \\
\hline & Data collection & \\
\hline & Data analysis & $\begin{array}{l}\text { Nov. 11th } 2012- \\
\text { Apr. 12th } 2013\end{array}$ \\
\hline
\end{tabular}




\subsection{Phase 1a: Survey of Young Carers Services in Social Services}

\subsubsection{Participants.}

The aim was to include all twenty-two local authorities in Wales. Efforts were made to identify the Lead officers for the young carer service. Where there was no such post, the names were sought of alternative officers with responsibility which included the young carer service. Responses were received from 12 local authorities.

\subsubsection{Measures.}

\section{Development of questionnaire.}

There were no ready-made measures or relevant surveys whose measure could be drawn on (see Section 4.1.1) and there were therefore no relevant norms available. It was evident that the first phase was a factfinding exercise and it would be necessary to develop two be-spoke questionnaires, one for Social Services and one for YCPs.

To address the first research aim, seven research questions (RQs) had arisen from the literature review and from the informal interviews with professionals in the field. In order to encourage responses from busy professionals, the questionnaire was kept fairly brief with seven sections and seventeen sub-sections (see Table 9 and Appendix D).

The first question for Social Services needed to establish whether there was a dedicated Lead Officer for the young carer service. The remainder was a mixture of closed and open items. The closed items (Items 2, 3, 4, 5a and 5c) were dichotomous or Likert questions yielding categorical data on RQs $1,2,3$ and 6 . The open questions (Items $5 b, 6$ 
and 7) required text responses providing qualitative data on RQs 1, 3, 4 and 5. To answer 6 and 7 (Amount and source of current investment in the Projects in Wales), the data from both the Social Services and the Project surveys were analysed together.

Each item addressed one or more RQ as follows:

Table 9

How the items in the Social Services survey addressed the RQs

\begin{tabular}{lcccccc} 
Item & RQ 1 & RQ 2 & RQ 3 & RQ 4 & RQ 5 & RQ 6 \\
\hline & D'ment of service & $\begin{array}{c}\text { P'ship } \\
\text { working }\end{array}$ & Access & Evaluation & Challenges & $\begin{array}{c}\text { Relative } \\
\text { import. }\end{array}$ \\
\hline 2(a) & $\checkmark$ & & & & \\
\hline 2(b) & $\checkmark$ & $\checkmark$ & & & \\
\hline 2(c) & & $\checkmark$ & & & \\
\hline 3 & & $\checkmark$ & $\checkmark$ & & \\
\hline 4(a) & $\checkmark$ & & & & \\
\hline 4(b) & $\checkmark$ & & & & \\
\hline 4(c) & $\checkmark$ & & & & \\
\hline 5(a) & & & $\checkmark$ & & \\
\hline 5(b) & & $\checkmark$ & & \\
\hline 6(a) & $\checkmark$ & & $\checkmark$ & \\
\hline 6(b) & $\checkmark$ & & $\checkmark$ & \\
\hline 6(c) & $\checkmark$ & & & \\
\hline 7(a) & & & & \\
\hline 7(b) & & & & \\
\hline (b) & & & & \\
\hline
\end{tabular}




\section{Piloting of survey measure.}

The draft SS survey was piloted with two senior managers in Social Services. They recommended that the Common Assessment Framework be included as an option in the question on tools used for assessment and this was implemented, together with some minor alterations in layout. The final text was translated into Welsh, designed and printed and an accompanying bi-lingual letter was prepared explaining the research and promising the anonymity and confidentiality of the responses. The letter and questionnaire were to be e-mailed to an identified contact in each Social Services authority with a suggested turnround time. The piloting was intended to test the content validity, comprehensibility and feasibility of this questionnaire and demonstrate that it was satisfactory. As there were no previous surveys of a similar remit, there are no norms with which to compare the results from this measure to test its criterion validity. It would have been inappropriate to use a re-test to check reliability and stability.

\subsubsection{Procedure}

\section{Recruitment.}

The population of interest in this survey was the professionals leading on the social service for young carers in the twenty-two local authorities in Wales. Recruiting participants was facilitated by contacts in the earlier work for the study. As a result of one of the preliminary interviews with a Senior Manager in a local authority Social Services, the researcher was invited to give a presentation to COLIN. The Chair of COLIN offered to 
circulate the questionnaire. The offer was welcomed as this would ensure reaching the most recent list of relevant contacts and would lend some weight to the research.

\section{Data collection.}

The questionnaire was e-mailed by COLIN to their contact list with the researcher's accompanying letter explaining the status and purpose of the research, promising anonymity and confidentiality and offering a subsequent report on the findings. No deadline was given but a turnround of three weeks was suggested. Six completed questionnaires were returned within four weeks plus one questionnaire referring on to a different officer. This led to a sequence of five contacts in that authority, none of whom were able to complete the questionnaire. COLIN e-mailed a reminder to their members and four more questionnaires were returned within the next six weeks. Where exchanges had developed with a contact, further e-mail conversation was essayed as an attempt to elicit additional responses but this was judged to be persuasive and never coercive. The researcher had again been invited to speak to a national meeting of COLIN and it was hoped that this might prompt extra responses.

After detecting the appropriate person to approach in two authorities, two more had been returned by June 12 th, 2013, making a total of twelve. There was one response in Welsh. Each response received a thank you e-mail and some conversations developed as a result. In 
September, 2013, a summary of the interim progress was circulated to their members by COLIN.

\section{Recording and coding.}

In order to preserve anonymity as promised by the ethical application, when questionnaires were returned, the authorities were indicated by a number and the contact details page was separated from the completed questions and the two sets of information stored separately.

As the maximum possible number of responses was 22 , the qualitative data were typed into a Word document labelled by an identity number and was tabulated and coded manually. The quantitative data were collated and represented alphanumerically to protect identities and input manually into an Excel spread sheet.

\subsection{Phase 1b: Survey of YCPs}

The responses to the survey are reported and summarised here in order of the RQs 1-7.

\subsubsection{Participants.}

The second population was all the YCPs in Wales. Twenty three had been identified by Children in Wales and later three more Projects were identified through the Internet.

\subsubsection{Measures.}

\section{Development of questionnaire.}

A draft questionnaire was developed based on three elements: 
- the literature review and in particular on the existing evaluations of YCPs

- interviews with professionals working in the field

- discussions with the workers in the host charity

Since the same RQs applied to the Projects as to Social Services, some items covered the same themes; that is development of the service, partnership working, access to the service (including referrals), evaluation, challenges. This was in addition an opportunity to collect evidence on how the Projects functioned and on current investment in this service. A study of the data from the two surveys together might afford a view on the importance of the role of the Projects in provision for young carers and investment in them.

The draft questionnaire had eleven items with thirty-one subsections. It was a mixture of closed Boolean and Likert items providing categorical data. There were also some open questions providing qualitative data (see Table 17 and Appendix E). The last item (11.3) gave the respondents the opportunity to make any observation they felt they wanted to.

\section{Piloting of survey measure.}

The draft was discussed with the host Project Leader and piloted with a manager in the host Project. It was suggested by them that the sources of referrals should include 'Other YCP' and 'A private organisation'. They were helpful in clarifying the full list of qualifications which might be 
obtained by YCP staff. They advised also on all the activities which a YCP might be expected to carry out. Amendments were made accordingly.

\subsubsection{Procedure.}

The text was then translated, designed and printed preparatory to emailing to all Projects in Wales together with an accompanying bi-lingual letter explaining the research and promising the anonymity and confidentiality of the responses.

\section{Recruitment.}

A preliminary interview with a Wales children's charity had led to an offer to circulate the finalised questionnaire to the twenty-three Projects across Wales listed in their contact list.

\section{Data collection.}

The bi-lingual questionnaire was accompanied by a bi-lingual covering letter explaining the status and purpose of the research, assuring anonymity and confidentiality and offering feedback on the research. It was e-mailed to all twenty-three identified Projects by Children in Wales.

A three week period was suggested for responding. Six completed forms were returned by the suggested date and a reminder was then sent out by the charity. A further mail-out was carried out by the researcher to the three additional Projects identified from the Internet and to Projects where there had been some earlier difficulty in identifying the appropriate respondent. Three more were received by e-mail within the next month and one was received by post. The last one was received five months after the first e-mail. One of the 10 responses was in Welsh. 


\section{Recording and coding.}

Each Project was allocated a number and the contact details page was then separated from the completed questionnaires. The contact details, completed questions sheets and identity key were stored separately.

As the likely number of responses was limited, the qualitative data were typed into a Word document and coded manually. The quantitative data were collated and entered on an Excel spread-sheet and represented alphanumerically.

\subsection{Phase 2: Survey of Young Carers}

\subsubsection{Participants $(n=62)$.}

In total 62 young carers participated in Phase 2 of the study. Of these, 61 participants were drawn from 10 YCPs. Data from an additional participant from a non-specialist youth club was included since she fulfilled the criteria on the MACA scale as a young carer. The number coming from each Project varied from one to 13 and consisted in total of 32 females and 30 males. There was a low rate of withdrawal after initial interest, only three being lost after the SEMERC measure and a further four declining to take the literacy tests.

\subsubsection{Measures.}

Four key areas had been identified through the literature review as outcomes which could and should be measured: Educational Attainment, Emotional Literacy, Health and Social Capital. 
The study required measures suitable for the age and situation of the participants. These factors limited the optimum length of interview and the extent to which precise and accurate data could be expected. The design and procedures had also to bear in mind that this was their one night out and interviewees could only be expected to leave their activities and to concentrate for a limited time. The amount of data that could be collected was therefore restricted by consideration of the interviewees' welfare and how long their interest could be engaged.

\section{Educational Attainment.}

An established measure of educational attainment could provide data on objective outcomes and would supply norms for comparison with an agerelated group in the general population. For this purpose the BAS III (Reading and Spelling subtests) was selected. This is a UK developed and age-appropriate standardised measure of literacy. The Reading and Spelling subtests have internal reliability quotients of 0.91 to 0.98 respectively. The measure yields both standard scores and age equivalents. The test has been used also with another vulnerable population (Rees, 2013) allowing comparison of the participants' scores with an allied population.

\section{Emotional Literacy.}

In order to answer RQs which relate to emotional literacy, a standardised measure of emotional literacy was chosen to produce objective data. The measure developed by SEMERC was selected for its age-appropriate design and for the availability of an illustrated computerised version. The 
design and medium was thought to be attractive to the interviewees. They could complete it themselves if they wished or in tandem with the researcher and the use of a laptop was convenient for whatever circumstances transpired for interviews. An important feature of this programme, in anticipation of the lower educational attainment in young carers signalled by the literature review, was that it was designed to accommodate special educational needs.

The measure yields an overall Emotional Literacy score which included five components: self-awareness, self-regulation, motivation, empathy and social skills. The Student version did not provide separate scores for the five components but on balance this was less important than the accessibility of the programme and the fact that this was not meant by itself to inform a specific intervention. The measure has good internal reliability for the self-report form of 0.76 .

\section{Level of caring activities.}

The MACA-YC18 (Joseph et al., 2009) was chosen to provide data on the level and categories of caring activities carried out. It is a self-report measure with 18 items and six subscale scores for types of tasks. A Likert scale allows three grades for each type of activity: $A$ lot of the time; Some of the time; Never. The classification of tasks is clear and easy to understand. It uses appropriate style and vocabulary for the participants. 
The MACA YC-18 is reported to have an internal consistency reliability quotient of 0.78 . Individual subscale reliability quotients range from 0.45 to 0.91 (Joseph et al., 2009)

Development of be-spoke questionnaire (biographical factors, caring profile, Emotional Literacy, Educational Attainment, Health and Social Capital).

A be-spoke interview schedule (see Appendix G) was chosen to gather information on:

- the biographical and caring factors which might be contributing to outcomes,

- supplementary qualitative data on Educational Attainment and Emotional Literacy,

- the health of young carers in this sample and

- acquisition of social capital.

Analysis of the data addressing the above questions would supply the answers to the RQs 12,13 and 14 on differences in outcomes between Projects and on variables with the strongest association with positive and adverse outcomes.

Apart from the subject matter of the data collection, there were three elements to be considered:

- the sensitivity of their situation as carers,

- the communication skills to be expected in that age group and 
- the level of conceptualisation in their development at that stage.

It was the combination of these three elements which made it difficult to find a suitable tool already in existence. This strengthened the decision to design a be-spoke questionnaire. Lessons were learnt from the measures studied in the course of the literature review, both quantitative and qualitative. These were useful for examples of outcomes, indicators employed and methods of conducting surveys with children and young people. The example of YCOPI (Pakenham et al., 2006) which had drawn its wording from prior qualitative interviews inspired the idea of involving some young carers in the development of this questionnaire. Other examples of studies about the demographics and activities of young people were studied to look for relevant norms for example the WGCYPWM, Health Behaviour in School-aged Children (Wales), Sports Council Wales Activity of Young People (2009). The bespoke measure was developed, drawing on the literature review, with the participation of a group of young carers $(n=5)$.

The Reference Group session was held in a central venue and the Project workers provided transport and a meal. A script had been prepared including giving a brief idea of what the research was about and about research method. A set of six profiles of fictional young carers with photos was presented designed to include all the main issues as identified by preliminary research and supported by statistical evidence. This was intended to start the discussion, to offer a way into the 
analytical process and to allow discussion away from sensitive personal concerns. However the participants were soon giving comments from their own experience. A list of issues was charted up with their comments. Then they were asked to mark each item with a coloured sticker: red for not very important, green for important and amber for middle value. They asked if they could refine it by sticking two or three of the same colour on an item or one green and one amber where it was in between. In this way the issues were identified in order of priority.

The next step was to consider how questions about these issues should be phrased. Sets of sample questions with a variety of indicators had been collated and printed out on the issues they might choose and with these in their hands they discussed the ones relating to the issues they had chosen as most relevant. They were able to dismiss some because the indicators were not suitable or because the measures were not feasible for their age group; then they were examined for the suitability of the language used. They liked the use of Likert scales for some items.

They made a striking comment on bullying. They were of the opinion that this was so common for all children that it was not just a factor for young carers and on which it was not worth including a question. Equally striking was their opinion that distinguishing between face-to-face and social networking was pointless as they did not regard them as different.

One question on whether the respondent took exercise or not was rejected as the 'nerd' question which might upset someone who couldn't 
take part because of a physical condition and as a result the question was re-phrased and sport was included as only one option in a list of activities. Two of the sub-questions on feelings about caring were suggested by them. The eventual question on free time spent with friends adopted their wording. Most influential were their comments on questions requiring numerical answers e.g. how many times have you been late for school in the last month? Their view was that many young carers would not be able to answer because of their age but also because these details were not always retained in the stress of their lives. A draft was drawn up by the researcher and advice sought from land later with the advice of the Project workers in the host charity.

Piloting of questionnaire.

The Pilot Group of three volunteers met in the same way as the Reference Group. They started by filling in the draft questionnaire. One immediate advantage of this pilot was that it indicated that some questions needed re-wording as they were unclear as they stood. The second was their advice on suitable vocabulary. For example they found 'responsibilities' and 'tasks' acceptable but were not keen on 'duties'. They liked the term 'look after' and suggested that 'help look after' might be confusing. The term for the family member they preferred was 'the person you look after' or 'the person you care for'. The numerical measures had been retained in some questions in the draft specifically to get their views and, like the Reference Group, they remarked that these would be difficult to answer. 
Since the main aim was to obtain objective outcomes, this was disappointing advice but had to be accepted.

After this session, the draft was amended and then read and commented on by managers in the host project before it was ready for interviews with young carers.

The final design comprised eleven items with 33 sub-sections. This structured questionnaire consisted of Likert scales and categorical items to provide objectified and quantifiable responses. This made it easier and quicker for the interviewees of this age group to answer but did not preclude their offering additional comments or anecdotal evidence. The responses in each section were scored separately and totalled as composite scores for each of the four outcomes.

\subsubsection{Procedure.}

\section{Recruitment.}

Rapport with professionals.

One of the functions of Phases $1 \mathrm{a}$ and $1 \mathrm{~b}$ had been to help develop a rapport with the professionals thus facilitating the research. This was prompted by appreciation of the workload borne by most of those involved in this field and the need to learn as much as possible about their parameters to maximise their convenience. For the sake of the success of the research, it would make contact and responses more likely. Hence the personalised responses to all e-mails, the willingness to engage in conversation where that was invited, the summaries of findings sent out to professionals after the data collection and the offer 
to re-visit Projects to report on findings if wished. This was particularly important since recruitment of participants depended on the response of the Project staff. For this process they abided by their own ethical guidelines informed by their practical experience.

Table 10

Recruitment timetable

\begin{tabular}{lll}
\hline Project ID & First approach & Last interview \\
\hline 16 & Month 28 & Month 34 \\
\hline 14 & Month 24 & Month 34 \\
\hline 23 & Month 29 & Month 34 \\
\hline 22 & Month 29 & Month 33 \\
\hline 24 & Month 29 & Month 32 \\
\hline 9 & Month 29 & Month 38 \\
\hline 15 & Month 29 & Month 38 \\
\hline 18 & Month 29 & \\
\hline 2 & Month 29 & Month 38 \\
\hline 5 & Month 29 & Month 34 \\
\hline 8 & Month 29 & \\
\hline 1 & Month 29 & \\
\hline 20 & Month 29 & \\
\hline 13 & Month 29 & Month 35 \\
\hline
\end{tabular}

Recruitment at host Project.

Participants were recruited for three activities: assisting with the development of a draft questionnaire in a Reference Group, testing the draft questionnaire in a Pilot Group and participating in the chosen tests including the resulting questionnaire. The workers at the host charity 
explained at a club meeting then the researcher visited and gave out information sheets and consent forms Appendices $\mathrm{K}, \mathrm{L}, \mathrm{M}$ and $\mathrm{N}$ ). Reminders were sent out by the Project Leader. After wide interest in the Reference and Pilot process, five of the members chose to take part in those two groups.

\section{Recruitment in wider area.}

A summary of the findings of the survey of the YCPs had been circulated to all Projects in Wales by the children's charity on behalf of the researcher and this facilitated a follow-up with a request to Project staff to invite young carers to take part as interviewees for the survey of young carers. When a positive response was received, copies of the papers to go to young carers were attached and an offer of more detailed information on the method, a phone call or a visit to discuss it further. The papers for the young carers were an explanatory letter and assent form for them, a different letter and a consent form for their parents and a consent form for the 16 year olds. Some Projects requested more detailed information on the questions to be asked, the ethical approval, the status of the research and the arrangements for interviews.

The population of interest in this phase was young carers aged 11 to 16 inclusive who were attendees at YCPs. This age group focused on a particular educational phase, that is those attending secondary schools, thus excluding issues of post-16 education, training or employment. The minimum age of 11 also made it easier to design a questionnaire which the range of the age group would be able to respond to in a meaningful 
way. The sample was to be of both genders with no specifications as to the relationship to the Cfp or their condition as this would allow testing for associations between outcomes and biographical and caring factors.

The original intention was to gather a random sample but because direct contact with the Project members was not possible the invitation to take part had to be passed on to them through the Project workers. As a result, some Projects did not respond and some parents failed or declined to sign consent forms thereby excluding those young people from participation.

The original area was to have been the county covered by the host charity but it became clear early on that, in order to recruit a large enough sample, it would be necessary to expand the area for recruitment to include the sixteen Projects of a wider area. The sample was in practice a non-probability sample.

The first phase survey of Projects demonstrated that work within the service on assessing and identifying young people as carers was quite advanced and it was felt to be safe to rely on the Projects' process for ensuring that participants were within the legal definition of 'young carer'.

\section{Data collection.}

The interviews mostly took place in the club venues with familiar staff on hand if needed. The possibility of administering the questionnaire in a group had been considered but it was clear from experience in the first Project that individual interviews were the best way. A separate space 
was usually provided but always one with a window or the door remaining ajar so as to ensure confidentiality but not hide the participant and interviewer. In the first two Projects, thinking not to overload interviewees, the measures were completed in two separate sessions but this varied later between one and three sessions according to the choice of the interviewee.

In one local authority area, the Project did not take the form of regular club meetings but held regular one-to-one meetings with the identified young carers in their schools. Volunteers in this Project were interviewed at school either in free periods or as part of their time for counselling.

The MACA questionnaire providing the data on the level of caring activity was included within the be-spoke questionnaire for ease of administration and presentation and to avoid the necessity for the young carers of a separate fourth measure. The design of the MACA was kept in mind in the design of the other questions so that they could be combined seamlessly.

The survey forms were completed together sometimes with the interviewee taking over. This was most frequent with the MACA item on caring activities. Participants were assured repeatedly of the confidentiality and anonymity of their responses.

There were occasions when the interviewees clearly wanted to talk and the interviewer listened but if possible without intervening or influencing what was being said. From 10 to 20 minutes was average for 
each test but one interview took an hour for the Emotional Literacy SEMERC measure alone. One interview of the three measures took an hour and a half. On no occasion was an interviewee upset although there were several whose manner of response showed signs of the stress of their lives.

All interviewees were provided with a certificate, a thank you letter and a list of helpful organisations, phone-lines and web-sites. A prize draw for a voucher of $£ 20$ was later drawn and awarded to one of the interviewees. The researcher offered to return to present the certificates and if wished to help create a presentation event. In two Projects, the presentations became a celebration with a buffet and a local person with an interest in carers presenting the certificates. In three the researcher made the presentation. In three other Projects the certificates, thankyou letters and lists of helpful organisations were posted. Where there were no club events, they were handed over individually at the interview.

\section{Recording and analysis.}

Each interviewee was accorded a numerical identity and the numbered questionnaires were stored separately from the numbered contact sheets. They were stored on a memory stick in a locked drawer in a locked room in the University.

The data were entered manually into an Excel document. The quantitative data were recorded according to questionnaire items and individuals. The qualitative data were attached to the relevant questionnaire item in a separate column. The quantifiable data were then 
coded and transferred to an SPSS file. The statistical tests were mainly Frequencies for descriptive data, t-tests and ANOVA for significant differences in means. Correlations were used to seek associations and Binary Logistic Regression to test the strength of associations and their predictive value. 


\section{Chapter 7}

\section{Findings}

\subsection{Phase 1a: Survey of service for young carers in Social Services.}

The responses to the survey are reported and summarised here in order of the RQs 1-7. Twelve responses were received from the 22 local authorities in Wales (55\%). There was heterogeneity of geographical spread, urban/rural and socio-economic profile. The sample consisted of local authorities from all quintiles when ranked on the Welsh Index of Multiple Deprivation (WIMD, 2011) Child Index.

\subsubsection{How well developed are services for young carers? (RQ 1)}

Lead Officers.

In some authorities, there was difficulty in identifying the appropriate person with responsibility for the young carers' service and for only one was it a sole responsibility. In others it appeared to be a joint responsibility with other areas of service: the Children's Service, the Carers Service, a Family approach or in one case a partnership of statutory providers. One interpreted "the Young Carers Service" as being the local YCP and responsibility for this was attributed to the Framework Partnership because that was the source of its funding.

Young Carers Strategies.

It can be seen from Table 11 that the majority had a strategy already or were in the process of developing one. 
Table 11

Development of young carers service

\begin{tabular}{lcc}
\hline \multicolumn{1}{c}{ Questionnaire Item } & Yes (\%) & No (\%) \\
\hline $\begin{array}{l}\text { Are you the person with lead responsibility } \\
\text { for the service to young carers within your } \\
\text { authority? }\end{array}$ & $9(75)$ & $3(25)$ \\
$\begin{array}{l}\text { Is this a sole responsibility with no additional } \\
\text { responsibilities? }\end{array}$ & $1(8)$ & $8(67)$ \\
\hline $\begin{array}{l}\text { Does your authority have a Young Carers } \\
\text { Strategy? }\end{array}$ & $5(42)$ & $7(58)$ \\
\hline
\end{tabular}

The majority reported not having a strategy but most of those were in the process of developing one.

Assessment tool.

Table 12

Assessment tool used to assess young carers

\begin{tabular}{|c|c|c|c|c|}
\hline I.D. & CAF & $\mathrm{CiN}$ & Adult carer & In-house \\
\hline 1 & $\checkmark$ & $\checkmark$ & & \\
\hline 2 & & & & $\checkmark$ \\
\hline 3 & & $\checkmark$ & & $\checkmark$ \\
\hline 4 & & $\checkmark$ & $\checkmark$ & \\
\hline 6 & & $\checkmark$ & & \\
\hline 10 & & $\checkmark$ & & \\
\hline 11 & & & & $\checkmark$ \\
\hline 14 & & & $\checkmark$ & $\checkmark$ \\
\hline 15 & & $\checkmark$ & & \\
\hline 18 & & $\checkmark$ & & $\checkmark$ \\
\hline 19 & & & & $\checkmark$ \\
\hline 22 & & $\checkmark$ & & \\
\hline
\end{tabular}

CAF - Common Assessment Framework

CiN - Children in Need

In - In-house tool 
Table 12 shows that there was a considerable diversity and combinations of tools used but Children in Need (CiN) assessment was still the majority approach in assessing young carers. Since five of the authorities were using more than one tool, this suggests that assessment may be a staged process. It also invites further exploration of the in-house tools in use.

Responsibility for assessment.

Table 13

Who carries out the assessment of young carers

\begin{tabular}{|c|c|c|c|c|}
\hline I.D. & SWA & SWC & SWY & Other \\
\hline 1 & & $\checkmark$ & & $\checkmark$ \\
\hline 2 & & & $\checkmark$ & $\checkmark$ \\
\hline 3 & & & $\checkmark$ & $\checkmark$ \\
\hline 4 & $\checkmark$ & $\checkmark$ & & $\checkmark$ \\
\hline 6 & & $\checkmark$ & & \\
\hline 10 & & $\checkmark$ & & \\
\hline 11 & & $\checkmark$ & & $\checkmark$ \\
\hline 14 & & & & $\checkmark$ \\
\hline 15 & & $\checkmark$ & & \\
\hline 18 & & $\checkmark$ & & $\checkmark$ \\
\hline 19 & $\checkmark$ & $\checkmark$ & & $\checkmark$ \\
\hline 22 & & $\checkmark$ & & \\
\hline
\end{tabular}

Although assessment fell in practice to a particular worker or workers, there were only two authorities citing a dedicated worker for this role: in one of those it was a Young Carers Assessment and Development 
Worker. Of the eight answering Other, four stated that they had delegated the assessment function to the YCP although in one of these the protocol to be used had been developed by Social Services. Two more referred to the assessment being undertaken by 'the Young Carers Service' but it is not clear whether this was part of the statutory or of the commissioned service. Two authorities could be seen to have retained the assessment function fully.

Of the eight respondents who ticked Other, five specified the YCP. Otherwise two respondents specified a Young Carers Support worker and one named the Young Carers Assessment and Development Worker.

Whilst Social Services have statutory responsibility for identifying and assessing young carers, the assessment and referral process appeared to vary from local authority to authority. How young carers overall become eligible for services was not standardised and especially so for referral to the Projects so it is not possible to say whether there was any common threshold which would apply to young carers who were referred to Projects. The activity of Social Services overall in reaching young carers, carrying out assessments and then providing support was not harmonised. 


\subsubsection{How much partnership working is there? (RQ 2)}

Strategic meetings.

Table 14

Regular strategic meetings regarding young carers held with other relevant agencies

\begin{tabular}{lccc} 
Regular strategic meetings with the following & Yes & No & No reply \\
\hline The Educ. Department. in your local authority & 9 & 2 & 1 \\
\hline Healthcare providers in your area & 9 & 2 & 1 \\
\hline Third sector (not for profit) orgs. & 9 & 2 & 1 \\
\hline Other relevant organisations & 8 & 3 & 1 \\
\hline
\end{tabular}

All except one of the authorities had regular meetings with the three relevant agencies named in the questionnaire although one of these indicated that meetings take place on an ad hoc basis only. Other organisations with whom meetings were held regularly were other Social Services Depts. including Adults Services (2), Leisure Services (2), Youth Services (1), Police (1), school nurses (1), joint planning partner agencies (2), partners in the Carers Plan (2) and the Children and Young People's Plan (1) and another local authority with whom they are developing a strategic response to the UHB footprint (1). Two mentioned the Carers Measure (WG, 2010) as a useful aid in encouraging the contribution of Health and other agencies in addressing Young Carers needs and one refers specifically to the need for Health to engage as a future partner. One authority did not reply to this question. 
Sources of referrals.

The level of referrals from the various sources might have reflected each of the other agencies' level of awareness of young carers as an issue and how far they had been alerted to their own potential partnership role in providing access to services for young carers (see Table 15). One factor which emerged strongly from this and later questions on responsibility for assessment, eligibility criteria and evaluation was that of close interdependence between the statutory social care sector and the third sector managed Projects.

\subsubsection{How accessible are the services? (RQ 3)}

Of the five who gave no reply to Sources of referrals, two authorities had no information at all as it was all held by the YCP. Other sources of referrals specified under Other, were: internally from other social care staff (1), other Children's Services (4), Police (1), Hospital (1), mutual exchange between Children's Social Services and the local Project (1). 
Table 15

Sources of referrals to Social Services

\begin{tabular}{lccccc}
\hline $\begin{array}{l}\text { From where do you receive } \\
\text { referrals of young carers? }\end{array}$ & All & Most & Some & None & $\begin{array}{c}\text { No } \\
\text { reply }\end{array}$ \\
\hline Self-referral & - & 1 & 9 & - & 2 \\
\hline Adult Social Services & - & 1 & 8 & 1 & 2 \\
\hline Education Welfare Services & - & 1 & 6 & 2 & 3 \\
\hline $\begin{array}{l}\text { Education Psychology } \\
\text { Services }\end{array}$ & - & & 5 & 4 & 3 \\
\hline $\begin{array}{l}\text { Additional Educational } \\
\text { Support }\end{array}$ & - & 1 & 6 & 2 & 3 \\
\hline G.P. & - & - & 4 & 6 & 2 \\
\hline Health Visitor & - & - & 5 & 5 & 2 \\
\hline School Nurse & - & 1 & 8 & - & 3 \\
\hline $\begin{array}{l}\text { 3rd Sector (not for profit) } \\
\text { org. }\end{array}$ & - & - & - & 9 & 3 \\
\hline Private Sector Organisation & - & 2 & 4 & - & 6 \\
\hline YCP & & & 5 & 2 & 3 \\
\hline Other & - & 1 & 5 & 2 \\
\hline
\end{tabular}

Eligibility criteria.

Ten had developed criteria but of these one allowed the local Project to define the eligibility criteria and one agreed the criteria in partnership with their local Project. Six responses contributed important data on the operational definitions in use. Four were age-defined; one specified the local authority boundary. Two included the relationship with the person cared for as parent or sibling and one used the general term of 'relative'; 
otherwise relationship was not specified. Three used CiN criteria but one of these said that their local Project assessed referrals using the MACA and PANOC. Only one mentioned specifically the impact of caring on the child as a criterion.

\subsubsection{How do service providers evaluate their service for young carers? ( $R Q$ 4)}

Evaluation (see Table 16).

The item on evaluation was three-fold: from the points of view of performance management, the service user and attributing success to the intervention (Mallinson \& Bovaird, 1988). A range of methods was employed, both qualitative and quantitative, and many used more than one method even several. Some based their assessments on strategic frameworks, for example the National Service Framework for Children, the local Children and Young People's Plan; generic tools were used such as the Team Around the Family, a local Results Based Accountability tool, Section 17 CiN Care Plan; others had developed specific tools for assessing young carers. 
Table 16

Methods Social Services use to evaluate their service for young carers: Number of respondents using each method.

\begin{tabular}{lll}
\hline Item & $\begin{array}{l}\text { 6(a) How you } \\
\text { evaluate how } \\
\text { effective Social } \\
\text { Services is in its } \\
\text { work with young } \\
\text { carers generally? }\end{array}$ & $\begin{array}{l}\text { 6(c) How you } \\
\text { determine whether } \\
\text { input from Social } \\
\text { Services has been } \\
\text { successful for } \\
\text { individual young } \\
\text { carers? }\end{array}$ \\
\hline Assessment \& Review & 4 & 4 \\
\hline $\begin{array}{l}\text { Feedback and } \\
\text { consultation }\end{array}$ & 3 & 4 \\
\hline $\begin{array}{l}\text { Qu. data \& P.I.s } \\
\text { Monitoring the Project }\end{array}$ & 2 & 2 \\
\hline $\begin{array}{l}\text { Theoretical/strategic } \\
\text { measure }\end{array}$ & 1 & 3 \\
\hline No info. & 1 & 1 \\
\hline
\end{tabular}

Note. Some responses include more than one element so the total adds up to more than the number of respondents.

\subsubsection{What do the service providers perceive to be the challenges? (RQ 5)}

Challenges.

There were two open questions on challenges: challenges for Social Services and challenges for young carers. Concerning challenges to Social Services, nearly all cited funding, resources and capacity. The second most cited challenge was the lack of understanding and recognition of young carer issues in outside services (eight of the respondents). This prevented young carers being identified and referred to the service. 
The challenges to young carers posited by Social Services respondents fell largely under four headings with six comments on each: the adverse emotional effects of caring on the young person, the difficulties of accessing support, difficulties in education and the problems arising from the social setting for example isolation, bullying.

\subsubsection{What is the relative importance of the Projects in provision} for young carers? (RQ 6)

What is the amount and source of current investment in Projects in Wales? (RQ 7)

These questions were not addressed directly in the questionnaires for Phases $1 \mathrm{a}$ and $1 \mathrm{~b}$ but the responses to the two above RQs in both surveys will together provide the material for the discussion on Phases $1 a$ and $1 b$ (Section 6.7.1). 
Table 17

How the items in the Projects survey addressed the RQs

\begin{tabular}{|c|c|c|c|c|c|c|c|}
\hline Item & RQ 1 & RQ 2 & RQ 3 & RQ 4 & RQ 5 & RQ 6 & RQ 7 \\
\hline & $\begin{array}{l}\text { Service } \\
\text { devel. }\end{array}$ & $\begin{array}{l}\text { P'ship } \\
\text { working }\end{array}$ & $\begin{array}{l}\text { Access } \\
\text { to } \\
\text { service }\end{array}$ & $\begin{array}{l}\text { Evaluat } \\
\text {-ion. }\end{array}$ & Challenges & $\begin{array}{l}\text { Relative } \\
\text { import. } \\
\text { of YCPs }\end{array}$ & $\begin{array}{l}\text { Invest- } \\
\text { ment }\end{array}$ \\
\hline 1 & & & $\checkmark$ & & & & \\
\hline 2.1 & & & $\checkmark$ & & & & \\
\hline 2.2 & & $\checkmark$ & $\checkmark$ & & & & \\
\hline 2.3 & & & $\checkmark$ & & & & \\
\hline 2.4 & & & $\checkmark$ & & & & \\
\hline 3 & $\checkmark$ & $\checkmark$ & $\checkmark$ & & & & \\
\hline 4.1 & & & & & & $\checkmark$ & $\checkmark$ \\
\hline 4.2 & & & & & & & $\checkmark$ \\
\hline 4.3 & & & & & & & $\checkmark$ \\
\hline 5.1 & $\checkmark$ & & & & & & \\
\hline 5.2 & $\checkmark$ & & & & & & $\checkmark$ \\
\hline 5.3 & $\checkmark$ & & & & & & $\checkmark$ \\
\hline 6.1 & & & $\checkmark$ & & & $\checkmark$ & \\
\hline 6.2 & & & $\checkmark$ & & & $\checkmark$ & \\
\hline 6.3 & & & $\checkmark$ & & & $\checkmark$ & \\
\hline 6.4 & & & $\checkmark$ & & & $\checkmark$ & \\
\hline 6.5 & & & $\checkmark$ & & & $\checkmark$ & \\
\hline 6.6 & & & $\checkmark$ & & & $\checkmark$ & \\
\hline 6.7 & & & $\checkmark$ & & & $\checkmark$ & \\
\hline 6.8 & & & $\checkmark$ & & & $\checkmark$ & \\
\hline 7.1 & $\checkmark$ & & & & & & \\
\hline 8.1 & & & & & & $\checkmark$ & \\
\hline 8.2 & $\checkmark$ & & & & & $\checkmark$ & \\
\hline 8.3 & $\checkmark$ & & & & & $\checkmark$ & \\
\hline 9.1 & $\checkmark$ & & & $\checkmark$ & & & \\
\hline 9.2 & $\checkmark$ & & & $\checkmark$ & & & \\
\hline 9.3 & $\checkmark$ & & & $\checkmark$ & & & \\
\hline 9.4 & $\checkmark$ & & & $\checkmark$ & & & \\
\hline 10.1 & $\checkmark$ & $\checkmark$ & & & & $\checkmark$ & \\
\hline 10.2 & & $\checkmark$ & & & & & \\
\hline 10.3 & & & & & & $\checkmark$ & \\
\hline 11.1 & & & & & $\checkmark$ & & \\
\hline 11.2 & & & & & $\checkmark$ & & \\
\hline
\end{tabular}




\subsection{Phase 1b: Survey of Young Carers Projects}

Responses were received from 10 (44\%) local authority areas in Wales. There was heterogeneity of geographical spread, urban/rural and socioeconomic profile. There were responses from Projects in all the quintiles of the WIMD Child Index (2011).

All ten who responded were provided originally by Third Sector organisations, two of them managing Projects in two areas. Since the survey started, one of the third sector Projects was taken in-house by a local authority.

\subsubsection{How well developed are the services for young carers? (RQ}

\section{1)}

\section{Staffing.}

Table 18 shows the total of staff employed across ten Projects. Four of the Projects had no full-time staff and volunteers outnumber paid staff in three Projects. Six of the ten Projects had a dedicated manager post.

Table 18

Number of staff and whether any of them are former young carers

Type of staff Total staff employed

No. of former young carers employed

\begin{tabular}{lcc}
\hline Full-time & 7 & 2 \\
\hline Part-time & 32 & 5 \\
\hline Volunteers & 18 & 6 \\
\hline Total & 57 & 13 \\
\hline
\end{tabular}


Combining the data from columns 2 and 3 (Table 18) shows that former young carers made up almost $23 \%$ of all staff (both paid and unpaid) and $17 \%$ of paid staff. In one Project as much as $38 \%$ of all staff were former young carers. Only two Projects had no former young carers among the staff. The majority of staff had some qualifications and a quite high proportion at degree level. The Project worker in one Project was a qualified and experienced social worker.

Table 19

Highest qualification of staff members

\begin{tabular}{lc}
\hline \multicolumn{1}{c}{ Qualifications } & Total \\
\hline No formal qualification & 3 \\
\hline Level 4 (e.g. GCSE level / BTEC L2 / NVQ L3) & 4 \\
\hline $\begin{array}{l}\text { Level } 5 \text { (A level or equivalent / BTEC L3 / NVQ } \\
\text { L3) }\end{array}$ & 9 \\
\hline Level 6 (Graduate level / NVQ L4) & 19 \\
\hline Level 7 (Post-graduate level /NVQ L5) & 7 \\
\hline Total & 42 \\
\hline
\end{tabular}

Assessment process.

All the responding Projects used some form of assessment tool and some used two or more. One Project used two of their own design with each new member, one for the core Project and one for their education Project. Two Projects used MACA and PANOC.

\subsubsection{How much partnership working is there? (RQ 2)}

There is considerable overlap with the responses to RQ 2 and 3 so the findings are taken together (see 7.2.3) 


\subsubsection{How accessible are the services? (RQ 3)}

Sources of referrals.

All 10 Projects operated an open referral system, that is any professional could refer a young person. All accepted self-referrals although one required parental consent and one other offered the option of up-to-date medical evidence about the Cfp. None of the Projects were gender or ethnicity specific. GPs were the poorest source of referrals for the majority of Projects but school nurses appeared to be a comparatively good source.

Table 20

Sources of referrals to YCPS

\begin{tabular}{lccccc}
\hline \multirow{2}{*}{ Source of referrals } & \multicolumn{5}{c}{ Frequency of referrals } \\
\cline { 2 - 6 } & All & Most & Some & None & No data \\
\hline Self-referral & - & - & 7 & 2 & - \\
\hline Adult Social Services & - & - & 5 & 4 & - \\
\hline Ed. Welfare Services & - & - & 9 & - & - \\
\hline Ed. Psych. Services & - & - & 4 & 3 & 2 \\
\hline Add. Ed. Support & - & 1 & 7 & 1 & - \\
\hline G.P. & - & - & 2 & 6 & 1 \\
\hline Health Visitor & - & 1 & 4 & 2 & 2 \\
\hline School Nurse & - & - & 8 & 1 & - \\
\hline $\begin{array}{l}\text { 3rd Sector (not for } \\
\text { profit) organisation }\end{array}$ & - & 2 & 5 & 1 & 1 \\
\hline Private Sector org. & - & 1 & 2 & 3 & 3 \\
\hline YCP & - & - & 6 & 1 & 2 \\
\hline Other & - & 1 & 3 & - & 2 \\
\hline
\end{tabular}

NB: Three respondents gave data about other sources without indicating the amount of referrals. 
Sources specified under the 'Other' category were: other Social Services Depts. including Children's Services (6), Integrated Family Support Services (1), Adult Community Mental Health Teams (2), Child and Adolescent Mental Health Services (2), Foster-carers Independent Support Service (1), other Education Depts. (1), Schools (2), Youth Inclusion and Support Panel (1), from within the charity (1), Children's Hospital Cancer Ward (1) and the person being cared for (1).

Numbers supported.

The number catered for in all ten Projects at any one time totalled 732, varying from 27 in one Project up to 140 in another. However the number catered for in a year totalled 1,221.

Eligibility criteria for YCPS.

There were some variations in operational definition between Projects. Most had an upper age limit of 18 but two had 16 and one had 25. A lower age limit was only mentioned in two and that was eight years. Most had no restrictions on the condition of the Cfp but one focused on Mental Health. Only two specified Impact as a criterion. 
Table 21

Operational definition of "young carer" in Projects

\begin{tabular}{|c|c|c|c|c|}
\hline Pr. & Cfp & $\begin{array}{l}\text { Role sole or } \\
\text { supporting }\end{array}$ & Definition of role & $\begin{array}{l}\text { Level of } \\
\text { care }\end{array}$ \\
\hline 4 & $\begin{array}{l}\text { Parent / } \\
\text { Sibling }\end{array}$ & Both & Responsibility & Adult \\
\hline 9 & - & Not specified & Responsibility & - \\
\hline 11 & - & Both & $\begin{array}{l}\text { Responsibility or } \\
\text { 'Looks after' }\end{array}$ & Adult \\
\hline 14 & - & Both & $\begin{array}{l}\text { Responsibility or } \\
\text { 'provides care' }\end{array}$ & - \\
\hline 15 & Anyone & Not specified & Responsibility & - \\
\hline 16 & $\begin{array}{l}\text { Parent/ } \\
\text { Sibling }\end{array}$ & Supporting & $\begin{array}{l}\text { 'Provides care } \\
\text { for' }\end{array}$ & - \\
\hline 17 & Parent & Not specified & 'caring role' & Significant \\
\hline 22 & $\begin{array}{l}\text { Family } \\
\text { member }\end{array}$ & Not specified & 'Provides care' & - \\
\hline 23 & $\begin{array}{l}\text { Family } \\
\text { member }\end{array}$ & Supporting & 'Helps care for' & - \\
\hline 24 & $\begin{array}{l}\text { Parent/ } \\
\text { Family } \\
\text { member }\end{array}$ & Not specified & 'Cares for' & - \\
\hline
\end{tabular}


Services offered by Projects.

Table 22

Activities offered by each Project

\begin{tabular}{|c|c|c|c|c|c|c|c|c|c|c|c|}
\hline Service & 4 & 9 & 11 & 14 & 15 & 16 & 17 & 22 & 23 & 24 & Total \\
\hline $\begin{array}{l}\text { Social and/or } \\
\text { sporting } \\
\text { activities }\end{array}$ & $\checkmark$ & $\checkmark$ & $\checkmark$ & $\checkmark$ & $\checkmark$ & $\checkmark$ & $\checkmark$ & $\checkmark$ & $\checkmark$ & $\checkmark$ & 10 \\
\hline $\begin{array}{l}\text { Support } \\
\text { group } \\
\text { discussions }\end{array}$ & $\checkmark$ & $\checkmark$ & $\checkmark$ & $\checkmark$ & $\checkmark$ & $\checkmark$ & $\checkmark$ & $\checkmark$ & $\checkmark$ & $\checkmark$ & 10 \\
\hline $\begin{array}{l}\text { Information } \\
\text { and advice } \\
\text { e.g. welfare } \\
\text { claims }\end{array}$ & $\checkmark$ & $\checkmark$ & $\checkmark$ & $\checkmark$ & $\checkmark$ & $\checkmark$ & $\checkmark$ & $\checkmark$ & $\checkmark$ & $\checkmark$ & 10 \\
\hline $\begin{array}{l}\text { Befriending or } \\
\text { mentoring } \\
\text { opportunities }\end{array}$ & - & $\checkmark$ & $\checkmark$ & $\checkmark$ & $\checkmark$ & $\checkmark$ & - & - & $\checkmark$ & - & 6 \\
\hline Advocacy & $\checkmark$ & $\checkmark$ & $\checkmark$ & - & $\checkmark$ & $\checkmark$ & $\checkmark$ & $\checkmark$ & $\checkmark$ & $\checkmark$ & 9 \\
\hline $\begin{array}{l}\text { One-to-one } \\
\text { support }\end{array}$ & $\checkmark$ & $\checkmark$ & $\checkmark$ & $\checkmark$ & $\checkmark$ & $\checkmark$ & $\checkmark$ & $\checkmark$ & $\checkmark$ & $\checkmark$ & 10 \\
\hline Counselling & - & $\checkmark$ & - & - & - & - & - & - & $\checkmark$ & - & 2 \\
\hline $\begin{array}{l}\text { Drop-in } \\
\text { sessions }\end{array}$ & $\checkmark$ & $\checkmark$ & $\checkmark$ & - & $\checkmark$ & - & $\checkmark$ & $\checkmark$ & $\checkmark$ & - & 7 \\
\hline Other & $\checkmark$ & - & $\checkmark$ & - & - & $\checkmark$ & $\checkmark$ & $\checkmark$ & $\checkmark$ & - & 6 \\
\hline
\end{tabular}


Table 23

Details of Other Project activities

\begin{tabular}{|c|c|c|c|c|}
\hline \multicolumn{5}{|c|}{ Project } \\
\hline 4 & Trips out & $\begin{array}{l}\text { School } \\
\text { holiday } \\
\text { activities }\end{array}$ & $\begin{array}{l}\text { Residential } \\
\text { holidays }\end{array}$ & \\
\hline 11 & $\begin{array}{l}\text { Educational } \\
\text { Support }\end{array}$ & $\begin{array}{l}\text { Support with } \\
\text { Appointments }\end{array}$ & Training & \\
\hline 16 & $\begin{array}{l}\text { Referral for } \\
\text { counselling }\end{array}$ & $\begin{array}{l}\text { Buddies } \\
\text { outings }\end{array}$ & & \\
\hline 17 & $\begin{array}{l}\text { Consultation } \\
\text { on Project }\end{array}$ & $\begin{array}{l}\text { Help with } \\
\text { transition }\end{array}$ & $\begin{array}{l}\text { Family } \\
\text { mediation }\end{array}$ & $\begin{array}{l}\text { Family support } \\
\text { incl. parenting } \\
\text { classes }\end{array}$ \\
\hline 22 & Signposting & Training & $\begin{array}{l}\text { Support } \\
\text { with educ., } \\
\text { training + } \\
\text { employ. }\end{array}$ & \\
\hline 23 & Respite & Socialisation & Trips out & $\begin{array}{l}\text { Residential } \\
\text { hols. }\end{array}$ \\
\hline
\end{tabular}

Awareness raising.

All the Projects worked with all three of the listed types of organisation although it was markedly less frequent with Health than with the other two agencies.

Table 24

Frequency of delivery of awareness raising sessions by YCPs to each agency

\begin{tabular}{lccc}
\hline Agencies & Most & Some & None \\
\hline Education/Schools & 7 & 2 & 0 \\
\hline Health & 1 & 8 & 0 \\
\hline Social Services & 7 & 2 & 0 \\
\hline Other & 3 & 3 & 0 \\
\hline
\end{tabular}


Other targets mentioned were sections of Social Services (Substance

Mis-use Services, Multiple Intervention Programme, Team Around the Family), some youth services (Youth Intervention, Youth Inclusion and Support Panel, Youth Offending Service) and third sector organisations including other Young Carer Projects.

However it is unclear whether they all meant the same thing by 'awareness raising. Under 'Other', one Project referred to activities raising awareness of their own Project rather than of the identification of young carers and their issues.

Level of awareness.

This was marked on a scale of 1 to 5,1 being not at all aware. The Projects' perception of the audiences' level of awareness is shown in Table 25. This shows that Social Services scored most highly here. Health alone scored a 1 (no awareness) and was overall a little below Education.

Table 25

Rating of level of awareness of the needs of young carers in agencies who have received awareness training on a scale of 1 to 5, 5 being very aware and 1 having no awareness

\begin{tabular}{lccc}
\hline & \multicolumn{4}{l}{ Number of agencies rated } \\
\cline { 2 - 4 } Scores & Education/Schools & Health & Social Services \\
\hline 1 & 0 & 1 & 0 \\
\hline 2 & 3 & 3 & 0 \\
\hline 3 & 5 & 4 & 5 \\
\hline 4 & 0 & 1 & 2 \\
\hline 5 & 1 & 0 & 2 \\
\hline
\end{tabular}




\section{Funding.}

The main relationship here was, as might be expected, with the local authority. Eight of the Projects received funding from their local authority in amounts varying from $45 \%$ to $100 \%$ of their total income. Only one had no local authority funding at all. Health was a source of funding for only one Project and that for only $6 \%$ of income. Only one Project was receiving significant grant-aid from elsewhere. Fundraising and donations were a potential source of income and one Project raised $40 \%$ of its income this way. Only one did not secure any income by fund-raising. Two respondents did not complete this section.

The global picture emerging from this data is that seven Projects across seven local authorities drew down $£ 413 \mathrm{k}$ from their local authorities. This was supplemented by $£ 40 \mathrm{k}$ from the provider organisations themselves. Income from grant-aid totalled $£ 89 \mathrm{k}$. Fundraising earned $£ 126 \mathrm{k}$. The proportion of funding for these Projects from the local authorities worked out therefore at $61 \%$ supported by $39 \%$ generated by the Projects themselves.

\subsubsection{How do the service providers evaluate their service for young carers? (RQ 4)}

\section{Aims of Project.}

The responses varied from brief definitions to 80 -word descriptions. The most frequent concept mentioned was 'support' which was mentioned ten times. Support fell into four main categories. Practical support in 
managing the caring role was provided in the form of respite, information and advice, advocacy at school. Action to improve quality of life was tackled by providing activities and social opportunities; fun merited two mentions in this context. Emotional support was offered in the form of a listening ear, help with increasing self-confidence and resilience.

Evaluation of success of Project.

All Projects carried out some form of evaluation in-house and most employed more than one method, covering different aspects of evaluation: outcomes for individuals, evaluating the programme and performance management.

Many of the methods of evaluating the Projects depended on the outcomes for individual young carers, relying on reviews, feedback by questionnaire and assessments by staff. Three used evaluation sheets after activities; one used quantitative data on the overall performance of the Project. A consultation evening is run by one Project and another holds a Young Carers AGM and has a Young Carers Committee and one brings in former young carers to contribute to the consultation. Four of the Projects involved parents or families in the review or feedback process.

Specific techniques utilised were exit evaluations, an in-house results-based-accountability card, the MACA and PANOC questionnaires, a 'my life now circle' and a Distance Travelled star system.

Four of the Projects had had an independent evaluation in the last five years; four had not and two did not complete this question. 
'Success' for a young carer.

Responses seemed to fall into two main categories: maintaining the caring role and improvement in outcomes. Firstly, success was seen either as not having caring duties inappropriate for a child or reducing the adverse impact of the caring role or developing coping mechanisms. Secondly, success was expressed by some as personal progress, for example by active involvement in education, training or employment, achieving self-set goals, maintaining a hobby. Other Projects referred to measuring outcomes in quantifiable form, for instance as laid out in a service plan or by the 'Distance travelled' system. One mentioned 'outcomes we considered we wanted for each individual'.

\subsubsection{What do the service providers perceive to be the challenges? (RQ 5)}

Challenges for the service.

By far and away the most frequently mentioned was funding with eleven overt citations, blaming funding cuts, rising costs, unreliability and the effect on activities and staffing. Other concerns about capacity, receiving six mentions, were closely linked to funding. These included inability to deal with the increasing number of cases coming to them, staffing difficulties with low-paid jobs, lack of a service for the over 18s. There were two comments on the changing profile of young carers, one specifying the increasing complexity of need. Other worries were the lack of co-operative working between services, the practical problems of 
working in a rural area and reaching hidden young carers. One respondent expressed concerns about what would happen to the young carers if the Project had to end.

Perceived challenges for young carers.

Aspects of emotional wellbeing topped the list of concerns. These included bullying, stigma, neglect, isolation. Education and their future training and employment opportunities was the second area causing concern. The next most frequently expressed apprehensions were about their social lives, poverty, awareness of young carers' issues and access to services. In one case the latter was linked to rurality. These were followed by issues referred to once or twice: the lack of a service for over $18 \mathrm{~s}$ and access to training useful in their caring role.

7.2.6 What is the relative importance of the Projects in provision for young carers? (RQ 6)

What is the amount and source of current investment in Projects in Wales? (RQ 7)

As for the survey of YCPs, these questions will be dealt with in the discussion section on Phases $1 \mathrm{a}$ and $1 \mathrm{~b}$ (Section 8.2.6 and 8.2.7). 


\subsection{Phase 2: Survey of young carers}

\subsubsection{Profile of sample.}

The responses to the survey are reported and summarised here in order of the questions in the questionnaire.

Where available, comparisons are shown with data for the agematched population and with other studies of young carers. Dearden and Becker's study of 6,178 young carers in 2004 is a major source of data for this purpose. Where no norms are quoted, this is because no appropriate data were found.

There was some variation in the value of $\mathrm{n}$ in each measure due to withdrawals from some measures as illustrated in Table 26. Noncompletion of one component of a composite precluded inclusion in the composite result.

An additional variation in the value of $\mathrm{n}$ occurred where a participants had not complete a particular item in the questionnaire. 
Table 26

Details of variation of number in sample by completion and noncompletion of each measure

\begin{tabular}{lcccccc}
\hline \multirow{2}{*}{ ID } & \multicolumn{7}{c}{ Measures } \\
\cline { 2 - 7 } 2 & R \& S & SS & Questionn. & EAI & ELI & COI \\
\hline 5 & $\checkmark$ & $\checkmark$ & - & - & - & - \\
\hline 13 & - & $\checkmark$ & - & - & - & - \\
\hline 23 & - & $\checkmark$ & $\checkmark$ & - & $\checkmark$ & - \\
\hline 24 & - & $\checkmark$ & $\checkmark$ & - & $\checkmark$ & - \\
\hline 41 & - & $\checkmark$ & $\checkmark$ & - & $\checkmark$ & - \\
\hline 53 & - & $\checkmark$ & - & - & - & - \\
\hline $\begin{array}{l}\text { All other } \\
\text { cases }\end{array}$ & $\checkmark$ & $\checkmark$ & $\checkmark$ & $\checkmark$ & $\checkmark$ & $\checkmark$ \\
$\mathrm{n}$ & $\mathrm{n}=56$ & $\mathrm{n}=62$ & $\mathrm{n}=59$ & $\mathrm{n}=55$ & $\mathrm{n}=59$ & $\mathrm{n}=55$ \\
\hline$\checkmark$ completed measure & $\checkmark$ & $\checkmark$ & - & $\checkmark$ & - \\
- & did not complete measure & & & &
\end{tabular}

\subsubsection{Biographical Data.}

Gender.

There was a balance of male and female participants: 30 male, 32 female. Previous research has tended to find more females than males acting as young carers, for example Dearden and Becker (1995, 1998, 2004).

Age.

All participants were age 11 to 16 at the time of recruitment which was between January and July 2014 . On $31 / 03 / 2014$, their mean age was 13.71 years (SD 1.65). 
Ethnicity.

Only two of the sample in this study (3\%) were not White British. In the population in Wales age 10-15 inclusive, non-whites number nearly $6 \%$ so this is below the level in the general population and falls below the $16 \%$ non-white in the Dearden and Becker 2004 survey $(n=6,178)$.

Types of families.

Table 27 shows the distribution of family types.

Table 27

Distribution of family types $(n=59)$

\begin{tabular}{lcc}
\hline \multicolumn{1}{c}{ Options } & $\mathrm{n}$ & Valid \% \\
\hline 2 parents/step parents and sibling/s & 22 & 37.3 \\
Mother and sibling/s & 22 & 37.3 \\
Mother only & 5 & 8.5 \\
Grandmother only & 3 & 5.1 \\
2 parents/step parents no sibs & 3 & 5.1 \\
Mother and Grandmother and & 2 & 3.4 \\
sibling/s & 1 & 1.7 \\
Two parents and Grandmother & 1 & 1.7 \\
Father, Grandmother + sibling/s. & & \\
\hline
\end{tabular}

The number not living with two parents in this sample constitutes 55\% of the sample. This compares with $23 \%$ of dependent children living in Ione parent families in the general population in England and Wales (ONS, 2014) but close to the $56 \%$ figure in Dearden \& Becker's sample. However analysis of the LSYPE (2013) did not show strong evidence that young carers are more likely to live in lone parent families. 
Step parents.

Of the 59 participants, nine (15\%) lived with a step-parent. This is slightly higher than the $11 \%$ of under $16 \mathrm{~s}$ in England and Wales (ONS, 2014).

Free school meals.

The number receiving free school meals was $42(71.2 \%)$ compared to $15(25.4 \%)$ not receiving free meals. Two other participants may or may not have qualified for FSM since one went home for dinner and another could not eat school dinners because of a digestive condition. In the age matched population in Wales, the percentage of pupils aged $11-16$ in secondary schools who take free school meals is $17 \%$ (WGCYPWM, 2010).

Empathetic adult at home.

Asked whether they have an adult at home with whom they can share their feelings, $48(81.4 \%)$ said Yes and $11(18.6 \%)$ said No. Thirty-five named their mother as the adult and in 21 cases the mother was the only confidante. They named also as confidant their father (9), sister (4), grandmother (4), step-parent (3) and brother (2). 
Quality of family relationship (Famrel)

Table 28

Do family members shout at one another? $(n=57)$

\begin{tabular}{lcc}
\hline Options & $\mathrm{n}$ & Valid \% \\
\hline Never & 9 & 15.8 \\
\hline Some of the time & 35 & 61.4 \\
\hline A lot of the time & 13 & 22.8 \\
\hline
\end{tabular}

The majority of families of the participants ( $84 \%)$ shouted at one another sometimes or often (Table 28 ).

Having their own health condition.

Nearly half the respondents replied that they had a health condition themselves (44\%). Two were not sure. This compares with the figure of $15 \%$ of $11-16$ year olds in the general population in Wales with a long-term illness, a disability or a medically diagnosed condition reported in Health Behaviour in School-aged Profile of Children (WG, 2014).

Table 29

Breakdown of participants' conditions $(n=59)$

\begin{tabular}{lc}
\hline \multicolumn{1}{c}{ Health condition } & Total \\
\hline Having Physical Disability or LLTI & 19 \\
\hline Having Mental health & 2 \\
\hline Having Neuro-developmental condition & 12 \\
\hline Total & 33 \\
\hline
\end{tabular}


Because of multiple conditions, the total in Table 29 adds up to more than the 26 saying that they had their own health condition. Twelve had more than one condition, seven having two conditions and five having three conditions.

\subsubsection{Caring profile.}

A total of 59 of the young carers in this sample cared for 73 family members. Forty-eight ( $81 \%)$ cared for one person, eight (14\%) cared for two people, three $(5 \%)$ cared for three people. One of the three caring for 3 people had been caring for four people till just before the survey. This shows $19 \%$ caring for more than one person which is almost the same as the Dearden \& Becker 2004 sample.

Relationship to the person cared for.

Of the 73 people cared for, 38 mothers formed the largest group (47\%). Eight fathers were cared for (13\%), six grandmothers and 20 siblings. One stepmother was also a Cfp. Eight had responsibilities also for nondisabled siblings. This is not dissimilar to the figures in Dearden and Becker's 2004 survey. 
Quality of relationship with Cfp.

Table 30

How well they get on with the person they are caring for $(n=58)$

\begin{tabular}{lll}
\hline Options & $\mathrm{n}$ & Valid \% \\
\hline Poor & 2 & 3.4 \\
\hline Not very good & 1 & 1.7 \\
\hline Alright & 7 & 12.1 \\
\hline Quite good & 25 & 43.1 \\
\hline Very good & 23 & 39.7
\end{tabular}

Those getting on quite well or very well with the person(s) they cared for represented $82.8 \%$ of the sample.

Condition of person cared for.

Physical disability and limiting long-term illness were grouped as one condition as shown in Table 31.

Table 31

Conditions of people cared for

\begin{tabular}{ll}
\hline Health condition & $\mathrm{n}$ \\
\hline Having one or more PD or LLTIs & 70 \\
\hline Having one or more Mental Health conditions & 14 \\
\hline Having an Addiction issue & 1 \\
\hline Having one or more Learning Disabilities & 11 \\
\hline $\begin{array}{l}\text { Having one or more Neuro-developmental } \\
\text { conditions }\end{array}$ & 7 \\
\hline Others (Ageing) & 2 \\
\hline
\end{tabular}

Forty-four of the people cared for had one condition. Of those with multiple conditions, 20 had two conditions and 9 had three conditions. 
PD/LLTI was the largest group of conditions of the persons cared for and a similar situation had been reported in previous studies.

Predictability of condition.

Table 32

Whether their condition can change at any time without warning

\begin{tabular}{lll}
\hline Values & $\mathrm{n}$ & \% \\
\hline Often & 30 & 41.1 \\
\hline Sometimes & 24 & 32.9 \\
\hline Not often & 11 & 15.1 \\
\hline Not at all & 5 & 6.8 \\
\hline Not sure & 3 & 4.1 \\
\hline
\end{tabular}

The largest proportion of people cared for had conditions that changed without warning often or sometimes. Those that never changed unpredictably were a small number.

Sole, main or supporting carer.

Table 33

Sole, main or supporting carer $(n=59)$

\begin{tabular}{lll}
\hline Status & Carers & Total no. of Cfps \\
\hline Sole carer & 4 & 4 \\
\hline Main carer & 9 & 9 \\
\hline Supporting carer & 41 & 49 \\
\hline Sole and supporting & 1 & 2 \\
\hline Main and supporting & 4 & 9 \\
\hline
\end{tabular}

Being a main carer or sharing care could mean co-operating with any number from one to six other people. For five of the main carers and also 
for the three sole carers, there was no-one older with whom to share the responsibilities.

Regular help.

Table 34

Regular help from outside the family $(n=59)$

\begin{tabular}{lll}
\hline Values & $\mathrm{n}$ & \% \\
\hline No & 25 & 42.4 \\
Yes & 24 & 40.7 \\
Mixed or multiple situation & 2 & 3.4 \\
Don't know & 8 & 13.6 \\
\hline
\end{tabular}

For nearly half, no help was received from external sources. In two of these cases, the respondents said that the family had stopped the service because it was unsatisfactory. For the two in mixed situations, help was forthcoming for one Cfp but not for the other or others. There were some who could not give a clear-cut answer: they did not know or did not know what happened when they were at school.

Duration of caring.

This question often received imprecise answers such as All my life and $A s$ long as I can remember $(\mathrm{n}=6)$. 
Table 35

Duration of caring

\begin{tabular}{lll}
\hline Values & Frequency & $\%$ \\
\cline { 2 - 3 } Can't remember & 6 & 10.2 \\
1-2 years & 3 & 5.1 \\
2-3 years & 18 & 30.5 \\
4-5 years & 11 & 18.6 \\
6-7 years & 7 & 11.9 \\
8 years & 3 & 5.1 \\
10 years & 1 & 1.7 \\
11 years & 3 & 5.1 \\
12 years & 1 & 1.7 \\
"All my life" or & 6 & 10.2 \\
"As long as I can remember" & & 100.0 \\
Total & 59 &
\end{tabular}

The mean was 5.25 years (SD 3.85). The median was 4 and the mode was 3 . The distribution is lighter at the bottom end and heavier at the top end than the Dearden and Becker sample.

Time spent daily on caring activities.

17 young carers could not quantify the time spent because it varied each day or for example between weekday and weekend, the current state of the Cfp or whether others were available to help on that day. 
Table 36

Time spent on caring each day $(n=59)$

\begin{tabular}{lll}
\hline Values & $\mathrm{n}$ & \% \\
\hline Up to one hour & 14 & 23.7 \\
\hline 1-2 hours & 8 & 13.6 \\
\hline 2-3 hours & 7 & 11.9 \\
\hline $4-5$ hours & 6 & 10.2 \\
\hline 5-6 hours & 1 & 1.7 \\
\hline All time available & 6 & 10.2 \\
\hline Varies & 3 & 5.1 \\
\hline Not sure/Don't know & 14 & 23.7 \\
\hline
\end{tabular}

There are more in this sample spending over 20 hours per week than in the Dearden and Becker 2004 sample (18\%). This is more also than in the LSYPE cohort (Woolley, 2013) where $62 \%$ cared for up to five hours per week while only $8 \%$ cared for more than 15 hours per week.

\subsubsection{MACA-YC18 Caring activities.}

Types of caring activity.

Participants were asked how often they carried out each type of activity, scoring two for a lot of the time, one for sometimes and zero for not at all. The six activity scores were then totalled to provide an overall score for each individual. Individual scores were then totalled to give a group score for each activity (see Table 37 ). 
Table 37

Amount of each activity at group level

\begin{tabular}{lc}
\hline Types of tasks & Score \\
\hline Domestic tasks (cleaning, cooking, washing up) & 250 \\
\hline $\begin{array}{l}\text { Emotional care (company, emotional support, } \\
\text { supervision) }\end{array}$ & 215 \\
\hline $\begin{array}{l}\text { Household tasks (shopping, repairs, lifting heavy } \\
\text { objects) }\end{array}$ & 179 \\
\hline Personal care (bathing, toileting, medication) & 71 \\
\hline Sibling care (looking after siblings not cared for) & 64 \\
\hline $\begin{array}{l}\text { Household responsibilities (paying bills, collecting } \\
\text { benefits) }\end{array}$ & 39 \\
\hline Total & 818 \\
\hline
\end{tabular}

At a group level, the most performed activities were domestic tasks and providing company. Personal care accounted for only $9 \%$ of the time spent caring by the group in this sample. The distribution is approximately the same as in Dearden and Becker 2004 except that the order of the amount of domestic tasks and emotional care is reversed.

Level of caring activity.

Individual MACA scores are classified as Low (1-9), Moderate (10-13), High (14-17) and Very high (18<). Approximately $25 \%$ of this sample fell into each of the Low, Moderate, High and Very High categories. The mean for the sample was 13.81 (SD 5.58) which is categorised as Moderate on the MACA scale.

The range of individual scores for the amount of caring activity ran from 6 (Low) to 31, at the top of the Very High category. 


\subsubsection{Outcomes}

Research Aim 2:

To examine the relationships between outcomes and factors which may have contributed to them.

What are the outcomes on the chosen measures? (RQ 8)

\section{EAI.}

Table 38

Reading and Spelling

\begin{tabular}{lclll}
\hline Test & $\mathrm{N}$ & Mean (SD) & Category & $\mathrm{T}$ \\
\hline $\begin{array}{l}\text { Reading BAS } \\
\text { III }\end{array}$ & 56 & $\begin{array}{l}90.80 \\
(14.78)\end{array}$ & $\begin{array}{l}\text { Low } \\
\text { average }\end{array}$ & $4.52 * * *$ \\
\hline $\begin{array}{l}\text { Spelling BAS } \\
\text { III }\end{array}$ & 56 & $\begin{array}{l}86.98 \\
(12.70)\end{array}$ & $\begin{array}{l}\text { Below } \\
\text { average }\end{array}$ & $6.45 * * *$ \\
\hline
\end{tabular}

$* * * p<0.001$

The mean of the young carers was below the average for their age group.

Comparison of group means with norm group for EAI.

Independent t-test analyses were conducted on the results of the Reading and Spelling Standard Scores. As individual participant scores were not available for the norm group, it was necessary to elicit the 'sum of squares' for the norm group. As the mean, standard deviation and number of participants in the norm group was known it was possible to do this and to perform the t-test manually. 
Reading: there is a statistically significant difference in the means. At the group level, young carers performed far less well on the 'reading' measure than their peers at the group level.

Table 39

Statistical comparison of performance of young carers' group with an aged matched general population norm group on Reading.

\begin{tabular}{|c|c|c|c|c|}
\hline Test & Groups & $\mathrm{N}$ & Mean (SD) & $\mathrm{T}$ \\
\hline Reading & Norm group & 1035 & $100(15)$ & $4.52 * *$ \\
\hline \multirow[t]{2}{*}{ BAS III } & & & & \\
\hline & $\begin{array}{l}\text { Young carers } \\
\text { group }\end{array}$ & 55 & $90.8(14.78)$ & \\
\hline
\end{tabular}

Spelling: there is a statistically significant difference in the means. At the group level, young carers performed far less well on the 'spelling' measure than their peers. The mean standard scores for reading and spelling fall below the norm.

Table 40

Statistical comparison of performance of young carers' group with an age matched general population norm group on Spelling.

\begin{tabular}{lllll}
\hline Test & Groups & $\mathrm{N}$ & Mean (SD) & $\mathrm{T}$ \\
\hline $\begin{array}{l}\text { Spelling } \\
\text { BAS III }\end{array}$ & Norm group & 1035 & $100(15)$ & $6.45^{* * *}$ \\
& $\begin{array}{l}\text { Young carers } \\
\text { group }\end{array}$ & 55 & $\begin{array}{c}86.98 \\
(12.7)\end{array}$ & \\
\hline
\end{tabular}

$* * * p<0.001$ 
Performance@school.

The qualitative measures shown in Tables 41 and Figure 5 complement the objective measures of Literacy.

Table 41

Performance at school

\begin{tabular}{llll}
\hline \multirow{2}{*}{ Item } & \multicolumn{3}{l}{ Frequency } \\
\cline { 2 - 4 } & $\begin{array}{l}\text { Never } \\
(\%)\end{array}$ & $\begin{array}{l}\text { Sometimes } \\
(\%)\end{array}$ & $\begin{array}{l}\text { Often } \\
(\%)\end{array}$ \\
\hline $\begin{array}{l}\text { How often are you late } \\
\text { for school because of caring? }\end{array}$ & $40(68)$ & $18(31)$ & $1(2)$ \\
\hline $\begin{array}{l}\text { How often do you miss a day } \\
\text { of school because of caring? }\end{array}$ & $37(63)$ & $19(32)$ & $3(5)$ \\
\hline $\begin{array}{l}\text { How often do you miss out on } \\
\text { homework because of caring? }\end{array}$ & $37(63)$ & $18(31)$ & $4(6)$ \\
\hline
\end{tabular}

Those who were never late, never missed school and never missed completing homework were in the majority. Only a small number missed out often because of caring. This is not incompatible with the results from Dearden and Becker's sample showing $27 \%$ experiencing difficulties in education.

Concentration in school.

The fourth indicator of Performance at school asked whether the respondent worried about the family while they were at school (see Figure 5). This was used as an indicator of their ability to concentrate on school work. The data show that a majority did worry about their families when they were in school and only a quarter said that they did not worry. 
Number worrying while at school

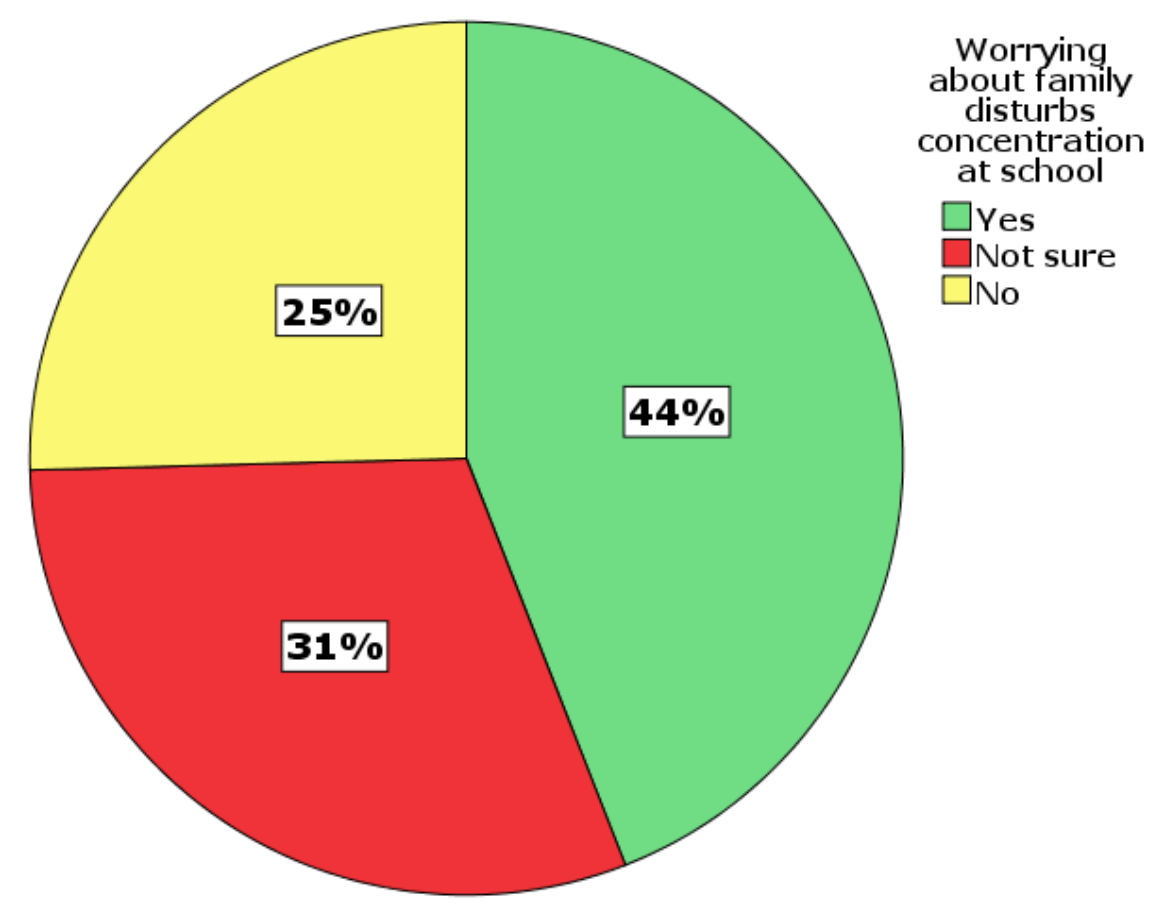

Figure 5: Percentages of those who worried about family while at school

The four separate items in Performance at school were combined to produce an overall score (see Table 42). 
Performance at school composite.

Table 42

Performance at school composite weighted score

\begin{tabular}{lc}
\hline Mean & 55.93 \\
Median & 60.00 \\
Mode & 60.0 \\
Std. Deviation & 15.987 \\
Skewness & -0.739 \\
Std. Error of Skewness & 0.311 \\
Kurtosis & 1.434 \\
Std. Error of Kurtosis & 0.613 \\
Minimum & 0.00 \\
Maximum & 80.00 \\
\hline
\end{tabular}

The high mean, median and mode suggest a fairly positive result at a group level.

The scores for Reading, Spelling and Performance at school were then added together to produce a composite Educational Attainment score (see Table 43). 
EAI Composite.

Table 43

EAI composite weighted score

\begin{tabular}{lr}
\hline Mean & 234.11 \\
Median & 232.00 \\
Mode & 253.00 \\
Std. Deviation & 30.37 \\
Skewness & -0.12 \\
Std. Error of Skewness & 0.32 \\
Kurtosis & 0.90 \\
Std. Error of Kurtosis & 0.63 \\
Minimum & 146.00 \\
Maximum & 309.00 \\
\hline
\end{tabular}

The most frequent score for the EAI is higher than the mean and the median.

\section{ELI.}

SEMERC.

Table 44

Group SEMERC scores

\begin{tabular}{llll}
\hline Test & Groups & $\mathrm{N}$ & Mean (SD) \\
\hline Emotional & Young carers & & \\
Literacy: & group & 62 & $70.23(9.83)$ \\
ELAII & & & \\
\hline
\end{tabular}

Independent t-test analyses were conducted on the results of the SEMERC test to determine the participants' mean score difference from the general population mean. There is a statistically significant difference 
in the means. At the group level, young carers rate their emotional literacy less positively than their peers rate their own emotional literacy (Table 45).

Table 45

Statistical comparison of performance of young carers' group with an age matched general population norm group on ELI

\begin{tabular}{l|l|l|l|l}
\hline Test & Groups & $\mathrm{N}$ & Mean (SD) & $\mathrm{t}$ \\
\hline $\begin{array}{l}\text { Emotional } \\
\text { Literacy: }\end{array}$ & Norm group & 1697 & $74.60(9.6)$ & $3.59 * * *$ \\
\hline ELAII & $\begin{array}{c}\text { Young carers } \\
\text { group }\end{array}$ & 62 & $70.23(9.83)$ & \\
\hline
\end{tabular}

$* * * p<0.001$ 
Feelings as a result of caring.

The results of qualitative measures shown in Table 46 and Figure 6 complement the objective measure of Emotional Literacy.

Table 46

Feelings as a result of caring

\begin{tabular}{llcc}
\hline Variable & Values & & \\
\hline Feelings because of caring & $\begin{array}{c}\text { Not at } \\
\text { all }(\%)\end{array}$ & $\begin{array}{c}\text { Some of } \\
\text { the time } \\
(\%)\end{array}$ & $\begin{array}{c}\text { A lot of } \\
\text { the time } \\
(\%)\end{array}$ \\
\hline $\begin{array}{l}\text { Pleased that you are helping } \\
\text { someone in your family? }\end{array}$ & $0(0)$ & $23(39)$ & $36(61)$ \\
\hline $\begin{array}{l}\text { Feeling that you are } \\
\text { good at managing things? }\end{array}$ & $5(9)$ & $28(48)$ & $26(44)$ \\
\hline Stressed? & $14(24)$ & $31(53)$ & $14(24)$ \\
\hline Tired? & $15(25)$ & $26(44)$ & $18(31)$ \\
\hline Alone? & $38(65)$ & $12(20)$ & $9(15)$ \\
\hline
\end{tabular}

All of the respondents reported that they felt pleased at helping a family member some of the time or a lot of the time. 


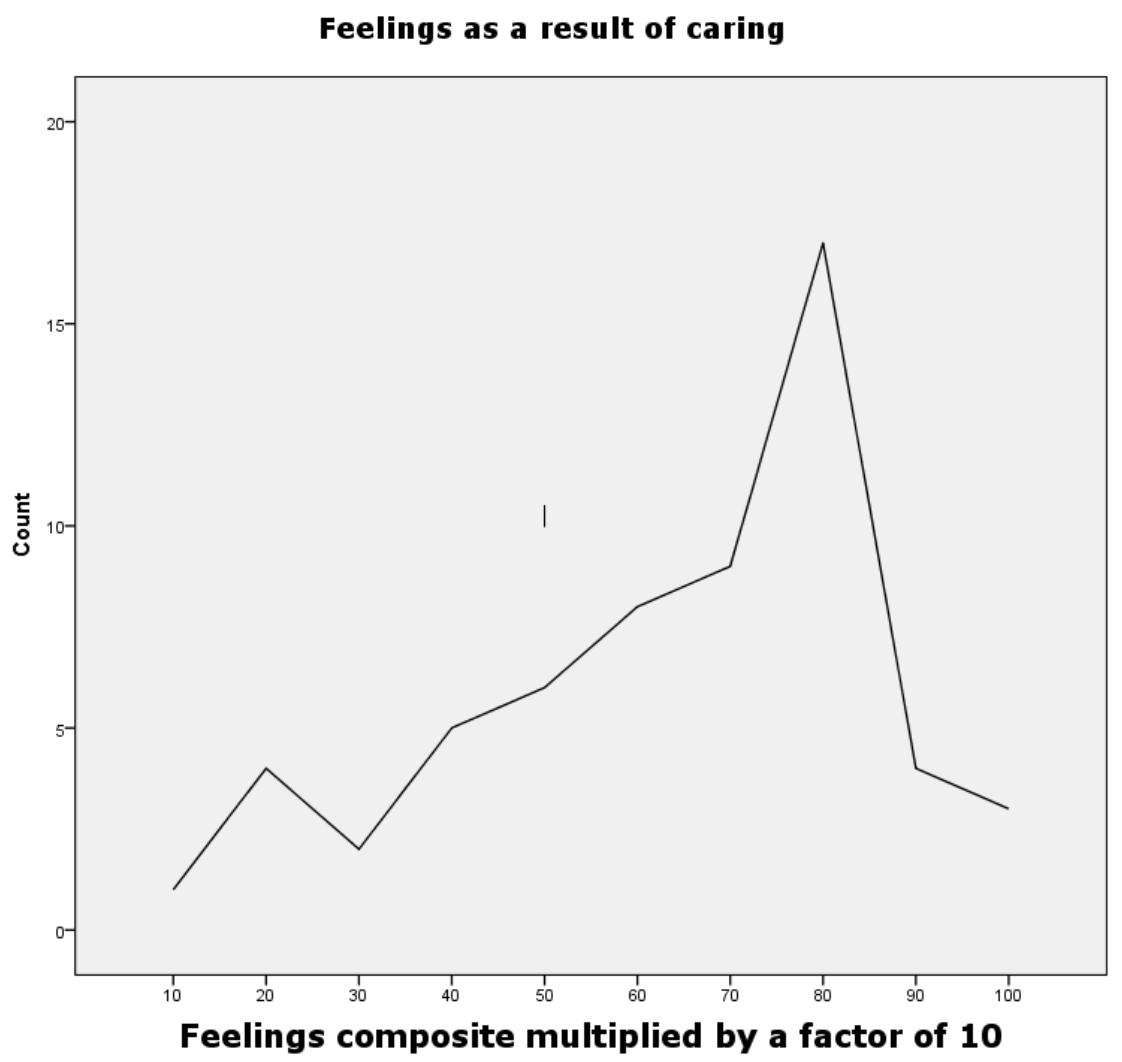

Figure 6. Composite of scores of sample on five indicators for Feelings

Figure 6 illustrates the negative skew in this variable.

The scores for SEMERC and Feelings as a result of caring were then added together to produce a composite Emotional Literacy Index (see Table 47). 
ELI composite.

Table 47

ELI composite

\begin{tabular}{lc}
\hline Mean & 134.22 \\
Median & 141.00 \\
Mode & $153^{\mathrm{a}}$ \\
Std. Deviation & 28.52 \\
Minimum & 60 \\
Maximum & 187 \\
\hline
\end{tabular}

a. Multiple modes exist. The smallest value is shown

Similarly to Educational Attainment, the most frequent score for Emotional Literacy is higher than the mean and the Median.

HI

Five indicators were used as self-report measures of outcomes for Health: self-assessment of health, experiencing minor complaints, dental checks, sight checks and smoking.

Self-assessment.

The most common response was fairly healthy $(36=61 \%)$. Fifteen $(25 \%)$ judged themselves very healthy, $7(12 \%)$ not very healthy and one was not sure. 
Minor complaints.

Table 48

Experiencing minor complaints

\begin{tabular}{l|l|c|c|c}
\hline \multicolumn{2}{l|}{} & \multicolumn{2}{|l|}{ Gender } & \multirow{2}{*}{ Total } \\
\cline { 3 - 4 } \multicolumn{2}{l|}{} & Female & Male & \\
\hline $\begin{array}{l}\text { Health indicator } \\
- \\
\begin{array}{l}\text { how often they } \\
\text { experience }\end{array}\end{array}$ & $\begin{array}{l}\text { A lot of the } \\
\text { time }\end{array}$ & 11 & 3 & 14 \\
\cline { 2 - 5 } $\begin{array}{l}\text { complaints } \\
\text { come of the }\end{array}$ & $\begin{array}{l}\text { Some } \\
\text { time }\end{array}$ & 16 & 18 & 34 \\
\cline { 2 - 5 } & Not at all & 3 & 8 & 11 \\
\hline \multicolumn{2}{l}{ Totals } & 30 & 29 & 59 \\
\hline
\end{tabular}

Females experienced minor complaints more than males. An independent sample t-test of difference in experiencing minor complaints according to gender showed a statistically significant difference $(t=-2.714 ; \mathrm{p}=$ $.009)$.

Dental and sight checks.

Table 49

Dental and sight checks

\begin{tabular}{lcccccc}
\hline Item & \multicolumn{6}{l}{ Frequency } \\
\cline { 2 - 7 } & $\begin{array}{l}\text { This } \\
\text { school } \\
\text { year }\end{array}$ & $\begin{array}{l}\text { Last } \\
\text { school } \\
\text { year }\end{array}$ & $\begin{array}{l}2 \text { or } \\
\text { more } \\
\text { years } \\
\text { ago }\end{array}$ & $\begin{array}{l}\text { Can't } \\
\text { reme } \\
\text { mber }\end{array}$ & Never & Total \\
\hline Last dental check & 29 & 12 & 3 & 15 & 0 & 59 \\
\hline Last sight check & 20 & 26 & 1 & 8 & 4 & 59 \\
\hline
\end{tabular}

$25 \%$ had not attended or could not remember attending dental checks.

$20 \%$ had not attended or could not remember attending sight checks. 
Smoking.

Six of the $59(10 \%)$ respondents said that they smoke cigarettes. This compares with $5 \%$ average amongst $11-16$ year olds in Wales although that rises to $9 \%$ amongst 16 year olds. All those answering Yes in this sample were either 15 or 16 at the date of the interview.

HI Composite.

Table 50

HI Composite weighted score

\begin{tabular}{lc}
\hline & Health Composite multiplied \\
\hline Mean & 96.95 \\
Median & 100.00 \\
Mode & $110^{\mathrm{a}}$ \\
Std. Deviation & 22.07 \\
Minimum & 60 \\
Maximum & 130 \\
\hline
\end{tabular}

a. Multiple modes exist. The smallest value is shown

The most frequent score (110) was higher than the mean and the median.

\section{SCI}

Within the domain of Social Capital, four categories were identified: AOS (activities outside school hours), PR (peer relationships), CPG (coping), ASP (aspirations). Each had a number of indicators (see Figure 4). 
AOS.

Table 51

Group activities outside school hours at a group level

\begin{tabular}{lccc}
\multicolumn{1}{c}{ Activity } & Not at all & Sometimes & Often \\
\hline Sports & 32 & 6 & 21 \\
\hline Dance & 52 & 2 & 5 \\
\hline Music & 46 & 4 & 9 \\
\hline $\begin{array}{l}\text { Specific subject } \\
\text { clubs }\end{array}$ & 44 & 6 & 9 \\
\hline Uniform groups & 47 & 2 & 10 \\
\hline Youth clubs* & 7 & 12 & 40 \\
\hline Discos/gigs & 42 & 14 & 3 \\
\hline
\end{tabular}

* Young Carer clubs were included in this category but where another Youth Club was also attended this was credited as an additional group activity.

In group activities, taking part in a sport was the most frequent.

Fourteen participants (24\%) pursued more than one group sporting activity.

One person scored zero for group activities and for 10 other respondents $(17 \%)$ the only score was for attending the YCP.

Table 52

Individual activities outside school hours at a group level

\begin{tabular}{lccc}
\hline \multicolumn{1}{c}{ Activity } & Not at all & Sometimes & Often \\
\hline Sports/exercise & 26 & 14 & 19 \\
\hline Music/arts & 29 & 6 & 24 \\
\hline $\begin{array}{l}\text { Computer } \\
\text { games }\end{array}$ & 15 & 10 & 34 \\
\hline
\end{tabular}


Table 53

Played computer games in the last term

\begin{tabular}{lcccc}
\hline \multicolumn{1}{c}{ Gender } & Not at all & Sometimes & Often & Total \\
\hline Female & 13 & 8 & 9 & 30 \\
\hline Male & 2 & 2 & 25 & 29 \\
\hline
\end{tabular}

In individual activities, computer games including video games was the most popular individual activity. More males than females played computer and video games more often. An independent sample t-test showed that this was a statistically significant difference $(t=-4.89, p=$ $.000)$. Arts activities were the least popular individual activity at a group level although six reported playing instruments as an activity and eight creative activities. Two people scored zero for individual activities and six people pursued only one activity only some of the time.

Table 54

Use of public facilities

\begin{tabular}{lccc}
\hline \multicolumn{1}{c}{ Public facility } & Not at all & Sometimes & Often \\
\hline Public library & 36 & 13 & 10 \\
\hline Pool/Leisure Centre & 30 & 12 & 17 \\
\hline Comm. Centre & 45 & 7 & 7 \\
\hline Religious activity & 54 & 1 & 4 \\
\hline Cinema & 19 & 34 & 6 \\
\hline
\end{tabular}

In the use of public facilities, the largest group were those who went to the cinema sometimes or often. The least frequent activities were 
attending a religious event or an activity in a Community Centre. A number of the interviewees asked what a community centre was. Eleven people scored zero for use of public facilities and nine visited only one public facility only sometimes.

Paid and unpaid work.

The number who had done paid work was 19 and the same number but not the same people had done unpaid or voluntary work. Twenty-seven people had done neither paid nor unpaid work while six had done both.

Table 55

Composite scores at group level for each type of social activity

\begin{tabular}{lcccc}
\hline & $\begin{array}{l}\text { Group } \\
\text { activities }\end{array}$ & $\begin{array}{l}\text { Individual } \\
\text { activities }\end{array}$ & $\begin{array}{l}\text { Use of } \\
\text { public } \\
\text { facilities }\end{array}$ & $\begin{array}{l}\text { All social } \\
\text { activities }\end{array}$ \\
\hline Mean & 4.37 & 3.32 & 2.63 & 11.61 \\
\hline Median & 4.00 & 3.00 & 3.00 & 12.00 \\
\hline Mode & 3.00 & 3.00 & 3.00 & 7.00 \\
\hline SD & 2.22 & 1.65 & 1.99 & 5.16 \\
\hline Minimum & 0 & 0 & 0.00 & 3.00 \\
\hline Maximum & 10 & 7 & 7 & 23.00 \\
\hline
\end{tabular}

Overall for the sample as a whole most of the social activities took place in groups. 
Peer group relationships.

Table 56

Friendships

\begin{tabular}{lcc}
\hline Response & $\begin{array}{c}\text { Friend to share } \\
\text { feelings with }\end{array}$ & $\begin{array}{c}\text { Uses social } \\
\text { networking sites }\end{array}$ \\
\hline No & 11 & 12 \\
\hline Yes & 46 & 46 \\
\hline Not sure & 2 & 1 \\
\hline
\end{tabular}

Approximately $20 \%$ did not have a friend with whom they could share their feelings.

Table 57

Free time spent with friends

\begin{tabular}{lcc}
\hline & $\mathrm{N}$ & $\mathbf{\%}$ \\
\hline In the last $1 / 2$ weeks & 39 & 66.1 \\
\hline Last month & 9 & 15.3 \\
\hline Last year & 3 & 5.1 \\
\hline Can't remember & 6 & 10.2 \\
\hline Not at all & 2 & 3.4 \\
\hline
\end{tabular}

The majority had been able to spend free time outside school with friends but for a significant number this did not happen often or did not happen at all. 
Looking after appearance.

Table 58

Time to look after appearance

\begin{tabular}{ll}
\hline Responses & Number (\%) \\
\hline No & $11(18.6)$ \\
\hline Yes & $36(61.0)$ \\
\hline Not interested & $12(20.3)$ \\
\hline
\end{tabular}

When asked whether they had time to look after their appearance, 37

said Yes, 10 said No and 12 said Not interested. Three of those who said they did have time added that they got up early or stayed up late to make time.

PR composite.

Table 59

Peer relationships composite

\begin{tabular}{ll}
\hline Mean & 6.97 \\
Median & 7.00 \\
Mode & 9.00 \\
Std. Deviation & 2.11 \\
Range & 7.00 \\
Minimum & 2.00 \\
Maximum & 9.00 \\
\hline
\end{tabular}

In the composite score for peer relationships, the mode (40) was higher than the median and $20(32 \%)$ had the maximum score of 40 . 
Coping.

The lowest scores in coping mechanisms acquired appeared to be in the two areas of training to help with caring and advice on entitlements.

Table 60

Results on coping indicators

\begin{tabular}{lccc}
\hline Responses & $\begin{array}{c}\text { Knows where to go } \\
\text { for advice and } \\
\text { information (\%) }\end{array}$ & $\begin{array}{c}\text { Has had training } \\
\text { to help with } \\
\text { caring (\%) }\end{array}$ & $\begin{array}{c}\text { Has had advice on } \\
\text { entitlements (\%) }\end{array}$ \\
\cline { 2 - 4 } & $\mathrm{N}$ & $\mathrm{N}$ & $\mathrm{N}$ \\
\hline No & $8(14)$ & $40(68)$ & $34(58)$ \\
\hline Yes & $41(69)$ & $19(32)$ & $25(42)$ \\
\hline Not sure & $10(17)$ & & \\
\hline
\end{tabular}

Four of those who did receive training relevant to caring, for example first aid, had received it at school or in other leisure activities rather than at the Project.

Using the Internet for information.

Excluding video games, this appeared to be one area with the most positive responses although there was a small number of adverse replies and one person was not able to access the Internet at home.

Table 61

Has used Internet to look for information

\begin{tabular}{lcc}
\hline & $\mathrm{n}$ & $\%$ \\
\hline In the last week & 39 & 66 \\
\hline Last month & 7 & 12 \\
\hline Last year & 4 & 7 \\
\hline Never & 8 & 14 \\
\hline No PC or no signal at home & 1 & 2 \\
\hline
\end{tabular}


Composite for Coping.

The composite scores for Coping showed a considerable spread.

Table 62

Composite scores for Coping

\begin{tabular}{lc}
\hline Mean & 5.34 \\
\hline Median & 5.00 \\
\hline Mode & $5.00^{\mathrm{a}}$ \\
\hline Std. Deviation & 2.24 \\
\hline Minimum & 1.00 \\
\hline Maximum & 9.00 \\
\hline
\end{tabular}

a. Multiple modes exist. The smallest value is shown

Aspirations.

In analysing the responses, it became apparent that the options offered were not clear alternatives. Firstly the researcher was told that work experience is now often a part of the school curriculum in years 10 and 11 and this was not necessarily a choice made by the student so this was omitted from the scoring. Secondly the choice between leaving or staying at home was also not clear and several participants answered yes to both because, as they explained, they intended to leave home but only when they left for education or career or when the caring situation allowed it to happen so again this was omitted from the scoring. Thirdly, where applying for a training course was the only positive response unlinked to employment, apprenticeship, further or higher education, it was decided to score Training on its own as zero. 
For 35 of the 41 intending to look for a job, this was combined with intending to study at College or University.

Table 63

What they would like to do after leaving school

\begin{tabular}{lccc}
\hline \multicolumn{1}{c}{ Option } & Yes & No & Don't know \\
\hline Look for a job & 40 & 8 & 11 \\
\hline $\begin{array}{l}\text { Study at College or 6th } \\
\text { form }\end{array}$ & 46 & 8 & 5 \\
\hline Get an apprenticeship & 22 & 25 & 12 \\
\hline Go to University & 32 & 16 & 11 \\
\hline Training course & 28 & 12 & 19 \\
\hline Travel & 32 & 17 & 10 \\
\hline Specific ambition & 33 & 12 & 14 \\
\hline
\end{tabular}

Table 64

Composite for Aspirations

\begin{tabular}{lc}
\hline Mean & 9.25 \\
Median & 10.00 \\
Mode & 10.00 \\
Std. Deviation & 2.81 \\
Minimum & 2.00 \\
Maximum & 14 \\
\hline
\end{tabular}

Social Capital composite.

The scores for all four sub-scales were collated to show composite scores for Social Capital: 
Table 65

Scores at group-level for each sub-scale of Social Capital

\begin{tabular}{llllll}
\hline \multicolumn{1}{c}{ Index } & \multicolumn{2}{l}{ Frequency } & & \\
\hline Sub-scale & Min & Max. & Mode & Mean & SD \\
\hline All social activities & 3 & 23 & 7 & 11.61 & 5.16 \\
\hline $\begin{array}{l}\text { Peer group } \\
\text { relations }\end{array}$ & 2 & 9 & 9 & 6.97 & 2.11 \\
\hline Coping & 1 & 9 & 5 & 5.34 & 2.24 \\
\hline Aspirations & 2 & 14 & 10 & 9.25 & 2.81 \\
\hline Social Capital & 48 & 141 & 99 & 99.51 & 25.11 \\
\hline
\end{tabular}

There were a number however with low scores in one or some of the sub-scales: for example 12 scored three or less out of a possible nine on the composite Coping indicator.

\section{COI}

The scores for the four key outcome indices were totalled to provide a Composite Outcome Index (see Table 66).

Table 66

Composite of EAI, ELI, HI and SCI

\begin{tabular}{lc}
\hline Mean & 566.07 \\
Median & 564.00 \\
Mode & $455.00^{\mathrm{a}}$ \\
Std. Deviation & 67.92 \\
Minimum & 39.00 \\
Maximum & 71.00 \\
\hline
\end{tabular}

a. Multiple modes exist. The smallest value is shown 


\subsubsection{Tests of association}

For the tests of association between outcomes (RQs 9, 10, 11 and 12), the scores were all converted to z-scores, to facilitate procedures for testing data with different metrics.

The relationships between outcomes were then investigated using Pearson product-moment correlation co-efficient. The measures tested were the four main outcome indices and their components: EAI (including R, S and PS), ELI (including SS and F), HI and SCI (including AOS, $P R, C P G$ and ASP). The $p$ and $r$ values of all associations are shown in Table 67. 
Table 67

Correlations between outcome indices

\begin{tabular}{|c|c|c|c|c|c|c|c|c|}
\hline $\begin{array}{l}\text { Outcome } \\
\text { indices }\end{array}$ & EAI & $\mathbf{R}$ & $\mathbf{S}$ & PS & ELI & SS & $\mathbf{F}$ & HI \\
\hline \multicolumn{9}{|l|}{ EAI } \\
\hline \multicolumn{9}{|l|}{$\mathbf{R}$} \\
\hline \multicolumn{9}{|l|}{$\mathbf{S}$} \\
\hline \multicolumn{9}{|l|}{ PS } \\
\hline ELI & - & - & - & $\begin{array}{l}.44 \\
.000 \\
(59) \\
\end{array}$ & & & & \\
\hline SS & $\begin{array}{l}.23 \\
.092 \\
(59) \\
\end{array}$ & - & - & $\begin{array}{l}.23 \\
.079 \\
(59)\end{array}$ & & & & \\
\hline $\mathbf{F}$ & - & $\begin{array}{l}-.23 \\
.093 \\
(55)\end{array}$ & $\begin{array}{l}-.26 \\
.059 \\
(55)\end{array}$ & $\begin{array}{l}.47 \\
.000 \\
(59)\end{array}$ & & & & \\
\hline HI & - & - & - & $\begin{array}{l}.32 \\
.015 \\
(59)\end{array}$ & $\begin{array}{l}.31 \\
.018 \\
(59)\end{array}$ & $\begin{array}{l}.28 \\
.031 \\
(59)\end{array}$ & $\begin{array}{l}.27 \\
.037 \\
(59)\end{array}$ & \\
\hline SCI & - & - & - & - & $\begin{array}{l}.23 \\
.079 \\
(59)\end{array}$ & $\begin{array}{l}.29 \\
.025 \\
(59)\end{array}$ & $\begin{array}{l}.23 \\
.079 \\
(59)\end{array}$ & $\begin{array}{l}.26 \\
.050 \\
(59)\end{array}$ \\
\hline AOS & - & - & - & - & - & $\begin{array}{l}.24 \\
.067 \\
(59)\end{array}$ & - & - \\
\hline PR & - & - & - & - & $\begin{array}{l}.25 \\
.057 \\
(59) \\
\end{array}$ & $\begin{array}{l}.24 \\
.074 \\
(59) \\
\end{array}$ & $\begin{array}{l}.217 \\
.098 \\
(59) \\
\end{array}$ & - \\
\hline CPG & - & - & - & - & - & - & - & - \\
\hline ASP & - & - & - & - & - & $\begin{array}{l}.24 \\
.071 \\
(59)\end{array}$ & - & $\begin{array}{l}.28 \\
.034 \\
(59)\end{array}$ \\
\hline
\end{tabular}




\section{Is there any association between Educational Attainment and} other outcomes? (RQ 9)

There were no statistically significant correlations either adverse or positive between EAI and any of the other three main outcomes or their sub-scales although there was a trend towards a correlation between EAI and SS $(r=.23, n=59, p=.092)$. There were no statistically significant correlations between the components $\mathrm{R}$ and $\mathrm{S}$ and any of the other outcomes or their sub-scales although there were trends towards adverse correlations between $R$ and $F(r=-.23, n=55, p=.093)$ and between $\mathrm{S}$ and $\mathrm{F}(r=-.26, n=55, p=.059)$ with lower scores on Reading and Spelling associated with higher scores on Feelings resulting from caring.

However there were strong positive correlations between PS and ELI ( $r$ $=.44, n=59, p=.00)$, with $\mathrm{HI}(r=.32, n=59, p=.015)$ and with $\mathrm{F}(r$ $=.47, n=59, p=.00)$ and a trend towards correlation with SS $(r=.23$, $n=59, p=.079)$. This shows better Performance at school to be associated with higher levels of Emotional Literacy, better Health outcomes and higher scores on Feelings resulting from caring.

\section{Is there any association between Emotional Literacy and other outcomes? (RQ 10)}

As described under RQ 9, ELI showed a positive correlation with PS (see Table 67). There was also a positive correlation with $\mathrm{HI}(r=.31, \mathrm{n}=59$, 
$\mathrm{p}=.018$ ) with higher levels of Emotional Literacy associated with better Health outcomes.

Trends towards correlations were observed with SCI $(r=.23, n=59$, $\mathrm{p}=.079)$ and $\mathrm{PR}(\mathrm{r}=.25, \mathrm{n}=59, \mathrm{p}=.057)$ with higher levels of Emotional Literacy associated with higher scores for Social Capital outcomes and higher scores for Peer Relationships but not at statistically significant levels.

In the sub-scales of ELI, there was a positive correlation of statistical significance between SS and HI $(r=.28, n=59, p=.031)$, with higher scores in SEMERC scores associated with higher scores for Health outcomes. There was also a positive correlation between SS and SCI ( $r$ $=.29, n=59, p=.025)$ with higher scores for SS associated with higher scores for SCI outcomes.

There were positive correlations although not at a statistically significant level between SS and the three sub-scales of SCI: AOS ( $r=$ $.24, n=59, p=.067), \operatorname{PR}(r=.24, n=59, p=.074)$ and $\operatorname{ASP}(r=.24$, $n=59, p=.071$ ) with higher scores for SS associated with higher scores for those three components of Social Capital.

There were positive correlations of statistical significance between $\mathrm{F}$ and $\mathrm{HI}(r=.27, n=59, p=.037)$, with higher scores for feelings resulting from caring associated with higher scores for Health outcomes. There was a trend towards correlation between $\mathrm{F}$ and SCI $(r=.23, n=$ $59, p=.079)$ with higher scores for Feelings associated with higher scores for Social Capital. 
There were positive correlations of statistical significance between HI and SCI $(r=.26, n=59, p=.05)$, with higher scores for Health outcomes associated with higher scores for Social Capital, and between $\mathrm{HI}$ and the sub-scale ASP $(r=.28, n=59, p=.034)$, with higher scores for Health outcomes associated with higher scores for Aspirations.

\section{Is there any significant statistical evidence of an association} between outcomes and any factor in the biographical and caring data? (RQ 11)

Pearson product-moment correlation co-efficient and Spearman's rho were used to test for associations between the outcomes and factors in the biographical and caring profiles. The results are shown in Tables 67, 68 and 69.

Biographical factors.

Correlations between outcomes and biographical factors are shown in Table 68. 
Table 68

Pearson correlations between outcome indices and biographical factors

\begin{tabular}{llll}
\hline Variable & Outcome & Rho & $\mathrm{p}$ \\
\hline Having their own health condition & ELI & -.40 & .00 \\
& $\mathrm{~F}$ & -.42 & .00 \\
\hline Type of health condition & EAI & -.54 & .01 \\
& $\mathrm{~S}$ & -.46 & .02 \\
\hline Quality of family relationships & ELI & -.41 & .00 \\
& $\mathrm{SS}$ & -.32 & .02 \\
& $\mathrm{~F}$ & -.38 & .00 \\
& $\mathrm{COI}$ & -.33 & .02 \\
\cline { 2 - 4 } Empathetic adult at home & ELI & .28 & .03 \\
& $\mathrm{SS}$ & .30 & .02 \\
& $\mathrm{AOS}$ & .27 & .04 \\
\hline No. of occupants at home & CPG & -.32 & .01 \\
\hline
\end{tabular}

The biographical factor showing the strongest and most numerous correlations is the quality of family relationships which also has a correlation with COI. The factor with the second most numerous correlations is having an empathetic adult at home. 


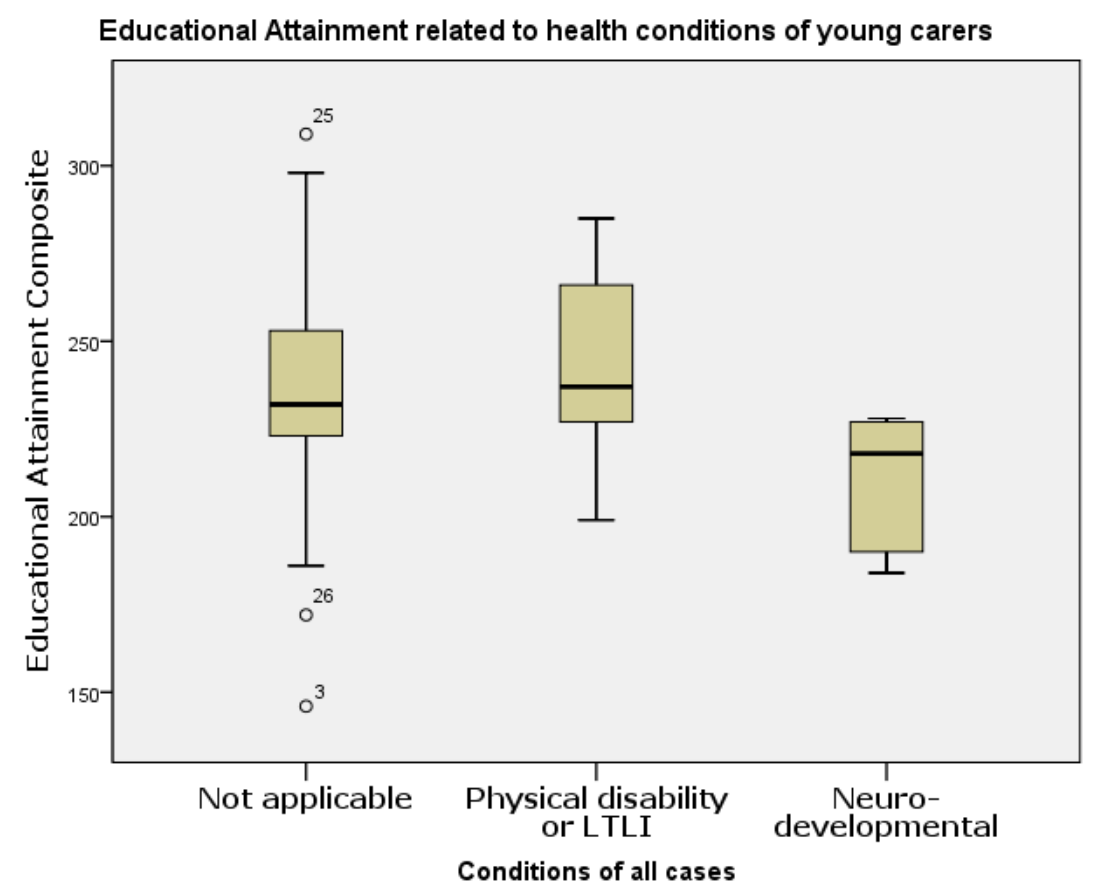

Figure 7. Correlation of Educational Attainment with health conditions of young carers in this sample

There do not appear to be any biographical factors which are correlated at a statistically significant level with either $\mathrm{HI}$ or SCI although there are some correlations with the sub-scales AOS and CPG.

It is worth noting that the biographical factors which appeared to have no correlations with any outcome in this sample were gender, living in a single parent family, living with step parents and having free school meals. 
Caring profile.

Table 69

Correlations of caring factors with outcome indices

\begin{tabular}{llll}
\hline Variable & Outcome & Rho & $\mathrm{p}$ \\
\hline Time spent & ELI & -.40 & .01 \\
& $\mathrm{~F}$ & -.43 & .01 \\
\hline Duration & EAI & .34 & .02 \\
& $\mathrm{R}$ & .40 & .00 \\
& $\mathrm{~S}$ & .40 & .00 \\
& ELI & -.25 & .07 \\
\hline Getting regular help & EAI & -.38 & .01 \\
\hline Number of Cfps & ELI & -.29 & .02 \\
& $\mathrm{~F}$ & -.30 & .02 \\
\hline Condition of Cfp & HI & -.26 & .05 \\
\hline Sole, main or supporting & PSI & -.27 & .04 \\
carer & CPG & -.30 & .02 \\
\hline No. of people sharing care & HI & .28 & .03 \\
\hline Older people sharing care & HI & .28 & .03 \\
\hline
\end{tabular}

The length of time spent caring each day and the duration of caring are correlated adversely with outcomes in ELI and its sub-scales. Where the condition of the Cfp is Learning Disability or Neurodevelopmental, there is an adverse correlation between the condition of the Cfp and outcomes in ELI and CPG (see Figure 8). 
There is also a correlation between the number of Cfps and outcomes in $\mathrm{HI}$.

Effect of health condition of Cfp on coping ability

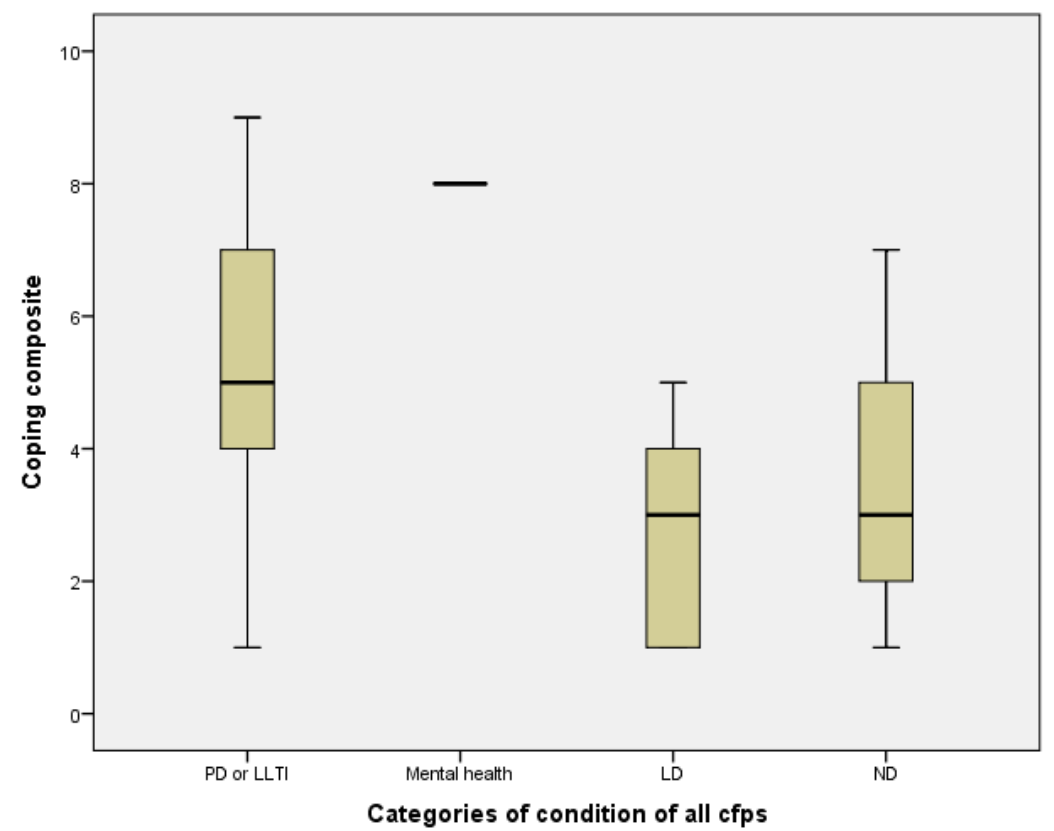

Figure 8. Scores for Coping according to the health condition of the Cfp

Duration of caring is positively correlated with outcomes in EAI, R and $\mathrm{S}$ and getting regular help is adversely correlated with outcomes in EAI.

The status of the young carer, sole, main or supporting, is correlated with PS (see Figure 9). 
Effect of carer status on Performance at School

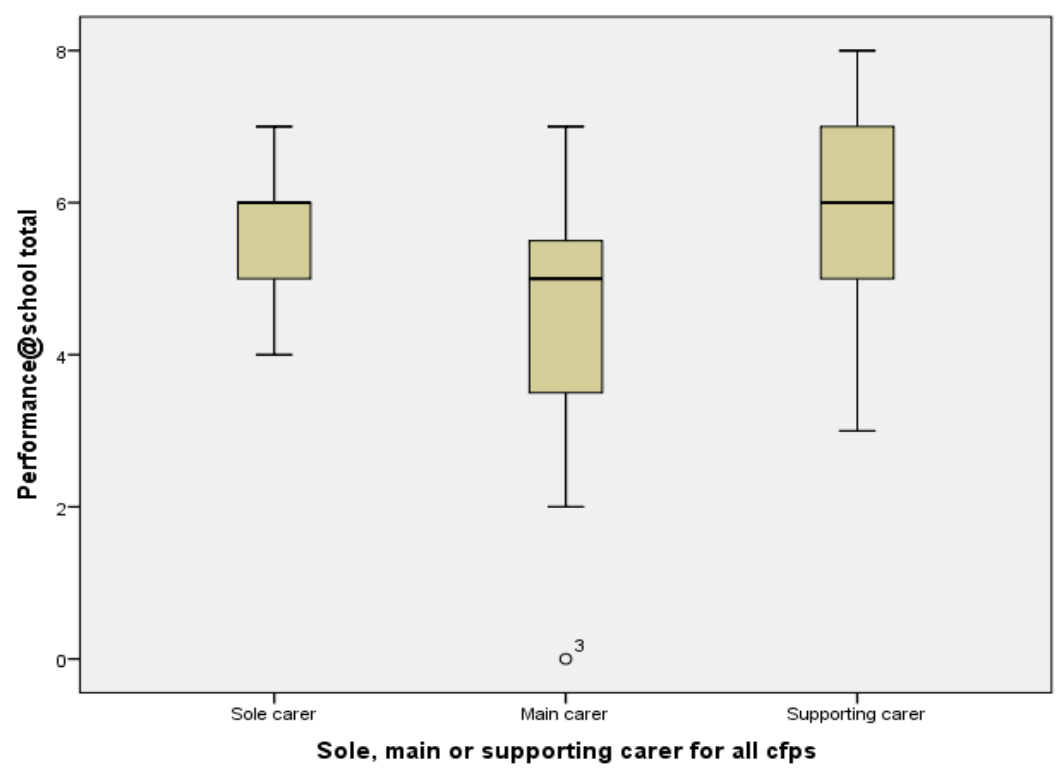

Figure 9. Scores for Performance at School according to status as sole, main or supporting carer

Other people sharing the caring and sharing with older people are factors correlated with positive outcomes for HI (see Figs. 10 and 11).

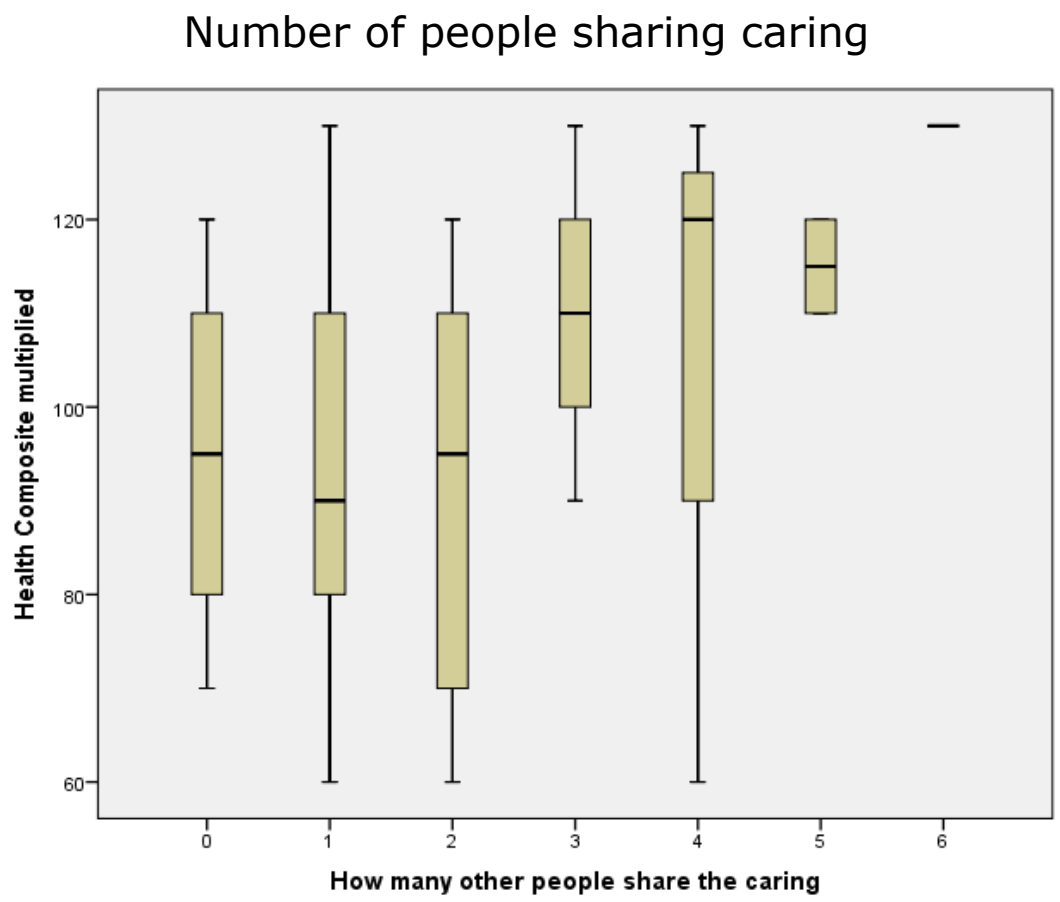

Figure 10. Number of people sharing caring 
Number of older people sharing caring

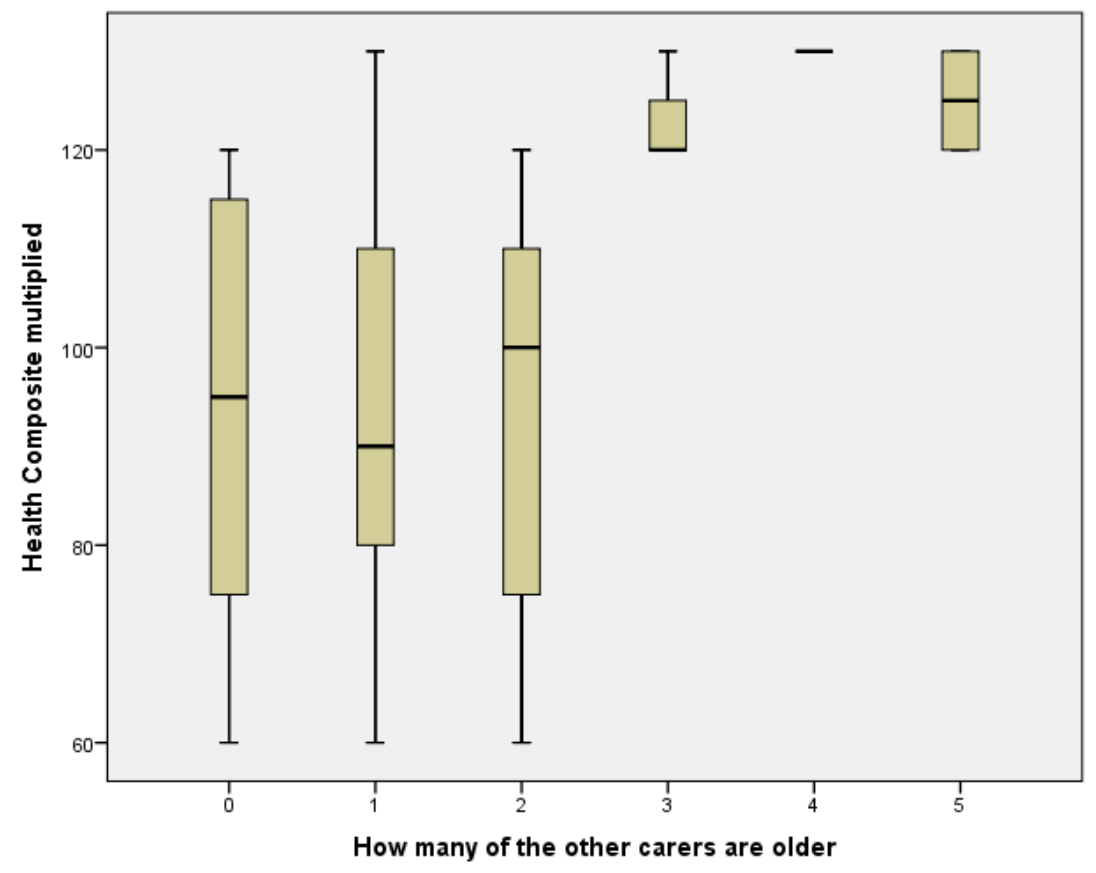

Figure 11. Number of older people sharing caring 
Level and type of caring activity.

Table 70

Correlations of levels of caring activity measured by MACA with outcome indices

\begin{tabular}{|c|c|c|c|}
\hline Variable & $\begin{array}{c}\text { Outcome } \\
\text { Index }\end{array}$ & Rho & $P$ \\
\hline \multirow[t]{4}{*}{ MACA } & ELI & -.47 & .00 \\
\hline & $\mathrm{F}$ & -.49 & .00 \\
\hline & PS & -.27 & .04 \\
\hline & COI & -.30 & .03 \\
\hline \multirow[t]{5}{*}{ Emotional care } & ELI & -.46 & .00 \\
\hline & $\mathrm{F}$ & -.43 & .00 \\
\hline & SS & -.35 & .01 \\
\hline & PS & -.28 & .03 \\
\hline & COI & -.39 & .00 \\
\hline \multirow[t]{4}{*}{$\mathrm{HH}$ resps $^{1}$} & ELI & -.36 & .01 \\
\hline & SS & -.27 & .04 \\
\hline & $\mathrm{F}$ & -.34 & .01 \\
\hline & COI & -.285 & .035 \\
\hline \multirow[t]{4}{*}{ Sibling care } & PS & -.27 & .04 \\
\hline & ELI & -.30 & .02 \\
\hline & $\mathrm{F}$ & -.33 & .01 \\
\hline & COI & -.29 & .03 \\
\hline $\mathrm{HH}$ tasks $^{2}$ & SCI & .27 & .04 \\
\hline
\end{tabular}

HH resps ${ }^{1}$ Household responsibilities

$\mathrm{HH}$ tasks $^{2}$ Household tasks 
The overall level of caring activity, measured by the MACA scale, is correlated adversely with a number of outcomes indicating that the higher the level of caring activity the poorer the outcomes for ELI, F, PS and COI.

The types of caring activity vary in their impact. The strongest correlations are the adverse associations of providing Emotional care with ELI and F. That has also an adverse association with S and COI. Household responsibilities are also adversely correlated with ELI, F, SS and COI.

Caring for a sibling in addition to caring for a Cfp is adversely correlated with ELI, F, PS and COI.

Carrying out household tasks shows a positive correlation with Social Capital.

There does not appear to be any correlation between providing personal care or domestic tasks and any outcome.

It should be noted that in this sample no associations with EAI or HI are shown for level or type of caring activity.

\section{Are there any differences in outcomes at group level between Projects? (RQ 12)}

One way ANOVA was used to compare the mean scores in all the outcome indices and their sub-scales.

There were few statistically significant differences of means between Projects in the main outcome indices. There was one difference of means for $\mathrm{R}(\mathrm{p}=.03)$ but not for EAI. There was also a difference of means for 
PR $(p=.02)$. There was however no significant statistical difference in means for any of the other outcome indices.

Table 71

Measuring differences in Means in outcomes between Projects

\begin{tabular}{llll}
\hline Outcome indices correlations & $\mathrm{F}$ & $\mathrm{p}$ \\
\hline Educational Attainment & EAI & 1.36 & .23 \\
& $\mathrm{R}$ & 2.21 & .03 \\
& $\mathrm{~S}$ & 1.68 & .12 \\
& $\mathrm{PS}$ & .81 & .62 \\
\hline Emotional Literacy & ELI & 1.39 & .21 \\
& $\mathrm{SS}$ & .60 & .81 \\
& $\mathrm{~F}$ & 1.68 & .11 \\
\hline Health & $\mathrm{HI}$ & .65 & .76 \\
\hline Social Capital & $\mathrm{SCI}$ & .79 & .64 \\
& $\mathrm{AOS}$ & .83 & .60 \\
& $\mathrm{PR}$ & 2.50 & .02 \\
& $\mathrm{CPG}$ & 1.08 & .40 \\
& $\mathrm{ASP}$ & 1.13 & .40 \\
\hline COI & & .61 & 0.80 \\
\hline
\end{tabular}

Within the Activities section of the Social Capital Index, two areas showed significant statistical differences in means between Projects and those were:

- participation in religious activities $(p=0.000)$ where two of the eleven Projects had members involved, one Project having three, and the other nine had none and

- youth club attendance $(p=0.000)$ which might arise from the fact that two of the Projects do not organise weekly or 
fortnightly 'club' events like the other Projects. This does not however rule out attendance at other Youth Clubs which is true of some participants in some Projects but the inference is that most participants in these two Projects do not attend other Youth Clubs either.

\subsubsection{Predictors of positive and adverse outcomes} Research Aim 3:

To identify the relative importance of factors affecting outcomes for young carers

Which of the variables have the strongest association with positive outcomes for young carers? (RQ 13)

Which of the variables have the strongest association with adverse outcomes for young carers? (RQ 14)

To address these questions, binary logistic regression was performed to assess the impact of the biographical and caring factors on each outcome and to calculate the strength of the contribution of the significant factors to the outcome. In the case of each outcome, a model was tested containing the independent variables which had already shown significant Pearson or Spearman correlations with the outcome index. COI.

The impact of six factors on the overall outcomes for young carers (COI) was tested. The six independent variables were the quality of family 
relationships, household responsibilities, providing emotional care, the level of caring activity, the sibling care, hours spent caring daily.

Table 72

Binary Logistic Model of Relation Between COI Outcome and Biographical and Caring Factors

\begin{tabular}{lccccc}
\hline & B & Wald & df & Sig. & Odds Ratio \\
\hline Famrel & 3.84 & 6.90 & 1 & .01 & 46.43 \\
H.H. resps. & 2.37 & 4.89 & 1 & .03 & 10.66 \\
Emcare & 1.10 & 4.08 & 1 & .04 & 2.99 \\
Sibcare & 1.01 & 3.45 & 1 & .06 & 2.74 \\
MACA & -.51 & 4.41 & 1 & .04 & .60 \\
Constant & -7.97 & 4.63 & 1 & .03 & .00 \\
\hline
\end{tabular}

The full model containing all the predictors was statistically significant, $\chi^{2}$ $(5, N=34)=24.27, p<.000$, indicating that the model was able to distinguish between respondents in the group with positive and those with adverse outcomes. $\mathrm{R}^{2}$ in this model was 0.68 and the model correctly classified $79.4 \%$ of cases.

The strongest predictor of outcomes was the quality of family relationships, recording an odds ratio of 46.43 . This indicated that respondents who lived in a family with poor quality of relationships were over 46 times more likely to be in the lower group with poor outcomes than those who lived in a family with good quality of relationships. In addition the higher the level of household responsibilities or emotional care, the more likely they were to experience adverse overall outcomes. 
In this model each of the factors makes a unique contribution to the model except for caring for a sibling $(p=.06)$ which showed some contribution but not statistically significant.

\section{EAI.}

The impact of three factors on the outcomes in Educational Attainment for young carers (EAI) was tested. The three independent variables were regular help from an external source, which health condition they had and duration of caring.

Table 73

Binary Logistic Model of Relation Between EAI Outcome and Biographical and Caring Factors

\begin{tabular}{lccccc}
\hline & B & Wald & df & Sig. & Odds Ratio \\
\hline Reghelp(Yes) & 3.37 & 6.64 & 1 & .01 & 29.13 \\
WhichcondAll(PD) & .26 & .05 & 1 & .82 & 1.30 \\
Duration & -.42 & 4.46 & 1 & .04 & .66 \\
Constant & -.12 & .01 & 1 & .93 & .88 \\
\hline
\end{tabular}

The full model containing all the predictors was statistically significant, $\chi^{2}(5, N=33)=20.91, p<.001$, indicating that the model was able to distinguish between respondents in the lower and the higher Educational Attainment groups. $\mathrm{R}^{2}$ in this model was 0.63 (Nagelkerke) and the model correctly classified $81.8 \%$ of cases.

The strongest predictor of outcomes $(p=.01)$ was regular help from an external source, recording an OR of 29.13. This indicated that those in the lower group of Educational Attainment were 29 times more likely to be receiving help from an external source. 
The result for duration of caring indicates that the longer the young person has been caring the more likely they will tend to be in the higher group for Educational Attainment.

Two factors make unique contributions to the model: receiving regular help and the duration of caring.

\section{ELI.}

The impact of six factors on the outcomes for young carers in Emotional Literacy was tested. The six independent variables were the quality of family relationships, household responsibilities, providing emotional care, whether they have a health condition themselves, the level of caring activity, hours spent caring daily.

Table 74

Binary Logistic Model of Relation Between ELI Outcome and Biographical and Caring Factors

\begin{tabular}{lrrrrr}
\hline & \multicolumn{1}{c}{ B } & Wald & df & Sig. & Odds Ratio \\
\hline Owncond(ND) & 9.50 & 3.85 & 1 & .05 & 13342.43 \\
Famrel & 6.67 & 5.69 & 1 & .02 & 784.45 \\
H.H. resps. & 2.80 & 3.55 & 1 & .06 & 16.45 \\
Owncond(PD) & .56 & .11 & 1 & .74 & 1.76 \\
Emcare & 1.10 & 1.99 & 1 & .16 & 3.01 \\
MACA & .15 & .33 & 1 & .57 & 1.17 \\
Timespent & .14 & .31 & 1 & .58 & 1.15 \\
Constant & -23.53 & 5.51 & 1 & .02 & .00 \\
\hline
\end{tabular}

The full model containing all the predictors was statistically significant, $\chi^{2}$ $(7, N=38)=39.47, p<.000$, indicating that the model was able to 
distinguish between respondents in the group with positive outcomes and those in the group with adverse outcomes.

$\mathrm{R}^{2}$ in this model was 0.86 (Nagelkerke) and the model correctly classified $94.7 \%$ of cases.

Only two of the independent variables make a unique contribution to the model: having their own health condition and the quality of family relationships. Household responsibilities also make a contribution but it is not statistically significant.

Where the health condition is neuro-developmental, this is a predictor of an adverse outcome. Family relationships indicated that respondents who lived in a family with a poor quality of relationships were many times more likely to report poor outcomes than those who lived in a family with a good quality of relationships.

The level of household responsibilities had an Odds Ratio of 16.45 indicating that the higher the level of household responsibilities, the less likely the young carer was to have a high score for Emotional Literacy. HI.

The impact of three factors on the Health outcomes for young carers was tested. The three independent variables were the number of Cfps, the number sharing the caring and the number of older people sharing the caring. 
Table 75

Binary Logistic Model (1) of Relation Between Health Outcome and Biographical and Caring Factors

\begin{tabular}{lrrrrr}
\hline & \multicolumn{1}{c}{$\mathrm{B}$} & Wald & df & Sig. & \multicolumn{1}{c}{ Odds Ratio } \\
\hline Cfpnumber & 19.88 & .00 & 1 & 1.00 & 431173193.79 \\
Sharecare & .12 & .02 & 1 & .88 & 1.13 \\
Oldershare & -.78 & .67 & 1 & .41 & .46 \\
Constant & -18.92 & .00 & 1 & 1.00 & .00 \\
\hline
\end{tabular}

The full model containing all three predictors was statistically significant, $\chi^{2}(3, N=37)=12.81, p<.005$, indicating that the model was able to distinguish between respondents in the group with positive outcomes and those in the group with adverse outcomes.

$\mathrm{R}^{2}$ in this model was 0.39 and the model correctly classified $67.6 \%$ of cases. It was therefore a significant but not a strong predictor of Health outcomes.

The model was amended to omit Cfp number (see Table 76).

Table 76

Binary Logistic Model (2) of Relation Between Health Outcome and Biographical and Caring Factors

\begin{tabular}{lccccc}
\hline & $\mathrm{B}$ & Wald & $\mathrm{df}$ & Sig. & Odds Ratio \\
\hline Sharecare & .052 & .00 & 1 & .95 & 1.05 \\
\hline Oldershare & -.95 & 1.01 & 1 & .32 & .39 \\
\hline Constant & 1.68 & 5.63 & 1 & .02 & 5.34 \\
\hline
\end{tabular}

The second model containing two predictors was statistically significant, $\chi^{2}(2, N=37)=7.39, p<.025$, indicating that the model was able to distinguish between respondents in the group with positive outcomes and those in the group with adverse outcomes. 
$\mathrm{R}^{2}$ in this model was 0.24 and the percentage accuracy in classification of cases was again $67.6 \%$. It was therefore a significant but not a strong predictor of Health outcomes.

\section{SCI.}

The only factor which showed a Pearson correlation with SCI was household tasks. Three other factors showed correlations with sub-scales of SCI: having an empathetic adult at home with social activities, the condition of the Cfp with coping and the number of household occupants with coping. A model containing these four was tested for its impact on SCI.

\section{Table 77}

Binary Logistic Model (1) of Relation Between Social Capital Outcome and Biographical and Caring Factors

\begin{tabular}{lccccc}
\hline & B & Wald & df & Sig. & Odds Ratio \\
\hline Occnos & .24 & .87 & 1 & .35 & 1.27 \\
Cfpallconds(LD) & .17 & .01 & 1 & .91 & 1.18 \\
Cfpallconds(ND) & -.14 & .01 & 1 & .93 & .87 \\
H.H. tasks & -.65 & 4.58 & 1 & .03 & .52 \\
Empad(Yes) & -1.62 & 1.67 & 1 & .20 & .20 \\
Cfpallconds(MH) & -20.86 & .00 & 1 & 1.00 & .00 \\
Constant & 2.26 & 1.64 & 1 & .20 & 9.62 \\
\hline
\end{tabular}

This model was not statistically significant $(p=.080)$ so the model was re-run omitting the conditions of the Cfps. 
Table 78

Binary Logistic Model (2) of Relation Between Social Capital Outcome and Biographical and Caring Factors

\begin{tabular}{lccccc}
\hline & B & Wald & df & Sig. & Odds Ratio \\
\hline Occnos & .26 & 1.29 & 1 & .26 & 1.29 \\
HH tasks & -.65 & 5.21 & 1 & .02 & .52 \\
Empad(Yes) & -1.72 & 1.96 & 1 & .16 & .18 \\
Constant & 2.24 & 1.65 & 1 & .20 & 9.36 \\
\hline
\end{tabular}

The full model containing all three predictors was statistically significant, $\chi^{2}(3, \mathrm{~N}=39)=10.23, \quad p<.017$, indicating that the model was able to distinguish between respondents in the group with positive outcomes and those in the group with adverse outcomes.

$\mathrm{R}^{2}$ in this model was 0.31 and the model correctly classified $74.4 \%$ of cases. It was therefore a moderately significant predictor of SCI outcomes.

Only one factor makes a unique contribution to the model and that is the level of household tasks. 
Table 79

Research Questions and Findings

RQs Findings

1. How well developed are the services for young carers?

There is evidence of a service being established mainly in Social Services and the third sector with evidence of more specialist provision in the latter. The awareness and contribution of other agencies is less well developed.

2. How much partnership working is there?

There is evidence of some partnership working at a strategic level between Social Services and some other agencies but the closest partnership in the provision of services is between Social Services and the Young Carers Projects.

3. How accessible are the services?

The Projects receive referrals from a broader range of sources than Social Services and more self-referrals but there is a strong awareness on the part of the providers that they are not reaching all those who need support.

There is evidence that some young carers and their families are reluctant to use the statutory service for fear of the family being broken up.

4. How do the service providers evaluate their service for young carers?

Social Services were making very thorough efforts to evaluate their provision but some did not yet seem to be differentiating clearly between performance indicators, measuring outcomes and methods of identifying what could be attributed to Social Services intervention. Projects had developed more specialised methods, often using numerous approaches and were able to be more young-carer-centred. Less than half the projects responding seemed to have had an external evaluation other than by the Social Services who had commissioned them.

5. What do the service providers perceive to be the challenges?
There was considerable commonality between the views of Social Services and the Projects. Regarding their own challenges, both suffered from inadequate resources and uncertainty about funding. They were both concerned about the emotional wellbeing of young carers, about their ability to access support and about negative treatment by others while the Projects 
emphasised the difficulties facing young carers in education, training and employment.

6. What is the relative importance of the Projects in provision for young carers?
The Projects have become of critical importance in provision as evidenced by the contracting out of the service by most local authorities, by the sharing or delegating of the functions of assessment, review and data recording and by the provision at the Projects of a range of specialised types of support.
7. What is the amount and source of current investment in Projects in Wales?

8. What are the outcomes on the chosen measures?
In this sample local authorities provide $61 \%$ of the Projects' costs mostly on an annual basis and the projects raise about 39\% from other grants and fund-raising; current investment is therefore unstable and well under the cost of the projects which are already working to a low-cost budget.

The lower mean scores of this group in EAI and ELI confirm the findings of previous research about the poorer outcomes for young carers compared to their age group in the general population.

The range in scores was however quite wide, with some individuals scoring well above the norm for their age group in the general population and others scoring worryingly low, particularly in SCI. There was evidence of a positive outlook and personal effort by some, reminding us that young carers are not a homogenous group and low attainment in these areas is not an inevitable outcome.

9. Is there any association between Educational attainment and other outcomes?

10 Is there any association between Emotional literacy and other outcomes?
The most striking finding was that there was no statistical evidence at this stage in the young carers lives in this sample of any association either negative or positive between EAI and other outcome indices.

However there was a strong positive association between PS and ELI.

There was a statistically significant association between ELI and HI.

An additional correlation was found between $\mathrm{HI}$ and SCI which was statistically significant at .05 level. 
11 Is there any significant statistical evidence of an association between any factor in the biographical data or the caring profile? outcomes and

The factors with the strongest associations with outcomes are the quality of family relationships, the level of caring activity as measured by the MACA, providing emotional care and carrying out household responsibilities. The poorer the family relations, the poorer the outcomes in ELI and in COI. The higher the level of the caring activities, the lower the ELI and COI.

EAI was associated with the young carer having a health condition where that condition was neuro-developmental. There were also two counter-intuitive findings: a negative association with Regular help, possibly because those in most need had been targeted for support, and a positive association with duration of caring, a potential explanation being adjustment over time into the caring role.

HI showed a positive association with having people to share the caring and where there were older people sharing.

There was a wide range of individual scores for SCI but only one factor showed an association with SCI and that was the level of household tasks. This could be due to the resulting incursion into free time.

12 Are there any differences in outcomes at group level between Projects?

There was a statistically significant difference in means between Projects for $\mathrm{R}$ but none for the composite EAI.

There were also significant differences in means in the sub-scale PR for religious activities and youth club attendance.

However these differences may not have any implications for the effectiveness of the models of service or of the individual Projects since they are sited in economically and culturally different areas and each receives referrals subject to the assessment processes of other agencies.

13 Which of the variables have the strongest association with positive outcomes for young carers?
The only factor with a predictive value for EAI is the duration of caring.

Factors with predictive value for ELI were the young carer having their own health condition where that was neuro-developmental, the quality of family relationships and household responsibilities.

Predictors of COI are the quality of family 
relationships, providing emotional care.

14 Which of the variables have the strongest association with adverse outcomes for The variables with the strongest association with adverse outcomes are the young carers having a health condition themselves, a high level of caring activity as measured by the MACA, the greater the amount of emotional care provided young carers? and a higher level of household responsibilities. The only statistically significant predictor for SCI was the level of household tasks. 


\section{Chapter 8}

\section{Discussion}

\subsection{Reflections on the Literature Review}

\subsubsection{The concept and definition of young carer.}

The literature review described the changing nature of childhood across time and place and the shifting definitions of young carer deduced by different agencies. One possible explanation for the difficulty in defining the concept is that young carer is a social construct but the fluctuation has also been because the experience of caring is not uniform. The data in this study re-affirm that there is a wide range of conditions of the people cared for and of relationships between carer and cared for. It constitutes a spectrum across individual experiences from low to high levels of activity (Becker, 2007). It may also present a continuum (Skovdal, 2011), altering in its nature and level from time to time within an individual's life of caring, as in Bronfenbrenner's ecological model (1984). Young carers themselves are individuals and not a homogenous group so will have varied characteristics and ambitions. The data from the Phase 2 survey add to the understanding of the breadth and range of outcomes for young carers particularly in their social lives.

It was clear from the literature review that the concept of young carer had become firmly established although the evidence from this study shows that the definition has not become any clearer or more specific and the interpretation of the term is still diverse. For practitioners this has implications for definition, identification, targeting, resources and 
practice and raises the spectre of unmet need. In this study in Wales, while a definition has been established in legislation (Carers Strategies (Wales) Measure, 2011), the survey shows that eligibility for services still varies between local authorities and between YCPs.

The tension still exists between the need for precision for service planning purposes and at the same time the drive to keep it as wide as possible so as not to exclude anyone who might need support. The heterogeneity of young carers themselves as demonstrated in this study does not suggest that there is an easy solution.

On the other hand another kind of tension could be said to have eased and that is between eliminating young caring (Keith \& Morris, 1996) and eradicating harmful conditions and damaging levels of activity (White, 1994). The indisputable acceptance of the part young carers play in the social care economy revealed in this study confirms a move towards the second position.

\subsubsection{Types of support available and barriers to take-up.}

The literature review discussed the types of service and the degree to which agencies provided support. At the same time a range of barriers were identified, some of them arising from the young carers' viewpoint and their own emotional condition.

Two networks, Social Services and YCPs, were identified by the literature review as the main sources of support for young carers. Shortcomings in provision (Dearden \& Becker, 2004) and the positive role played by YCPs (Gray et al., 2007) were commented on. It also 
looked at other agencies and how much they were aware of and able to support young carers: health professionals (McAndrew et al., 2012; Sprung and Laing, 2014) and teachers (Barry, 2011) for example. It was remarked however that there was a lack of empirical studies about the effectiveness of interventions (Fraser \& Pakenham, 2008).

What this study has done is firstly to carry out a structured review in a geographical area of the statutory and of the YCP service. It has used measures and provided comparable data on how these services operate and how they are developing. The responses from the young carers in the Phase 2 survey confirms the value and significance of the YCPs.

Since the stress in Welsh Government policy was seen from the literature review to have adopted a cross-cutting approach, the responsibility of other agencies in achieving the wellbeing of young carers increases proportionately. Responses from a combination of service providers and young carers in this study have given an initial picture in that geographical area of the degree to which other agencies have developed their role in contributing to the support that young carers need. The results have confirmed the concerns about awareness of young carers issues which found expression in the literature review and have highlighted the areas where work still needs to be done to make support available across sectors.

There is much emphasis in the literature review on the young carers as a hidden population (Banks et al., 2002; Warren, 2008; Children's Society, 2013). Lobbying and campaigning has helped to bring the 
existence and needs of young carers to public attention. However the major role played by Social Services and the YCPs should not obscure the potential of other models of service to reach those as yet unsupported. This survey discovered that some YCPs are working in schools for example to develop awareness and to reach unsupported young carers. Publicity work and awareness raising reported by some of the Projects in this survey are explaining the reality of young caring to new groups and audiences.

The wide and ready use of social media and of the Internet for information displayed by the young carers in the survey offers another possible route for communication and support. Young carers in the Reference Group said that they saw no difference between face-to-face friends and those in virtual networks. The lack of exploration of the implications of this in the context of young carers was commented on by Aldridge and Wates in 2005 and quoted by Gray et al. in 2008. Little was found with reference to this in the literature review subsequent to 2008 but clearly methods need to be adapted for this new reality.

\subsubsection{Outcomes for young carers.}

From the literature review, it could be ascertained that there was general agreement amongst researchers about the adverse outcomes for some young carers. The recognition of positive outcomes increased as research expanded.

However there are some features of the results in this study which confuse previous findings. The indicator used to measure socio-economic 
status was having free school meals and the data show that in this sample this is not associated with any outcome either positive or adverse which seems to challenge the argument that deprivation and disadvantage is a causal factor in adverse outcomes (Newman, 2002). Poor outcomes in this study are not inevitably linked either to a high level of caring activity. There are young carers in this study with poor outcomes who have quite low levels of caring activity. It can be argued therefore that it could be not just the caring burden or the socio-economic status which leads to poor outcomes but the combination of problems such as caring plus poor family relationship or caring plus caring for a non-disabled sibling or caring plus poor educational performance. Socioeconomic status or a high level of activity might be two of several or more problems which can predict poor outcomes. The aim in these circumstances might be to "reduce the stockpile of problems" (Gilligan, 2000 , p. 38) whether those problems are in the caring itself or even in a poor outcome in one of the correlated domains discussed here.

\subsubsection{The voice of young carers.}

The literature review illustrates how the status and meaning of young carer has changed over time and location and the results from this study highlight the variety of individual differences beyond the influence of their historic, geographical and social context. The combination of personal circumstances of the participants, of motivation and responses varies greatly even across this comparatively small sample $(n=62)$. The adults 
they are to become are already emerging and deserve to be listened to for this reason alone.

There is evidence, as shown in the literature review, of young carers as a social group moving from the periphery to the centre of discussion of their situation (see Sections 5.1 - 5.3). The data from young carers in this study show that the Projects help them to develop their self-identification as young carers and their ability to talk about their role to others including professionals both informally and in formal presentations. Others have carried out theatrical performances and flash mobs to raise public awareness. This can be empowering and improve self-confidence. Heyman and Heyman (2013) observe how one young carer became politicised through this process. In this sense the Projects and the activities emerging from them can take further their self-awareness and encourage young carers' voices and in so doing foster agency.

\subsection{Phase 1: Survey of Social Services and YCPs}

The data from this first phase of the research furnish three streams of information: the answers to the RQs relating to Social Services, answers relating to the YCPs and areas of common ground.

\subsubsection{How well developed are services for young carers? (RQ 1)}

Every local authority provided a statutory service to young carers. To that extent there was then a network of support. Social Services staff were committed but there were indications that the service was still in the development stage. Some authorities appeared to be solving the 
problem of developing a specialist provision by commissioning or delegating to an external service.

In Social Services, the considerable progress with Young Carers Strategies was a positive sign; one authority had a dedicated social worker for young carers. Assessment in the majority of areas was still with the CiN tool although some authorities were using in-house tools for assessment rather than the generic $\mathrm{CiN}$ tool and it would be interesting to know more about 'the measures used in these'.

There are signs that there is still some work to be done. It proved difficult in some authorities for example to identify the person with responsibility for the young carer service. Since seven of the young carers interviewed did not know whether there was regular help coming in, this leaves some uncertainty as to whether all the young carers had been involved in the assessment process. In comments on evaluating the service, a lack of clarity was observed in distinguishing between the three aspects of evaluation. These points suggest that this process is still a work in progress but moving forward subject to resources.

There was at least one YCP in every local authority area in Wales. In the Projects, although some functions were shared, the Projects offered support of a different and complementary type. Much was learned about the aims of the Projects from the literature review, from the survey of Projects and from the young carers in Phase 2. There was evidence of the development of a specific service for young carers. They provided a wide range of services based on the perceived needs of young carers 
with a great deal of common ground between Projects. In this sample, the majority had dedicated managers' posts. Staff and volunteers had good levels of education and training and from anecdotal evidence there appeared, in spite of limited resources, to be a culture of continuous professional development. Much work had been done on the evaluation of young carers' progress and outcomes were talked about.

The involvement of former young carers illustrated one unique feature of the Projects. Their participation both as volunteers and employees has enriched the culture of understanding and strengthened the focus. It provided also a positive experience for the former young carers concerned and afforded role models for members of the Project.

\subsubsection{How much partnership working is there? ( $R Q$ 2)}

Firstly there was evidence of strong partnership between Social Services and the Projects. The sharing and in some cases the delegation of responsibilities for assessment, eligibility criteria and evaluation demonstrated close inter-dependence between the statutory social care sector and Projects managed mostly by the Third sector. Two LAs said that it was the Projects which kept records of young carers and four of the ten LA respondents kept no waiting lists. Referrals went both ways between the two services and this way of working was productive particularly in the light of the evidence that some young carers and their families often prefer initially to get involved with a voluntary organisation than with social workers. The LA was the main funding source for the 
Projects, providing $61 \%$ of the income of the ten Projects, and this was in itself further evidence of the close relationship.

There was convincing evidence of partnership working between Social Services and other agencies also. Responsibility was shared in some authorities between the generic Children's Service and the Adult Service. The participation in strategic meetings with other agencies assisted the Welsh Government's policy of making young carers a cross-cutting issue. It suggested that partnership was progressing although the rate of referrals and the comments by the Projects on their awareness raising indicated some gaps in awareness in some other agencies.

The wide range of sources of referrals to both Social Services and the Projects was encouraging and it may reflect other agencies' growing level of awareness of young carers as an issue and how far they have been alerted to their own potential partnership role in providing access to services for young carers (see Tables 13 and 18). It is interesting to note in the pattern of referrals which sources appeared most frequently in the Most column and which in the None column. There was a lower level of referrals from Health sources and the least awareness raising sessions which reflects what was discovered from the literature review (p. 282, Table 15; p. 289, Table 20; p. 293, Table 24). This contrasts with the positive data about regular strategic meetings so may arise from differing levels of awareness and co-operation within Health between the strategic and front-line services such as G.P.s. 
Neither Social Services nor YCPs mentioned schools as sources of referrals but in some counties the YCPs were working in the schools to raise awareness, to encourage identification and even to provide support in groups or one-to-one.

\subsubsection{How accessible are the services? ( $R Q$ 3)}

In the light of the difficulties with defining young carer, eligibility criteria were an important indicator of access. There was a considerable degree of variation between local authorities (see p. 281 and Table 12) and between Projects (see p. 290 and Table 21).

Both Social Services and the Projects were taking referrals from a wide range of sources. The Projects were mostly generic and did not restrict access. The worry is that the official number being identified, assessed and provided with some kind of support is nowhere near the number of young carers calculated to live in Wales. Whilst the hidden nature of caring by young people was recognised as a huge obstacle to reaching them, even now the Projects could not take on all those who are referred to them or do come to them for help. The combined total of the annual number of Project members and the waiting lists for these ten Projects alone brings us to 1,289 which is above the 649 appearing for the same year in the Welsh Government data-base (StatsWales, 201314) for young carers identified, assessed and receiving a service across Wales (see Appendix B). Not all those included in the 649 were necessarily referred to the YCP and not all those in the YCPs number were necessarily included in the Social Services number. Furthermore the 
figure of 1,289 applies only to the 10 who responded of the 26 YCPs in Wales.

One of the Project respondents pointed out also that there were practical problems with involving all the young carers who were referred to them from across the whole of their catchment area especially in very rural areas. Most Projects provided transport to and from events, an expensive budget item. Some Projects had to run in a number of centres to cover their catchment area. In two areas the service ran on a different model, one by providing individual support to young carers rather than organising regular social events and one by organising occasional events.

How to reach hidden young carers was a concern. As explained by respondents in the section on challenges to the services, funding and capacity are the main challenges. Those comments exemplified considerable common ground between Social Services and Projects. The implication is their fear that the need could not be met even by their combined current capacity.

\subsubsection{How do the service providers evaluate their service for young carers? ( $R Q$ 4)}

Banks et al. as long ago as 2002 wrote that: "Independent, external evaluations and assessments of outcomes are lacking. Nor has there been much comparative work to describe different types and models of YCPs and assess their respective merits". The literature review 
summarised those evaluation reports which could be found since Banks et al.'s comment.

Independent evaluations can be assumed to be useful for grant applications, commissioning for commissioners. From the responses to the questions on evaluation, it is clear that a lot of thought and work had gone into this in both the statutory and third sector services and in some cases this was a shared process. Feedback from the young carers and sometimes also from families was a significant factor in many of the responses.

However, whilst the responses were rich and all methods were useful, there was some evidence of a lack of methodological clarity in Social Services with not enough separation between the three aspects of performance (performance management, outcomes for the service user and attributing success to the intervention). Several gave similar responses to more than one item, either because the responses did not respond to the three separate angles or because the overlap reflects the fact that the methods of evaluation themselves overlap. A similar lack of clarity about evaluation and attribution was commented on by McMurray et al. (2008) in their study of social workers' understanding of resilience.

This is not to say that Social Services have not been successful in its support of young carers but the evidence of attribution of success specifically to Social Services intervention rather than to other possible factors such as school support, family relationships, the resilience of the 
individual, the work of the Projects, therefore remains uncertain on the basis of these data and the evaluation methods used.

What stood out from the responses of the Projects was the common focus on the empowerment of the young participants, helping them develop life skills, enabling change and building up their capacity. All the Projects responding were managed by Third sector organisations and from the records this could be seen to be true for the majority of YCPs in Wales (Young Carers Network, Children in Wales web-site). There were five different charitable organisations involved in managing the Projects who responded, each with its own structure and operation. It is not surprising therefore that there appeared to be a wide variety of method and practice. However, in spite of the variety in methods, there appeared to be a common set of values and aspirations throughout Wales. They were all young person centred and there was strong emphasis on the active involvement of former young carers in the evaluation process.

Evaluating success for young carers entails evaluation of the effectiveness of the Projects themselves. Clearly Projects take evaluation seriously and four of the Projects in this survey had commissioned external evaluations of their service. No details of these evaluations were asked for in this survey but it would be interesting to know more about them. It might be helpful if this were to be common practice and if there were some common standards. 


\subsubsection{What do the service providers perceive to be the challenges? (RQ 5)}

This is another area where there was a remarkable degree of commonality between Social Services and the Projects. For both service providers, funding and capacity were the main concern and respondents from each network expressed concerns for the problems experienced by the other, suggesting a shared outlook to a significant extent. This shared concern illustrated too the inter-dependence of the statutory and third sector in providing an adequate service. Both were only too aware of the gaps they identified in the service, namely those over 18 and reaching the hidden young carers, which are again associated with the question of resources.

One feature of the funding situation for the Projects was the increasing competitiveness for funds. This applied to charitable funds but also to the competitive tendering process which is being used increasingly by statutory bodies. Milbourne (2009) remarked: "Competitive funding and performance frameworks embedded in local area commissioning undermine collaboration and constrain innovative, front-line work, the very work for which community-based organisations have gained positive reputations for addressing social problems" ( $p$. 293). Newman (2002) commented: "In common with many other services which lie largely outside the statutory sector, dedicated young carer services suffer from a chronic problem with short-term funding". (p. 620) 
This hinders co-operation between the statutory and third sectors. Watson et al. (2014), writing about Children's Centres, commented on the adverse effects of "power differentials and poor inter-professional collaboration" (p. 372) and how it affected the potential for service users to build social capital especially of the bridging type.

In the views expressed about challenges for young carers, there was again considerable common ground. Aspects of emotional wellbeing topped the list of concerns. These included bullying, stigma, neglect, isolation. Education and their future training and employment opportunities was the second area causing concern. The next most frequently expressed apprehensions were around the social circumstances of being a young carer: their social lives, poverty, awareness of their issues and access to services. In one case the latter was linked to rurality. These were followed by a few references again to the lack of a service for those over 18 and access to training which would be useful in their caring role.

Fox (1995) was concerned about different professionals having different models of caring and hence emphasising different aspects of what was important for the young carer leading to the lack of a "unitary discourse". Little evidence of this emerged from the data in this sample since there seemed to be much common conceptual ground between statutory and charitable organisations. 


\subsubsection{What is the relative importance of the Projects in provision for young carers? ( $R Q$ 6)}

The conclusions to this question draw on the data in the Social Services survey as well as from the survey of the Projects themselves. The legally required service for young carers is to assess them and provide a service if needed and this duty is acquitted by the statutory service or delegated to or shared with the Projects. The Projects cater for the wider needs of young carers as firmly evidenced by research since 1993.

Firstly the collaborative work done between the two sectors furnished evidence of their importance. Referrals by Social Services were both made by them to the Projects and received from the Projects. The key functions of assessment, review and evaluation were shared to a considerable extent with the professionals in the Projects. It is observed from the text responses that four Social Services Depts. state that they had delegated this function to the YCP although in one of these they stated that a Young Carers Assessment tool had been agreed with the Project. Two authorities could be seen to have retained the assessment function fully whilst two shared the assessment process. Although assessment might fall in practice to a particular worker or workers, there were only two authorities citing a dedicated worker for this role. There was one example of 'the Young Carers Service' being used to describe the local Young Carers' Project.

Secondly, based on this sample, the numbers involved provided further evidence of the importance of the YCPs. The number catered for 
in all 10 Projects at any one time totalled 732, varying from 27 in one Project up to 100 in another. However the combined number catered for in a year totalled 1,221 not including waiting lists. From this we can conclude that there is some movement into and out of the Projects within a year. Six of the Projects had waiting lists with a total of 68 young carers listed so it is clear that there was already a demand for the service which the Projects could not satisfy. With just these ten Projects, the combined total of the annual number and the waiting lists brings us to 1,289 which was evidently a major contribution relative to Social Services direct cross-Wales support for between 700 and 800 in 2014/15 (StatsWales, 2016). This alone demonstrates the current and potential importance of the Projects.

The Projects appeared to be the main support outside the statutory service available for the referral of young carers. In the second phase, the data yielded a picture of what the Projects meant for young carers themselves and whether this confirmed or otherwise the above conclusions. Comparing the results from the two surveys builds the impression that the Projects have developed a model of support specifically for young carers beyond what the statutory agencies can satisfy. This is the third factor in demonstrating the importance of the Projects. They appear to be the place where a specialist service for young carers is developing in a way not available to the statutory service, perhaps because of their ability to focus centrally on the individual experience and needs of the young carer. Whilst Social 
Services were mostly working with a Child in Need definition, the Projects were utilising broader and looser criteria which open the door to open referral and a wider network of agencies. They drew referrals from a wider range of sources than Social Services. Part of the reason for this, as stated in the literature review (Mahon \& Higgins, 1995), is that many young carers and their families might be more likely to approach an independent than a statutory organisation for help so this may be a role more appropriate for the Projects since the fear of Social Services by young carers and their families might deter some who need the support. The development of the practice was evidenced by the use of specialist assessment and evaluation tools for young carers, the array of targeted activities and the comparatively greater ease of access. The Projects offer young carers access to empathetic professionals in addition to the social work professionals, thus extending the number and range of adults able to exercise a protective function in developing resilience. The involvement of former young carers is likely to enrich the practice and accessibility of the Projects to anxious young people, suggesting that they are able to offer elements of support which are not available to Social Services.

In addition some of the Projects extended their remit by involvement in schools thus assisting the local authority to carry out the statutory duty placed on them by the Carers Strategies (Wales) Measure (WG, 2010) to "provide appropriate information and advice to carers". They raised awareness of young carer issues and supported some of those 
identified either in the Projects or on school premises. Neither should it be ignored that the cost of the support provided by the Projects fell only partially on the statutory services (see RQ 7), since most Projects are managed by the third sector.

Projects seemed to be conscious of the need for professional development as illustrated by the high qualifications level of staff and volunteers. Heyman (2013) pointed out the growing awareness of a professional practice specific to young carers workers and suggested that there is a need for recognition of a profession working within this increasing specialism.

The data seem to indicate that by actual division of labour alone the role of the Projects is essential. At the time of this study, they appeared to provide the main, possibly the only direct support for young carers themselves outside the statutory social care agency. This may or may not indicate intentionality but either way it does suggest implications for the development of the service.

The importance of the Projects in the extent of their provision and their involvement with the statutory authorities prompts a question about evaluation of the effectiveness of the support they provide and the way they provide it. In the UK, some evaluative research exists on dedicated Young Carer Projects (Newton \& Becker 1999; Dearden and Becker 2000a; Centre for Child and Family Research, 2002) and on models of good practice (Frank and McLarnon, 2008) but little using a comparative method. Evaluation of the outcomes for the young carers in 
their care is something that the Projects are very concerned with as evidenced by the diverse and multiple and sometimes innovative methods they use. It is noted however that not all Projects use independent evaluations and the practice of evaluation in this context might benefit from some attention. The diversity of the Projects would suggest that there is value to be had from an independent evaluation of

a Project but this is still under-used as a helpful practice.

\subsubsection{What is the amount and source of current investment in}

\section{Projects in Wales? (RQ 7)}

As explained in 7.2.3 and 7.2.6, the number of young carers attending Projects exceeded the number supported by Social Services and some of the statutory responsibilities were undertaken by the Projects. The annual cost of the seven Projects in this sample who disclosed their financial information ranged from $£ 50 k$ to $£ 245 k$. The average annual cost for young carer participants across the whole year worked out at $£ 715$ per head.

Not all the respondents gave financial information but seven Projects did so for the year before the survey. For providing this service, those seven Projects drew down £414k from their seven local authorities, the major source of income, reflecting the close partnership between the statutory and third sector organisations. This was supplemented by $£ 40 \mathrm{k}$ from the provider organisations themselves. Income from grant-aid totalled $£ 90 \mathrm{k}$. Fund-raising earned $£ 126 \mathrm{k}$. The proportion of funding for 
these Projects from the local authorities worked out therefore at $61 \%$ supported by $39 \%$ generated by the Projects themselves.

There was a remarkable degree of commonality with Social Services when it came to identifying the challenges for young carers and even for their respective services. Funding and capacity were the main concern for both and concerns were even expressed for the problems experienced by the other, suggesting a shared outlook on a significant topic.

Concerns were expressed about the amount and the reliability of the funding obtained. In this sample, where $39 \%$ of the funding came from their own efforts, it is clear that the continuing existence of most of these Projects depends upon their ability to generate income themselves. From the responses to the question on challenges, funding was evidently an important limitation on how far the demand could be met.

Funding was often on an annual basis. This left the Projects relying on annual budgets and uncertain sources for a large part of their income. In the chosen area at the start of the study, there were sixteen Projects operating. By the end of the data collection period, two of these had ceased to function. If this sample is representative, it seems evident that investment in the Projects is less than is needed for the current service and certainly for dealing with as yet unmet need. Apart from the funding issue, the market processes which are being introduced are an additional cause of instability. 


\subsection{Phase 2: Survey of Young Carers}

For the purpose of this study, acceptance by a YCP provided a useful and practical marker and so was adopted as the criterion for inclusion in the category of young carer, relying on the experience and judgement of workers close to the source.

\subsubsection{Representativeness of sample.}

Some of the results in this study confirm trends reported in the literature review (Dearden \& Becker, 1995, 1998, 2004) of the young carer demography and the caring profile.

The size of the sample allows challenges to the representativeness of its results as described in Section 6.6 .4 but the spread through WIMD areas of authorities from which the respondents were drawn contributes to its representativeness.

Examining the biographical and caring factors offers evidence both for and against this challenge. There are some variables for which it is possible to find valid comparators in previous research or statutory data. Where this is available it has been commented on but for some no record of relevant quantifiable data were found.

In this study the proportion of disabled siblings cared for continued to rise as did the number of Cfps with Neuro-developmental and Learning Disabilities and the provision of emotional care increased as opposed to personal care. The result showing that socio-economic status in this sample was not associated with any outcomes either positive or adverse 
seems to contradict the argument that deprivation and disadvantage is a causal factor in adverse outcomes (Newman, 2002).

The incidence of lone parent families in this sample and the take-up of free school meals marked the group out as being of a lower socioeconomic status than the age-matched population but comparing closely with statistical analysis of other studies of young carers. The spread of conditions of the people cared for and of their relationships to the young carers were similar to previous studies. The under-representation of BAME young carers may not be in line with the age-matched population but the difficulties of recruiting participants for the sample is certainly similar to the experience of other researchers.

One feature which might classify the sample as unrepresentative would be the more equal gender split than in most earlier studies but this may be a reflection of changing mores. It is illustrated in the UK by the even balance of male and female carers in the most recent LSYPE study in 2013 ( $n=9,000)$. Skovdal et al. (2009) noticed that the gender gap appeared to be decreasing even in Kenya against a strong traditional culture. The skew in this sample towards a heavier workload than in prior studies, for example in hours spent caring weekly and in duration of commitment, was another feature which differentiated it slightly.

There was no evidence in previous studies of the proportion of young carers with their own health condition/s but compared to the general population a high number in this sample had one, two or three health conditions of their own. Smyth et al. (2011b, p. 510) wrote that "young 
carers are more likely than their non-carer peers to... have a disability themselves". The conditions stated here included physical, sight, hearing disabilities and limiting long-term illnesses as well as neurodevelopmental conditions such as ADHD, Dyslexia, Dyspraxia, Asperger's, Autism. It would be surprising if the neuro-developmental conditions did not affect educational attainment. This means that these are young people who face the double challenge of coping with their own problem and at the same time caring for another family member.

Using the MACA as the measure of the level of total activity allowed an accurate comparison with the comprehensive Dearden and Becker survey (2005). The amount of work undertaken by this sample appeared to be similar to that in the 2004 study. The amount of personal intimate care was not high overall either in this or in the 2004 sample although this is one of the factors which has often been regarded as the marker of being a young carer (DoH, 1999, GHS, 2000). It was identified by Becker (2010) in a commissioned study for the BBC as a "proxy indicator" of being a young carer. In this sample the amount of personal care provided was not high and neither was it associated with any outcomes.

In the domain of Social Capital, it is particularly difficult to discuss how representative the sample is because of the lack of comparators. Although the adverse effects of caring on social life have been reported, little descriptive or quantitative data has been gathered and analysed up to now so there is an absence of norms which can be used for this 
sample. No data were found which permit accurate comparisons with young carers of the same age group or with young non-carers. For this reason, these data may not be generalisable but they facilitate statistical tests of correlation with biographical and caring factors, with other outcomes for this group and whether and how far they were in a position to acquire social capital. It does seem that more information on the social capital aspects of young carers lives would be useful. That could also provide a base-line for further research in this area.

\subsubsection{Primary and secondary outcomes.}

The subject of this study is outcomes for young carers although it must be reiterated that the outcomes considered in this research design can only be the short-term or primary outcomes as they are currently evidenced. The corollary to this limitation is that some of the short-term outcomes will lead to long-term or secondary outcomes and were chosen for measurement for that reason. The development of emotional literacy, literacy skills, health, social capital in the form of the acquisition of experience in the teen years are likely to make adult life easier or harder, more or less rewarding and those outcomes themselves then may become factors associated with the long-term positive or adverse outcomes.

The short- and long-term perspectives raise doubts about targeting support for those young people apparently most in need. For example, there are young people in this study whose level of caring activity is quite low but they have low scores in peer relationships and coping. So 
level of activity as a sole indicator of need might miss the risk of longterm adverse effects. This is why Blyth (1997) quotes from the FACNTF (2000, para 3.58) that some children may experience problems "not sufficiently serious to receive services under Social Services priorities". However, without early intervention, there may be adverse consequences for their outcomes in the long-term.

\subsection{Outcomes}

\subsubsection{Outcomes on the chosen measures (RQ 8).}

\section{Educational attainment.}

It is the prevailing assumption that educational attainment and especially literacy are powerful predictors of future success. The WGCYPWM (2011) presents educational attainment as a factor in all aspects of wellbeing, rating it as even more important to health than to future income (WG, 2011). For that reason it is an important index for young carers. The majority of research has been unanimous in reporting the adverse effect of caring on educational attainment for young carers. No record could be found of any objective measures being used previously so there is no material for comparison with the results of the Reading, Spelling and Emotional Literacy measures used in this study. The comparisons available, with norms for young non-carers and with another vulnerable group, do however provide additional evidence of the previously observed poorer literacy and emotional literacy performance of young carers. 
Educational Attainment includes not only the cognitive abilities but also the behavioural aspects such as attendance, punctuality and completion of homework. Welsh Government reports a correlation between higher rates of absence and lower attainment levels as measured at age 11, 14 and 15 (WGCYPWM, 2011). With that in mind, under the heading of Performance at School, this study has gathered qualitative self-report data on attendance, punctuality, completion of homework and concentration. Previous data have given evidence of an adverse effect of caring on these aspects of performance but there is also the probability that other factors are in play here. In this sample anecdotal evidence from the participants, unlike the literacy tests, highlighted the influence of their own motivation and sometimes of their parents' involvement. Two participants remarked that they always finished their homework by not going to bed until it was done. Several others said that they never missed out on homework because their parents wouldn't let them. These reflect the dual importance of the family influence and the personal motivation which are distinct from caring factors.

It can be seen that for nearly half the respondents one effect in school of being a young carer is worrying about the family. This single problem might be ameliorated if schools understood this routinely and made allowances. For example they could allow young carers to have mobile phones where appropriate. The function of this would be to set 
their minds at rest if they knew that they could be alerted when there was a crisis.

What also emerged from conversation around the survey was the variation in teachers' attitudes. More than one participant said that their teachers insisted on homework being done on time regardless of the home situation. The brief inquiry into how far schools are accommodating young carers (Appendix $\mathrm{H}$ ) and the low response from schools to recruiting participants for a control group suggests that there may still be some way to go before young carers are routinely recognised and able to rely on supportive and appropriate treatment.

\section{Emotional literacy.}

The low mean in the quantitative SEMERC measure was cognate with previous findings on young carers. It was supplemented with subjective data on their feelings as a result of caring. The five items for this item were identified during the discussion with the Reference Group. While the objective SEMERC results showed a mean below that of non-carer peers, the group results for Feelings show a negative skew (see Table 46 and Figure 6). Most significant is the fact that every one of the respondents felt satisfied at helping a family member some or a lot of the time. The overwhelming majority (92\%) also felt that they were competent either some or a lot of the time. Asked about negative feelings, a large majority felt stressed and tired but only a minority ever felt alone. There is no data to provide a comparison for this measure either with other young carers or with non-carers. Without a control 
group, it is uncertain how far involvement in a Project would have prevented feeling alone.

\section{Health.}

Existing data displayed evidence of the damaging effect of caring on health.

Dental and sight checks were asked about as a clue to the care they and their families took with their health. Dental health is included as a health indicator by the Welsh Government in their Wellbeing Monitor for Children and Young People (2011). The survey of children's dental health in Wales (ONS, 2015) stresses the adverse effect poor oral conditions can have emotionally and health-wise. It gives the percentage of those in Wales who have never attended the dentist at 12 and 15 years as less than $1 \%$. The number in the young carer sample who did not remember having or had never had a dental check (25\%) suggests that dental health is not always a priority for the families of young carers or for young carers themselves. Regarding a norm for vision, the recommendation of the General Ophthalmic Service in Wales (StatsWales, 2015) is that those of 15 years and under should have annual sight checks. The respondents who did not remember having or had never had a sight check was $20 \%$. That number is worrying in a sample with such a high proportion of participants with neurodevelopmental conditions and in the light of recent research on the increasing incidence of short sight in children (Williams et al, 2015). It recalls the comments by McAndrew (2012) that young carers' health 
often suffers because they do not access health professionals either through lack of their own time or because health professionals are not trained to recognise young carers (Sprung \& Laing, 2014).

In this sample over $11 \%$ smoked. The option of not answering was offered specifically as one of the options in this question but no-one was reluctant to give an unequivocal answer so it may be safe to assume that this is an accurate result. A survey of $11-16$ year olds in Wales (WG, 2014) gives the proportion of respondents who smoke weekly as $6 \%$. This is lower than in this sample but that report shows that the rate rises with age. Those smoking in this sample were all in the top of the age group so that suggests that it is consistent with the figures in the report. Assuming the link between smoking and stress and given the proportion of those experiencing stress some or a lot of the time $(77 \%)$, this might have been expected to be even higher.

In spite of evidence of the adverse effects of young caring, $73 \%$ in this sample assessed themselves as either very or fairly healthy. Allowance must be made for the age group of the sample which might not experience harmful effects till the later stages of caring but it does suggest a tendency towards a positive outlook at this age. This echoes the positive outlooks already conveyed by the data on Feelings as a result of caring.

\section{Social capital.}

The range of scores in all aspects of Social Capital has already been remarked on. Without comparative data, it is difficult to comment on 
outcomes for young carers in this domain but some of the lower scores would be enough to cause concern not just for young carers. It may not be possible to ascertain whether it is caring or other circumstances which limit access to social capital in either the micro-, macro- or exo-system but it may be that support for them as young carers could improve the poor outcomes for some of these young people.

The experience of some young people in this survey is a nil score for the use of public facilities or computer games as the only hobby or no sporting activity at all either in a group or individually. It can be argued that the debate about the cause is irrelevant; at this point the outcome is adverse. It is in providing this kind of support that the Projects may contribute by showing what is available, by rousing interest and by broadening experience.

\section{Overall outcomes}

The quality of the family relationship had the strongest predictive value for overall outcomes: the poorer the family relationship, the poorer the overall outcome. This must surely be considered as further evidence of the need for regular help to contribute to relieving family stress.

Some types of caring activity are also influential: providing emotional care, sibling care and household responsibilities. These serve as a reminder of the importance of responsibility as a distinguishing factor of caring as opposed to helping. 


\subsubsection{Correlations between outcomes (RQs 9 and 10).}

The first noticeable result is the contrast between the comparative isolation of Literacy from other outcomes. Clearly the comparatively few or weak positive and adverse correlations do not distract from its importance as a current and future outcome in itself but it does suggest that bringing about improvement may not be linked to positive movement in the other domains of a young carer's life. Adding to this the adverse correlation shown between Literacy and a neuro-developmental condition, although applicable also to non-carers, implies an increased responsibility for schools and colleges to recognise and reduce difficulties arising from students' caring in at least one area if this inequality is to be addressed (see 7.1.3).

In contrast Performance at School has strong positive correlations with both Emotional Literacy and Health. The results for this sample are mostly quite positive and do not disagree with Warren's comment that the behaviour of the majority of young carers in this regard is not necessarily affected in a major way by their duties (2007). The factor in this domain giving rise to most concern is the high number who worried about their family while at school. This can affect academic performance and recalls the comment by young carers that schools need training to give young carers help "in any way possible" (Wales Young Carers Network Report, 2007).

Health itself has a broad range of associations across the other three domains: Emotional Literacy, Performance at school and Social Capital. 
Correlations do not show causality so these tests cannot show whether Health is the beneficiary or the benefactor of other positive outcomes. In either case, it brings into focus the importance of health professionals in optimising health outcomes for young carers.

Social Capital has only two statistically significant associations but together with its sub-scales it has also a cluster of trends towards Emotional Literacy and Health. This suggests that positive and adverse outcomes in Social Capital may be associated with a combination of domains but leaves the areas of Emotional Literacy and Health as the two outcomes with the strongest inter-relationship.

\subsubsection{Correlations with biographical and caring factors (RQ 11).}

Before commenting on the associations which did appear, it is worth noting some which showed weak evidence of correlation with outcomes or no evidence at all. This cannot dismiss the possibility that they are influential but it may be that other factors over-ride them in this sample.

Amongst the biographical factors for example, the influence on outcomes of having a step-parent is often examined in research generally but in this sample it was un-related statistically to any outcome either positive or adverse. In fact, a step-parent was named by several as the adult with whom feelings could be shared. Other biographical factors which do not appear to have any correlation with outcomes are gender, lone parent family and family structure. The size of the family household has a correlation with Health only indirectly by virtue of the number of older carers or the number of carers sharing. The correlation 
is weak and these factors tend in themselves to be mostly collinear although one young carer remarked on the persistent absence of other members of the family from caring duties.

The view has been expressed that adverse effects which are attributed to caring are actually the result of factors such as deprivation (Newman, 2002). So it is interesting to note that in this sample FSM as an indicator of socio-economic status showed no correlations with any of the outcomes either positive or adverse. An anecdotal illustration of this is one young carer who was in a lone-parent family and eligible for FSM but the person cared for was an adult with higher education and the situation showed signs of a very well organised household and family time spent in constructive activities.

In the caring profile, factors which do not show a correlation with any outcome are the relationship to the Cfp and the predictability of the condition of the Cfp. The lack of correlation is counter-intuitive in the light of previous findings. For example the relationship to the Cfp might affect Emotional Literacy outcomes through its effect on the degree of parentification. It could have been reasonably foreseen that there would be a practical impact of the predictability or otherwise of the Cfp's condition if not the emotional effect. In this sample, no correlations were found for these two factors with any outcomes. Another or a larger sample might produce more conclusive data on these factors.

It is surprising that data on young carers do not always include information on whether they are sole, main or supporting carers since 
the greater responsibility and higher workload associated with being a sole carer would have been expected to have an impact on outcomes. It is even more surprising that the correlations do not then show that outcomes are worst for sole carers and best for supporting carers. This indicates that there may be a more complex explanation which would benefit from more comparative data and research with a larger sample.

The number of people cared for can be a proxy for time and energy spent. This factor is adversely correlated with Emotional Literacy and Health outcomes. Being one of a number of carers and thus sharing the workload seemed to be associated with slightly more positive Health outcomes. Having an older carer to share with had a positive correlation with health outcomes perhaps because it took off the pressure of responsibility. These are factors which might be easily and usefully included in an assessment.

The condition of the Cfp is adversely correlated with the Emotional Literacy outcome. It is also correlated with the coping measure where a neuro-developmental condition is adversely correlated and even more so where it is a Learning Disability.

There are two correlations with Educational Attainment which deserve comment. The first is the adverse correlation with Regular help. This means that young carers in households which get help with caring from an external source have poorer outcomes. The logical sequence might have been reversed here by targeting, resulting in those with the more difficult circumstances being assessed as needing help more urgently or 
poor outcomes in educational attainment coinciding with other adverse confounding factors. Duration of caring has a positive correlation with Educational Attainment, that is the longer they have been caring, the higher their Educational Attainment scores. This recalls the comments by Dearden et al. (1995) on the socialisation of young people into their role as carer. Equally it may demonstrate the development in the life course of competence at managing that role.

When Literacy was tested for correlations separately from Performance at School, the only factor which showed a strong correlation was the type of condition experienced by the young carer when the condition was neuro-developmental. This is not of course unique to young carers but the association means that adequate attention needs to be paid to this educational disadvantage in young carers in schools.

It might be expected that the level of caring activity, as measured by MACA, would be correlated with outcomes and indeed it is strongly correlated adversely with Emotional Literacy and its component Feelings as a result of caring and with Performance at School as well as with the Overall composite outcome index. When caring is broken down into different types of caring activity however, some do not appear to have any correlation with any outcomes.

Providing personal care is described by Warren $(2007,140)$ as the distinguishing marker of young carer and it appears in Becker's 2010 study as a critical factor in defining a young person as a carer. Yet in this sample personal and intimate care shows no correlations with any 
outcome in spite of the importance attributed to this type of activity by most researchers.

Responsibility however occurs as a correlated factor with outcomes. Caring for a sibling in addition to the person cared for, though not in itself a caring activity, is correlated adversely with a number of outcomes, presumably because of the responsibility involved and the time factor. Household responsibilities which include paying bills and managing household finances again entails taking on adult responsibility and is adversely correlated with Emotional Literacy and the Overall outcome.

The activity most significantly correlated with outcomes is Emotional Care. Supervising and providing company absorbs precious time as well as soaking up emotional energy. Bibby $\&$ Becker (2000) said that this is not recognised as being the most important and most difficult duty. It too confers responsibility on the carer. Like the MACA score, it is powerfully correlated adversely with Emotional Literacy and with the Overall composite outcome. Even when supervising and providing company for a loved person, long hours of this can, as observed in one case, leave the young carer wrecked with tiredness and for that reason finding it difficult to respond to opportunities and stimuli.

Few strong correlations associations exist with Social Capital. Where they do exist, they are not strong and the probability measure is not high. The level of domestic tasks has a positive but weak correlation with Social Capital (rho $=.273, \mathrm{p}=.037$ ) which might be caused by the 
feeling of competence engendered by performing regular familiar tasks such as washing up, cleaning.

With so little in the way of correlations and yet so wide a range of scores for Social Capital (48-141), it poses the question as to whether there are other influential factors operating. The amount of hobbies and leisure activities in which some were engaged was surprising. There were examples of young people involved in three or four groups or individual interests of quite varied kinds and a number in creative activities. It could be that there are other variables which have not been included here but would show correlation. Dearden and Becker (2002) suggested this explanation earlier for research being unable to explain the causes of educational disadvantage. Similarly different personal levels, difficult to quantify, of energy, drive, or curiosity for example might over-ride other factors. Similar to outcomes in Performance at School, there may be an element of motivation or resilience which operates outside the categories of biography or caring activity. This is re-enforced by the range of scores for social activities coupled with the absence of correlations or factors with strong predictive value for outcomes.

\subsubsection{Difference in outcomes between Projects (RQ 12).}

The Projects are located in areas with varying demographic, socioeconomic and cultural profiles and therefore in the particular challenges confronting the Projects. There were very few differences in the biographical and caring profiles of the populations of the ten Projects. Yet 
the results of data analysis reveal very few differences in outcomes between Projects.

ANOVA tests were applied and the only statistically significant differences in means were in:

$\square \quad$ the ages of participants where the mean age on $31 / 03 / 14$ ranged from 11.83 in one Project to 15.33 in another

$\square \quad$ the proportion who lived with non-biological parents $(p=$ 0.003) which was true of some participants in three Projects and none in the remaining eight Projects

$\square \quad$ the proportion of those who cared for people whose conditions changed without warning $(p=0.029)$ where the conditions of half or more of the Cfps changed often in seven of the Projects and none changed often in three of the Projects.

Since the young people entering the Projects are those who happen to come to them either by referral or self-referral, it would in any case be of doubtful value to attribute any difference to the particular Project or its way of working.

The reverse may be true however in that the Project's way of working may be affected by the young people who come to them. A factor such as the difference in means of the Reading score may be co-incidental but might affect the way the Project is managed. There is a considerable difference between Projects in the mean age and so the programme of activities might be adapted for the age range. Transport or distance issues may account for Projects in rural local authority areas adopting a 
service based in schools rather than on regular social meetings. It may not be useful therefore to draw conclusions on standards, methods or outcomes or on the best model of service delivery on the basis of these data.

The survey of YCPs asked about methods of evaluation and it was noted that whilst much work had been undertaken by all a minority had had independent evaluations. Projects are clearly aware of the need to examine their own quality and standards but the instability of funding revealed by the responses in Phase 1 raises the question as to whether the role and function of the Projects is clear to those commissioning and sponsoring them. It is possible that a recognised and shared evaluation process could help them with grant applications, tendering and fundraising as well as providing useful data capable of comparative analysis. They could be useful for funding and commissioning agencies themselves.

\subsubsection{Predictors of positive and adverse outcomes (RQs 13 and} 14).

The variables which logistic regression showed to have predictive value were often found to predict both positive and adverse outcomes.

The biographical factor with the greatest Odds Ratio in predicting outcomes was the quality of family relationships. This contributed to the statistically significant models predicting outcomes for the Overall outcome and Emotional Literacy outcome. Poorer family relationship was a predictor of a poorer Overall outcome and a lower level of Emotional 
Literacy. Another two factors which showed strong predictive value of both Overall outcome and Emotional Literacy were providing emotional care and household responsibilities. The strong correlations of Emotional Literacy with other outcome indices implies the importance of these predictive factors.

Predictors of outcomes for Educational Attainment were less useful. Regular help, with a high OR, and duration of caring were statistically significant but, as explained above, it is not clear that they were causal.

\section{Health outcome.}

Although Health inter-acts strongly with other outcomes, it finds few predictors amongst the biographical and caring factors and those showing predictive value come from a narrow base. Those with significant Odds Ratios are limited to the number sharing caring duties and the number of older people sharing. It could be argued that the common theme here is responsibility and that this is the element affecting Health outcomes. Its importance is increased because of the inter-connection of Health with Emotional Literacy and Social Capital.

\section{Social capital.}

Whilst there were few correlations with biographical and caring factors, Binary Logistic Regression revealed that Household tasks had predictive value caring for more Cfps $(O R=2.30)$. This was the only statistically significant factor. One of the implications of this factor might be that the time taken for housekeeping tasks impinges on opportunities for social activities outside and hobbies at home. 


\subsection{Features Concerning Young Carers Emerging from This Study}

\subsubsection{Factors which can and cannot be changed.}

Identifying biographical and caring factors associated with positive or adverse outcomes is only the first half of the story. As Metzing-Blau and Schnepp (2008) wrote, some of those factors cannot be controlled. For example medical intervention may not be able to affect the condition or the predictability of the condition of the Cfp.

Amongst those factors associated with the widest range of outcomes, the health condition of the young carer is a pre-existing factor which cannot be changed. It does though indicate the importance of health professionals understanding the obstacles faced by young carers, recognising them and taking any appropriate action including referring them to Social Services or YCPs.

Two biographical factors which did correlate strongly with outcomes are having an adult at home with whom they could share their feelings and the quality of family relationships. The state of family relationships may exist prior to the development of a caring situation. In this sample $19 \%$ did not have someone at home in whom they could confide. Three of these said also that they did not have a friend with whom they could share feelings. Nearly $23 \%$ said that their family shouted at each other $a$ lot of the time. Not surprisingly, the results of these measures showed a correlation with Emotional Literacy but also with the Overall Composite outcome. The data shows that those reporting poorer family relations are much more likely to have a lower level of Emotional Literacy and adverse 
outcomes. This is a familial factor not directly related to caring but it should be recognised that it is likely to be exacerbated by the stress within the household caused by illness or disability. Given this logical assumption, the result highlights the need for support to relieve the caring workload by whatever means are appropriate, both facilitating the independence of the Cfp and by decreasing the workload of the young carer by regular help and by respite. Even if the subjective burden cannot be lessened through support measures, at least the level of the objective burden can be reduced (Montgomery et al, 1985).

\subsubsection{Importance of social capital.}

The data about young carers' lives outside caring and outside school forms an important part of the foundation of later outcomes. The justification for collecting this data is the influence of social and communal activities in building social and human capital for the longterm and the potential of caring to interfere with this aspect of their agerelated development.

Data on social activities were intended as indicators both intrinsically of the level of current pleasurable leisure activity of the interviewees as young people as a measure of their current wellbeing and as possibly having predictive value for their ability to engage in activities in adult life.

The group activities would indicate their involvement with a peer or interest group outside their family. There is evidence of healthy 
participation by the majority but the lower or nil scores of some cannot be ignored.

The individual activities were intended to gauge their personal and internal resources and how far they had developed a hinterland. The data on time spent caring and tiredness indicates that they might have been restricted in doing so by a lack of time caused by their responsibilities or by a lack of spare emotional energy. The capacity to be engaged in interesting, productive or creative activities outside a structured environment such as school or college can be seen as building up a resource for later life. The range of scores is very wide with a majority engaging in their own hobbies. Some $(n=8)$ have more creative pastimes than usual, reporting song composition, creative writing and art as an activity. One had been published on-line. However at the other end of the scale two participants scored zero and six scored one only marking a worrying limitation on their lives which might have long-term consequences.

Their use of public facilities was meant to discover not just the level of activity but also their awareness of and familiarity with resources available in their community. The high number scoring zero is evidence again of gaps in their social experience. A low number were engaged in paid work but this may be due equally to the age limitation on children and young people working (14 upwards) or to unavailability of suitable work. There was a low number engaged in unpaid work also. 
Peer relationships, coping and aspirations are additional important aspects of building social capital. This study attempted to gather data on their networking opportunities but also an aspect of their mental wellbeing in having support from other people. Six participants scored a three or less for the composite Peer Group relationships while 11 reported not having a friend with whom they could share their feelings. Eight had never had or could not remember having free time to spend with friends and four of these were also amongst those without a friend.

The questions in the section on coping aimed to gather clues about the growth in their ability to cope with life situations not just in the here and now but how far they are being equipped for future challenges by acquiring skills and learning of sources of advice. Three or less was scored by sixteen young people.

Similarly to the other sections, the questions on Aspirations intended to uncover how caring had affected their long-term view and, in this particular case, whether any factors were associated with positive aspirations or with a lack of ambitions.

Responses provided data for measuring more than one value in each aspect. To take the first variable as an example, participation in group sports activities could be indicators of social and co-operative skills as well as of physical and mental health. Across the four types of activities, the results reflect together on the present and possibly on the future potential physical and mental health of the participants. 
It assumes particular importance also for long-term effects in employability or career terms in the light of the below average mean score for Literacy. According to Heyman and Heyman (2013), the effect of low Literacy rates has been exaggerated by Government because of the fear of an increasing rate of NEETs. In this situation, the acquisition of social capital offers another route to a satisfying life in the long term.

One feature of this domain is the wide range of scores. The extent of engagement of some young people is quite remarkable when set against the background of their caring responsibilities. One was involved in three local Projects at the time of the interview as well as sport and a second club. Another practised and played two musical instruments in addition to sporting activities. Secondly the paucity of strong correlations with any biographical or caring factor does not help to explain positive or adverse outcomes. Thirdly, in spite of some positive individual results, there is a cluster of young carers with very poor outcomes. This is why it should be a major cause for concern on all counts where there were zero and low scores. This is especially true where it was clear from comments made by participants that there was not necessarily any end in sight to the caring situation.

For twelve respondents, the only score for group activities was for attending the YCP. Insofar as they mitigate against gaps in the lives of young carers, Projects can be seen to contribute a significant element to their personal growth and sometimes provide a unique opportunity for 
social activities for young carers which is an important part of most young people's lives.

\subsubsection{Agency.}

Because it is a social construct, the status and meaning of 'young carer' can change over time and location. Young Carers have now become part of the social care structure (Smyth et al. (2011). It can be said with obvious basis in fact that they are part of the social care economy. It is difficult to see how for strategic, financial and policy reasons this could be dismantled. As pointed out by Smyth et al. (2011), this awards them agency.

At a personal level, there is evidence in this study which supports the contention that many young carers have a positive attitude. The high level of satisfaction at helping someone in the family in this sample indicates that many young carers want to care. The high proportion of quite good and very good relationships with the Cfp suggests positive bonds. The level of health in their self-estimates is good in a majority. Participation in social activities is wide-spread and in some cases impressive.

The argument for recognising their agency would seem to be supported by the evidence of positive attitudes amongst many young carers and of the benefits accruing from the caring experience and should be legitimised by recognition and support. As early as 1995, Mahon et al. are diverging somewhat from the trend towards pathologising young caring by suggesting that the distinction between 
normal and deviant is not useful. Returning to White's point, perhaps the effort should be to eliminate inappropriate or excessive caring and to prevent harm rather than to eliminate young caring. In many situations, providing appropriate support and equipping the young carer to cope better with their tasks would make their lives easier, might avoid adverse impact on health outcomes without treating their situation as unfavourable. The data shows that there are a high proportion of the participants who did not know of somewhere to go for advice, had not received any training for caring such as manual handling, administering medication or had not had advice on entitlements. It should be recognised that some of these responses could have been because the participant didn't remember what they had heard, that they did not conceptualise what they had received in the Project in this way or even that they missed that particular session. Project staff do provide some of this type of support but they are conscious that this is time out for the young people and they do not want it to emulate school. Nevertheless this might be something that the statutory and Project service could look at together to see how, where and when they could best address this gap in coping skills to make their lives easier. To these types of support could be added facilitating information on conditions and prognosis and the availability of 'child-friendly' books, pamphlets about long-term conditions which are in short supply (Howatson-Jones \& Coren, 2013, p. 2). Genetic advice might be needed where parents have heritable conditions (Aldridge \& Becker, 1993; McAndrew, 2012) and consideration 
of when and how it is appropriate to the individual young carer to learn about this.

The argument for developing an agency approach would seem to be supported by the evidence of positive attitudes amongst many young carers and of the benefits accruing from the caring experience. However it must be emphasised that this must not be at the expense of those with poor outcomes and the potential for adverse long-term outcomes.

\subsection{The Service}

\subsubsection{Unmet need.}

There is credible research which has established that the number of young carers is in practice so much higher than the number being currently identified, assessed and assisted by Social Services.

Dearden and Becker (2004) observed that $18 \%$ of their large sample had received an assessment which was an increase on the $11 \%$ in the 1997 study. It has been noted from the Welsh Government statistics (StatsWales, 2014/15) that of the 791 who had been identified as young carers in that year 720 had received an assessment. This represents an enormous improvement although the number identified is still well below the number of young carers estimated to exist in Wales.

The changeability of definition has been partly responsible for the difficulty in making a reasonable assessment of the number of young carers in the population who need support as has the changing nature of the caring duties. The hidden nature of the population hinders the 
measurement of outcomes. One flaw in research into outcomes is that the majority of participants contactable are already in the service.

The implications for policy makers and service providers are in planning services, in reaching those who would benefit from support and deciding on whether and how to target services. All the evidence from the service providers was that they were already over-stretched and anxious about their ability to satisfy the needs of those identified as young carers. It is safe to conclude therefore that the number of those in need of support is also greater than the number of those being supported. This raises the question of what is the best model of service in the circumstances for providing the amount of support needed and producing the best outcomes.

A high proportion of young carers in Projects have a low level of caring activity. In this study $25 \%$ have a low level on the MACA scale. This brings us back to the question of what distinguished those who help at home from those who are 'young carers'. It might raise a question about the criteria for referral: whether those with a low level of caring activity are referred to or accepted into the Projects because of the exceptional vulnerability of those particular young people not necessarily for the level of caring. It could be because of other factors in the family situation apart from the young person's caring responsibilities and that it is the combination of problems which create the need. If this is the only form of support available, this may be covering for another type of need which is at present unmet. 
The numbers who did and did not have regular help were evenly divided. An important question is why eight couldn't answer this question at all. This may be because they had not understood the situation, because they had not been fully involved in discussion with the social worker, because there had not been a young carer's assessment or because they had not been included in the family assessment.

\subsubsection{The significance of the Projects.}

It was observed from the Phase 1 data that the Projects had made progress in developing a dedicated service for young carers. It could be argued that they are the only specialist service. Across Wales the Projects appear from this study to have much common and shared ground in their values, aims and practice with no meaningful differences in outcomes between them in spite of being managed by different organisations. They have a network for regular meetings and discussions. What has developed in the last 15 years is a specialist service tailored to the needs of young carers. They have proved worthy of being commissioned or funded and having functions delegated to them by the statutory authorities. To match this, there is a growing sense of a specialist profession amongst Project managers and staff.

It can be seen from the survey results of the Projects that it is a place where the young carers can meet for discussions with peers and adults who understand their problems. It is a safe place where they do not have to explain themselves. It affords an opportunity for those without an empathetic adult at home to talk to an adult about their problems and 
feelings if they need to: "confidants and mentors, and guarantors of a child's welfare" as Gilligan described them (2004, p. 96). All Projects offer one-to-one sessions and some either offer counselling or a referral to a counselling service. The Project programmes provide a mixture of information, training, coping skills specific to young carers. At the same time all the Projects in the sample offer a social life and experiences and activities for which they may otherwise have narrow opportunities. They are able to do this by working round the young carers' practical difficulties, such as transport, timing or respite. One interviewee, in the midst of giving mostly adverse answers to Social Capital questions, pointed to the group and said 'That's why I come here'. In short they play a significant role in their acquisition of social capital.

Another role performed by most of the Projects is that of advocacy. Projects workers are often involved in improving situations in education, health and other areas. A long-standing issue for social workers has been the perceived conflict between their role as an advocate for the service user and their position as an employee. Even though advocacy for the young carer is wider than with Social Services, this might be why it is more appropriate for the third sector to deliver this service and why some young carers and families prefer to approach a non-statutory agency.

The range of scores in all domains warns against regarding young carers as a homogenous group. Because of their young-carer focused ambience, Project workers are able to assess and support the specific 
needs of individual young carers. It can be argued that a generic service would not be able to perform these functions and this is why the Projects are needed.

\subsubsection{The effectiveness of the Projects.}

It is clear from the data that each Project can vary according to local circumstances. For example urban and rural areas adapt to the different local challenges. Some Projects do not offer regular club events. An approach employed in some rural areas to reach unidentified young carers is to base the service in the schools. The outcomes between those who do and don't offer club events do not differ in this sample. This is not conclusive or generalisable but raises the question about which elements in the service contribute most to positive outcomes. For example is it the social group aspect or the individual attention which fulfils the greatest need? Or is it the opportunity to be with their peers in a relaxed environment? Or is it the personal contact with empathetic adults other than their immediate family? Or is it the attention, the listening ear which can be provided equally well by workers in the clubs or by link workers in schools. The lack of a control group in this study precluded the comparison of outcomes between young carers supported by a Project and those not supported. This would seem to be a critical gap in our knowledge.

Even though there is a lack of research into outcomes from Projects, there have been plentiful expressions by participants and parents and professionals of the value of the Projects. The Projects are often reported 
to be the one place where young carers can come together and be open about their identity and its effects on their lives. Part of the success of many of the Projects is the opportunity they offer to discuss problems privately or in group sessions and to acquire coping skills.

Set against this, there is some limited evidence of non-effect. Frazer \& Pakenham (2008) said that group comparisons failed to show statistically significant intervention effects in their study of young carers of parents with mental illnesses. There were clinically significant improvements in mental health literacy, depression, and life satisfaction eight weeks after treatment compared to the control group but the authors concluded, however, that there was insufficient evidence supporting the effectiveness of these interventions. Further comparative research with control groups could clearly be helpful in establishing the effectiveness of Projects and which elements are critical in achieving it.

\subsubsection{The stability of the service.}

If the evidence in this study is accepted that the Projects add to the amount of service available and make a unique contribution, funding then becomes a critical question. Funding for the existing service leave alone for any extension was a major concern for responders to this survey. In Wales, since the beginning of this study two Projects had ceased to operate due to funding shortfall. This concern is backed by the survey by Action for Children (2011) of their own Projects in England, Scotland and Wales. This found that almost one in 10 already knew that their Project would close, and a further one in five said they were at risk 
of closure. The decrease in funding described by Action for Children offers a worrying example of what can happen even to valued services. Since the service to young carers now relies so heavily on the existence of the Projects, they should surely not be relying on unstable and unpredictable funding or the narrow funding base revealed by Phase 1 of this study.

It is possible that the role and function of Projects is not always clear to those commissioning and funding them. Methods of evaluation were a subject of the questionnaire to the Projects and it was noted that a minority had arranged for independent evaluations. Projects do a great deal of work individually on examining their own standards and practice but it may be that an agreed evaluation process would help them deal with grant applications and tendering. It might help commissioning and funding bodies as well to understand the role and value of YCPs.

\subsubsection{Models of service.}

The service in Wales at the present time seemed from this study to rest mainly on two planks: Social Services and the YCPs. It is Social Services who have responsibility for and carry out or delegate the statutory responsibilities of assessment and reviews and providing support for the family of the young carer at home. Other personal support and assistance is provided where resources make it possible. Beyond that function, YCPs provided a wide range of social and emotional support.

This is cause for concern on three connected fronts. Firstly, as described above, the stability of the service is under question. Secondly 
there is the issue of capacity. Both statutory and third sector providers worried about resources and funding. Projects were starting to build up waiting lists and had to prioritise those in most need. In those circumstances providers both statutory and third sector are hampered in their efforts not just to provide an adequate service but to develop a specialist service which can assess and support with confidence and accuracy. How the capacity issue can be dealt with is a weighty question.

Social Services assessments sometimes judge that attending a Project would not necessarily benefit a young carer. Indeed sometimes young carers themselves do not want to be referred to a Project. Some cannot get a place in a Project because Projects are by their own account full. Yet those young carers may still need support even if it is not to be the Project which provides it. Consequently it might be advisable to consider alternative models of service.

However important the role of Projects in improving outcomes, it might be concluded that other agencies and other models of service could perhaps also be effective in reaching, identifying and supporting hidden young carers for the reasons explored in Section 4.2.2. If there is unmet need with the service in its current form, perhaps we should be looking at additional types of service which will reach the parts that others do not reach.

The Phase 1 survey discovered that link workers in schools were managed by several Projects in Wales already. These are a step away 
from the club model and suit the area in which they operate. They may also help towards realising the role that schools can play in identifying and supporting young carers.

The huge potential of digital media has yet to be explored and evaluated in this context. As early as 2002, Banks et al. suggested that a large number of young carers would be helped by moving away from the "traditional 'center-based' approach" (2002b, p. 243). Social media are beginning to be used in other fields and related methods could perhaps be adapted for this purpose. The extent to which young carers in this sample use social networking and the internet suggests that this would be a natural means of communication for them especially in the problem of hidden young carers faced by the conventional services. Drost \& Schippers (2015) conclude from their study that it is "anonymously accessible at all hours...It makes it possible for site visitors to emerge from their hiding and to find information and use support at their own pace. In short, it can be highly empowering. (p. 63)

There is already quite a range of web-sites, some of which are interactive, some of which display local knowledge. To disseminate information about these and advice on which are reliable and trustworthy would be useful. Methods used by inter-active websites include confidential chat rooms, surgeries and seminars. There are phone helplines, some specific to young carers, to be found through web-sites. This would not be a solution for everyone since, as one young interviewee remarked, when you have a problem you need to talk with someone 
face-to-face. However it could contribute to filling the gaps. Furthermore attitudes to digital media are changing very fast and this form of provision may become more effective with time.

There is much policy discussion generally about telehealth, telemedicine and telecare. One example of this particular type of IT would be to alert the services when a crisis develops. Another could be to contact a young carer when there is a problem at home. There was a high number in this sample who said that they worried about their families whilst at school and there was a positive correlation with Emotional Literacy $(t=-2.656 ; p=.011)$, with Feelings as a result of caring and with the Overall outcome $(t=-2.255 ; p=.030)$. The use of telecare could be a way of putting young carers' minds at rest in school if they knew that they would be alerted in the event of their being needed. As far as it was possible to determine by the brief inquiry at the start of this study, there may be little use of a telecare service with young carers at the moment (see Appendix C). It might be useful to explore further how this could be facilitated as one way to alleviate stress.

Research shows that learning, if disrupted by caring duties, can have a life-long impact. Life course theorists would argue though that as learning is a life-long process there may be opportunity for 'catch up' learning to take place later. Schools are starting to use digital sites for homework and additional Project work hence the use of digital media could be considered for compensating for the interrupted studies of young carers and for post-caring support/intervention too. 
In this age of digital communication, more understanding is needed about how it can be adapted and utilised for the self-identification and support of young carers. It is perhaps time to explore this avenue imaginatively and creatively.

\subsection{Welsh Government Policy}

The argument between the differing suitabilities of a dedicated and a mainstream service for young carers was presented early on in the life of the young carer service by Mahon \& Higgins (1995). They discussed the advantages of having the service delivered either by a statutory or by a voluntary agency. They identified one important factor favouring third sector initiatives as the reluctance of young carers or their families to allow the involvement of statutory workers. As was seen in the Phase 1 survey, in practice the majority of the Projects in Wales were delivered by not-for-profit organisations and against a background of co-operation a fairly clear separation of roles has developed between the statutory and third sectors.

In policy terms, the Welsh Government has followed the path which has proved effective in disability policy by moving it from primarily a Social Services responsibility to a being a cross-cutting issue: '"fully integrated into all Welsh Government policies and strategies affecting carers" (WG, 2013, p. 31). The broadest definition of carer has been adopted. They are both carers and children in need; their needs should feature in all policy areas. In practice this would depend on generic services catering for some young carers' needs. This relies on all relevant 
agencies understanding the issues, being able to identify young carers and their needs and having the will and the resources to accommodate the needs of a young person with caring responsibilities. Arguing for the agency of young carers would seem to support the approach of the Welsh Government, treating young carers as young people with normal desires and ambitions. It would in the process cast inescapable responsibility on other agencies to accommodate their needs.

This study may raise some questions about the degree to which the cross-cutting approach has been successful so far in supporting young carers aged 16 and under in Wales: how far agencies other than Social Services have moved to being aware, to identifying and to including young carers; to what extent they are able to match the Project environment where young people can mix, safe in the knowledge that their difficulties are understood by both peers and adults; how much their services are accessible to young carers.

\subsubsection{Secondary schools.}

Some of the anecdotal evidence from participants in this study revealed that teachers didn't always acknowledge or allow for the difficulties a young carer faced. Yet the role of the school in supporting the young carer is critical. Recommendations were made from 2004 onward that a named member of staff in each school should be designated as responsible for young carers (Children's Commissioner for Wales, 2009; Princess Royal Trust, 2010; WAG, 2002). The need for the involvement of schools was emphasised in the Guidelines to the Carers Strategies 
(Wales) Measure (2012). The brief inquiry early in this study (2013) had asked whether these had been implemented. Although some progress was being made, it was still some way from realisation across Wales. The Carers Strategy 2013-16 talks of the "important role" (para 4.4) and "vital role" (para 5.5) that schools and colleges have in identifying and supporting young carers (WG, 2013) referring to the UNCRC. The toolkit (WG, 2014) has been designed specifically for professionals in Health, Education and Social Services and it is hoped that this will assist the development of practice. The initial steps made in secondary schools as observed in this study (Appendix $\mathrm{H}$ ) will probably now be making further progress.

Where YCPs are working in schools, presumably this will raise awareness amongst staff and bring about a change of culture where young carers are not yet identified and understood. If the YCP work goes as far as providing support for individuals, this will presumably replace the school's function to some extent. When there are examples of both models working fully, it may be possible to gather empirical evidence on whether there is any difference in outcomes and which is the more effective model.

\subsubsection{Health.}

In this current study, the pattern of referrals to Social Services and Projects and the awareness of recipients in awareness raising sessions suggests that Health is not as strong a partner as could be wished. In a recent literature review trainers of health professionals remarked on the 
lack of leadership and training in preparing health staff in the community to recognise and accommodate the needs of young carers (Sprung \& Laing, 2014).

\subsubsection{Leisure and youth services.}

Attempts were made in this study to recruit young carers not in Projects through some leisure and youth services. There was only one volunteer. There are multiple possible explanations for this. However, over the large network contacted, it would perhaps have been surprising to have so few responses if there had been a general awareness and inclusion of young carers.

If the Welsh Government is to ensure that recognition of and support for young carers is included in all policy strands, this will need to be backed by stringent and continuous monitoring of provision, of both quantity and quality, by maintaining an overview of how all the relevant agencies are performing and drawing attention to any gaps.

\subsection{Limitations of This Study}

There were a number of inevitable difficulties when working with this population of children and young people and of young carers as outlined in Section 6.3.

\subsubsection{Socialised responses.}

Firstly there was an increased risk of socialised responses in the power imbalance implicit in interviews with young people by adults. In this sample the young people seemed to understand the research process and as much as possible was done to assure them of confidentiality and 
anonymity in order to encourage willingness to give honest answers. Responses were mostly immediate and unhesitating which suggests that they were frank. There were one or two responses which could be suspected of not being honest, for example denying interest in their appearance when their appearance contradicted this, but this was infrequent.

\subsubsection{Time restrictions.}

Given the opportunity this study afforded to talk directly to young carers and to find out about their lives, there was no end to the questions which could have been asked. However, as described in the development of the measures, there were considerable limits on the extent of the questionnaire and of the interviews themselves resulting from the age group, from the spread of ability and from the wish not to encroach too long on the precious social time of the young people.

\subsubsection{Expectations of what participants can contribute.}

The intention to gather quantitative data conflicted with the age and situation of the participants. It would have been unreasonable to expect as much detail and precision in answers to quantitative questions as when working with adults or compared to working with original data and this expectation was confirmed by the comments of the young carers who assisted with the development of the questionnaire.

\subsubsection{Recruiting the sample.}

Difficulty was experienced with recruitment of the sample. Recruiting from a hidden population was compounded by a number of other factors. 
Obtaining parental consent in troubled and sometimes dysfunctional families was a poorly rewarded exercise. It seemed particularly bureaucratic to ask for signed parental consent in Projects where there was already block parental consent for trips and photographs. Access was complicated by the practicality of making arrangements with Projects as they had often to change dates, venues and programmes at short notice. In addition it was not certain that individual young carers would be present even when they had signed up or could guarantee to attend when promised.

\subsubsection{Representativeness.}

Sample size in this study was dependent on two factors: available resources, that is time and cost, and responses from the sampling frame. Hence it was a small sample with a high margin of error.

The representativeness of the sample was compromised by the lack of young carers from BAME communities and the small number of those caring for adults experiencing alcohol problems or substance mis-use. So the sample was less inclusive than would have been wished. A wide range of possible reasons for this can be proposed: for example that young carers in those situations did not choose to come forward for interview. It was suggested by some Project workers in the organisations approached that the young people did not want to admit to their situation. The literature review revealed contradictory views on the level of young caring in BAME families but more needs to be known about them. More research in that area could discover whether there is 
an unidentified pool needing assessment and whether and how their experience and need differs from those of young white British carers.

It has not been unusual for researchers to encounter this problem (Becker, 2009; Mahon \& Higgins, 1995; Svanberg, 2010). Additionally there was only a small component of cases with mental health or addiction problems and this may also cast doubt on the representativeness of the sample.

\subsubsection{Control group.}

Tarapdar (2007) reported on the methodological shortcomings of large scale surveys which depend on young carers identified through YCPs. The inability to carry out one of the initial aims of comparing outcomes for young carers in Projects with those not in Projects was disappointing. The hidden nature of young caring in the population and the reasons for this were explored in the section on barriers to take-up (Section 4.2.2) and this forewarned that it was always going to be difficult to reach young carers outside the Projects even through recognised sources of referrals. Waiting lists was one route which had been identified but it was not clear where and by whom waiting lists were kept. There were no referrals from pastoral heads of care in secondary schools. Requests to youth, disability and sports organisations brought no referrals. Kennan et al. (2012), recruiting for study of young carers in Ireland where there were no specific services for young carers, tried a vigorous poster and leafleting campaign to a thousand schools, youth information centres and youth cafés but received only one response. In addition it 
could be argued that waiting lists were not a valid source of unsupported young carers because their outlook might have already been affected in a positive direction by the prospect of future support (Fraser \& Pakenham, 2008).

It is well documented that gate-keepers, that is social workers, Project workers, heads of pastoral care, youth workers, are rightly protective of those for whom they have responsibility but it may be that some are over-protective (Carter, 2009). Heavy workloads and stress must be recognised as one possible reason for requests from researchers being a low priority. Another reason, although an unwelcome one, might be that some of the agencies approached were not pro-active in identifying young carers. Thomas et al. (2003) researching in Wales remarked on a poor response from schools and speculated that this might be due to a failure to recognise the particular situation of young carers.

Soon after the study began, it became apparent that it was not going to be possible to recruit a control group within the available time and resources. As a result, it was necessary to re-focus the research aims. This was a disappointment from an academic point of view as it would have been extremely valuable to go beyond measuring outcomes in this sample towards testing for differences in outcomes between those in Projects, those not in Projects and those with any other type of support. Without a control group, it is not possible to conclude whether any of the positive outcomes were attributable to participation in the Projects. 
In this situation, the nearest the study could come to any evidence on this issue was to compare the outcomes for those who belonged to Projects which provided regular club-type support $(n=53)$ with outcomes for those who did not $(n=9)$. Even this is not a valid comparison since two of the latter Projects provided occasional events and some of the Projects organising regular club events also gave oneto-one sessions where needed. Nevertheless it is worth noting that there did not appear to be any statistically significant differences in outcomes between Projects which did or did not organise regular club events.

\subsubsection{Conditions of ethical approval.}

The difficulties encountered in this study but by no means unique to it prompt consideration of the ethical approval process. No challenge is raised to the basic principles of ethical considerations embodied in the relevant codes or to the requirements of approval of this study. However, from the point of view of the researcher, the practice on the ground of reaching participants, establishing communication and arranging for data collection proved to be considerably more messy than envisaged beforehand. Too narrow a prescription of what is appropriate in approaching participants can be unrealistic.

Furthermore, the gate-keepers' role of protecting children sometimes acts as an obstacle to children's participation and hearing their voices. Some researchers claim that the vulnerability of children is exaggerated and that consequently ethical requirements are unrealistic (Carter, 2009; Kennan et al., 2012, Valentine et al., 2001). It is argued that the ethical 
demands to protect children from harm should be less onerous and that this would facilitate children's participation and promote their agency.

\subsection{Dissemination and Utilisation}

On the completion of the study, those findings which have proved to be substantive and to contribute to the sum of knowledge about interventions for young carers will be relevant to the makers of policy and holders of budgets that affect young carers. If they are to be useful, it will be to contribute to the decisions on how best to support young carers and to direct efforts.

As explained above, the engagement with the Social Services and YCP networks in the research process is expected to create an interest in the results and findings. This will be re-enforced by sending reports to the respondents to the surveys and to the lead officers and any contacts in Social Services Depts. made during the survey process. They will be sent to all Project leaders and, where different, to the respondents from the Projects. An approach will be made to COLIN to offer a presentation of the findings to an all-Wales meeting as a follow-up to the original presentation of the research plan.

In addition, reports of the findings will be sent to those who were interviewed in the preliminary phase. Contacts made during inquiries to Local Education Authorities (LEAs) and those responsible for telecare in the Welsh Government and local authorities will also be sent brief reports of the findings. Brief summaries of the findings will be sent personally to a list of third sector organisations concerned with young carers and to 
those in the political and policy field who have been identified in the course of research to have an interest in the subject. Opportunities will be sought to have the findings reported in academic and current affairs media. The findings may provide material suitable for publication in peer-reviewed journals; if so, articles will be prepared and submitted. 


\section{Chapter 9}

\section{Conclusions}

The intentions of this study were to identify areas where there are still gaps in our knowledge and especially those which could benefit from future work, to contribute to a better understanding of the outcomes for young carers and to consider the practical implications for the services.

The conclusions fall into six categories: provision, outcomes in Educational Attainment, outcomes in Emotional Literacy, outcomes in Social Capital, understanding the needs of young carers from BAME families and correlations between outcomes which may be of use to service planners and providers.

\subsection{Provision}

The findings were that there were two main services for young carers in Wales: Social Services and the YCP network. The YCPs have developed the skills and programme of a specialist service and there has been sufficient subjective evidence that young carers enjoy and benefit from attendance at a YCP. There has been less objective evidence of their effectiveness or of which aspects of the support is most significant in contributing to positive outcomes. Much work has been done by both services on measuring outcomes but it would be advantageous for Social Services to do further work to validate attribution of success to their own intervention and for YCPs across Wales to work together to agree a template for self-evaluation. Evidence of their effectiveness would be invaluable in planning services and gaining recognition of their critical 
importance. In particular it would help to know which elements in their activities are most useful and cost-effective.

Analysis of the data from the YCPs who responded showed little in the way of differences of means at group level in the main outcomes. The statistically significant differences that did appear, in the subsets Reading $(F=2.21, p=.03)$, participation in religious activities $(p=.00)$ and youth club attendance $(p=.00)$, may not have any implications for the effectiveness of the individual Projects or their models of service delivery since they are sited in economically and culturally different areas and each receives referrals subject to the assessment processes of other agencies.

In spite of effort by existing providers, there appears to be extensive unmet need and they are themselves very conscious of the magnitude of the problem. In view of this gap in our knowledge and the practical difficulties of delivering a service to this group, it is suggested that other additional models of service could also be considered and assessed for effectiveness. To exacerbate the problem, the YCP network is insecure because of funding issues. In fact resources were identified as a problem for both services.

The following actions are therefore recommended:

- The YCPs play a major role in the current service and owing to their unique input may continue to do so whether, or until, other service models are developed. For this reason, the 
future of their funding needs to be reviewed at a national level.

- It would be helpful in assisting the Projects to present their own case individually and as a network if a joint effort could be made by them to develop and agree a common template for self-evaluation.

- There should be a study of outcomes from Projects employing a control group design.

- A study of different models of support for young carers and the outcomes should be carried out in order to evaluate the comparative effectiveness of the different models of service.

\subsection{Outcomes in Educational Attainment}

A shortage of objective data on levels of literacy was observed during the literature search and the use of the objective measure BAS3 produced new quantitative data on literacy for analysis. The results showed that the literacy level of young carers was lower at a group level than in the agematched population. This is cognate with previous qualitative evidence of the negative effects of caring.

In seeking predictors of outcomes, literacy appeared to be comparatively isolated from outcomes in the other domains. Furthermore the only biographical or caring factor showing a correlation with literacy was the type of health condition of the young carer $(r=-.54, p=.01)$, those with neuro-developmental conditions having lower attainment scores at a group level. This correlation is not likely to be unique to 
young carers but does raise the question of the important contributory role which schools might play in preventing adverse outcomes in this area.

The lack of responses to this study from secondary schools in Wales leaves a question about how far schools are pro-active and successful in identifying and supporting young carers according to guidance issued by various organisations since 2002. One recommendation is made regarding these findings:

- A review should be undertaken into how far existing guidelines are being implemented by educational establishments in Wales on identifying and supporting young carers.

\subsection{Outcomes in Emotional Literacy}

The use of the objective measure SEMERC produced new quantitative data for analysis of emotional literacy. As for literacy, this confirms the previous qualitative evidence of the negative effects of caring. The Emotional Literacy Index of young carers was lower at a group level than in the age-matched population.

Analysis of the data from the interviews with young carers showed strong evidence of the interconnectedness of Emotional Literacy with the two domains Health and Social Capital and also with the performance element of Educational Attainment. This would seem to support the concept of young caring as a cross-cutting matter and thus to vindicate the WG approach. 
Notwithstanding the WG policy intention, evidence in this study suggests that so far provision might be resting on a narrow base unlike the services the policy requires. The Carers Strategy for Wales 2013-16 lists the agencies needed for strategic provision for young carers. As well as Social Services, it includes agencies in the fields of education, health and social/leisure activities. It would be helpful to monitor how far these agencies are aware of young carer issues and how successful they are in reaching and supporting young carers as part of the national picture. Reflection on the literature and the data obtained in this study suggest that the following actions might be helpful in developing a fully supportive service for young carers in Wales and, if the integrated approach of the Welsh Government to young carers is to be effective, it will require:

- that responsibility be designated in Wales at a national level for monitoring strategically the effective implementation and development of support for young carers

- that the extent to which Youth and Leisure services are equipped to provide access to their service for young carers be monitored

\subsection{Outcomes in Social Capital}

The exploration of the young carers' social and leisure activities produced much new empirical data which allowed analysis of social capital outcomes in relation to young carers, a comparatively unexplored area. This aspect of the study contributed to the body of knowledge in that it had for the first time established norms in this aspect of data and 
facilitated a base-line for comparative research. This new data provides a platform on which to build.

Yet the comparative lack of correlations with biographical and caring factors infers that there could be other variables outside the scope of this study which would explain why some young carers are able to overcome their circumstances to live a very full social life and this needs exploration.

The importance of a greater understanding of social capital in young carers has been strongly argued in this thesis and it is believed that a comparative study would increase comprehension of this aspect of the life-cycle of young carers. It is suggested therefore that a means should be sought:

- to study further the outcomes in Social Capital, comparing results for young carers with those not in Projects and young people who are not carers.

\subsection{Understanding the Needs of Young Carers in BAME Families}

It is evident from this study that there are gaps in our knowledge of young carers which require further examination. Difficulty in recruiting participants from BAME families was experienced by previous researchers and replicated in seeking volunteers for this study. Yet BAME families form an increasing proportion of the population. This is a significant sector of the young carer population and is so far under-represented in research. It indicates therefore the desirability of a specific effort to examine the needs of this group and the possibility of any differences in 
experience and outcomes from young carers in the general population. An area recommended for future research is therefore:

- the incidence of young carers in the BAME community and whether their experience and needs differ from those of young carers in the general population and if so in what ways.

\subsection{Correlations and Potential Predictors of Outcomes}

A better understanding of the outcomes for young carers and evidence of valid predictors of positive and adverse outcomes might assist providers in the statutory service and this study has sought to explore some possible associations. It is hoped that these findings supply food for thought about which factors are useful as predictors and which are less so.

Those which concern the degree of stress at home such as the caring workload and the degree of responsibility might be expected to act as predictors of outcomes. Any support which can reduce the impact should improve the outcomes especially for those with lower scores. What has been less highlighted until recently is the way in which many young carers seem to have absorbed their role and to have developed a positive outlook. It has been argued in this study that there appears to be little chance of eliminating caring by children and young people and that to try to do so might in any case be against the inclination of many young carers themselves. It might also lessen the chance of hidden carers coming forward for support. A recognition of the impressive maturity and competence of many young carers and of the contribution they make 
means that supporting their skills and prospects might be a better way forward. It might be preferable to accept their contribution as constructive and in so doing lend them agency. 
Appendix A

Research Objective, Aims and Questions

\begin{tabular}{|c|c|c|}
\hline $\begin{array}{l}\text { Research } \\
\text { objective }\end{array}$ & Research aims & Research questions \\
\hline \multirow[t]{6}{*}{$\begin{array}{l}\text { To explore } \\
\text { outcomes } \\
\text { for young } \\
\text { carers. }\end{array}$} & $\begin{array}{l}\text { 1. To map and } \\
\text { evaluate } \\
\text { extent of } \\
\text { existing } \\
\text { provision for } \\
\text { young carers } \\
\text { in Wales. }\end{array}$ & $\begin{array}{l}\text { 1. How well developed are the } \\
\text { services for young carers? } \\
\text { 2. How much partnership working } \\
\text { is there? } \\
\text { 3. How accessible are the services? } \\
\text { 4. How do the service providers } \\
\text { evaluate their service for young } \\
\text { carers? } \\
\text { 5. What do the service providers } \\
\text { perceive to be the challenges? } \\
\text { 6. What is the relative importance } \\
\text { of the Projects in provision for } \\
\text { young carers? } \\
\text { 7. What is the amount and source } \\
\text { of current investment in Projects } \\
\text { in Wales? }\end{array}$ \\
\hline & $\begin{array}{l}\text { 2. To examine } \\
\text { the } \\
\text { relationships } \\
\text { between } \\
\text { outcomes and }\end{array}$ & $\begin{array}{l}\text { 8. What are the outcomes on the } \\
\text { chosen measures? } \\
\text { 9. Is there any association } \\
\text { between Educational Attainment } \\
\text { and other outcomes? }\end{array}$ \\
\hline & $\begin{array}{l}\text { factors which } \\
\text { may have } \\
\text { contributed to }\end{array}$ & $\begin{array}{l}\text { 10.Is there any association } \\
\text { between Emotional Literacy } \\
\text { and other outcomes? }\end{array}$ \\
\hline & them. & $\begin{array}{l}\text { 11.Is there any significant } \\
\text { statistical evidence of an } \\
\text { association between outcomes } \\
\text { and any factor in the } \\
\text { biographical data? }\end{array}$ \\
\hline & & $\begin{array}{l}\text { 12. Are there any differences in } \\
\text { outcomes at group level } \\
\text { between Projects? }\end{array}$ \\
\hline & $\begin{array}{l}\text { 3. To identify the } \\
\text { relative } \\
\text { importance of } \\
\text { factors } \\
\text { affecting } \\
\text { outcomes for } \\
\text { young carers. }\end{array}$ & $\begin{array}{l}\text { 13. Which of the variables have } \\
\text { the strongest association with } \\
\text { positive outcomes for young } \\
\text { carers? } \\
\text { 14. Which of the variables have } \\
\text { the strongest association with } \\
\text { adverse outcomes for young } \\
\text { carers? }\end{array}$ \\
\hline
\end{tabular}




\section{Appendix B}

Data on Numbers of Young Carers and Population in Wales

[Data from StatsWales web-site].

Nos. of young carers identified, assessed and provided with services: excerpt from StatsWales collating local authority submissions.

Table A:

Data for young carers in Wales identified, assessed and provided with a service (StatsWales)

\begin{tabular}{lccc}
\hline Year & $\begin{array}{c}\text { Number } \\
\text { identified }\end{array}$ & $\begin{array}{c}\text { Number } \\
\text { assessed }\end{array}$ & $\begin{array}{c}\text { Number } \\
\text { receiving a } \\
\text { service }\end{array}$ \\
\hline $2006 / 7 *$ & 451 & 354 & 283 \\
\hline $2007 / 8 *$ & 745 & 572 & 556 \\
\hline $2008 / 9$ & 888 & 663 & 674 \\
\hline $2009 / 10$ & 933 & 793 & 792 \\
\hline $2010 / 11$ & 1,065 & 980 & 971 \\
\hline $2011 / 12$ & 1,070 & 969 & 948 \\
\hline $2012 / 13$ & 869 & 802 & 777 \\
\hline $20013 / 14$ & 810 & 696 & 649 \\
\hline $2014 / 15$ & 791 & 720 & 705 \\
\hline
\end{tabular}

Not a full data set for 22 authorities. 
Appendix C

Inquiry into Use of Telecare Service in Wales for Young Carers

Programmes to pilot and promote the use of telecare by local authorities were set up by all three UK governments from 2006. It seemed that this developing service might have potential for young carers so an exploration of the pilots was included in the preliminary work of identifying the most important services for young carers. Because this young carer study was to be located in Wales, the WAG Telecare Capital Grants (TCG) to local authorities seemed most relevant to this study. Funding had been distributed to local authorities for each to develop a telecare service appropriate for their area and its needs.

\section{Method}

The Telecare Learning and Information Network set up by the Social Services Improvement Agency (SSIA) was identified by the researcher as a useful way of contacting all the local pilots and the Co-ordinator in the WAG proved helpful in doing this. In preparing an approach to the local pilots, an issue emerged about the legal implications of having a minor as the named contact. A letter inquiring whether any referrals had been made for young carers and about the legal implications therefore was circulated by e-mail by the Co-ordinator via the Network in early February 2012 to the 22 Telecare Project Managers. A reminder was sent out by the Co-ordinator's office a month later. 


\section{Results}

The location of the Projects varied across Wales and the responses that were received came from varied sources: part of front-line social work and an existing alarm service and a stand-alone Telecare Project.

In all five replies were received. One said that they were aware of the potential but that it had not been pursued yet in their authority. Another gave much the same response and remarked on the lack of awareness of telecare in children's services compared to adult services. They did know though of one referral for a family from a young carers' worker to relieve the stress on a young carer so they felt that there was growing awareness. They made also the interesting point that alarms linked to mobile phones should be facilitated as most suitable for use by young people. There was a response from a third and fourth authority with no record of Telecare use with young carers but one did invite the researcher to visit and view their alarm and mobile response systems. A letter from a fifth authority came from the Young Carers Support Worker who dealt with cases from a family perspective. The letter had been passed to the person in Social Services who was responsible for the young carers service in this authority. She had mentioned it to a number of young carers who had been positive about the idea and she had made some referrals to the adult team for families where a young carer was involved with recommendations that telecare be considered. The problem with delivering it, she observed, was the cost factor which would inhibit its take-up by some families with young carers. 


\section{Conclusions}

The lack of responses from the other 17 authorities cannot be assumed to mean that there were no examples of use with young carers. It was interesting therefore to look for references to young carers in the local and national reports on the programme and the pilots.

The initial local strategies of eleven of the local authorities were available on the Welsh Government web-site in 2014. The references to carers in these documents revealed two aspects under consideration: carers playing a role in the delivery of services and carers as themselves vulnerable people. Of the eleven, five mentioned both aspects in the section on aims and benefits. Most of the strategies included both aspects in the planning sections and only two strategies failed to mention the needs of the carers at all. Some presented the concept of the carer and the service user together as a partnership. In none of them was there a reference to young carers.

The analysis of the data from the pilots on the impact of the T.C.G. prepared by consultants from Imperial College Business School (Bayer \& Barlow, 2010) made no mention of young carers. Whilst this does not preclude the possibility of there being young carers amongst the service users, it may be that this was not presented in the local authority data available to them.

The final report on the T.C.G. programme prepared for the WAG. (Barlow et al., 2010) did not acknowledge the references to the wellbeing of carers in the initial local strategies but it does acknowledge the 
wellbeing of carers amongst the benefits resulting from the pilots, citing "Peace of mind and independence for carers and users" and "Economic independence for carers who can go back to work" (p. 15). From the point of view of this study, there was no mention of the use of Telecare with young people with caring responsibilities and the specific issues for the use of telecare with young carers was not discussed or else had not been mentioned in the brief.

One of these issues would be the legality of a minor being the named responsible person. There was no response from the Welsh Government to a question about making referrals to a minor so advice was sought from the Law Department of Swansea University (August 2nd, 2012). Two complementary aspects of the situation were identified. Firstly there would be no problem with notifying a minor in itself but:

If they triage the call and make a determination as to the best responder then would passing the information on to a child carer to deal with and action be seen as falling below the standard of care expected of such a service should harm occur as a result? (Personal communication, 12/09/2012)

A legally acceptable solution, it has been suggested by a member of a Telecare service, would be for the monitoring service to respond to the alarm, take the necessary action, contacting other family members and then inform the young carer. This might be a workable solution if there are other family members available and willing to take on this role. An obstruction to this solution might be the known reluctance of families 
with young carers to share knowledge of their situation with outsiders. This issue needs to be discussed and a protocol established if concerns about legality are not to inhibit the use of telecare where young carers are involved.

Another issue which emerged from one of the responses was the difficulty when Telecare services were subject to a charge. An instance was quoted of a family not being able to afford the service. The SSIA web-site described access to the use of automatic pill dispensers for which there was a cost. This depended on the good will of the pharmacist to avoid service users being excluded from the service.

The T.C.G. scheme ended in 2009 and it was then left to local authorities to fund the continuance of the innovations. The post of Coordinator in the Welsh Government is no longer in place although cooperation continues at a local and regional level. In the light of this inquiry, it was concluded therefore that the potential of the telecare service to support young carers was still a distant prospect and did not seem to be a service that merited inclusion for a detailed report in this study. 
Appendix D

Social Services Questionnaire

\section{QUESTIONNAIRE to SOCIAL SERVICES in WALES}

To Local Authority Officers with responsibility for Young Carers

Name:

Title:

Local authority :

E-mail:

Phone:

Address:

Questionnaire Number:

For the researcher's use 


\section{QUESTIONNAIRE to SOCIAL SERVICES in WALES}

To Local Authority Officers with responsibility for Young Carers

Please fill in or tick the appropriate boxes:

\section{Contact details}

1 (a) Are you the person with lead responsibility for the service to young carers within your authority? $\square$ Yes $\square$ No If No, please go to Ql (c)

1 (b) Is this a sole responsibility with no additional responsibilities?
$\square$ Yes
No Please go to Q2

1(c) Please can you provide the name and title of the person with lead responsibility and return the questionnaire to me. There is no need to complete any further questions. Thank you for your response.

\section{Strategy}

2(a) Does your authority have a Young Carers Strategy?

$\square$ Yes $\square$ No $\square$ Currently developing a Young Carers Strategy

2(b) Do you hold regular strategic meetings regarding young carers with any of the following:

$\square$ The Education department in your local authority

$\square$ Healthcare providers in your area

$\square$ Third sector (not for profit) organisations

$\square$ Other relevant organisations (please specify below)

2(c) Do you contract out any part of your service for young carers to any external organisation?

$\square$ Yes $\square$ No

\section{Referrals}

From where do you receive referrals of young carers?

\begin{tabular}{|l|l|l|l|l|}
\hline SOURCE of REFERRAL & \multicolumn{1}{|c|}{ Mll } & \multicolumn{1}{|c|}{ Some } \\
\hline Self referral & & & & \\
\hline Adult social services & & & & \\
\hline
\end{tabular}




\begin{tabular}{|l|l|l|l|l|}
\hline Education welfare services & & & & \\
\hline Education psychology services & & & & \\
\hline Additional educational support (special needs) & & & & \\
\hline General Practitioner & & & & \\
\hline Health visitor & & & & \\
\hline School nurse & & & & \\
\hline 3rd sector (not for profit) organisation & & & & \\
\hline Private sector organisation & & & & \\
\hline Young Carers Project & & & & \\
\hline Other (please specify below) & & & & \\
\hline
\end{tabular}

\section{Assessment}

4(a) What assessment package/tools do you use with young carers?

$\square$ Common Assessment Framework

$\square$ Children In Need/Assessment Framework for Children and Families

$\square$ An adult carer assessment (Unified assessment materials)

$\square$ An in-house assessment

4 (b) Are you in the process of developing an assessment tool for young carers?

$\square$ Yes $\square$ No

4(c) Who carries out the assessments of young carers in your authority?

$\square$ Social worker employed by Adult Social Services

$\square$ Social worker employed by Children's Services

$\square$ Designated social worker for young carers

$\square$ Other (please specify below)

\section{Thresholds}

5(a) Have you established eligibility criteria for young carers to access services?

$\square$ Yes $\square$ No (If $\mathrm{No}$, please go to Q. 6)

5 (b) What criteria do you apply for young carers to access services? 


\section{Outcomes}

6(a) How do you evaluate how effective social services is in its work with young carers generally?

6(b) What do you consider 'success' for a young carer to be?

6(c) How do you determine whether input from social services has been successful for individual young carers?

\section{Your perspective}

7(a) What do you consider to be the three most significant challenges your service to young carers is facing in the near future?

\section{1 \\ 2 \\ 3}

7(b) Based on your experience, what do you consider to be the three most common challenges that young carers face?

\section{1 \\ 2 \\ 3}

$7(c)$ Is there anything you would like to add to the information above?

Many thanks for completing this questionnaire

Please e-mail or post the completed questionnaire by Fri., 30 Nov. to:

\section{$502251 @ s w a n s e a . a c . u k$}

or

Vanessa Webb (researcher), Room 318, Vivian Tower, Singleton Park, Swansea, SA2 8PP 
Appendix E

Young Carers Project Questionnaire

\section{QUESTIONNAIRE TO YOUNG CARERS PROJECTS IN}

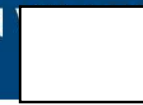

Name:

Project:

E-mail:

Phone:

Address:

Questionnaire Number:

For the researcher's use 


\section{QUESTIONNAIRE TO YOUNG CARERS PROJECTS IN WALES}

Please fill in or tick the appropriate boxes:

\section{Definition}

We understand that your project/service supports 'Young Carers' but, as you will be aware, the term 'Young Carer' is not always used consistently. In order for us to make sense of the data from this survey, please can you outline briefly how your project defines the term operationally:

\section{Access}

2.1 Do you operate an 'open' referral system, (i.e. can any professional refer a young person to you?)
$\square$ Yes
If 'Yes', please go to Q. 2.3
No

2.2 If ' $\mathrm{No}$ ', please list those who can refer to you:

2.3 Are children and young people able to self-refer to you?
$\square$ Yes
$\square$ No It depends

2.4 If you have ticked 'It depends', please give some indication of what is taken into account?

\section{Sources of Referrals}

Please indicate the source of your referrals:

\begin{tabular}{|l|l|l|l|l|}
\hline SOURCE of REFERRAL & All & Most & Some & None \\
\hline Self referral & & & & \\
\hline Adult social services & & & & \\
\hline Education welfare services & & & & \\
\hline Education psychology services & & & & \\
\hline Additional educational support services & & & & \\
\hline
\end{tabular}




\begin{tabular}{|l|l|l|l|l|}
\hline General Practitioner & & & & \\
\hline Health visitor & & & & \\
\hline School nurse & & & & \\
\hline 3rd sector organisation (not for profit) & & & & \\
\hline Private sector organisation & & & & \\
\hline Another Young Carers Project & & & & \\
\hline Other (please specify below) & & & & \\
& & & & \\
\hline
\end{tabular}

\section{The organisation}

4. 1 Which organisation is providing this project/service?

\subsection{Please indicate the approximate proportion of the project's income that comes from:}

\begin{tabular}{|l|l|}
\hline SOURCE & $\%$ \\
\hline Local authority (Council) & \\
\hline Own organisation's funds & \\
\hline Grant-aid & \\
\hline Fund-raising and donations & \\
\hline Other (please specify below) & \\
\hline
\end{tabular}

\subsection{What is the full annual cost of running your project?}

\section{$£$}

\section{Staffing}

5.1 Please indicate the number of staff you have and whether any of them are former young carers?

\begin{tabular}{|l|l|l|}
\hline Employment status & Staff nos. & No. of those that are former young carers \\
\hline Full-time & & \\
\hline Part-time & & \\
\hline Volunteers & & \\
\hline
\end{tabular}


5.2 Please indicate the number of staff whose highest qualification is currently:

\begin{tabular}{|l|l|}
\hline Qualification & Number \\
\hline No formal qualification & \\
\hline Level 4 (e.g. GCSE level / BTEC L2 / NVQ L3) & \\
\hline Level 5 (A level or equivalent / BTEC L3 / NVQ L3) & \\
\hline Level 6 (Graduate level / NVQ L4) & \\
\hline Level 7 (Post-graduate level /NVQ L5) & \\
\hline
\end{tabular}

5.3 Does the project have a member of staff whose dedicated role is to manage the project?

$\square$ Yes $\square$ No

\section{The young carers accessing the project}

6. 1 What is the age range of the children and young people for whom you accept referrals?
From:
To:

6.2 Is the remit of your project to work with:

$\square$ Males only $\square$ Females only $\square$ Both?

6.3 Is your project dedicated to any ethnic group?

$\square$ Yes $\square$ No

If 'Yes', please specify:

6.4 Is your project restricted to working with young people who are caring for adults with specific conditions (e.g. physical disability, mental ill-health or substance mis-use)

$\square$ Yes $\square$ No

If 'Yes', please specify:

6.5 On average how many young carers is your project working with at any one time?

6.6 On average how many young carers in total does your project work with each year?

6.7 Does your project have a waiting list?

$\square$ Yes $\square$ No If 'No', please go to Q. 7

6.8 How many young carers approximately are there currently on your waiting list? 


\section{Assessment}

7.1 Does your project undertake any of the following forms of assessment:

$\square$ Child in need (Section 17; Children Act 1989)

$\square$ Common Assessment Framework

$\square$ Adult Carer Assessment

$\square$ In-house young carer assessment

$\square$ Other

$\square$ None

If 'Other', please specify:

8. Activities:

8.1 In what setting do the main activities with young carers take place?

$\square$ Social Services venue/building

$\square$ Other (e.g. voluntary sector/community venue etc.)

8.2 Which of the following do you offer young carers? (Please tick as appropriate)

$\square$ Social and/or sporting activities

$\square$ Support group discussions

$\square$ Information and advice e.g. welfare claims

$\square$ Befriending or mentoring opportunities

$\square$ Advocacy

$\square$ One-to-one support

$\square$ Counselling

$\square$ Drop-in sessions

$\square$ Other

If 'Other', please specify:

8.3 Is the support you provide for young carers only or do you work with their adult family members if appropriate?

$\square$ With young carers only

$\square$ With adult family members if appropriate

9. Evaluation

9.1 The aims of this project are: 
9.2 Please describe briefly how you evaluate the success of the project:

9.3 Please explain how you determine what 'success' is for a young carer:

9.4 Has an independent evaluation of the Project taken place in the last five years?

$\square$ Yes $\square$ No

10. Inter-agency co-operation and awareness raising

10.1 Does the project carry out any awareness-raising activities?

$\square$ Yes $\square$ No

10.2 Which of the following agencies do you work with most frequently:

\begin{tabular}{|l|l|l|l|}
\hline AGENCIES & Most & Some & Not at all \\
\hline Education/Schools & & & \\
\hline Health & & & \\
\hline Social Services & & & \\
\hline Other (please specify below) & & & \\
& & & \\
\hline
\end{tabular}

10.3 In general how would you rate the level of awareness that the following agencies have of the needs of young carers on a scale of 1 to 5, 5 being very aware and 1 having no awareness (please tick as appropriate)?

\begin{tabular}{|l|l|l|l|l|l|}
\hline AGENCY & 1 & 2 & 3 & 4 & 5 \\
\hline Education/Schools & & & & & \\
\hline Health & & & & & \\
\hline Social Services & & & & & \\
\hline
\end{tabular}

\section{Challenges and issues}

11.1 What do you consider to be the three most significant challenges your service to young carers is facing in the near future? 
11.2 Based on your experience, what do you consider to be the three most common challenges that young carers face?
2
3

1

11.3 Is there anything you would like to add to the information above?

Many thanks for completing this questionnaire Please return it to $502251 @$ swansea.ac.uk by Dec. 3rd

\section{If you have any queries, please contact Vanessa Webb on}

07957844141 or e-mail $502251 @ s w a n s e a . a c . u k$ 


\section{Appendix $\mathrm{F}$}

Multidimensional Assessment of Caring Activities (MACA-YC18)

(Joseph et al., 2009)

\section{The caring jobs I do}

Below are some jobs that young carers do to help. Think about the help you have provided over the last month. Please read each one and put a tick in the box to show how often you have done each of the jobs in the last month. Thank you.

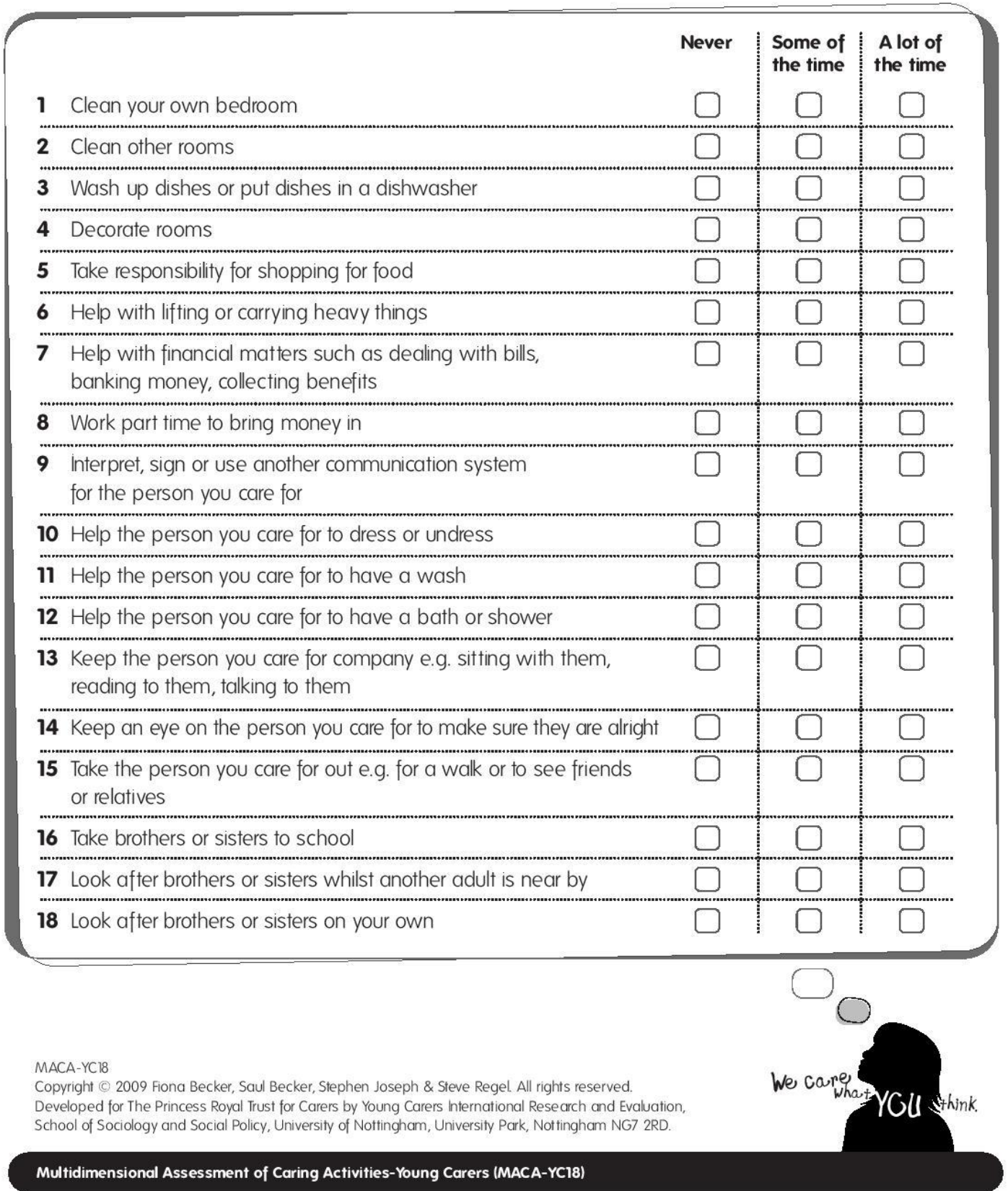


Appendix G

Young Carers Questionnaire

Group: 1

\section{Participant number:}

\section{FIRST QUESTIONNAIRE}

\section{About you and your family}

1.1 Who do you live with?

1.2 Do you have a long-term disability, illness or medical condition yourself?<smiles>O=[N+]=C1CCC1</smiles>

1.2.1. Can you tell me a little more about that?

1.3 Do you have free school meals?

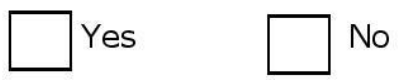

$\mathbf{1 . 4}$ If you go out what transport do you use mostly?

1.5 Is there an adult who you live with who you can share your feelings with?

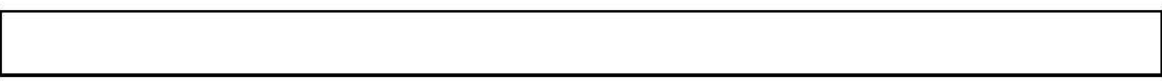

1.6 How well do you get on with the person you are caring for on a scale of 1 to 5,1 being Not well and 5 being Very well? Tick the box which applies best.

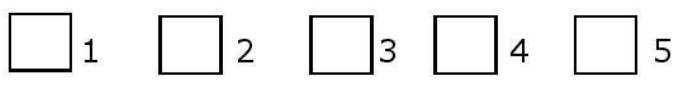

1.7 Do members of your family ever shout or yell at each other?

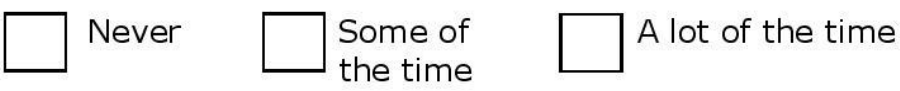

2. Looking after a family member

2.1 Who is the person you look after? 
2.2 Why do they need your help? Is it because of...

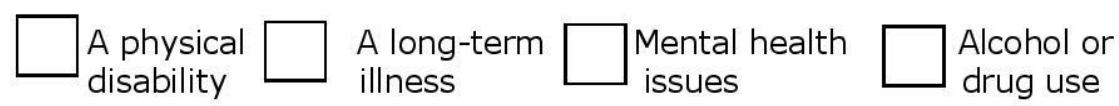

$\square$ disability $\square$ Something else?

2.3 Can their condition change at any time without warning?

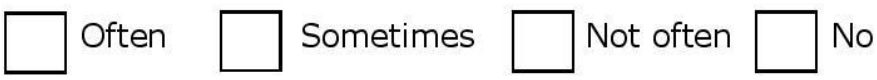

2.4 Are you the only carer in the family or do you share the work with someone else?

$\square$ Only carer $\square$ Share with someone else

2.4.1 [If applicable] Who else helps?

2.5 Does anyone from Social Services or a voluntary organisation call regularly to help?

$\square$ Yes $\square$ No $\square$ Don't know

2.6 About how long have you been looking after or helping the person you care for?

$\square$ years $\square$ Can't remember

2.7 Which of the following things do you need to do?

\begin{tabular}{|l|l|l|l|l|}
\hline $\begin{array}{l}\text { No } \\
\cdot\end{array}$ & Item & Never & $\begin{array}{l}\text { Some of } \\
\text { the time }\end{array}$ & $\begin{array}{l}\text { A lot of } \\
\text { the time }\end{array}$ \\
\hline $\mathbf{1}$ & Clean your own bedroom & & & \\
\hline $\mathbf{2}$ & Clean other rooms & & & \\
\hline $\mathbf{3}$ & $\begin{array}{l}\text { Wash up dishes or put dishes in a } \\
\text { dishwasher }\end{array}$ & & & \\
\hline $\mathbf{4}$ & Decorate rooms & & & \\
\hline $\mathbf{5}$ & Take responsibility for shopping for food & & & \\
\hline $\mathbf{6}$ & $\begin{array}{l}\text { Help with lifting or carrying heavy } \\
\text { things }\end{array}$ & & & \\
\hline $\mathbf{7}$ & $\begin{array}{l}\text { Help with financial matters such as } \\
\text { dealing with bills, banking money, } \\
\text { collecting benefits }\end{array}$ & & & \\
\hline
\end{tabular}




\begin{tabular}{|c|c|c|c|c|}
\hline No & Item & Never & $\begin{array}{l}\text { Some of } \\
\text { the time }\end{array}$ & $\begin{array}{l}\text { A lot of } \\
\text { the time }\end{array}$ \\
\hline 8 & Work part time to bring money in & & & \\
\hline 9 & $\begin{array}{l}\text { Interpret, sign or use another } \\
\text { communication system for the person } \\
\text { you care for }\end{array}$ & & & \\
\hline 10 & $\begin{array}{l}\text { Help the person you care for to dress or } \\
\text { undress }\end{array}$ & & & \\
\hline 11 & $\begin{array}{l}\text { Help the person you care for to have a } \\
\text { wash }\end{array}$ & & & \\
\hline 12 & $\begin{array}{l}\text { Help the person you care for to have a } \\
\text { bath or shower }\end{array}$ & & & \\
\hline 13 & $\begin{array}{l}\text { Keep the person you care for company } \\
\text { e.g. sitting with them, reading to them, } \\
\text { talking to them }\end{array}$ & & & \\
\hline 14 & $\begin{array}{l}\text { Keep an eye on the person you care for } \\
\text { to make sure they are alright }\end{array}$ & & & \\
\hline 15 & $\begin{array}{l}\text { Take the person you care for out e.g. } \\
\text { for a walk or to see friends or relatives }\end{array}$ & & & \\
\hline 16 & Take brothers or sisters to school & & & \\
\hline 17 & $\begin{array}{l}\text { Look after brothers or sisters whilst } \\
\text { another adult is near by }\end{array}$ & & & \\
\hline 18 & $\begin{array}{l}\text { Look after brothers or sisters on your } \\
\text { own }\end{array}$ & & & \\
\hline
\end{tabular}

2.8 How much time does it take you each day to do all those things?

About<smiles>C1CCC1</smiles>
minutes each day

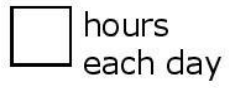

$\square$ Not sure

\section{How caring affects you}

3.1 How often are you late for school/college/work because of caring?

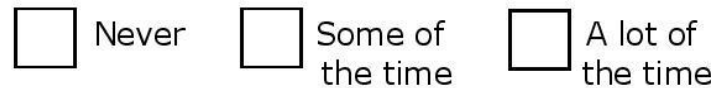

3.2 How often do you miss a day of school/college/work because of caring?

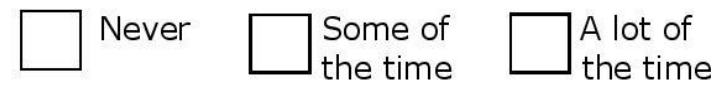

3.3 How often do you miss out on doing homework/project work because of caring?
Never
$\square \begin{aligned} & \text { Some of } \\ & \text { the time }\end{aligned}$
A lot of
the time 
3.4 When you are in school/college/work, do you find it difficult to concentrate because of worrying about your family?

$\square$ Yes $\square$ No $\square$ Not sure

3.5 How healthy would you say you are in general?

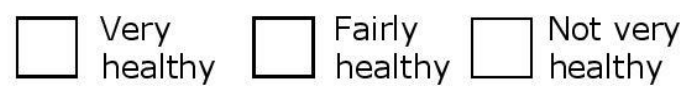

3.6 How often do you get headaches, stomach aches not badly enough to go to the doctor?

$\square$ Not at all $\square \begin{aligned} & \text { Some of } \\ & \text { the time }\end{aligned} \square$ A lot of the time

3.7 In the last year, would you say you have had any of the following feelings because of caring:

\begin{tabular}{|l|l|l|l|l|}
\hline & Item & Not at all & $\begin{array}{l}\text { Some of } \\
\text { the time }\end{array}$ & $\begin{array}{l}\text { A lot of } \\
\text { the time }\end{array}$ \\
\hline $\mathbf{1}$ & Stressed & & & \\
\hline $\mathbf{2}$ & $\begin{array}{l}\text { Pleased that you are helping } \\
\text { someone in your family }\end{array}$ & & & \\
\hline $\mathbf{3}$ & Tired & & & \\
\hline $\mathbf{4}$ & $\begin{array}{l}\text { Feeling that you are good at } \\
\text { managing things }\end{array}$ & & & \\
\hline $\mathbf{5}$ & Alone & & & \\
\hline
\end{tabular}

3.8 When did you last have a dental check?

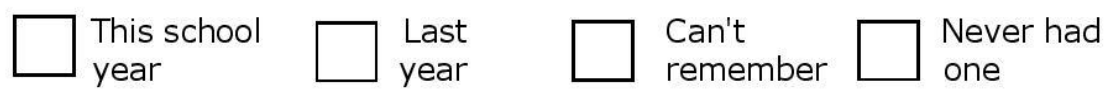

3.9 When was the last time you went for a sight check?

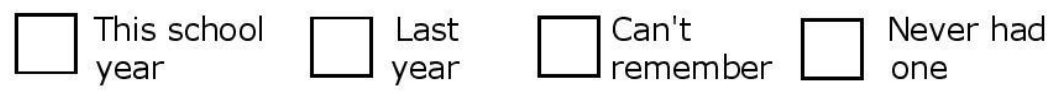

3.10 Do you smoke?

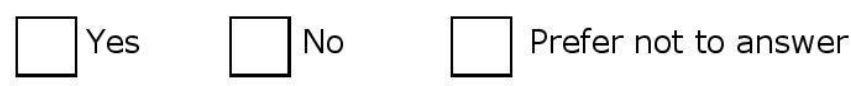

3.11 Do you feel you have enough time to look after your appearance?

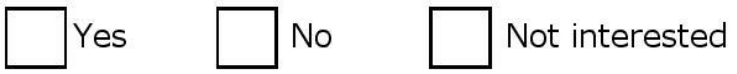




\section{Your activities outside school hours}

4.1 In the last term, have you taken part in any of the following club or group activities? Please tick any that apply:

\begin{tabular}{|l|l|l|l|}
\hline Activity & Often & $\begin{array}{l}\text { Some- } \\
\text { times }\end{array}$ & $\begin{array}{l}\text { Not at } \\
\text { all }\end{array}$ \\
\hline $\begin{array}{l}\text { Sports clubs: football, rugby, hockey, } \\
\text { netball, martial arts etc. }\end{array}$ & & & \\
\hline Music and movement, dance or ballet & & & \\
\hline $\begin{array}{l}\text { Group music activities: choir, orchestra, } \\
\text { playing in a band }\end{array}$ & & & \\
\hline $\begin{array}{l}\text { Club activities: art, drama, science, } \\
\text { computer, ornithology }\end{array}$ & & & \\
\hline Guides, Scouts, Rangers, Cadets & & & \\
\hline Youth club & & & \\
\hline Discos, gigs & & & \\
\hline Other (please specify) & & & \\
& & & \\
\hline
\end{tabular}

4.2 In the last term, have you done any of the following individual activities i.e. not in a club? Please tick any that apply.

\begin{tabular}{|l|l|l|l|}
\hline \multicolumn{1}{|c|}{ Activities } & Often & $\begin{array}{l}\text { Once or } \\
\text { twice }\end{array}$ & $\begin{array}{l}\text { Not at } \\
\text { all }\end{array}$ \\
\hline $\begin{array}{l}\text { Sports activities: e.g. gymnastics, } \\
\text { athletics, swimming }\end{array}$ & & & \\
\hline $\begin{array}{l}\text { Music or arts activities: e.g. } \\
\text { learning/practising an instrument, } \\
\text { writing }\end{array}$ & & & \\
\hline Computer games & & & \\
\hline Other hobbies (please specify) & & & \\
& & & \\
\hline
\end{tabular}


4.3 In the last term, have you been to or used any of these places in your local area i.e. not in or with your school? (Tick all that apply)

\begin{tabular}{|l|l|l|l|}
\hline \multicolumn{1}{|c|}{ Venue } & Often & $\begin{array}{l}\text { Some- } \\
\text { times }\end{array}$ & $\begin{array}{l}\text { Not at } \\
\text { all }\end{array}$ \\
\hline Library & & & \\
\hline Swimming pool/leisure centre & & & \\
\hline Community Centre & & & \\
\hline $\begin{array}{l}\text { Church, mosque or temple, other place of } \\
\text { worship }\end{array}$ & & & \\
\hline Cinema & & & \\
\hline
\end{tabular}

4.4 In the last term, have you done any unpaid voluntary work?<smiles>O=[N+]1CCC1</smiles>

4.5 In the last term, have you done any work for money? Please include anything you do around the house that you get paid for.<smiles>O=[N+]1CCC1</smiles>

\section{Friends}

5.1 Do you have someone you can share your feelings with?

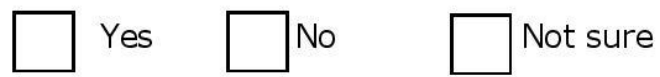

5.2 When was the last time you had free time outside school to spend with your friends?

$\square$ In the last week 2 weeks $\square$ In the last month

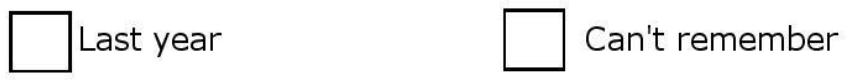

5.3 Do you use social networking sites at home?

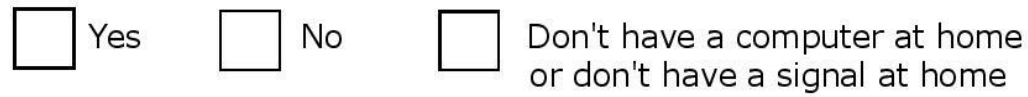

\section{General}

6.1 Do you have somewhere you know you can go for advice or information?

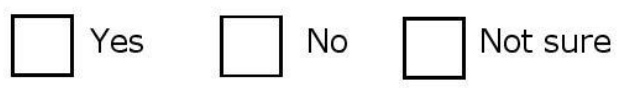


6.2 Have you had any training which would help you with your caring work e.g. about the condition of the person you look after, medication, manual lifting or anything useful for the type of caring work you do?<smiles>O=[W]C1CCC1</smiles>

6.3 Have you been given advice on what help you can get as a young carer such as support services, training, benefits and what you're entitled to?<smiles>O=[N+]1CCC1</smiles>

6.4 When was the last time you used the Internet to look for information outside school?

$\square \begin{aligned} & \text { Last } \\ & \text { week }\end{aligned} \square$ Last $\square$ month $\square_{\text {year }}^{\text {Last }} \square$ Never $\square \square_{\text {No signal }}^{\text {No PC at home }}$

\section{In the future}

What would you like to do when you leave school? Please tick the ones that apply - it might be more than one:

\begin{tabular}{|l|l|l|l|}
\hline Activity & Yes & No & $\begin{array}{l}\text { Don't } \\
\text { know }\end{array}$ \\
\hline Look for a job & & & \\
\hline Study at College or 6th form & & & \\
\hline Get an apprenticeship & & & \\
\hline Get work experience/work placement & & & \\
\hline Go to University & & & \\
\hline Training course & & & \\
\hline Continue to live at home & & & \\
\hline Leave home & & & \\
\hline Travel & & & \\
\hline Other (please say what it is) & & & \\
\hline
\end{tabular}


Appendix $\mathrm{H}$

Inquiry into Support for Young Carers in Secondary Schools in Wales

\section{Purpose}

Research and consultations with young carers have heard the view repeatedly that they need support at school if they are not to be disadvantaged by their caring responsibilities. There have been numerous recommendations that one of the ways of supporting young people in this hidden population is for schools to identify a lead teacher for young carers, a designated teacher with responsibility for seeing that young carers are identified and then supported appropriately in school. It is unclear how far these recommendations have been implemented so a brief inquiry was carried out.

\section{Method}

This being a preliminary inquiry only, it was narrowed down to a simple question: whether schools in the area had to date been able to implement these recommendations. This was communicated in a one page bi-lingual letter which also specified the recommendations. An upto-date list of Directors of Education in the 22 local authorities in Wales was obtained from the Welsh Local Government Association. The letter was e-mailed to the list on February 2nd 2012. Reminders were sent to non-responders two weeks later. Replies were received over a period up to July 2012. 


\section{Results}

Eleven Local Education Authorities (LEAs) did not reply at all. No further responses were received from the two that had sent holding replies. Both these had passed the inquiry to Social Services. Substantive replies were received from nine LEAs. Unfortunately one of these consisted of an explanation that they did not hold this information and attached a list of schools within the county borough for contact to be made with individual schools. One LEA may have misunderstood the letter and by implication the recommendations, appearing to interpret it as an inquiry about a county-wide lead on young carers but more positively the same authority wrote that young carers in the area had themselves asked for this and that the role might be taken on in the future by the pastoral care network in schools.

Two responses reported a full and pro-active approach to the young carer issue but not giving the requested information about provision in schools.

Structured responses to the policy recommendations were apparent in the detailed responses from five LEAs. There were slightly different pathways in each of them but they were all clearly finding feasible ways of implementing the recommendations. For example two of the above authorities were working through the third sector voluntary organisation who had been commissioned to provide a service for young carers. In one of these, the third sector organisation was carrying out awareness raising about young carers issues in the schools and this was 
accompanied by work to identify someone in each school to be responsible for identifying young carers. In the second, the third sector organisation was providing training in the secondary schools to lead to the identification of a link person in each school with responsibility for young carers, not necessarily someone on the teaching staff. They contributed also to the Personal and Social Education curriculum, advertised their own services and had a presence in the school, offering referral to their YCP outside school. They were able to report an increase in referrals. Another authority had followed the letter as well as the spirit of the recommendations by directly requiring all schools to identify a lead teacher and providing them with the Princess Royal Trust guidance packs; they said that they were achieving an encouraging level of compliance.

The approach taken in one of the five was to place the responsibility on class teachers in primary schools to refer to their Additional Learning Needs (ALN) Co-ordinator and on Heads of Year in secondary schools to refer to their Head of Inclusion/ALN. Another authority had placed the responsibility similarly but with referrals to be made to the Education Welfare Officer or the social worker with responsibility for young carers.

\section{Implications for Research}

It seems that the messages about the responsibility of schools towards young carers are gradually bearing fruit. Although there were no data from 13 authorities, that does not mean that no action was in place or being prepared. From those that did reply, there seemed to have been 
considerable positive action and in the year that has elapsed since the original inquiry it is possible that the situation has improved further. Nonetheless, with so little evidence of systematic support for young carers, it was decided that this was not as yet to be included in this study as a major service provider for young carers.

However the overall picture of outputs in schools does raise the question of what are the outcomes and have they improved both in individual authorities and overall in Wales. For example has the number of identifications increased? What are the methods developed by the schools to assist young carers so that their educational progress is optimised? What evidence is there of the educational attainment of young carers identified and supported by this development? How do the outcomes vary according to the methods of support? 
Appendix K

Parental information sheet

\section{Research with young carers}

My name is Vanessa Webb and I am a research student at Swansea University. I am carrying out a study of children and young people aged 11 to 16 who help to look after a family member. This letter is to describe the research and explain how your child could be involved if they wish.

What is the research for?

The idea is to find out how taking part in a project makes a difference to young carers. This will be done by gathering information from young people who help to look after a family member about their health, their education and their social lives. There are projects all over Wales and the UK and the results of this survey may be useful for the projects and for those who plan and provide support for young carers in the future.

What will the questions be about?

There will be three exercises. The first will ask them about what kind of person they are. The second one will be about caring, about their life and how they are getting on inside and outside school. There will also be a short word exercise to check that those taking part are typical of young carers generally.

What will they have to do?

All the exercises will be carried out in an individual interview with me. The first one will be completed on a laptop and will take about 10 minutes. The second will take up to 20 minutes. The word exercise will be carried out with each one individually and will take about 10 minutes. Will they get anything for taking part? 
There will be no payment but they will receive a certificate as evidence of their participation in the research. They will also be included in a prize draw with the other participants for a $£ 20$ voucher.

What if they change their minds about taking part? If they change their minds, they will be free to withdraw at any point without giving a reason and without any consequences. They can choose not to answer any individual question in the questionnaires if they prefer not to.

What will happen to the information from the questionnaires?

The answers will be completely confidential and anonymous. The participant's name will be separated from the questions they have answered so that no-one will know who has taken part or what any one person has said or which projects have taken part. The only time your child's answers would be shared with anyone would be if they say something that suggests that they may be at risk of significant harm. In that case I would have to let another appropriate person know.

At the end of the research, I am happy to go back to the Project if they wish me to report back on the results.

The research and quotes from it may be used in reports and articles, presentations at meetings and conferences and for educational purposes.

What do I need to do now if I am willing for my child to take part?

The next step will be for you to complete the parental consent form attached and for your child to complete the participant assent form attached to their letter. Once you have completed and signed the forms, please return them either to the Project Leader or directly to me at the address above.

Finally, if you have any queries, you can contact me by phone or e-mail and I will be happy to answer your questions. If you contact me with your queries, this doesn't mean that you have committed your child to taking part. 
Appendix L

Participant information sheet

Date:

For:

Dear Project member,

Research with young carers

My name is Vanessa Webb and I am a research student at Swansea University. I am carrying out a study of children and young people aged 11 to 16 who help to look after a family member and I am writing to invite you to help me with this. This letter is to describe the research and explain how you could be involved if you wish. If you want to take part, you will need your parents' permission so I have also written to them to explain why I am asking for your help.

What is the research for?

The idea is to find out how taking part in a project makes a difference to your life. This will be done by gathering information from you and others who are members of projects about your health, your education and your social lives.

There are projects all over Wales and the UK and the results of this survey will be useful for the projects and for those who plan and provide support for young carers in the future. For this purpose, the research and quotes from it may be used in reports and articles, presentations at meetings and conferences and for educational purposes.

What will the questions be about?

There will be two questionnaires. The first one will ask you about what it feels like to look after a family member. The second one will be about 
your life and how you are getting on inside and outside school. There will also be a short word exercise.

\section{What will you have to do?}

There will be sessions for completing the questionnaires in a group with your friends at your club evenings. Each of you will fill in your own questionnaires privately and each questionnaire will probably take about 30 minutes then you will carry on with the usual activities. The Project workers will be there to help you and I will also be there to explain anything that is unclear. If you prefer, you can ask to complete the questionnaires with the researcher on your own on a club evening. The word exercise will be carried out with each of you individually on a club evening and will take about 10 minutes.

\section{Will you get anything for taking part?}

There will be no payment but you will receive a certificate as evidence of your participation in the research. You will also be included together with all the other participants in a prize draw for a $£ 20$ voucher.

What will happen to the information from the questionnaires?

The answers will be completely confidential and anonymous. Your name and contact details will be separated from the questions you have answered so that no-one will know who has taken part or what any one person has said. The only time your answers would be shared with anyone would be if you say something that suggests that you may be at risk of significant harm. In that case I would have to let another appropriate person know.

At the end of the research, there will be an event at the Project to which you and all the participants will be invited where I can report back to you on the results.

What if I change my mind about taking part?

If you change your mind, you will be free to withdraw at any point without giving a reason and without any consequences. You can choose 
not to answer any individual question in the questionnaires if you prefer not to.

\section{What do I need to do now if I want to take part?}

The next step will be for you to complete the participant consent form attached and for your parents to complete the parental consent form attached to their letter. Once you have completed and signed the forms, please return them either to the Project Leader or directly to me at the address above.

Finally, if you have any queries, you can contact me by phone or e-mail and I will be happy to answer your questions. If you contact me with your queries, this doesn't mean that you have committed yourself to taking part.

Thank you for reading this explanation,

Yours sincerely,

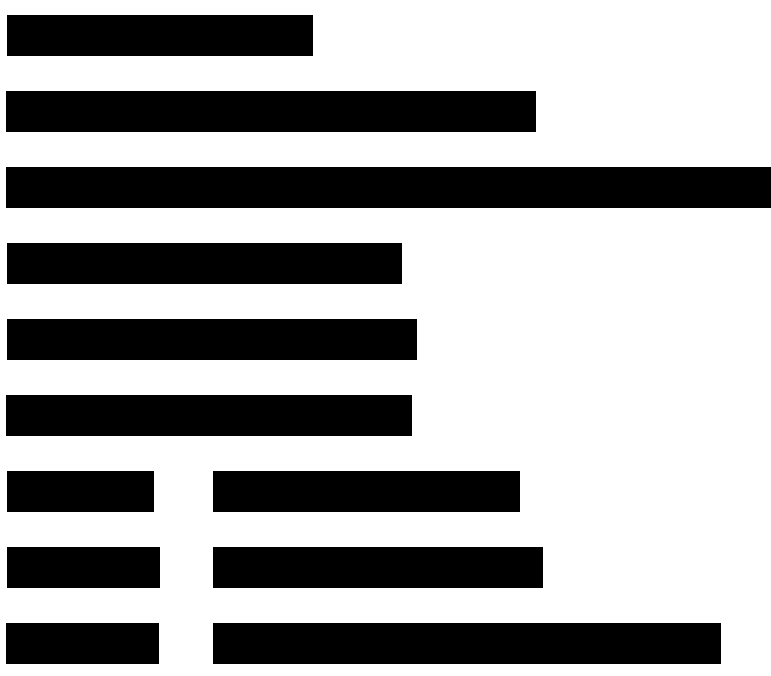


Appendix $M$

Parental consent form

PARENTAL CONSENT FORM for under 16s

Reference:

Title of research: To explore outcomes for young carers

Name of researcher: Vanessa Webb

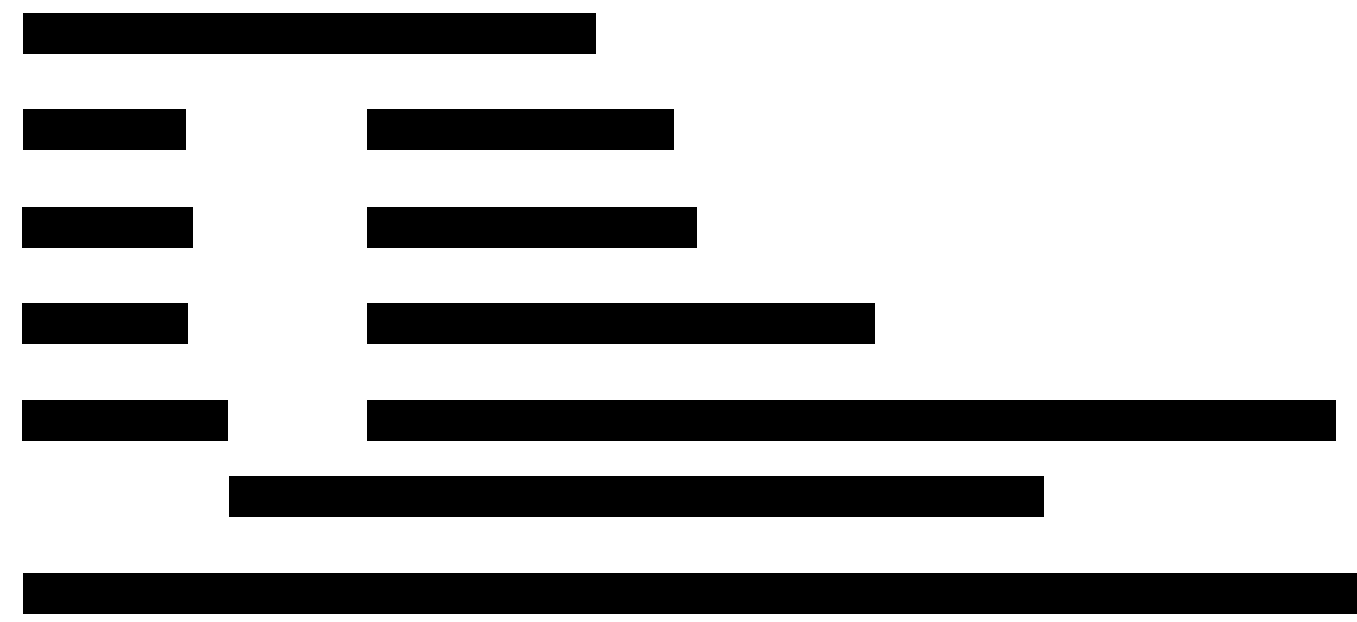

\section{Participant's name:}

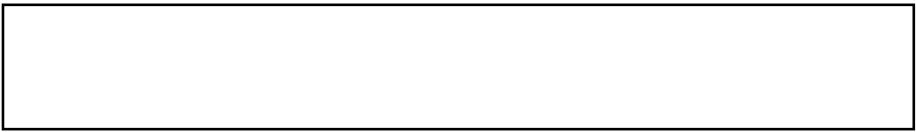

I confirm that I have read and understood the information about the study and my child's part in it and I have had the opportunity to ask questions about the project.

I understand that my child's participation is voluntary, that I am free to withdraw permission and that they are free to withdraw at any point and to decline to answer any particular question if they wish without giving a reason and without any consequences. 
I understand that their responses will be strictly confidential and that they will not be identified or identifiable in any written work or presentation in connection with the research.

I consent to their participation in this study.

Printed name:

Signature: 
Appendix N

Participant assent form

PARTICIPANT ASSENT FORM under 16

\section{Reference:}

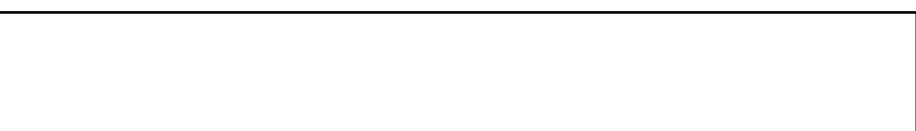

Title of research: Outcomes for young carers

Name of researcher: Vanessa Webb

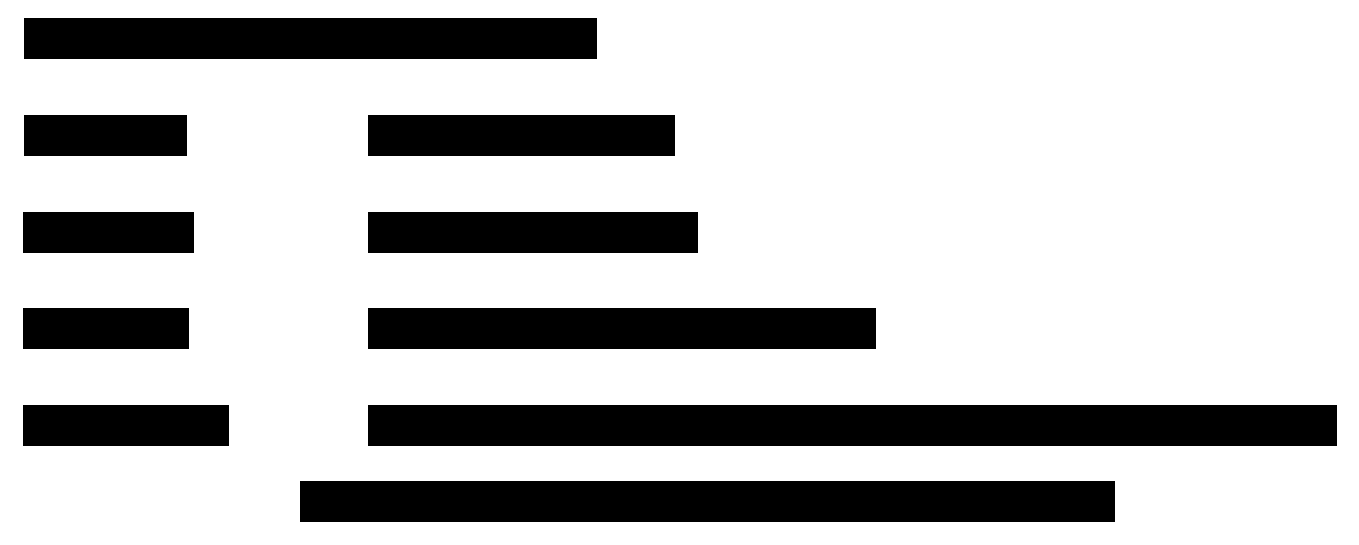

If you want to check that I am a research student at Swansea University, College of Human and Health Sciences, please contact my supervisor, Dr Paul Rees on : or P.G.Rees@swansea.ac.uk

\section{Participant's name:}

I confirm that I have read and understood the information about the study and my part in it. 
I understand that taking part is voluntary and that I can drop out at any point and that I can choose not to answer any particular question if I prefer not to without explaining why and without any consequences.

I understand that my answers will be strictly confidential and that no-one will be able to identify me in any writing or presentation of the research. I agree to take part in this study.

Printed name:

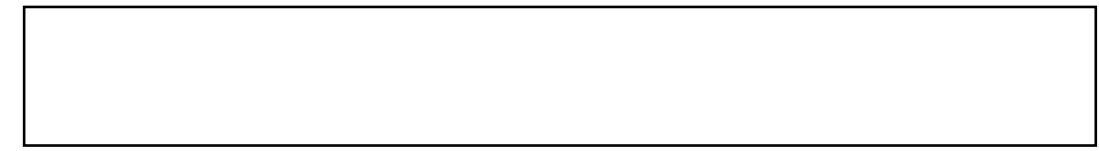

Signature:

E-mail:

Mobile: 


\section{References}

Abebe, Tatek (2012). AIDS-affected children, family collectives and the social dynamics of care in Ethiopia. Geoforum, 43(3), 540-550.

Action for Children (2011). The red book: Impact of United Kingdom government spending decisions on children, young people and families 2010/2011. Retrieved 08/11/2013 from:

www.actionforchildren.org.uk/media/4075296/annual_report_2012 .pdf].

Aldridge, J. (1995). Couldn't care more: A study of young carers and their needs. London: The Children's Society.

Aldridge, J. (2006). The Experiences of children living with and caring for parents with mental illness. Child Abuse Review, 15, 79-88.

Aldridge, J. (2008). All work and no play? Understanding the needs of children with caring responsibilities. Children \& Society 22(4), 253264.

Aldridge, J. (2009). Pictures of young caring. Criminal Justice Matters, $78(1), 38-40$.

Aldridge, J., \& Becker, S. (1993a). Children who care: Inside the world of young carers. Loughborough: Young Carers Research Group, Loughborough University. Retrieved 08/12/13 from www.saulbecker.co.uk

Aldridge, J., \& Becker, S. (1993b). Punishing children for caring: The hidden cost of young carers. Contract, 7(4), 376-387. 
Aldridge, J., \& Becker, S. (1993c). Children as carers. Archives of Disease in Childhood, 69(4), 459-462.

Aldridge, J., \& Becker, S. (1994). My child, my carer: The parents' perspective. Loughborough: Young Carers Research Group. Aldridge, J., \& Becker, S. (1996). Befriending young carers. A pilot study. London: Calouste Gulbenkian Foundation.

Aldridge, J., \& Becker, S. (1998a). Surge of support. Community Care, 1214, March 19th, 22-23.

Aldridge, J., \& Becker, S. (1998b). The national handbook of young carers projects. London: Carers National Association.

Aldridge, J., \& Becker, S. (1999). Children as carers: The impact of parental illness and disability on children's caring roles. Journal of Family Therapy, 21(3), 303-320.

Aldridge J, Becker S. (2003). Children caring for parents with mental illness: Perspectives of young carers, parents and professionals. The Policy Press: Bristol.

Aldridge, J., \& Wates, M. (2005). Young carers and their disabled parents: Moving the debate on. In T. Newman, \& M. Wates (Eds.), Disabled parents and their children: Building a better future. Ilford: Barnardo's.

Allatt, P. (1993). Becoming privileged: The role of family process. In I. Bates, \& G. Riseborough (Eds.), Youth and Inequality (pp. 139159). Buckingham: Open University Press. 
Allen, M. (2014. Local action on health inequalities: Reducing the number of young people not in employment, education or training (NEET). Health equity briefing 3: September 2014. London: Public Health England.

Ames-Reed, J. (1994). Young Carers Projects on Merseyside: Some guidelines for practice. Carers National Association, Crossroads, Liverpool Personal Social Services, North West Regional Health Authority.

Anderson, R., and Bury, M., (Eds.) (1988). Living with chronic illness:

The experience of patients and their families. London: Unwin Hyman.

Andreouli, E., Skovdal, M., \& Campbell, C. (2013). 'It Made Me Realise That I Am Lucky for What I Got': British Young Carers Encountering the Realities of Their African Peers. Journal of Youth Studies, 16(8), 1038-1053.

Aneshensel, C.S., Pearlin, L.I., \& Schuler, R.H. (1993). Stress, role captivity, and the cessation of caregiving. Journal of Health and Social Behaviour, 34(1), 54-70.

Ariès, P. (1962). Centuries of childhood. London: Jonathan Cape.

ARK (2013). Kids Life and Times Survey, 2013. Retrieved 08/08/15 from www.ark.ac.uk/klt

Audit Commission (2010) Against the odds: Targeted briefing - Young carers. London: Audit Commission. 
Aylward, N. (2009). Access to education and training for young adult carers. Leicester: National Institute of Adult Continuing Education. Baago, S. (2005 up-dated 2007). Inside the developmental "Black Box" of young carers: A literature review prepared for the Young Carers Initiative Niagara (YCIN). Ontario: The Ontario Trillium Foundation.

Baltes, P. B. (1987). Theoretical propositions of life-span developmental psychology: On the dynamics between growth and decline. Developmental Psychology, 23, 611-626.

Baltes, P.B., \& Staudinger, U.M. (Eds.) (1996). Inter-active minds: Lifespan perspectives on the social foundation of cognition. Cambridge: Cambridge University Press.

Baltes, P.B., Staudinger, U.M., \& Lindenberger, U. (1999). Lifespan psychology: Theory and application to intellectual functioning. Annual Review of Psychology 1999, 50, 471-507.

Banks, P., Cogan, N., Deeley, S., Hill., Riddell, S., \& Tisdall, K. (2001). Seeing the invisible: Children and young people affected by disability. Disability and Society, 16(6), 797-814.

Banks, P., Gallagher, E., Hill, M., \& Riddell, S. (2002a). Young carers: Assessment and services. literature review of identification, needs assessment and service provision for young carers and their families. Glasgow: Scottish Executive Central Research Unit, Publications Online. Retrieved 12/30/13 from http://wwwscotland.gov.uk/cru/resfinds/hcc23-00.asp 
Banks, P., Cogan, N., Deeley, S., Hill, M., Riddell, S., Tisdall, K. (2002b). Does the covert nature of caring prohibit the development of effective services for young carers? British Journal Of Guidance \& Counselling, 30(3), 229-246.

Barer, B.M. (1992). The relationship between older people and their home care workers. Journal of Gerontological Social Work, 19(1), 129-147.

Barlow, J., Bayer, S., Hendy, J., \& Wheelock, A. (2010). Telecare Capital Grant in Wales. Evaluation of T.C.G. implementation. Cardiff: Welsh Government.

Barnett, B., \& Parker, G. (1998). The parentified child: Early competence or childhood deprivation? Child Psychology and Psychiatry Review, 3(4), 146-166.

Barry, M. (2011). 'I realised I wasn't alone': The views and experiences of young carers from a social capital perspective. Journal of youth studies, 14(5), 523-539.

Bassani, C. (2007). Five dimensions of social capital theory as they pertain to youth studies. Journal of Youth Studies, 10(1), 17-34.

Bayer, S., \& Barlow, J. (2010). Analysis of data on the impact of telecare provided under the Telecare Capital Grant. London: Imperial Business School.

Becker, S. (1995) Introduction. In Becker, S. (Ed.), Young carers in Europe: An exploratory cross-national study in Britain, France, 
Sweden and Germany (pp. vii-x). Loughborough University: Young Carers Research Group, .

Becker, S. (2000). Young carers. In M. Davies (Ed.), The Blackwell Encyclopaedia of Social Work (p. 378). Malden, Mass.: Blackwell. Becker, S. (2002). Coleman. London: Carers UK.

Becker, S. (2007). Global perspectives on children's unpaid caregiving in the family research and policy on 'Young Carers' in the UK, Australia, the USA and Sub-Saharan Africa. Global Social Policy, $7(1), 23-50$.

Becker, S. (2008). Informal family carers. In K. Wilson, G. Ruch, M. Lymbery, \& A. Cooper. (Eds.), Social Work: An introduction to contemporary practice (pp. 426-455). London: Pearson Longman. Retrieved 1/12/14 from Dawsonera.com

Becker, S. (2010). Study of young carers. London: BBC.

Becker, S. (2013). Hidden from view. Foreword. London: Children's Society.

Becker, S. Personal communication Sept. 11th 2013.

Becker, S. and Dearden, C. (2000). What does it cost? Community Care 15, June 2000, 15-21 June, p. 27.

Becker, S., Aldridge, J., \& Dearden, C. (1998). Young carers and their families. Oxford: Blackwell Science Ltd. Retrieved 08/12/13 from http://www.carersuk.org/Professionals/ResearchLibrary

Becker, S., Dearden, C. and Aldridge, J. (2001). Children's labour of love? Young carers and care work. In P. Mizen, C. Pole, \& A. Bolton 
(Eds.), Hidden Hands: International Perspectives on Children's Work and Labour (pp. 70-87). Falmer Press, Brighton.

Becker, S., \& Becker, F. (2008). Service needs and delivery following the onset of caring amongst children and young adults: Evidence based review. Cheltenham: The Commission for Rural Communities.

Retrieved $12 / 31 / 13$ from

http://saulbecker.co.uk/v1/downloads/young_carers/Evidence\%20 review $\% 20$ on $\% 20$ young $\% 20$ carers $\% 20$ and $\% 20$ young $\% 20$ adult $\%$ 20carers\%202008.pdf

Becker, S., Dearden, C., \& Aldridge, J. (2000). Young carers in the UK: Research, policy and practice. Research, Policy and Planning, 8(2), $13-22$.

Bilsborrow, S. (1993). "You grow up fast as well..." Young carers on Merseyside. Health and Social Care in the Community, Sept. 93, $1(5), 315-18$.

Blackburn, C., Read, J., \& Spencer, N. (2012). Children with neurodevelopmental disabilities: Our children deserve better: Prevention pays. In Professor Dame S.C. Davies Annual report on children and young people's health from the Chief Medical Officer (Chapter 9). London: Department of Health.

Blair, S.L. (1992). Children's participation in household labor: Child socialization versus the need for household labor. Journal of Youth and Adolescence, 21(2), 241-258. 
Blazek, M. Smith, F.M., Lemesova, M., \& Hricova, P. (2015). Ethics of care across professional and everyday positionalities: The (un)expected impacts of participatory video with young female carers in Slovakia. Geoforum, 61, 45-55.

Blyth, E., Saleem, T., \& Scott, M. (1995). Kirklees Young Carers Project, October 1994-June 1995: Report to Kirklees Metropolitan Council. Huddersfield: The University of Huddersfield.

Blyth, E., \& Milner, J. (1997). Social work with children: The educational perspective. Harlow: Longman.

Bolas, H., Van Wersch, A., \& Flynn, D. (2007). The well-being of young people who care for a dependent relative: An interpretative phenomenological analysis. Psychology \& Health, 22(7), 829-850.

Borgonovi, F., \& Montt, G. (2012). Parental involvement in selected PISA countries and economies. Organisation for Economic Co-operation and Development Education Working Papers, No. 73. Paris: Organisation for Economic Co-operation and Development Publishing.

Bourdieu, P. (1986). The forms of capital. In J.G. Richardson (Ed.) Handbook of theory and research for the sociology of education (pp. 241-258). New York: Greenwood Press.

Bourdieu, P. (1989). Social space and symbolic power. Sociological Theory, 7(1), 14-25. 
Bourdieu, P. (1997). The forms of capital. In A.G. Halsey, A.H. Lander, H. Brown, \& A.S. Wells (Eds.), Education: culture, economy and society (pp. 46-58). Oxford: Oxford University Press.

Bourdieu, P. (1998). Practical reason: On the theory of action. Stanford University Press.

Bourdieu, P. (1998). State nobility: Elite schools in the field of power, Polity.

Boyle, R (2001). Young carers in West Lothian working in partnership: The way forward. A report of the development of initiatives and consultation with West Lothian young carers. West Lothian: Carers of West Lothian.

British Association of Social Workers (2012). Statement of principles. Retrieved 08/23/13 from www.basw.co.uk/codeofethics.

British Sociological Association (2004). Statement of ethical practice. Retrieved 08/23/13 from www.britsoc.co.uk/ethics.

Broadhurst, K., Paton, H., \& Corinne, M. (2005). Children missing from school systems: Exploring divergent patterns of disengagement in the narrative accounts of parents, carers, children and young people. British Journal of Sociology of Education, 26(1), 105-119.

Bronfenbrenner, U. (1979). The ecology of human development. Cambridge M.A.: Harvard University Press.

Bronfenbrenner, U., Alvarez, W.F., \& Henderson, C.R. (1984). Working and watching: Maternal employment status and parents' perception 
of their three-year-old children. Child Development, 55(4), 13621378.

Buckner, L., and Yeandle, S. (2007). Valuing carers - calculating the value of unpaid care. London: Carers UK.

Buckner, L., Yeandle, S. (2011). Valuing carers 2011: Calculating the value of carers' support. London: Carers UK.

Burton, A. (1989). Looking forward from Ariès? Pictorial and material evidence for the history of childhood and family life. Continuity and change, 4(4), Special issue 02 The Child in History.

Bury, M. (1982). Chronic illness as biographical disruption. Sociology of health and illness, 4(2), 167-182. First published on-line July, 2008. Retrieved 10/18/15 from www.basw.co.uk/codeofethics.

Bury, M. (1988). modeMeaning at risk: The experience of arthritis. In R. Anderson, R. Bury, M. (Eds.), Living with chronic illness: The experience of patients and their families. London: Unwin Hyman.

Bury, M. (2012). Chronic illness as biographical disruption. In J. Katz, S. Peace, \& S. Spurr (Eds.), Adult lives: A life course perspective (Chapter 5). Bristol: The Policy Press, Open University.

Bury, M., Cummins, S. (1999). Health and illness in a changing society. Sociology, 33(1), 207-208. Book review.

Butler, A.H., \& Astbury, G. (2005). The caring child: An evaluative case study of the Cornwall Young Carers Project. Children and Society, 19(4), 292-303. 
Carers Strategies (Wales) Measure 2010 (nawm 5) Cardiff: Welsh Government

Carers National Association (1999). Caring about carers: A national strategy for carers. London: Carers National Association, Department of Health.

Carers UK (2002) Without us...? Calculating the value of carers' support. London: Carers UK.

Carers UK (2005) A Manifesto for carers. London: Carers UK.

Retrieved 08/3/13 from

http://www.carersuk.org/NewsandCampaigns/CarersManifesto/5Re cognition].

Carers National Association web-site. Accessed 11/03/12.

Carers UK (2014). Facts about carers: Policy briefing. London: Carers UK.

Carter, B. (2009). Tick box for child? The ethical positioning of children as vulnerable, researchers as barbarians and reviewers as overly cautious. International Journal of Nursing Studies, 46(6), 858-864.

Cassidy, T., Giles, M. (2013). Further exploration of the Young Carers Perceived Stress Scale: Identifying a benefit-finding dimension. British Journal of Health Psychology, 18(3), 642-655.

Centre for Longitudinal Studies (2003). Millennium Cohort Study. London: Centre for Longitudinal Studies, University of London.

Children in Wales web-site. Retrieved (n.d.) from info@childreninwales.org.uk 
Children's Commissioner for Wales. (2009). Full of care. Swansea: Office of the Children's Commissioner for Wales. Retrieved (n.d.) from www.childcom.org.uk

Clements, L. (1995). 'Into the Light'. Community Care, 1090, Oct. 12th18th, 23-24.

Clements, L. (2005). Carers and their rights: The law relating to carers (1st edition). London: Carers UK.

Clements, L., \& Thompson, P. (2007). Community care and the law. London: Legal Action Group.

Clements, L. (2011). Carers and their rights: The law relating to carers (4th edition). London: Carers UK.

Cogle, F.L., and Tasker, G.E. (1982). Children and housework. Family Relations, 31(3), 395-399.

Cogle, F.L., Tasker, G.E., \& Morton, D.G. (1982). Adolescent time use in household work. Adolescence 17(66), 451-455.

Cohen, D., Greene, J.A., Toyinbo, P.A., \& Siskowski, C.T. (2012). Impact of Family Caregiving by Youth on Their Psychological Well-Being: A Latent Trait Analysis. Journal of Behavioral Health Services \& Research, 39(3), 245-256.

Coleman, J.S., Johnstone, J.W.C., and Jonassohn, K. (1961). The adolescent society: The social life of the teenager and its impact on education. New York: Free Press of Glencoe.

Coleman, J. S. (1987). Social capital and the development of Youth. Momentum, 18(4), 6-8. 
Coleman, J.S. (1988). Social Capital in the Creation of Human Capital. The American Journal of Sociology, 94, Supplement: Organizations and Institutions: Sociological and Economic Approaches to the Analysis of Social Structure. pp. S95-S120.

Collins, J., and Bayless, S. (2013). How caring for a parent affects the psychosocial development of the young. Nursing children and young people, 25(10), 16,18-21.

Connelly, R. (1992). Self-employment and providing child care. Demography, 29 Feb. 1992, 17-29.

ContinYou (consultants) (2008). An evaluation of Young Carers' Projects in Essex. Essex: Schools, Children and Families Directorate, Essex County Council.

Cook, T. (2007). The History of the carers' movement. London: Carers UK.

Crawford, K., \& Walker, J. (2008). Social work and human development (2nd edition). Exeter: Learning Matters.

Cree, V. (2003). Worries and problems of young carers: Issues for mental health. Child and Family Social Work, 8, 301-309.

Crossroads \& The Princess Royal Trust For Carers (2008). Economic evaluation of young carers' interventions. Retrieved 05/22/13 from www.scie-socialcareonline.org.uk

Cunningham, H. (2006). The invention of childhood. London: BBC Books. Cunningham, H. (2007). Social constructions of childhood. Community care, Sept. 2007, 12-13. 
Curry, N., Mundle, C., Sheil, F., Weaks, L. (2011). The voluntary and community sector in health. Implications of the proposed NHS reforms. London: The King's Fund and the National Council for Voluntary Organisations.

Dahlberg, L., Demack, S., \& Bambra, C. (2007). Age and gender of informal carers: A population-based study in the UK. Health and Social Care in the Community, Sept. 2007, 15(5), 439-445.

Dahlblom, K., Herrara, A.R., Peña, R., \& Dahlgren, L. (2009). Home alone: Children as caretakers in Leon, Nicaragua. Children \& Society, 23(1), 43-56.

Daly, M., \& Lewis, J. (2000). The concept of social care and the analysis of contemporary welfare states. The British Journal of Sociology, 51(2), 281-298.

Deacon, D. (1999). Young carers and Old hacks. The journal of young carers work, April 1999.

Dearden, C. (1998). The social and educational impacts of caring on children. Primary Practice, 13, 41-5.

Dearden, C., \& Becker, S. (1995a). The national directory of Young Carers Projects and initiatives. London: Carers National Association.

Dearden, C., \& Becker, S. (1995b). Young carers - the facts. Sutton: Reed Business Publishing. 
Dearden, C., \& Becker, S. (1996). Young carers at the crossroads: An evaluation of the Nottingham YCP. Young Carers Research Group, Loughborough University/Crossroads.

Dearden, C., \& Becker, S. (1997). Protecting young carers: Legislative tensions and opportunities in Britain. Journal of Social Welfare and Family Law, 19(2), 123-138.

Dearden, C., \& Becker, S. (1998). Young carers in the UK: A profile. London: Carers' National Association.

Dearden, C., Becker, S. (2000a). Growing up caring: vulnerability and transition to adulthood - Young carers' experiences. York, Joseph Rowntree Foundation.

Dearden, C. and Becker, S. (2000b) 'Young carers' transitions to adulthood. Childright, 167, June, pp. 8-10.

Dearden, C., \& Becker, S. (2000c). Listening to children: Meeting the needs of young carers. In H. Kemshall, \& R. Littlechild (Eds.), User involvement and participation in social care : Research informing practice (pp. 129-142). London : Jessica Kingsley.

Dearden, C., Becker, S. (2000d). Young, gifted and held back? Young carers about how their responsibilities affect their transition to adulthood. A lack of appropriate services is reinforcing social exclusion. Young People Now, 138, 24-25.

Dearden, C., \& Becker, S. (2000e). Sheffield Young Carers Project: The final evaluation. Loughborough: Young Carers Research Group, Loughborough University. Retrieved 02/01/14 from 
ycrg.org.uk/youngCarersDownload/Meeting\%20Young\%20Carers\% 20

Dearden, C., with Becker, S. (2002). Young Carers Projects. What do the Child and Family Research Evaluation Reports tell us about dedicated projects for young carers? Evidence, 4. Loughborough: Centre for Child and Family Research, Loughborough University. Retrieved 02/01/14 from https://dspace.lboro.ac.uk/2134/2926.

Dearden, C., and Becker, S. (2002). Young carers and Education. London: Carers UK.

Dearden, C., \& Becker, S. (2004). Young carers in the UK: the 2004 report. London: Carers UK.

Dennis, M.J. (1999). The International Labour Organisation Convention on the worst forms of child labor. The American Journal of International Law, 93(4), 943-948.

Department for Children Schools and Families (2009). Think Family toolkit. London: DCSF.

Department of Health (1989). Caring for people: Community care in the next decade and beyond. London: HMSO.

Department of Health. (1996). Carers (Recognition and Services) Act 1995: Policy guidance and practice guide. London: HMSO. Retrieved 01/17/12 from www.dh.gov.uk and www.carersnet.org.uk

Department of Health, Social Care Group (1998) Quality protects: Framework for action (1998). London: HMSO. 
Department of Health, Department for Education and Employment, \& Home Office. (2000). Framework for the assessment of children in need and their families. London: The Stationery Office.

Department of Health (2001). The Quality Protects programme:

Transforming children's services, 202-3, LAC (2001), 28.

Department of Health, London.

Department of Health (2002). Listening, hearing and responding: Department of Health core principles for the involvement of children and young people. Department of Health, London.

Department of Health. (2005). Carers and Disabled Children Act 2000 and Carers (Equal Opportunities) Act 2004 combined policy guidance. London: HMSO.

Department of Health (2010). Survey of carers in households - England, 2009-10 (NS). London: DoH.

Doran, T., Drever, F., Whitehead, M., \& Duncan, W.H. (2003). Health of young and elderly informal carers: Analysis of United Kingdom data. British Medical Journal, 327(7428), 1388.

Dorner, L.M. (2015). From relating to (re)presenting: challenges and lessons learned from an ethnographic study With young children. Qualitative Inquiry 21(4), 354-365.

Drost, L.M., Schippers, G.M. (2015). Online support for children of parents suffering from mental illness: A case study. Clinical Child Psychology and Psychiatry, 20(1), 53-67. 
Drugscope (2004). Northumberland Young Carers Project. Retrieved 20/08/13, from www.drugscope.org.uk/prism/Projects/northumberland-youngcarers-Project

Dugdale, G., \& Clark, C. (2008). Literacy changes lives: An advocacy resource. London: National Literacy Trust.

Dunn, L. (2004). Validation of the CHORES: A measure of school-aged children's participation in household tasks. Scandinavian Journal of Occupational Therapy, 11, 179-190.

Early, L., Cushway, D., \& Cassidy, T. (2006). Perceived stress in young carers: Development of a measure. Journal of Child and Family Studies, 15(2), 169-180.

Earley, L., Cushway, D., \& Cassidy, T. (2007). Children's perceptions and experiences of care giving: A focus group study. Counselling Psychology Quarterly, 20, 69-80.

Edwards, R. (1997). Young Carers Research Project. Glasgow: NCH Action for Children in partnership with Glasgow City Council Social Work Department South District.

Edwards, R. (2004). Present and absent in troubling ways: Families and social capital debates. The Sociological Review, 52(1), 1-21.

Eley, S. (2004). 'If they don't recognize it, you've got to deal with it yourself': Gender, young caring and educational support. Gender and Education, 16(1) (Mar 2004), 65-75. 
Fallon, D., Warne, T., McAndrew, S., \& McLaughlin, H. (2012). An adult education: Learning and understanding what young service users and carers really, really want in terms of their mental well being. Nurse Education Today, 32(2), 128-132.

FMR Ltd. (2007). Summary Report November 2007. Young Carers in North Lanarkshire. Edinburgh: Scottish Government.

Fox, N.J. (1995). Professional models of school absence associated with home responsibilities. British Journal of Sociological Education, $16(2), 221-242$.

Frank, J. (1995). Couldn't care more: A study of young carers and their needs. London: The Children's Society.

Frank, J., \& McLarnon, J. (2008). Young carers, parents and their families: key principles of practice. Supportive practice guidance for those who work directly with, or commission services for young carers and their families. London: The Children's Society.

Frank, J., Tatum, C. \& Tucker, S. (1999). On small shoulders: Learning from the experiences of former young carers. London: The Children's Society, Open University.

Franklin, A., \& Sloper, P. (2005). Listening and responding? Children's participation in health care within England. The International Journal of Children's Rights, 13, 11-29.

Franklin, A., \& Sloper, P. (2009). Supporting the participation of disabled children and young people in decision-making. Children \& Society, 23, 3-15. 
Fraser, E., \& Pakenham, K.I. (2008). Evaluation of a resilience-based intervention for children of parents with mental illness. Australian and New Zealand Journal of Psychiatry 42(12), 1041-1050.

Fraser, E., \& Pakenham, K.I. (2009). Resilience in children of parents with mental illness: Relations between mental health literacy, social connectedness and coping, and both adjustment and caregiving. Psychology, Health \& Medicine, 14(5), 573-584.

Fuller, E. (Ed.) (2011). Smoking, drinking and drug use among young people in England in 2010. London: National Health Service Information Centre for Health and Social care. Retrieved 11/08/15 from http://www.ic.nhs.uk/pubs/sdd10fullreport ISBN 978-1-84636-571-3

Furstenberg, F., \& Hughes, M.E. (1995). Social capital and successful development among at-risk youth. Journal of Marriage and Family, $57(3), \quad 580-592$.

Gillies, V.. \& Edwards, R. (2006). A qualitative analysis of parenting: Comparing the work of Coleman and Bourdieu. Qualitative Sociology Review, 2(2), 42-60.

Gilligan R. (1999) Enhancing the resilience of children and young people in public care by mentoring their talents and interests. Child \& Family Social Work, 4(3), 187-196. 
Gilligan, R. (2000). Adversity, resilience and young people: The protective value of positive school and spare time experiences. Children \& Society, 14(1), 37-47.

Gilligan R. (2004) Promoting resilience in child and family social work: Issues for social work practice, education and policy. Social Work Education, 23(1), 93-104.

Gladstone, B. M., Boydell, K. M., \& McKeeve, P. (2006). Recasting research into children's experiences of parental mental illness: Beyond risk and resilience. Social Science and Medicine, 62(10), $2540-2550$.

Goffman, E. (1963). Sigma: Notes on the Management of Spoiled Identities. Englewood Cliffs: Prentice-Hall.

Goodman, C. (1986). Research on the informal carer: A selected literature search. Journal of Advanced Nursing, 11(6), 705-712.

Granovetter, M. (1985). Economic action, social structure, and embeddedness. American Journal of Sociology, 91, 481-510.

Grant, G., Nolan, M., \& Keady, J. (2003). Supporting families over the life course: Mapping temporality. Journal of Intellectual Disability Research, 47(4-5), 342-351.

Grant, G., Repper, J., \& Nolan, M. (2008). Young people supporting parents with mental health problems: Experiences of assessment and support. Health and Social Care in the Community, 16(3) 271281. 
Gray, B., Robinsons, C., \& Seddon, D. (2008a). Invisible children: Young carers of parents with mental health problems: The perspectives of professionals. Child and Adolescent Mental Health, 13(4), 169-172.

Gray, B., Robinson, C. A., \& Seddon, D. (2008b). "Confidentiality smokescreens" and carers for people with mental health problems: The perspectives of professionals. Health and Social Care in the Community, 16(4), 378-387.

Griffiths, Sir Roy (1988). Community care: Agenda for action. A report to the Secretary of State for Social Services. Great Britain: Department of Health and Social Security.

Grimshaw, R. (1991). Children of parents with Parkinson's' Disease: A research report for the Parkinson's Disease Society. London: National Children's Bureau.

Hafford, C. (2010). Sibling caretakers in immigrant families: Understanding cultural practices to inform child welfare practice and evaluation. Evaluation and Program Planning, 33(3), 294-302. Hansard HC Deb Community Care, vol. 671, col. 1021 (18 July 1990) [Electronic version].

Hart, R.A. (1992). Children's participation: From tokenism to citizenship. Florence: United Nations International Children's Emergency Fund. Heal, S., Mapp, S., \& Clements, L. (1995). Young carers: Back them up. Community Care, 9(15), Nov 95, 21-3.

Heal, S. (1997). Keeping it in the family: Children and young people as carers. Youth and Policy, 55 (Jan 1997), 75-80. 
Health and Law Department, Swansea University (2012). Personal communication, August 2nd, 2012. Swansea University. Health and Social Care Information Centre (2013). Dental health survey of children and young people. London: Office for National Statistics. Heinz, W.R., \& Kruger, H. (2001). Life course: Innovations and challenges for social research. Current Sociology, 49(2), 29-53. Heyman, A. (2013). Partnership working between Young Carers Project and Social Services: The need for young carers work to establish itself as a profession. Social work and social sciences review, 16 (3), 50-64.

Heyman, A., \& Heyman, B. (2013). 'The sooner you can change their life course the better': The time-framing of risks in relationship to being a young carer. Health Risk \& Society, 15(6-7), 561-579. Her Majesty's Government (2010). Recognised, valued and supported: Next steps for the Carers Strategy. London: Her Majesty's Government.

Hobson, B. (2003). Recognition struggles and social movements: Contested identities, agency and power. Cambridge: Cambridge University Press.

Hoenig, J., \& Hamilton, M.W. (1966). The schizophrenic patient in the community and his effect on the household. International Journal of Social Psychiatry, 12(3), 165-176.

Holland, J. (2008). Young people and social capital: What can it do for us. London: London South Bank University. 
Hooper L.M. (2007) The application of attachment theory and family systems theory to the phenomena of parentification. Family Journal. 15(3), 217-223.

Howatson-Jones, L., and Coren, E. (2013). Scoping the Assessment Needs of Young Carers of Adults with a Long Term Condition. Journal of Nursing Care, 2, 129.

Hutt, J. (1999). Partnerships for progress community care in the 21st century. Conference presentation to Developing Partnerships: Research and development for health and social care. City Hall, Cardiff, $18^{\text {th }}$ June 1999.

Hwang, S.K. (2009). "Same but different": A visual ethnography of the everyday lives of siblings of autistic children in South Korea (Doctoral thesis). Retrieved 09/25/13 from EThOS data-base (EThOS/BI 516495).

Institute for Research and Innovation in Social Services (2010). Improving support for black and minority ethnic carers. Insight 07. Retrieved 08/12/14 from www.iriss.org.uk/sites/default/files/irissinsight-7.pdf

International Labour Organisation (1973). Convention concerning minimum age for admission to employment (Minimum Age Convention) (ILO No. 138). Geneva: ILO.

International Labour Organisation. (1999). Convention concerning the prohibition and immediate action for the elimination of the worst 
forms of child labour (ILO No. 182). Geneva: International Labour Organisation.

International Labour Organisation (2006). The end of child labour: Within reach. Director General's Report to the International Labour Organisation Conference, Geneva.

Invernizzi, A., \& Milne, B. (2002). Are children entitled to contribute to international policy making? A critical view of children's participation in the international campaign for the elimination of child labour. The International Journal of Children's Rights, 10(4), $403-431$.

Ireland, M.J., \& Pakenham, K.I. (2010). The nature of youth care tasks in families experiencing chronic illness/disability: Development of the Youth Activities of Caregiving Scale (YACS). Psychology \& Health, $25(6), 713-731$.

Jebb, E. (1923). Declaration on the rights of the child. Geneva: International Save the Children Union.

Jenkins, S., \& Wingate, C. (1994). Who cares for young carers? Their invisibility is the first thing to be addressed. British Medical Journal, $308,733-734$.

John, J., \& Griffith, R. (2011). The right for children and young people to participate in their own healthcare. In R. Davies \& A. Davies (Eds.), Children and young people's nursing: principles for practice. London: Hodder Arnold. 
Jones, C., and Czerniewicz, L. (2010). Describing or debunking? The net generation and digital natives. Journal of Computer Assisted Learning, 26(5), 317-320.

Joseph, S., Becker, F., \& Becker, S. (2009a). Manual for Measures of Caring Activities and Outcomes for children and young people. Essex: The Princess Royal Trust.

Joseph, S., Becker, S., Becker, F., \& Regel, S. (2009b). Assessment of caring and its effects in young people: Development of the Multidimensional Assessment of Caring Activities Checklist (MACA YC18) and the Positive and Negative Outcomes of Caring Questionnaire (PANOC1-YC20) for young carers. Child: Care, Health and Development, 35 (4), 510-520.

Kachorek L.V., \& Shifren K. (2003). Does early caregiving matter? The effect on young caregivers' adult mental health. International Journal of Behavioral Development, 27(4), 338-346.

Keenan, K.F., van Teijlingen, E., McKee, L., Miedzybrodzka, Z., \& Simpson, S.A. (2009). How young people find out about their family history of Huntington's disease. Social Science \& Medicine, 68(10), 892-1900.

Kennan, D., Fives, A., \& Canavan' J. (2011). Accessing a hard to reach population: Reflections on research with young carers in Ireland. Child \& Family Social Work, 17(3), 275-283. 
Keith, L., \& Morris, J. (1995). Easy targets: A disability rights perspective on the "children as carers" debate. Critical Social Policy, 15(44/45), 36-57.

Kennedy, G., Judd, T., Dalgarno, B., \& Waycott, J. (2010). Beyond natives and immigrants: Exploring types of net generation students. Journal of Computer Assisted Learning, 26, 332-343.

Kim, B.Y. (2008). The role of political ideology in the policy development of personal social services from 1960 s to 2000 s Britain. Ph.D. thesis. University of York.

King, V., \& Elder, G.H. (1995). American children view their grandparents: Linked lives across three rural generations. Journal of Marriage and Family, 57(1), 165-178.

Kirby, P., \& Bryson, S. (2002). Measuring the magic? Evaluating and researching young people's participation in public decision-making. London: Carnegie Young People Initiative.

Lackey, N.R., \& Gates, M.F. (1997). Combining the analyses of three qualitative data sets in studying young caregivers. Journal of Advanced Nursing vol. 26(4) (Oct 1997), 664-671.

Lackey, N.R. \& Gates, M.R. (2001). Adults" recollections of their experiences as young caregivers of family members with chronic physical illness. Journal of Advanced Nursing, 34 (3), 320-328.

Laing, M., \& Sprung, S. (2014). Enabling the health and wellbeing of carers through district nursing support. British Journal of Community Nursing, 19(7), 346-351. 
http://www.qni.org.uk/supporting_carers/carers_project_resources An article relating to this work was published in the British Journal of Community Nursing (BJCN) in July 2014 http://www.magonlinelibrary.com/doi/full/10.12968/bjcn.2014.19.7. 346

Larkin, M. (2009). Vulnerable groups in Health and Social Care. London: Sage.

LE Consultancy Wales (2010). Respite care in Wales. Final report to Welsh Government December 2010. Cardiff: Welsh Government. League of Nations (1924). Geneva declaration of the rights of the child. Geneva: United Nations.

Leonard, M. (2005). Children, childhood and social capital. Sociology, $39(4), 605-622$.

Lloyd, K. (2013). Happiness and well-being of young carers: Extent, nature and correlates of caring among 10 and 11 year old school children, Journal of Happiness Studies, 14(1), 67-80.

Lloyd, L. (2006). Call us carers: Limitations and risks in campaigning for recognition and exclusivity. Critical Social Policy, 26(4), 945-60.

Luthar, S.S., Cicchetti, D., Becker, B., Eye, E. von, Schuster, C., Roosa, M.M., \& Robinson, J.L. (2000). The construct of resilience: A critical evaluation and guidelines for future work. Child Development, $71(3), 543-575$.

Lyall, J. (1989). Stolen Youth. Nursing Times, 85, 16-17. 
Mahon, A., Glendinning, C., Clarke, K., \& Craig, G. (1996). Researching children: Methods and ethics. Children \& Society, 10, 145-154. Mahon, A., \& Higgins, J. (1995a). A life of our own. Young carers: An evaluation of three RHA funded projects in Merseyside. Manchester: University of Manchester, Health Services Management Unit.

Mahon, A., \& Higgins, J. (1995b). Projected successes. Community Care, 1093, Nov. 2-8 1995, 22-23.

Mahon, A., Clarke, K., \& Craig, G. (2007). Researching children: Methods and ethics. Children \& Society, 10, 145-154.

Mallinson, I., \& Bovaird, T. (1988). Setting objectives and measuring achievement in social care. British Journal of Social Work, 18, 309324.

Martire, L.M., Stephens, M.A.P., \& Townsend, A.L. (1998). Emotional support and well-being of midlife women: Role-specific mastery as a mediational mechanism. Psychology and Aging, 13(3), 396-404. McAndrew, S., Warne, T., Fallon, D., \& Moran, P. (2012). Young, gifted, and caring: A Project narrative of young carers, their mental health, and getting them involved in education, research and practice. International Journal of Mental Health Nursing, 21, 1219.

McDonald, J., Dew, K., \& Cumming, J. (2010). Change and adaptation in families with young carers. Australian Journal of Social Issues, 45(4), 459-475. 
McLaughlin, E., \& Ritchie, J. (1994). Legacies of caring: The experiences and circumstances of ex-carers. Journal of Health and Social Care in the Community, 2(4), 241-253.

McLuhan, M., and Fiore, Q. with Agel, J. (1967). The Medium is the Message: An Inventory of Effects. New York: Random House.

McMurray, I., Connolly, H., Preston-Shoot, M., \& Wigley, V. (2008). Constructing resilience: Social workers' understandings and practice. Health \& social care in the community, 16(3), 299-309. Means, R., Richards, S., \& Smith, R. (2008). Community care: Policy and practice (2nd edition). Hampshire: Palgrave MacMillan.

Meijer, S.A., Sinnema, G., Bijstra, J.O., Mellenbergh, G.J., \& Wolters, W.H.G. (2000). Social functioning in children with a chronic illness. Journal of Child Psychology and Psychiatry and Allied Disciplines, $41(3), 309-317$.

Meljeteig, P. (1999) Introduction: Understanding child labour. Childhood, $6(1)$, pp. 5-12.

Meredith, H. (1990). Young carers: A hidden workforce? Carelink, 10(7).

Meredith, H. (1991). Young carers: The unacceptable face of community care. Social work and social sciences review, 3, 47-51.

Meredith, H. (1992). Supporting the young carer. Community Outlook, $2(5), 15-18$. 
Metzing-Blau, S., \& Schnepp, W. (2008). Young carers in Germany: To live on as normal as possible - a grounded theory study. BMC Nursing, 7(15), 1-9.

Middleton, L. (1991). Young carers: Saints or slaves. Youth Clubs, June $1991,63,46-7$.

Milbourne, L. (2009). Remodelling the Third Sector: Advancing collaboration or competition in community-based initiatives? Journal of Social Policy, 38(2), $277-297$.

Miljeteig-Olssen, P. (1990). Advocacy of children's rights - The Convention as more than a legal document. Human Rights Quarterly, 12(1), 151.

Millenaar, J.K., Van Vliet, D., Bakker, C., Vernooij-Dassen, M.F.J., Koopmans, R.T.C.M., Verhey, F.R.J., \& De Vugt, M.E. (2014). The experiences and needs of children living with a parent with young onset dementia: Results from the Needs Young Dementia study. International Psychogeriatrics, 26(12), 2001-2010.

Mills, C. W. (1959). The sociological imagination. New York: Palgrave Macmillan.

Montgomery, R.J.V., Gonyea, J.G., \& Hooyman, N.R. (1985). Caregiving and the experience of objective and subjective burden. Family Relations, 34, 19-26.

Morgan, R. (2005). Finding what children say they want: Messages from children. Representing Children, 17(3), 180-189. 
Moore, T., \& McArthur, M. (2007). We're all in it together: Supporting young carers and their families in Australia. Health and Social Care in the Community, 15(6), 561-568.

Moore, T., McArthur, M., \& Morrow, R. (2009). Attendance, achievement and participation: Young carers' experiences of school in Australia. Australian Journal of Education, 53(1), 5-18.

Morrow, V. (1999). Conceptualising social capital in relation to the wellbeing of children and young people: A critical review. The sociological review, 47(4), 744-765.

Myers, W.E. (1999). Considering child labour: Changing terms, issues and actors at the international level. Childhood, 6(1), 13-26.

Nagl-Cupal, M., Daniel, M., Koller, M.M., \& Mayer, H. (2014).

Prevalence and effects of caregiving on children. Journal Of Advanced Nursing, 70(10), 2314-2325.

Netten, A. (2011). Overview of outcome measurement for adults using social care services and support. London: National Institute of Health Research, School for Social Care Research.

Newman, T. (2002). 'Young carers' and disabled parents: Time for a change of direction? Disability \& Society, 17(6), 613-625.

Newton, B., \& Becker, S. (1999). The Capital Carers. Loughborough: Young Carers Research Group.

Nicholas, E. (2003). An outcomes focus in carer assessment and review: Value and challenge. British Journal of Social Work, 33(1), 31-47. 
Nichols, K.R., Fam, D., Cook, C., Pearce, M., Elliot, G, Baago, S., Rockwood, K., \& Chow, T.W. (2013). When Dementia is in the house: Needs Assessment Survey for young caregivers. Canadian Journal Of Neurological Sciences, 40(1), 21-28.

Noble-Carr, C. (2002). Young Carers Research Project: Final report. Canberra: Carers Australia. Retrieved 09/23/14 from http://www.fahcsia.gov.au/sa/carers/pubs/YoungcarersReport/Pag es/default.aspx

O'Connor, S., Carney, T., House, E., Ferguson, E., Caldwell, F., \& O'Connor, R.C. (2010). Revision of the Hospital Anxiety and Depression Scale (HADS) to produce the Paediatric Index of Emotional Distress (PI-ED). PRO Newsletter. 43, 2-4. London: GL Assessment Ltd.

O'Dell, L., Crafter, S., de Abreu, G., \& Cline, T. (2010). Constructing "normal childhoods": Young people talking about young carers. Disability \& Society, 25(6), 643-655.

Office for National Statistics. Social Survey Division (2002). General Household Survey, 1996-1997 (3rd Edition). Colchester, Essex: United Kingdom Data Archive [distributor], July 2002. SN: 3804, http://dx.doi.org/10.5255/UKDA-SN-3804-1

Office for National Statistics (2006). Census 2001. London: Office for National Statistics. Retrieved 09/23/15 from https://www.nomisweb.co.uk 
Office for National Statistics (2009/10). Census 2001: Survey of carers. London: Office for National Statistics.

Office for National Statistics (2013). Analysis of 2011 Census. Retrieved 09/23/15 from www.ons.gov.uk.

Office for National Statistics (2014). Census 2011. Retrieved 09/08/15.from http://www.ons.gov.uk/ons/rel/census/2011census/detailed-characteristics-for-local-authorities-in-englandand-wales/index.html

Office for National Statistics (2015). Child Dental Health Survey 2013, England, Wales and Northern Ireland. London: Health and Social Care Information Centre.

Office for National Statistics (2014b). Dental health survey of children and young people. Statistical bulletin: Families and Households, 2014. Office for National Statistics and Health Information Centre. Office of Population Census and Surveys (1992). General Household Survey: Carers in 1990. Office of Population Censuses and Surveys, Monitor SS 92/2. London: HMSO.

Olsen, R., (1996). Young carers: Challenging the facts and politics of research into children and caring. Disability \& Society, 11(1), 4154.

Olsen, R. (2000). Families under the microscope: parallels between the young carers debate of the 1990 s and the transformation of childhood in the late nineteenth century. Children \& Society, 14, 384-394. 
Olsen, R., \& Clarke, H. (2003). Parenting and disability. Bristol: Policy Press.

Olsen, R., \& Parker, H. (1997). A response to Aldridge and Becker "Disability rights and the denial of young carers: the danger of zero-sum arguments". Critical Social Policy, 17, 125-133.

O'Neill, A. (1988). Young Carers: The Tameside Research. Tameside: Metropolitan Borough Council.

O'Neill, O. (1988). Children's rights and children's lives. Ethics, 98(3), 445-463.

Page, R. (1988). Report on the initial survey investigating the number of young carers in Sandwell secondary schools. Social Services Research, 17(6), 31-36. Sandwell: Sandwell Metropolitan Borough Council.

Pakenham, K.I., \& Bursnall, S. (2006). Relations between social support, appraisal and coping and both positive and negative outcomes for children of a parent with multiple sclerosis and comparisons with children of healthy parents. Clinical Rehabilitation, 20, 709-723.

Pakenham, K.I., Bursnall, S., Chiu, J., Cannon, T., \& Okochi, M. (2006). The psychosocial impact of caregiving on young people who have a parent with an illness or disability: Comparisons between caregivers and non-caregivers. Rehabilitation Psychology, 51(2), 113-126.

Pakenham, K.I., Chiu,J., Bursnall, S., \& Cannon, T. (2007). Relations between social support, appraisal and coping and both positive and 
negative outcomes in young carers. Journal of Health Psychology, 12(1), 89-102.

Pakenham, K.I., \& Cox, S. (2012). The nature of caregiving in children of a parent with multiple sclerosis from multiple sources and the associations between caregiving activities and youth adjustment overtime. Psychology \& Health, 27(3), 324-346.

Pakenham, K.I., Cox, S. (2015). The effects of parental illness and other ill family members on youth caregiving experiences. Psychology \& Health, 30(7), 857-878.

Parker, G., \& Clarke, H. (2002). Making the ends meet: Do carers and disabled people have a common agenda? Policy and Politics, $30(3), 347-359$.

Parker, G., \& Lawton, D. (1994). Different types of care, different types of carer: Evidence from the General Household Survey 1985. London: Her Majesty's Stationery Office and University of York, Social Policy Research Unit.

Payne, S., Smith, P., \& Dean, S. (1999). Identifying the concerns of informal carers in palliative care. Palliative Medicine, 13(1), 37-44.

Phelps, D., Leadbitter, H., \& Manzi, D. (2010). Supporting young carers: A resource for schools. London: The Princess Royal Trust for Carers and The Children's Society.

Pickard, L. (2004). The effectiveness and cost effectiveness of support and services to informal carers of older people. London: Audit Commission. 
Pollack, E.G. (2002). The childhood we have lost: When siblings were caregivers, 1900-1970. Journal of Social History, 36(1), 31-61.

Portes, A. (1998). Social capital: Its origins and applications in modern sociology. Annual Review of Sociology, 24(1), 1-24.

Price, D. (1992, February). A politician's view of care in the community. Paper presented at the annual conference of the British Association of Supported Employment, Newcastle-under-Lyme. Baseline, 48, 2-14. Annual conference of BASE at Newcastleunder-Lyme.

Princess Royal Trust web-site (merged with Carers UK 2012).

Purcal, C., Hamilton, M., Thomson, C., \& Cass, B. (2012). From assistance to prevention: Categorizing young carer support services in Australia, and international implications. Social Policy \& Administration, 46(7), 788-806.

Putnam, R.D. (1993). Making democracy work: Civic traditions in modern Italy. Princeton: Princeton University Press.

Putnam, R.D. (1995). Bowling alone - America's declining social capital. Journal of Democracy, 6(1), 65-78.

Qureshi, H. (1999). Outcomes of social care for adults: Attitudes towards collecting outcome information in practice. Health \& Social Care in the Community, 7(4), 257-265.

Rees, P. (2013). The mental health, emotional literacy, cognitive ability, academic attainment and 'resilience' of 'looked after children': A 
multidimensional, multiple-rater population based study. British Journal of Clinical Psychology, 52(2), 183-198.

Reinardy, J., Kane, R.A., Huck, S., Call, K.T., \& Shen, C-T. (1999). Beyond burden: Two ways of looking at caregiving burden. Research on Aging, 21(1), 106-127.

Researchworks (2002). Including children in household tasks: Is it worth the effort? Minneapolis: University of Minnesota. Retrieved 12/29/13 from www.cehd.umn.edu/research/highlights/Rossmann Revans, L. (2007). Support for young carers. Community Care; Dec 6, $2007 ; 1702,24-25$.

Rheingold, H.L. (1982). Little children's participation in the work of adults, a nascent prosocial behavior. Child development, 53, 114125.

Richardson, K., Jinks, A., \& Roberts, B. (2009). Qualitative evaluation of a young carers' initiative. Journal of Child Health Care, 13(2), 150-160.

Rickford, F. (2001a). Adopting sound policy. Community Care, 27, 3637.

Rickford, F. (2001b). A knowing silence. Community Care. 12, 22-23.

Robson, E. (2000). Invisible carers: Young people in Zimbabwe's homebased Healthcare. Institute of British Geographers. Area, 32(1), 59-69.

Robson, E., Ansell, N., Huber, U.S., Gould, W.T.S., \& van Blerk, L. (2006). Young caregivers in the context of the HIV/AIDS 
pandemic in Sub-Saharan Africa. Population Space and Place, 12(2), 93-111.

Roche, J., \& Tucker (2003). Extending the social exclusion debate - An exploration of the family lives of young carers and young people with ME. Childhood A global journal of child research, 10(4), 439456.

Romaine, S. (1994). Language in society. Oxford: Oxford University Press.

Rossmann, R. (2002). Including children in household tasks: Is it worth the effort? Researchworks. Retrieved 12/29/13 from www.cehd.umn.edu/research/highlights/Rossmann

Rutherford, M. (2009). Children's autonomy and responsibility: An analysis of child rearing advice. Qualitative Sociology, 32(4), 337353

Rutter, M., \& Madge, N. (1976). Cycles of disadvantage: A review of research. London: Heinemann.

Rutter, M. (1987). Psychological Resilience and protective mechanisms. American Journal of Orthopsychiatry, 57(3), 316-331

Rutter, M. (1990). Psychosocial resilience and protective mechanisms. In J. Rolf et al. (Eds.), Risk and Protective Factors in the Development of Psychopathology. Cambridge: Cambridge University Press.

Schlarmann, S., Metzing-Blau, S., \& Schnepp, W. (2008). Health-related quality of life (HRQOL) in children and adolescents as an outcome criterion to evaluate family oriented support for young carers in 
Germany. Bio Med Central Public Health, 8, 414, biomedcentral.com

Schlarmann, S., Metzing-Blau, S., \& Schnepp, W. (2011a). Implementing and evaluating the first German young-carers project: Intentions, pitfalls and the need for piloting complex interventions. The Open Nursing Journal, 5, 38-44.

Schlarmann, S., Metzing-Blau, S., \& Schnepp, W. (2011b). Germany's first young carers project's impact on the children: Relieving the entire family. A qualitative evaluation. The Open Nursing Journal, $5,86-94$.

Schweiger, W.K., \& O’Brien, M. (2005). Special needs adoption: An ecological systems approach. Family Relations, 54(4), 512-522.

Social Care institute for Excellence (2005). Implementing the Carers (Equal Opportunities) Act 2004. Retrieved 08/24/2014 from www.scie.org.uk/publications/guides/guide09/

Social Care Institute for Excellence (2009). Research briefing 11: The health and well-being of young carers. Retrieved 08/04/2013 from www.scie.org.uk?research briefings.

Seddon D.(1999). Negotiating caregiving and employment. In S. Cox \& J. Keady (Eds.), Younger people with dementia: planning, practice and development (electronic resource) (pp. 173-195). London: Jessica Kingsley Publishers. 
Seddon, D., Robinson, C.A., \& Napier, B. (2003). A study of young carers in Wales. Cardiff: Wales Office of Research and Development.

Seddon, D., Robinson, C., Tommis, Y., Perry, J., Woods, B., Russell, I., Reeves, C., Harper, G. and Boyle, M. (2008). A study of the effects of the Carers Strategy in Wales on the needs of carers and the services that they receive. Final Report to WORD, Welsh Assembly Government.

Segal, J., \& Simkins, J. (1996). Helping children with ill or disabled parents: A guide for parents and professionals. London: Jessica Kingsley.

Shaw, C., Brady, L.M., Davey, C. (2011). Guidelines for research with children and young people. London: Research Centre, National Children's Bureau.

Siddall, R. (1994). Lost childhood. Community Care, June 9th-15th 1994, 9-15.

Silverman, P.R. (1970). Widow as caregiver in a programme of preventive intervention with other widows. Mental Hygiene, 54(4), 540.

Skovdal, M. (2010a). Children caring for their "caregivers": Exploring the caring arrangements in households affected by AIDS in Western Kenya. Aids Care: Psychological And Socio-Medical Aspects Of Aids/HIV, 22(1), 96-103. 
Skovdal, M. (2010b). Community Relations and Child-led Microfinance:

A case study of caregiving children in Kenya. AIDS Care, 22 (2010), 652-1661.

Skovdal, M. (2011). Examining the trajectories of children providing care for adults in rural Kenya: Implications for service delivery. Children and Youth Services Review, 33(7) (Jul 2011), 1262-1269.

Skovdal, M., \& Ogutu, V.O. (2009). 'I washed and fed my mother before going to school': Understanding the psychosocial well-being of children providing chronic care for adults affected by HIV/AIDS in Western Kenya. Globalization and Health, 5, 1-10.

Skovdal, M., Ogutu, V.O., Aoro, C., \& Campbell, C. (2009). Young carers as social actors: Coping strategies of children caring for ailing or ageing guardians in Western Kenya. Social Science \& Medicine, 69(4), 587-595.

Smith, K.R., \& Zick, C.D. (1994). Linked lives, dependent demise? Survival analysis of husbands and wives. Demography, 31(1), 8193.

Smyth, C., \& Samia, M. (2010). Exploring young carers' agency. Qualitative Research Journal, 10(2).

Smyth, C., Blaxland, M., \& Cass, B. (2011a). "So that's how I found out I was a young carer and that I actually had been a carer most of my life". Identifying and supporting hidden young carers. Journal of Youth Studies, 14(2), 145-160. 
Smyth, C., Cass , B., \& Hill, T. (2011b). Children and young people as active agents in care-giving: Agency and constraint. Children and Youth Services Review, 33, 509-514.

Social Care Institute for Excellence (2009). Think Child, Think Parent, Think Family: A guide to parent mental health and child wellbeing. London: Social Care Institute for Excellence.

Social Exclusion Task Force (2008). Reaching out: Think Family. London: Her Majesty's Government Cabinet Office.

Social Research Association (2003). Ethical guidelines. Social Research Association. Retrieved 07/15/13 from the-sra.org.uk/research-ethics/ethics-guidelines

Social Services Improvement Agency. Good practice in Telecare. Retrieved 02/24/15 from www.ssiacymru.org.uk.

Social Services Inspectorate (1995). Guidance letter: Young carers CI (95)12. London: Social Services Inspectorate.

Social Services Inspectorate (1996) Carers (Recognition and Services) Act 1995: Practice guide. London: Her Majesty's Stationery Office. Sports Council Wales (2009). Young people's participation in sport. Cardiff: Sports Council Wales.

Sprung, S., \& Laing, M. (2014). Working with health care professionals to increase care awareness, identification and referral. London: The Queen's Nursing Institute Carers Project.

StatsWales (2015). Eye care statistics for Wales, 2014-15. Cardiff: Welsh Government. 
Stone, L. (1977). The family sex and marriage in England, 1500-1800. New York, Harper \& Row. Retrieved 01/01/2012 from www.humanitiesebook.org

Stone, L. (1981). Past achievements and future trends. Journal of interdisciplinary history, 12(1), 51-87.

Strathclyde Centre for Disability Research \& Centre for the Child and Society (1999). The extent, nature and needs of young carers in Easterhouse. Report submitted to Greater Glasgow Health Board and Easterhouse Carers Strategy Group. Glasgow: University of Glasgow.

Strugnel, C., \& Silverman, P.R. (1971). Funeral director's wife as caregiver. Omega Journal of Death and Dying, 2(3), 174-78.

Sturge, A., Frank, A., \& Coster, T. (1994). Who cares for young carers? British Medical Journal, 308(6942), 1510-1511.

Svanberg, E., Stott, J. and Spector, A. (2010) 'Just helping': Children living with a parent with young onset dementia. Aging \& Mental Health. 14(6), 740-751.

Tapscott, D. (1998). Growing up digital. The rise of the Net Generation. New York: McGraw-Hill.

Tapscott, D. (1999). Educating the Net Generation. Educational Leadership, 56(5), 6-11.

Tarapdar, S. (2007). 'I don't think people know enough about me and they don't care' - Understanding and Exploring the Needs of Young Carers from their Perspective. Open University's Children's 
Research Centre. Retrieved 19/07/2015 from www.open.ac.uk/researchProjects/childrens-research-centre. Thomas, N., Stainton, T., Cheung, W., Jackson, S., Sanders, R., Symonds, A., Doubtfire, S., \& Webb, A. (2003). Your friends don't understand: A study of young carers in Wales: perspectives of children and young people. Report for Wales Office of Research and Development for Health and Social Care (SCC00/1/003A). Centre for Applied Social Studies, Swansea: University of Wales. Thompson, A., Cohen, P., \& Clements, L. (1995). Young carers: Back them up. Community Care, (1090), 21-3.

Thurnham, P. (1990). Community care. Crimes amendment bill (no. 2). Hansard House of Commons Debate, 18 July 1990, vol. 176, col. 1021.

Travers, A. F. (1996). Carers. British Medical Journal; Aug 24, 1996; $313(7055), 482-486$.

Travis, M.J., \& Bruce, T. (1994). Who cares for young carers? British Medical Journal, 308, 341.

Trnobranski, P.H. (1995). Implementation of community care policy in the United Kingdom: Will it be achieved? Journal of advanced nursing, 21, 988-995.

Tyler, A. (1990). Helping the children to cope. Combat, 37, 16-20.

United Nations International Children's Emergency Fund (2009). Progress for Children (No. 8). Geneva: United Nations International Children's Emergency Fund. 
United Nations (1989). United Nations Convention on the Rights of the Child. London: HMSO. Retrieved 08/03/13 from www.unicef.org/crc Valentine, G., Butler, R. \& Skelton, T. (2001) The ethical and methodological complexities of doing research with 'vulnerable' young people. Ethics, Place and Environment, 4(2), 119-125.

Wales Young Carers Network Young Carers Report. (2007). A young people's report on young carers issues from the Network Conference $5^{\text {th }}-6^{\text {th }}$ October 2007. Gregynog: Young Carers Network. Walker, A. (1996). Young carers and their families: A survey carried out by the Social Survey Division of Office for National Statistics on behalf of the Department of Health. London: The Stationery Office. Walker, J.P., \& Lee, R.E. (1998). Uncovering strengths of children of alcoholic parents. Contemporary Family Therapy, 20, 521-538.

Ward, H., \& Cavanagh, J. (1997). A descriptive study of the selfperceived needs of carers for dependants with a range of long-term problems. Journal of Public Health Medicine, 19(3), 281-287.

Warren, J. (2007). Young carers: Conventional or exaggerated levels of involvement in domestic and caring tasks? Children \& Society, 21, 136-146.

Warren, J. (2008). Young carers: still 'hidden' after all these years? Research, Policy and Planning (2008) 26(1), 45-56.

Watson, D. L., Cameron, A. M., \& Aghtaie, N. (2014). The role of 'embeddedness' in the delivery of integrated children's services. Children and Youth Services Review 2014, 47(3), 370 - 377. 
Watson, S. (1999). Meeting the needs of young carers. Nursing standard (Royal College of Nursing (Great Britain) (1987) 13(31), 37-40.

Webb, V. (2012). Why we need a strategy for young carers. The Welsh Agenda, 54. Cardiff: Institute of Welsh Affairs.

Welsh Assembly Government (2000). Carers Strategy Implementation Plan. Cardiff: Welsh Assembly Government.

Welsh Assembly Government (2002). Caring for young carers - Raising awareness of young carers' issues. Cardiff: Welsh Assembly Government. Retrieved 19/08/13 from www.wales.gov.uk/topics/health \& social care/young carers Welsh Assembly Government (2002). Is someone you teach a young carer? A ydych chi'n dysgu gofalwr ifanc? Cardiff: Welsh Assembly Government. Retrieved 11/23/13 from www.wales.gov.uk/topics/health \& social care/young carers Welsh Assembly Government (2005). National Service Framework for Children. Cardiff: Welsh Assembly Government.

Welsh Assembly Government (2006). Carers Strategy Implementation: Consultation document. Cardiff: Welsh Assembly Government. Welsh Government (2007). Press release 29/08/07. Welsh Government (2007) Carers Strategy re-focused. Cardiff: Welsh Government. Retrieved 04/04/14 from www.wales.gov.uk Welsh Government (2008). All Wales Child Protection Procedures. Cardiff: Welsh Government. 
Welsh Government (2011). Rights of Children and Young Persons (Wales) Measure 2011.

Welsh Government (2011). Children and Young People's Wellbeing Monitor for Wales. Cardiff: Welsh Government.

Welsh Government (2011). Health Behaviour in school-aged children (Wales). Cardiff: Welsh Government.

Welsh Government (2011). Personal communication, August 11th, 2011.

Welsh Government. (2013). Welsh Health Survey 2011: Health of carers (Statistical bulletin 42/2013). Retrieved 02/01/14 from http://www.wales.gov.uk/docs/statistics/carers.

Welsh Government. (2013). Carers Strategy for Wales. Cardiff: Welsh Government.

Welsh Government Social Research (2015). Health behaviour in schoolaged children: Initial findings from the $2013 / 14$ survey in Wales. Welsh Government: Cardiff.

Welsh Government. Welsh Index of Multiple Deprivation. Retrieved $12 / 29 / 13$ from http://www.wales.gov.uk/statistics-and-research/welsh-indexmultiple-deprivation

Welsh Government Statistical Directorate. StatsWales. Retrieved 6/15/14 from https://statswales.wales.gov.uk

Welsh Office (1998). Better Health Better Wales. Cardiff; Welsh Office. West Lothian Council (2000). I never knew I could abseil! An evaluation of the West Lothian Carers Project Pilot Programme March 1999 to June 2000. West Lothian: West Lothian Council. 
White, B. (1994). Children, work and child labour. Development \& Change, 25(4), 849-878.

White, B. (1999). Defining the intolerable: Child work, global standards and cultural relativism. Childhood, 6(1), 133-144.

White, J. (1989). The costs of caring. Young People Now, 1, 42-43.

White, L.K., \& Brinkerhoff, D.B. (1981). Children's work in the family: Its significance and meaning. Journal of Marriage and the Family $43,789-798$.

Wiesenfeld, A.R., \& Weis, H.M. (1979). Hairdressers and helping: Influencing the behaviour of informal caregivers. Professional Psychology, 10(6), 786-92.

Williams, J. S. (1995). Who cares for the young carer? A time bomb waiting to explode. (Unpublished thesis for the Diploma in Voluntary, Community and Welfare Organisations). University College, Swansea.

Wilson, A. (1980). The infancy of the history of childhood: An appraisal of Philippe Ariès. History and Theory, 19(2) (Special issue 02).Wisdom, J., \& Cresswell, J.W. (2013). Mixed methods: Integrating quantitative and qualitative data collection and analysis while studying PatientCentered Medical Home Models. PCMH Research Methods Series. Rockville M.D.: Agency for Healthcare Research and Quality.

Woodhead, M. (1999). Combatting child labour: Listen to what the children say. Childhood, 6(1), 27-49.

Woolley, L. (2013). Hidden from view. London: Children's Society. 
Zelizer, V.A. (1981). The price and value of children: The case of children's insurance. American Journal of Sociology, 86(5), 10361056.

Zelizer, V.A.R. (1985). Pricing the priceless child: The changing social value of children. Princeton N.J.: Princeton University Press.

Zhang, L., Li, X., Kaljee, L., Fang, X., Lin, X., Zhao, G., Zhao, J., \& Hong, Y. (2009). 'I felt I have grown up as an adult': Caregiving experience of children affected by HIV/AIDS in China. Child: Care, Health and Development, 35(4), 542-550. 